\title{
TEST METHODS FOR EVALUATING THE OXIDIZATION POTENTIAL OF SULPHIDE -BEARING AGGREGATES AND ITS EFFECTS ON CONCRETE DURABILITY
}

\author{
by \\ Bassili Guirguis, M.Sc. \\ Alexandria University \\ 2007-2009
}

\author{
A dissertation \\ presented to Ryerson University \\ in partial fulfillment of the \\ requirements for the degree of \\ Doctor of Philosophy \\ in the program of \\ Civil Engineering
}

Toronto, Ontario, Canada, 2017

(C) Bassili Guirguis, 2017 


\section{Declaration of Authorship}

I hereby declare that I am the sole author of this dissertation. This is a true copy of the dissertation, including any required final revisions, as accepted by my examiners.

I authorize Ryerson University to lend this dissertation to other institutions or individuals for the purpose of scholarly research.

I further authorize Ryerson University to reproduce this dissertation by photocopying or by other means, in total or in part, at the request of other institutions or individuals for the purpose of scholarly research.

I understand that my dissertation may be made electronically available to the public. 


\begin{abstract}
TEST METHODS FOR EVALUATING THE OXIDIZATION POTENTIAL OF SULPHIDE -BEARING AGGREGATES AND ITS EFFECTS ON CONCRETE DURABILITY

Doctor of Philosophy

2017

\author{
Bassili Guirguis \\ Civil Engineering
}

Ryerson University
\end{abstract}

This research project focuses on the development and validation of test methods to evaluate the potential oxidation of sulphide-bearing aggregates, which can cause severe damage when used in concrete. The mechanism of damage is believed to consist of two parts: (a) the oxidation of sulphide minerals, which results in the formation of ferric hydroxide, and (b) the formation of sulphuric acid, which reacts with calcium hydroxide in concrete leading to an internal sulphate attack. Both parts produce a volume increase, damaging the concrete. A simple, quick and economical test method was developed and used to test thirty-one aggregates with different sulphur content. This test involves soaking the aggregate in an oxidizing agent at room temperature, washing the aggregate on a specific sieve, and drying it at $80^{\circ} \mathrm{C}$. The soaking and drying cycle is repeated and the disintegration of the aggregates is measured as \% mass loss. The composition of the oxidizing solution was evaluated, and the assessment of the aggregate was related to the presence of iron and sulphur ions 
in the solution after the test. The aggregate oxidation test developed here is anticipated to be adopted as a screening test method by North American standards due to its simplicity and applicability to a wide range of aggregates. The expansion of recently developed mortar bar samples containing a limited number of aggregates proves that the test can show expansion in aggregates with sulphide as well as high silica content; however, the high-silica aggregate did not show significant expansion in the second stage of the test, unlike the sulphide-bearing aggregates. The test was examined for its ability to evaluate the effects of supplementary cementing materials (SCM`s) on mitigating the damage in mortars containing sulphide-bearing aggregates. The results revealed that extended exposure to the oxidizing agent caused damage in the bar due to reasons other than the oxidation of sulphide phases when SCM with high reactive alumina is used. In addition, the results revealed that silica fume and low-calcium fly ash were effective in mitigating the damage, however, the efficacy of SCM`s is mainly linked to their ability to reduce the penetration of oxidizing agents into the mortar bars. These results need to be validated using field investigations. Concrete samples were tested under different conditions in an attempt to replicate the damage mechanisms in concrete samples under lab conditions. Some of the testing regimes showed promising results and are recommended for future studies. 


\section{Acknowledgments}

First, I would like to express my deepest gratitude and love to my wife, Meriana and my children, Joseph, Anne Marie and David for their patience.

I would also like to express my sincere gratitude to my supervisor Dr. Medhat Shehata for his guidance and friendship during my study. I would also like to thank Professor Hesham Marzouk, Professor Anwar Hossain, and Professor Daolun Chen, who kindly accepted to be my committee members, and Professor Samir Chidiac as the external examiner.

I would like to extend a special thank you to all of the technicians in the civil engineering department at Ryerson University for their assistance. I would also like to thank the soils and aggregates section at (MTO) for their assistance and support.

A special thank you goes out to my dear parents who have served me since the beginning of my life in this world, as well as my brother and sister and all of the rest of my relatives who have supported me. I would also like to thank my friends for all their help, support and encouragement. 


\section{Table of contents}

Declaration of Authorship..................................................................................................... ii

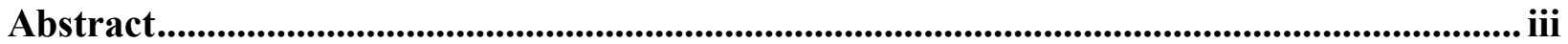

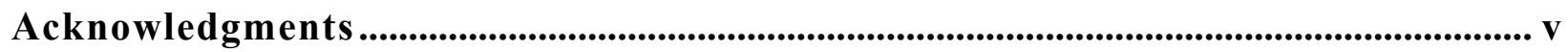

List of tables ....................................................................................................................................... xii

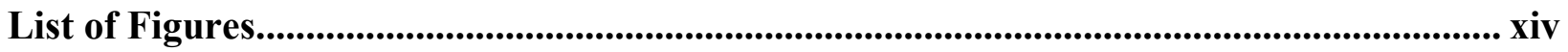

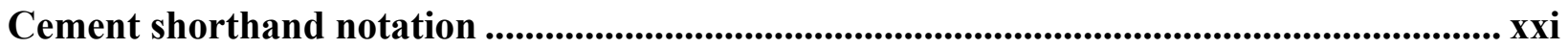

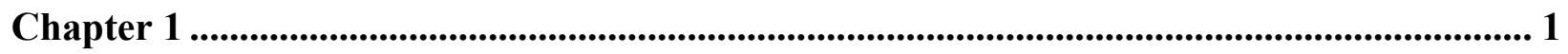

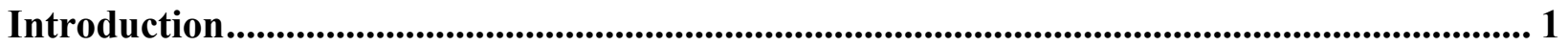

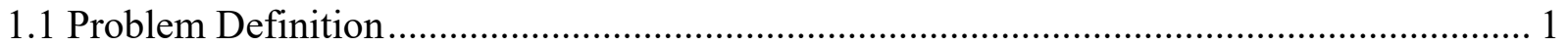

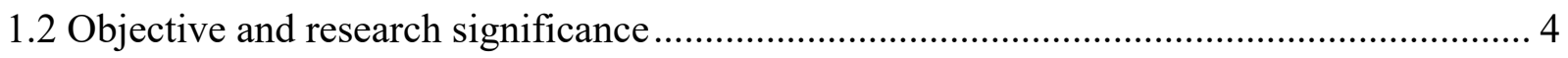

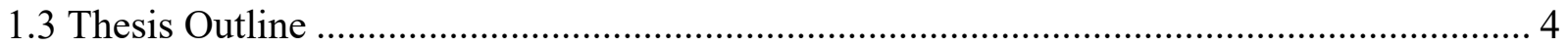

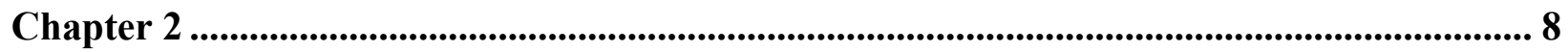

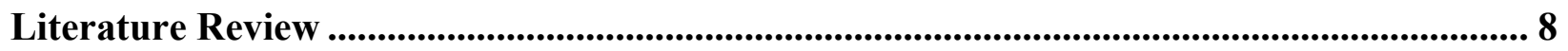

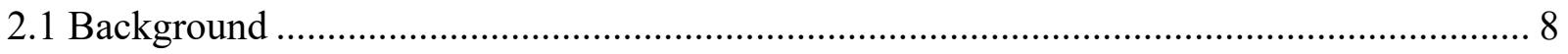

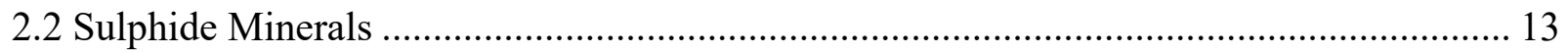

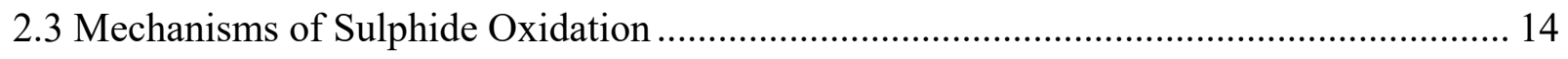

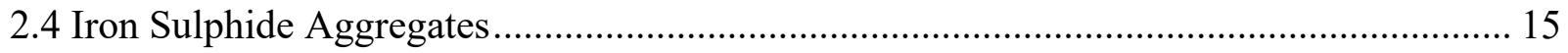

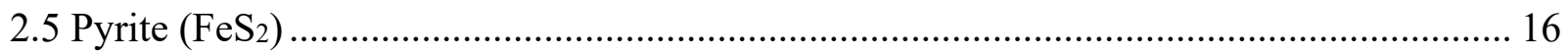




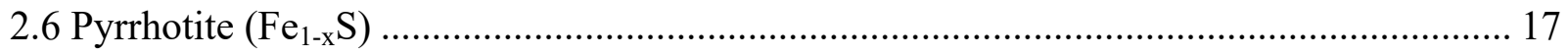

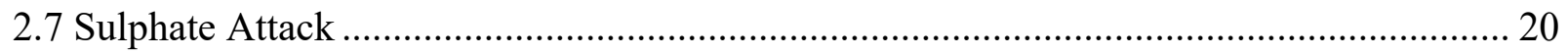

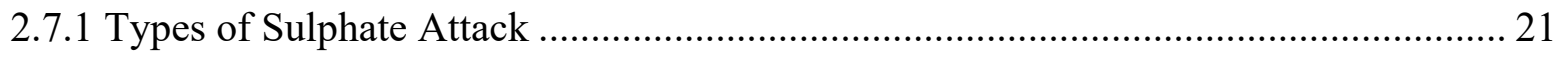

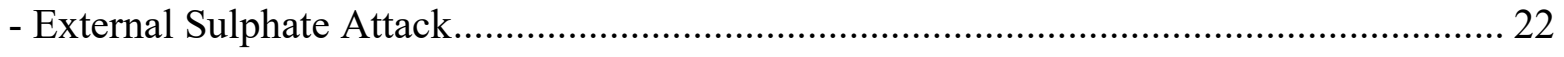

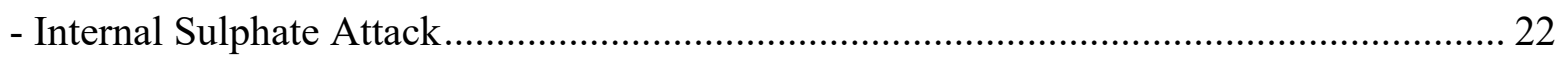

2.8 The Mechanism of an Internal Sulphate Attack ............................................................... 23

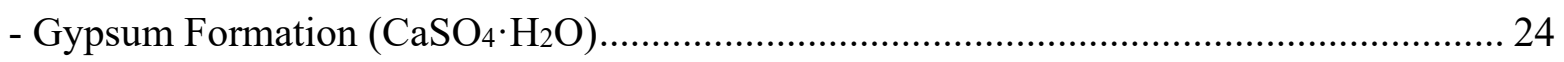

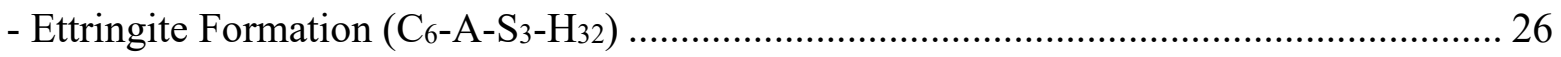

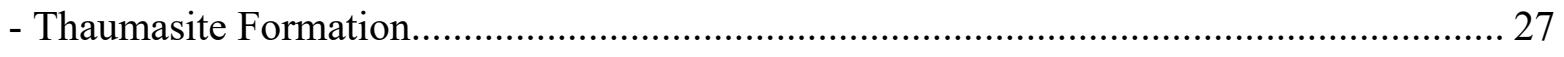

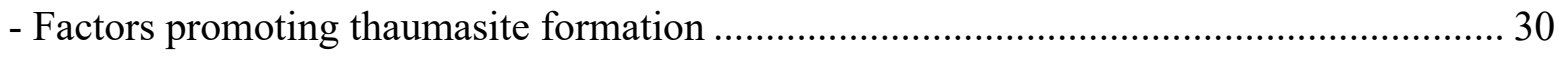

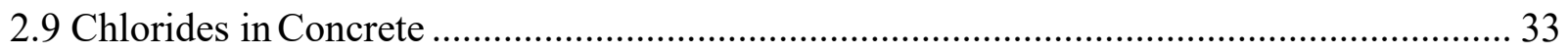

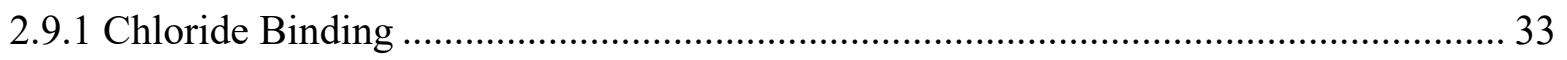

- Friedel's and Kuzel's Salts Mechanism........................................................................... 34

2.10 Supplementary Cementing Materials (SCMs) and their Effect on Concrete..................... 38

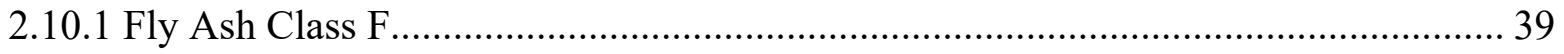

2.10.2 Ground Granulated Blast Furnace Slag (GGBFS) .................................................... 40

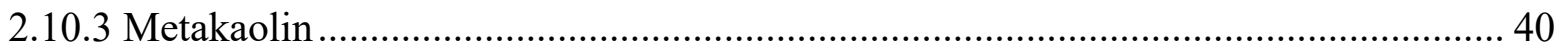

2.10.4 High Sulphate Resistance Cement............................................................................ 41

2.11 Current Proposed Test Protocol to Evaluate Sulphide-Bearing aggregate ………............ 42

Chapter 3 ............................................................................................................................................... 46

Development of a Screening Test for Aggregates ........................................................................... 46

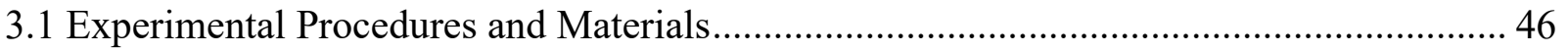




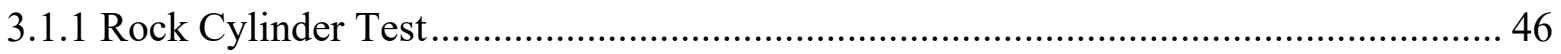

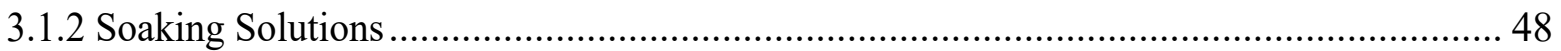

3.2 Development of a new Screening Oxidation Test............................................................ 48

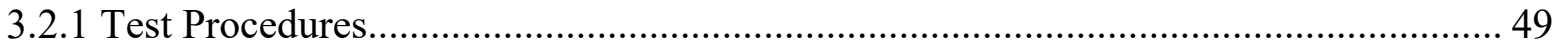

3.2.2 Measuring the Ion Concentrations in Oxidizing Solution ...................................... 52

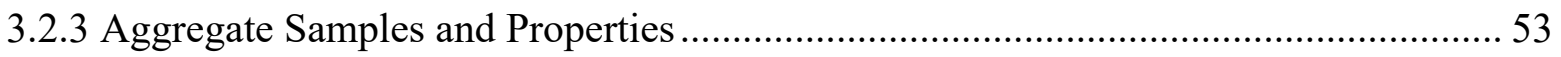

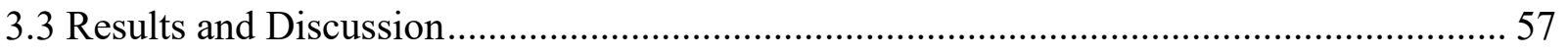

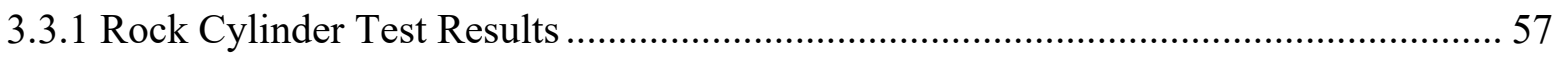

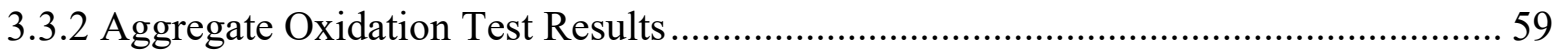

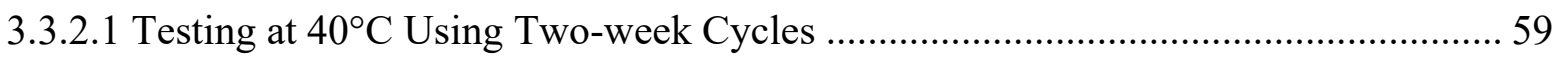

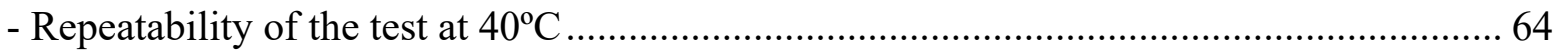

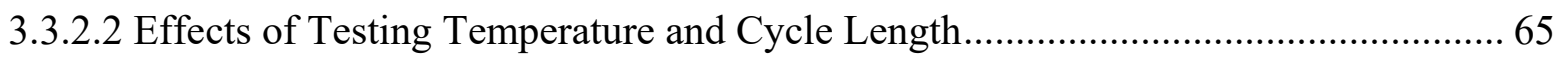

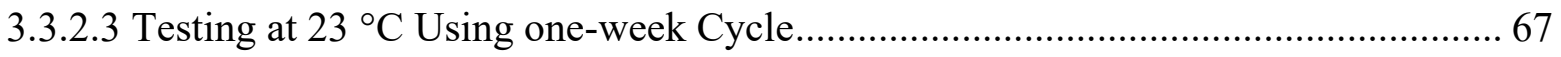

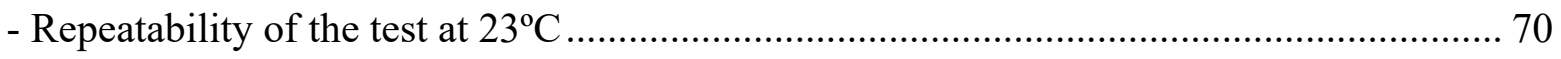

3.3.2.4 Summary of results for the aggregate oxidation test ............................................. 70

3.3.2.5 Application of the test to unprocessed coarse aggregate …….................................. 77

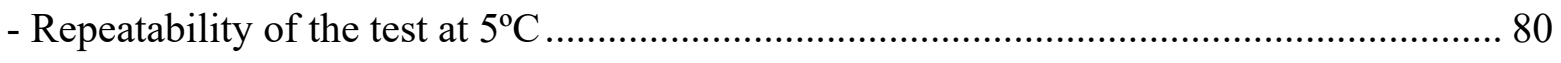

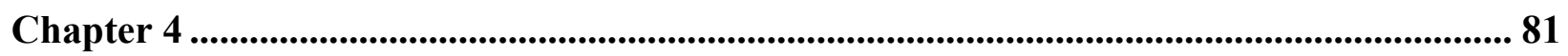

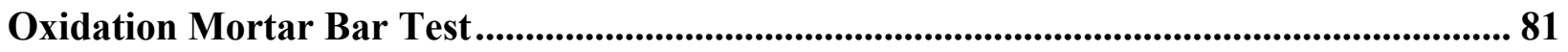

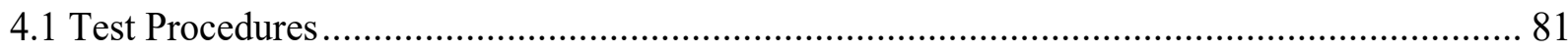

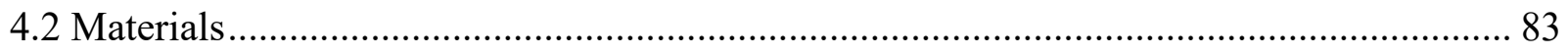

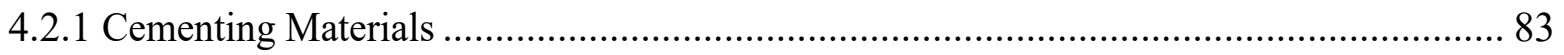




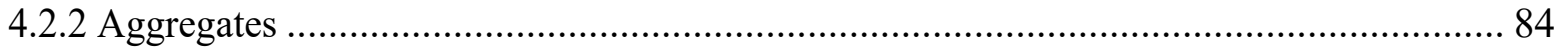

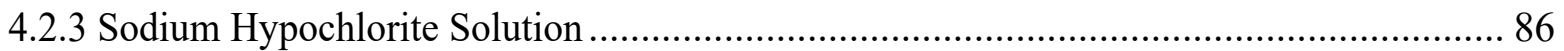

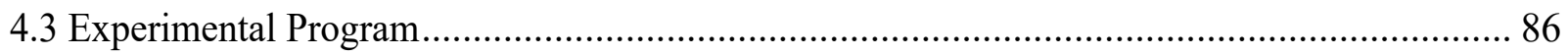

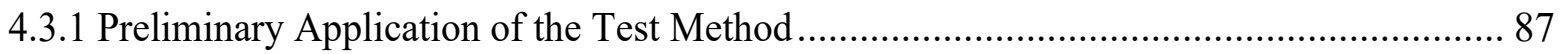

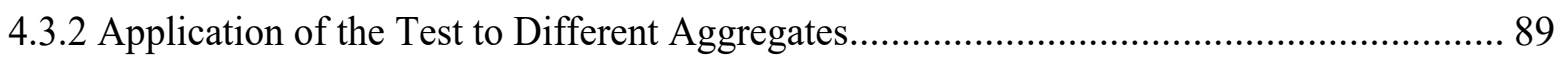

4.3.3 Investigating the ability of the test to evaluate the effects of mix parameters (SCM and W/C)

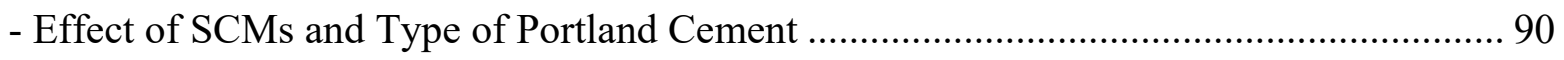

- Mass Gain and ion Penetrability of Mortar bar Samples with Different Cementing Systems

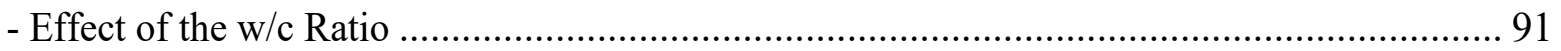

4.3.4 Paste Study to investigate phases produced under the testing conditions .......................... 92

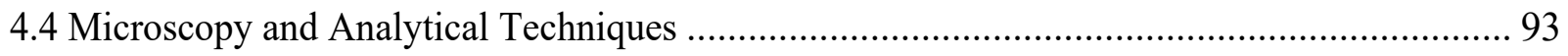

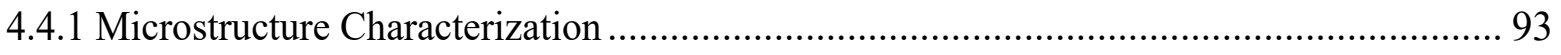

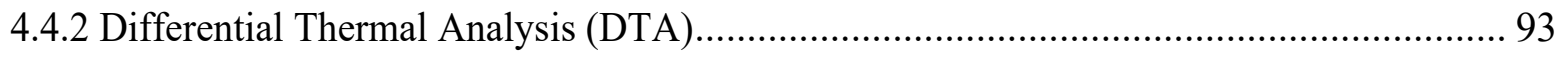

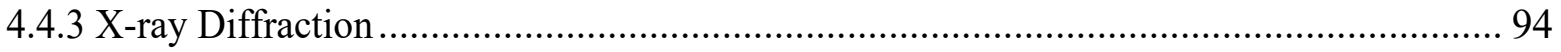

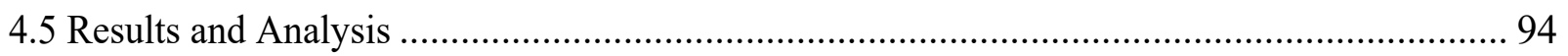

4.5.1. Phase composition of the raw SCM ......................................................................... 94

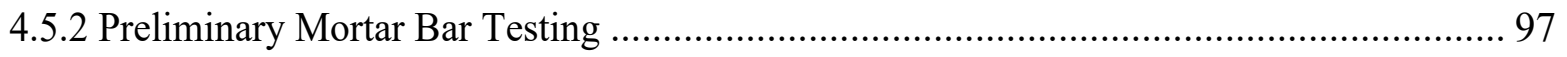

4.5.3 Application of the Test to a Wide Range of Aggregates ................................................ 102

- Microstructural Investigation of Aggregates..................................................................... 105

4.5.4 Investigating the ability of the test to evaluate the effects of mix parameters (SCM and w/c) 
- Mass Gain and ion Penetrability of Mortar bar Samples with Different Cementing Systems

- Expansion of Mortar Bar Samples without SCM............................................................ 114

- Testing Using a Soaking Period of 3 Hours ......................................................... 115

- Testing Using a Soaking Period of 24 Hours ........................................................ 121

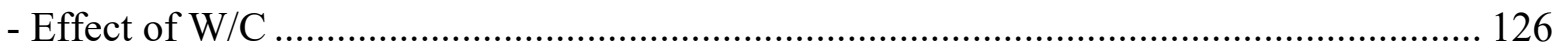

4.6 Microscopy and Analytical Techniques for the Mortar bar Samples ............................... 127

4.6.1 Mortar Bars Soaked in Sodium Hypochlorite for 3 hours ........................................ 127

4.6.2 Mortar Bars Soaked in Sodium Hypochlorite for 24 Hours ...................................... 132

4.7 Microscopy and Analytical Techniques for the Paste Samples .................................. 135

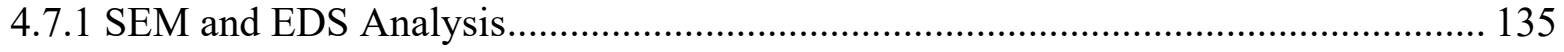

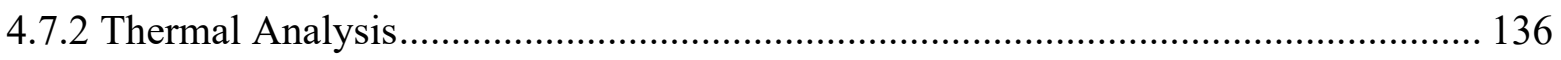

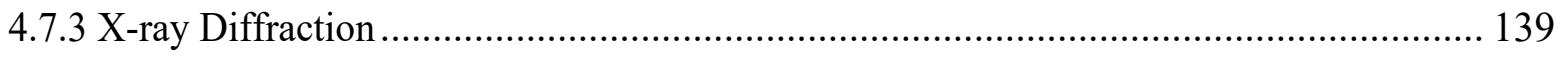

4.7.4 Analyses of the Mechanistic Tests Carried out on Paste samples .......................... 143

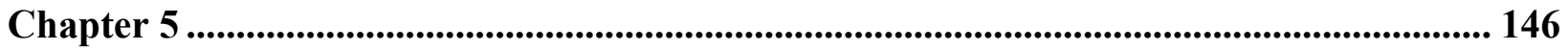

Concrete Expansion Tests ...................................................................................................................... 146

5.1 Experimental Program............................................................................................. 146

5.2 Samples Tested Under Different Exposures ........................................................... 148

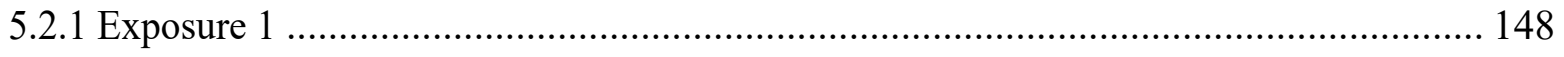

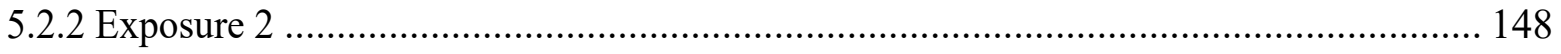

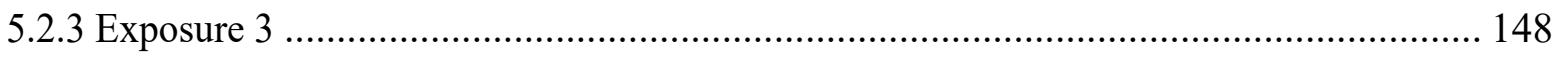

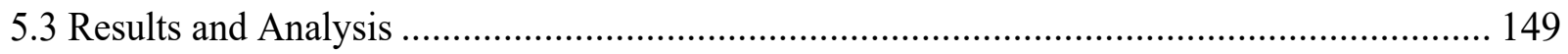




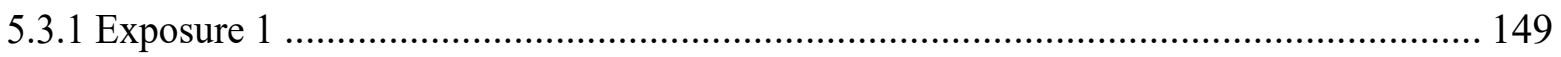

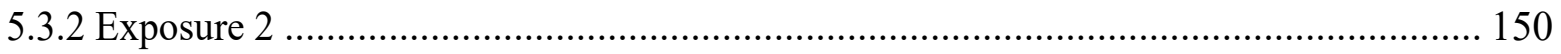

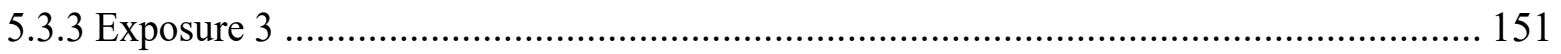

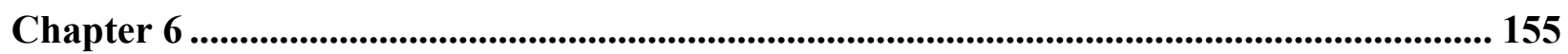

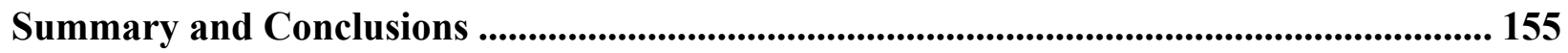

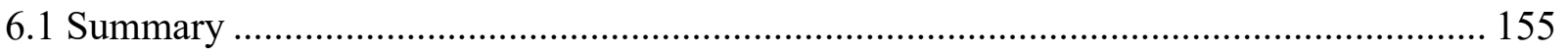

6.1.1 Aggregate Oxidation test ........................................................................ 156

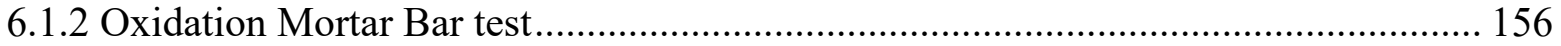

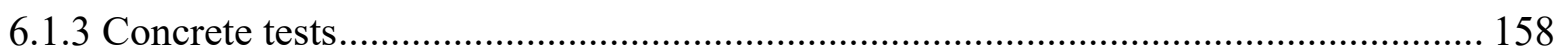

6.1.4 Suggested Aggregate Screening Flow Chart ..................................................... 159

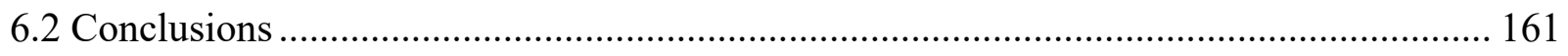

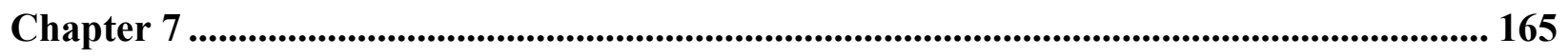

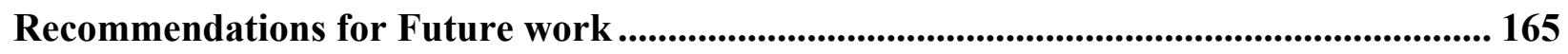

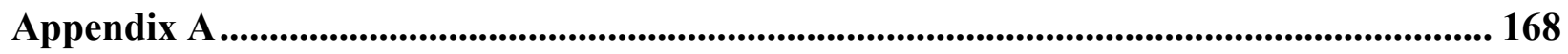

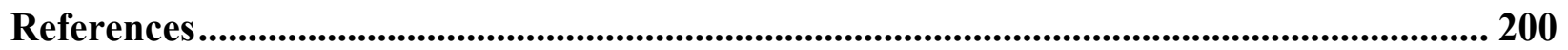




\section{List of tables}

\section{Chapter 3:}

Table 3 - 1: Aggregates mineralogy and Total Sulphur ( $\mathrm{Sr} \%)$ content .....

Table 3 - 2: Mass loss results and total Sulphur ( $\mathrm{Sr} \%)$ for aggregates tested at $40{ }^{\circ} \mathrm{C}$ using particle size $4.75 \mathrm{~mm}$ to $2.36 \mathrm{~mm}$. Each cycle was two weeks, and the solid to solution ratio was 1:10. 62

Table 3 - 3: Change in $\mathrm{pH}$, sulphur, and iron in sodium hypochlorite solution after one cycle of 12 days soaking at $40^{\circ} \mathrm{C}$. Initial $\mathrm{pH}$ of the solution was $12.2 \ldots$

Table 3 - 4: The standard deviation and coefficient of variation for MAS and C2 aggregates at $40^{\circ} \mathrm{C}$.

Table 3 - 5: Mass loss and total sulphur ( $\mathrm{Sr} \%)$ results for aggregates tested at $23{ }^{\circ} \mathrm{C}$ using particle size from $2.36 \mathrm{~mm}$ to $1.18 \mathrm{~mm}$ after cycles $1,2,4,7$. Each cycle was one week, and the solid to solution ratio was $1: 10$. 68

Table 3 - 6: Change in $\mathrm{pH}$, sulphur, and iron in bleach after one cycle of 5 days soaking at $23{ }^{\circ} \mathrm{C}$. The cycle reported here is cycle \# 1 . The initial $\mathrm{pH}$ of the solution was 12.4 . 69 Table 3 - 7: The standard deviation and coefficient of variation for MAS and C2 aggregates at $23^{\circ} \mathrm{C}$ 70

Table 3 - 8: Mass loss for coarse-size MAS and C2 aggregates at different temperatures.. ........ 78 Table 3 - 9: Mass loss and total sulphur ( $\mathrm{Sr} \%$ ) results for aggregates tested at $5^{\circ} \mathrm{C}$ using coarse aggregates without crushing after 1 cycles. The cycle was two weeks, and the solid to solution ratio was $1: 2$. 
Table 3 - 10: Standard deviation and coefficient of variation for MAS aggregates at $5^{\circ} \mathrm{C}$ with different sizes..

\section{Chapter 4:}

Table 4 - 1: Chemical composition of the Portland cement and SCMs (mass \%) determined using

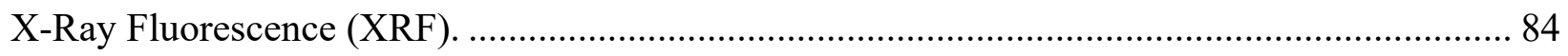

Table 4 - 2: Mineralogy of aggregates and their total sulphur ( $\mathrm{Sr} \%)$ content ......................... 85

Table 4 - 3: Silica ion concentration in solution under different temperatures. ....................... 109

\section{Chapter 5:}

Table 5 - 1: Summary of concrete sample testing exposures

\section{Appendix A}

Table A - 1: XRD Peak list [2 Theta \& Intensity (I\%)] for each mineral 168 


\section{List of Figures}

\section{Chapter 1:}

Figure 1 - 1: Cracking in concrete foundation [2] .......................................................... 2

Figure 1 - 2: Features of concrete deterioration [2] ........................................................ 2

Figure 1 - 3: Replacement procedures for the foundations and walls [2] .............................. 3

\section{Chapter 2:}

Figure 2 - 1: Types of Sulphide Minerals. ..................................................................... 13

Figure 2 - 2: Properties of Pyrite and Pyrrhotite................................................................. 15

Figure 2 - 3: Products of Pyrite aupon Exposure to the Atmosphere. ...................................... 17

Figure 2 - 4: Products of Pyrrhotite and Exposure to the Atmosphere.................................... 18

Figure 2 - 5: Breakdown of possible types of sulphate attack......................................... 21

Figure 2 - 6: Internal Products of a Sulphate Attack. .......................................................... 23

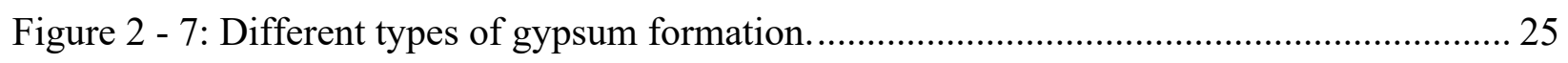

Figure 2 - 8: Possible Consequences of Thaumasite Presence. ................................................. 29

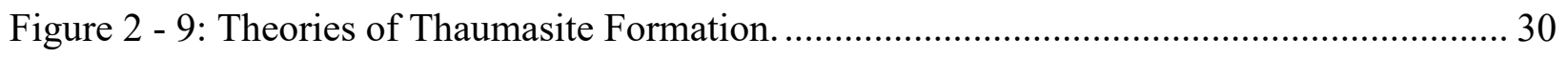

Figure 2 - 10: Factors promoting thaumasite formation ................................................... 32

Figure 2 - 11: A test protocol proposed to assess the probable reactivity of sulphide-bearing

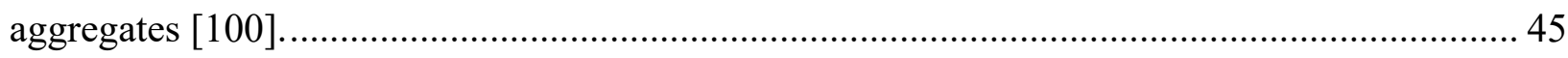




\section{Chapter 3:}

Figure 3 - 1: (a) Standard shape and size, (b) Rock cylinder sample prepared in the lab ............ 47

Figure 3 - 2: Apparatus for sample measurement ................................................................. 48

Figure 3 - 3: Expansion in the MW aggregate in two different solutions..................................... 58

Figure 3 - 4: MW oxidized samples and some iron oxide precipitated onto the container ...........58

Figure 3 - 5: Effects of particle size on mass loss using the B \& B aggregate, tested using a 2-

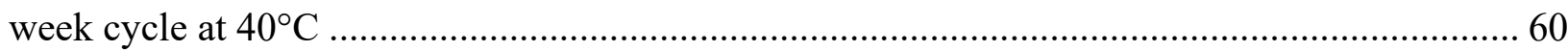

Figure 3 - 6: Effects of water and $\mathrm{NaClO}$ solution on mass loss of MW aggregate, tested using a

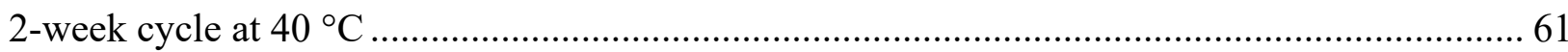

Figure 3 - 7: The colour of sodium hypochlorite solution after the first cycle (two-weeks) of the

test. 63

Figure 3 - 8: Effects of different temperatures on mass loss using B \& B aggregate size $4.75 \mathrm{~mm}$

to $2.36 \mathrm{~mm}$. 66

Figure 3 - 9: Effect of cycle length on mass loss using B \& B aggregate size 4.75 to $2.36 \mathrm{~mm}$.. 67

Figure 3 - 10: The colour of each container after the first cycle (one week) of the test............... 69

Figure 3 - 11: Comparison between mass loss using 1 long and 2 short cycles .......................... 71

Figure 3 - 12: Comparison of mass loss using three long and three short cycles ......................... 72

Figure 3 - 13: Mass loss of the 30 tested samples after one cycle of testing at $23{ }^{\circ} \mathrm{C}$ using size

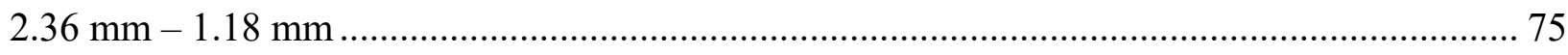

Figure 3 -14: Mass loss of the 30 tested samples after 3 cycles of testing at $23{ }^{\circ} \mathrm{C}$ using $2.36 \mathrm{~mm}$

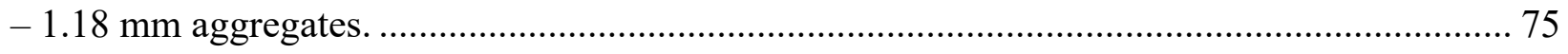




\section{Chapter 4:}

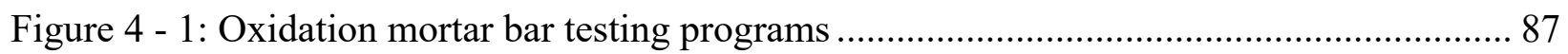

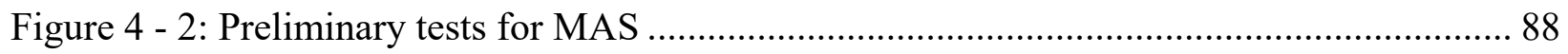

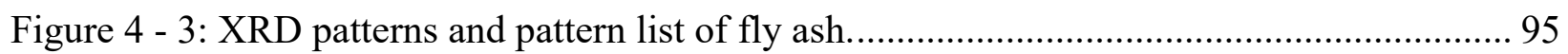

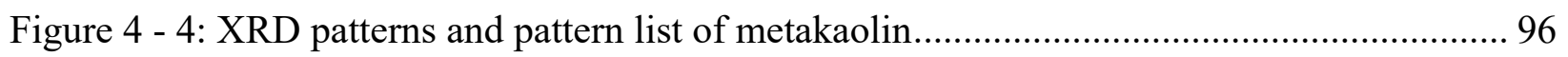

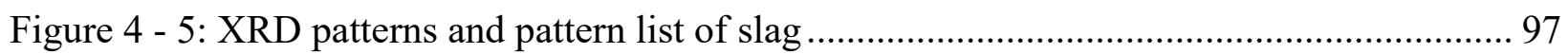

Figure 4 - 6: Expansion of mortar bar samples tested at $80^{\circ} \mathrm{C}$ with no control of $\mathrm{RH}$ in the first 13 weeks (improperly sealed container), followed by 13 weeks of testing at $5^{\circ} \mathrm{C}$ and $100 \% \mathrm{RH}$.

Figure 4 - 7: Expansion of mortar bar samples tested at $80^{\circ} \mathrm{C}$ and $80 \% \mathrm{RH}$ in the first 13 weeks,

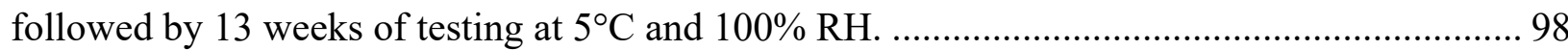

Figure 4 - 8: Containers used at $80^{\circ} \mathrm{C}$ and $80 \% \mathrm{RH}$ (a) With proper seals and (b) With no control of RH....... 99

Figure 4 - 9: Expansion in mortar bar samples made with different sulphide mineral aggregates.

Figure 4 - 10: Standard deviation and the expansion mean and for all mortar bar sets made with

MAS aggregate. 101

Figure 4 - 11: Expansion of MAS samples which placed in a fume hood for three hours ( $\mathrm{M} \mathrm{f}$ ) showing a slightly lower expansion than samples placed for half an hour in $23^{\circ} \mathrm{C}$ (M n.f)....... 102

Figure 4 - 12: Expansion in all control and aggregates with total sulphur $<0.05 \% \ldots \ldots \ldots \ldots \ldots \ldots . . . .103$

Figure 4 - 13: Expansion in samples with various sulphide contents........................................ 104

Figure 4 - 14: BSE image showing sulphide minerals in the C1 aggregate. ............................. 105 
Figure 4 - 15: Evidence of a white spots in the C2 aggregate containing iron oxide. 106

Figure 4 - 16: C2 aggregate before \& after aggregate oxidation test. 108

Figure 4 - 17: Evidence of ASR gel inside one of the air void in mortar bars with C2 aggregate

Figure 4 - 18: Evidence of ASR gel inside an air void in mortar bars containing Sud aggregates

Figure 4 - 19: Mass gain of mortar bar samples made with $\mathrm{P}$ aggregate soaked in 6\% sodium

Figure 4 - 20: Migration of chloride ions into the mortar bar samples after different time of

exposure.

Figure 4 - 21: Condition of different mortar bar samples after 26 weeks with no visible cracks in the picture. 115

Figure 4 - 22: Expansion of mortar bar samples containing P, MAS, and C1 aggregates cast with GU cement and soaked 3 hours in a sodium hypochlorite solution. 117

Figure 4 - 23: Expansion of mortar bar samples containing P, MAS and C1 aggregates cast with low heat hydration cement and soaked 3 hours in bleach. 117

Figure 4 - 24: Expansion of mortar bar samples containing P, MAS, and C1 aggregates cast with slag and soaked 3 hours in a sodium hypochlorite solution... 118 Figure 4 - 25: Expansion of mortar bar samples containing P, MAS, and C1 aggregates cast with fly ash and soaked 3 hours in a $6 \%$ sodium hypochlorite solution. 118 Figure 4 - 26: Expansion of mortar bar samples containing P, MAS, and C1 aggregates cast with high silica fume blended cement and soaked 3 hours in a sodium hypochlorite solution. 119 
Figure 4 - 27: Expansion of mortar bar samples containing P, MAS, and C1 aggregates cast with metakaolin and soaked 3 hours in sodium hypochlorite.

Figure 4 - 28: Expansions or mortar bar samples containing MAS aggregate and soaked for 3 hours or 24 hours in sodium hypochlorite solution

Figure 4 - 29: Expansion of mortar bar samples containing P, MAS, and C1 aggregates cast with GU cement and soaked for one day in sodium hypochlorite. 123 Figure 4 - 30: Expansion of mortar bar samples containing P, MAS, and C1 aggregates cast with fly ash and soaked for one day in sodium hypochlorite. 123 Figure 4 - 31: Expansion of mortar bar samples containing P, MAS, and C1 aggregates cast with metakaolin and soaked for one day in sodium hypochlorite.

Figure 4 - 32: Condition of mortar bar samples containing 10\% MK after 26 weeks of testing with a soaking period of 24 hours: (a) P aggregate, (b) MAS aggregate, (c) C1 aggregate....... 125 Figure 4 - 33: Expansion in mortar bar samples made with different W/C ratios ................... 126

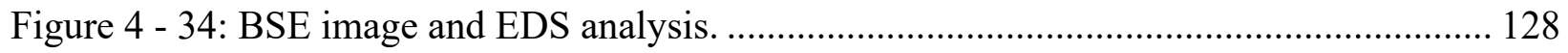

Figure 4 - 35: Elemental line scans of a sulphide phase intrusion in an MAS aggregate.......... 129 Figure 4 - 36: Ettringite/thaumasite formed in the paste of mortar bar samples with an MAS aggregate cast with GU-Portland cement.

Figure 4 - 37: Damage of paste of mortar bars with MAS samples cast with $10 \%$ metakaolin showing the formation of ettringite and Friedel's salt.

Figure 4 - 38: Damage in mortar bars with MAS aggregate cast with 10\% metakaolin. 133 Figure 4 - 39: Formation of Friedel's salt in a mortar bar with P aggregates and 10\% metakaolin. 
Figure 4 - 40: Damage in a mortar bar with C1 samples cast with 10\% metakaolin.

Figure 4 - 41: Friedel's salt formation in a large area in a MK paste sample exposed for 24 hours to a sodium hypochlorite solution. 136

Figure 4 - 42: DTA for the three cement paste samples cast with GU - PC, PC + 25\% FA \& PC + $10 \% \mathrm{MK}$ 137

Figure 4 - 43: XRD patterns and pattern list of PC-GU hydrated 140

Figure 4 - 44: XRD patterns and pattern list of PC-GU $+25 \%$ fly ash hydrated

Figure 4 - 45: XRD patterns and pattern list of PC-GU $+10 \%$ metakaolin hydrated...... 142

\section{Chapter 5:}

Figure 5 - 1: Volume change in concrete prisms containing different aggregates and kept at $60^{\circ} \mathrm{C}$ and $80 \% \mathrm{RH}$, using exposure 1

Figure 5 - 2: Expansion of concrete samples concrete samples made with MAS, C2, C1 and P aggregates using exposure 2: 4-days soaking in a 6\% sodium hypochlorite solution, 2 days in the oven at $60^{\circ} \mathrm{C}$

Figure 5 - 3: Expansion in MW and C1 aggregates with different replacement ratios using exposure 4: 1-day soaking in a 6\% sodium hypochlorite solution, 5 days in the oven at $60^{\circ} \mathrm{C} .152$ Figure 5 - 4: Expansion of concrete samples incorporating the CR aggregate using exposure 4 1-day soaking in a $6 \%$ sodium hypochlorite solution, 5 days in the oven at $60^{\circ} \mathrm{C}$ 


\section{Chapter 6:}

Figure 6 - 1: Suggested aggregate screening flow chart. .............................................. 160 


\section{Cement shorthand notation}

$$
\begin{aligned}
& \mathrm{C}=\mathrm{CaO} \\
& \mathrm{S}=\mathrm{SiO}_{2} \\
& \mathrm{H}=\mathrm{H}_{2} \mathrm{O} \\
& \mathrm{A}=\mathrm{Al}_{2} \mathrm{O}_{3} \\
& \mathrm{~F}=\mathrm{Fe}_{2} \mathrm{O}_{3} \\
& \underline{\mathrm{S}}=\mathrm{SO}_{3} \\
& \underline{\mathrm{C}}=\mathrm{CO}_{2} \\
& \mathrm{~N}=\mathrm{Na}_{2} \mathrm{O} \\
& \mathrm{K}=\mathrm{K}_{2} \mathrm{O} \\
& \mathrm{CH}=\mathrm{Ca}_{(}\left(\mathrm{OH}_{2}\right. \\
& \mathrm{CS} \underline{\mathrm{H}}{ }_{2}=\mathrm{CaSO}_{4} .2 \mathrm{H}_{2} \mathrm{O} \\
& \mathrm{CC}=\mathrm{CaCO}_{3} \\
& \mathrm{CSH}=\mathrm{C}_{3} \mathrm{~S}_{2} \mathrm{H}_{8}
\end{aligned}
$$




\section{Chapter 1}

\section{Introduction}

\subsection{Problem Definition}

In Trois-Rivieres region (Quebec, Canada), the foundation walls of more than 900 residential houses were affected by the oxidation of sulphide-bearing aggregates. The concrete foundations rapidly deteriorated and severely cracked within the first 3 to 5 years after construction, as shown in Figure $1-1$. The damage took the form of a network of cracks known as map cracking. Figure 1 - 2 shows the deteriorated foundation, deck slab, and pop-out in the wall. The aggregate used in this concrete was igneous rock with a trace amount of metamorphic rock and contained various components of sulphide minerals such as pyrite $\left(\mathrm{FeS}_{2}\right)$ and pyrrhotite $\left(\mathrm{Fe}_{(1-\mathrm{x}) \mathrm{S}} \mathrm{S}\right.$ [2]. A deterioration mechanism involving oxidation and internal sulphate attack is believed to have caused swelling and cracking in the concrete. The details of the mechanism and the factors that affect the rate and level of damage are not $100 \%$ understood; however, sulphate attack plays is believed to have the main role in the deterioration. A good understanding of deterioration mechanisms essential.

Figure 1 - 3 shows the replacement method used to remove all of the covering stones and masonry from the foundations and walls of the homes. The foundations were first demolished and then replaced [1]. This problem caused a significant amount of damage to the walls and foundations of these homes, resulting considerable economic loss. The home shown in Figure 1 - 
3 is one of the several houses that have undergone restorations to repair the deterioration caused by the sulphide mineral pyrrhotite.

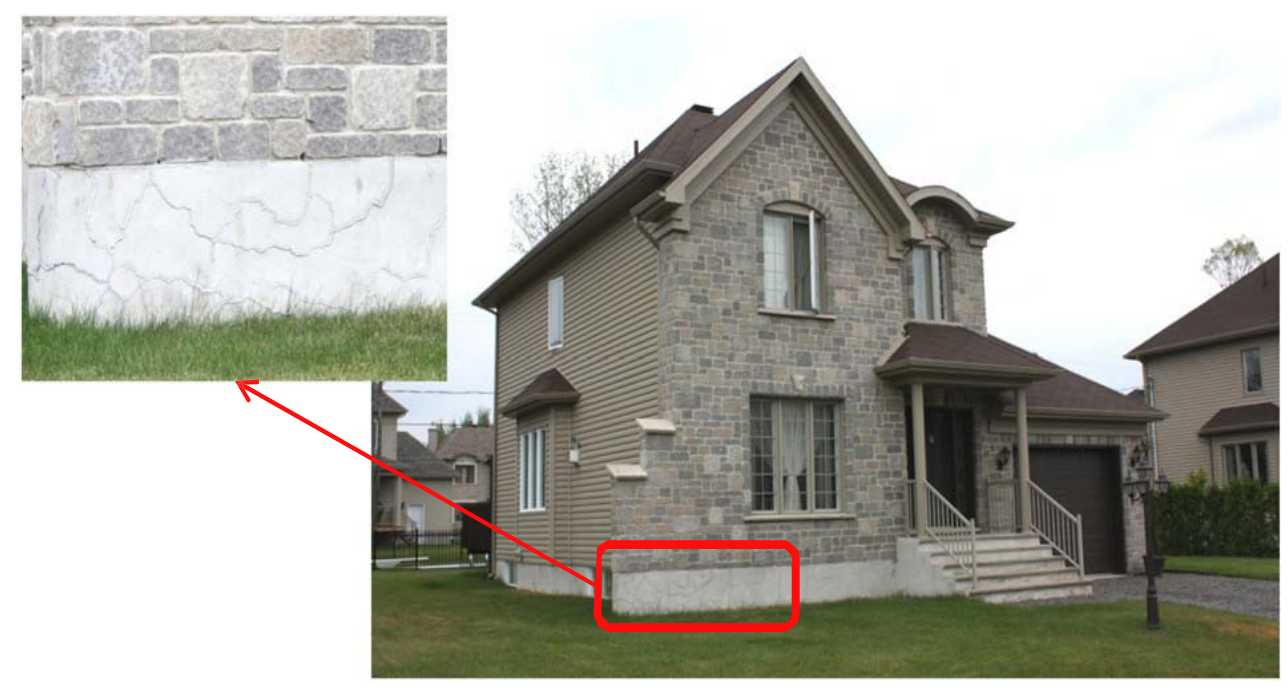

Figure 1 - 1: Cracking in concrete foundation [2].
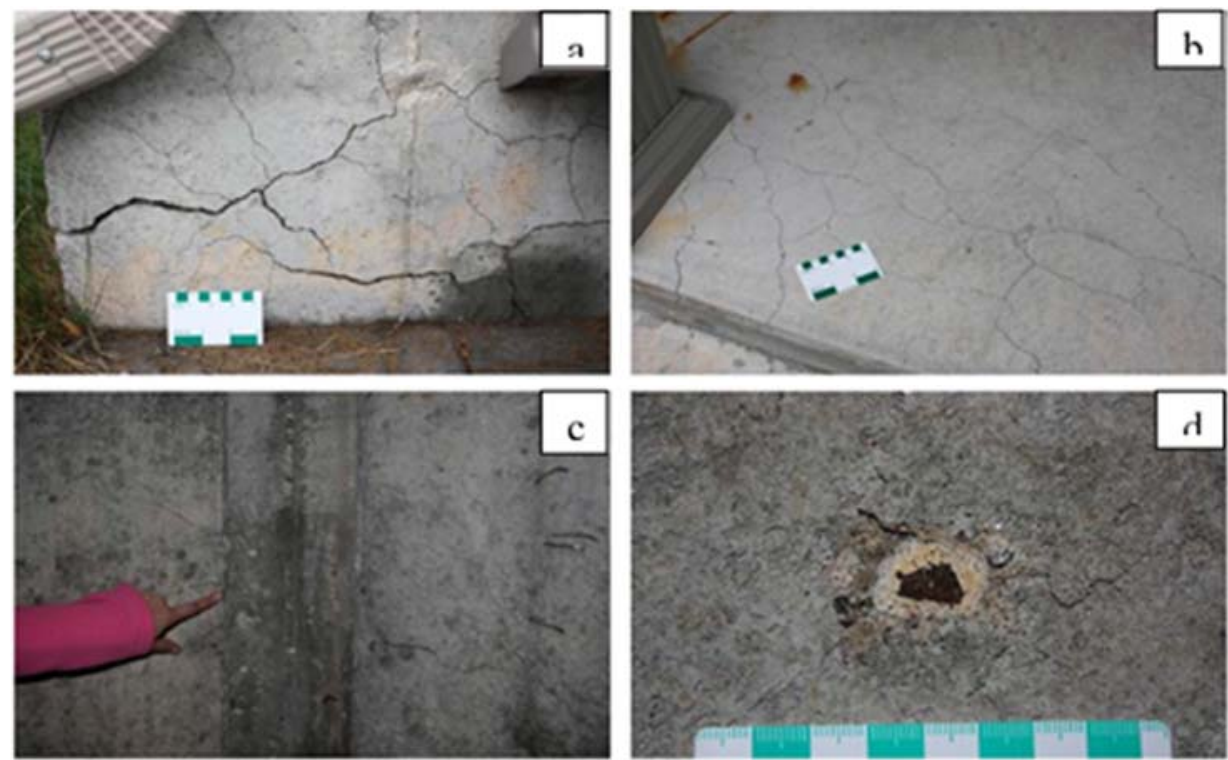

Figure 1 - 2: Features of concrete deterioration [2].

Figure 1 - 2, (a) Cracking in the concrete foundation of houses; (b) Map cracking in the entrance concrete deck slab; (C) Open cracks on the interior side of the concrete foundation, and (d) Popout on the interior side of a wall. 

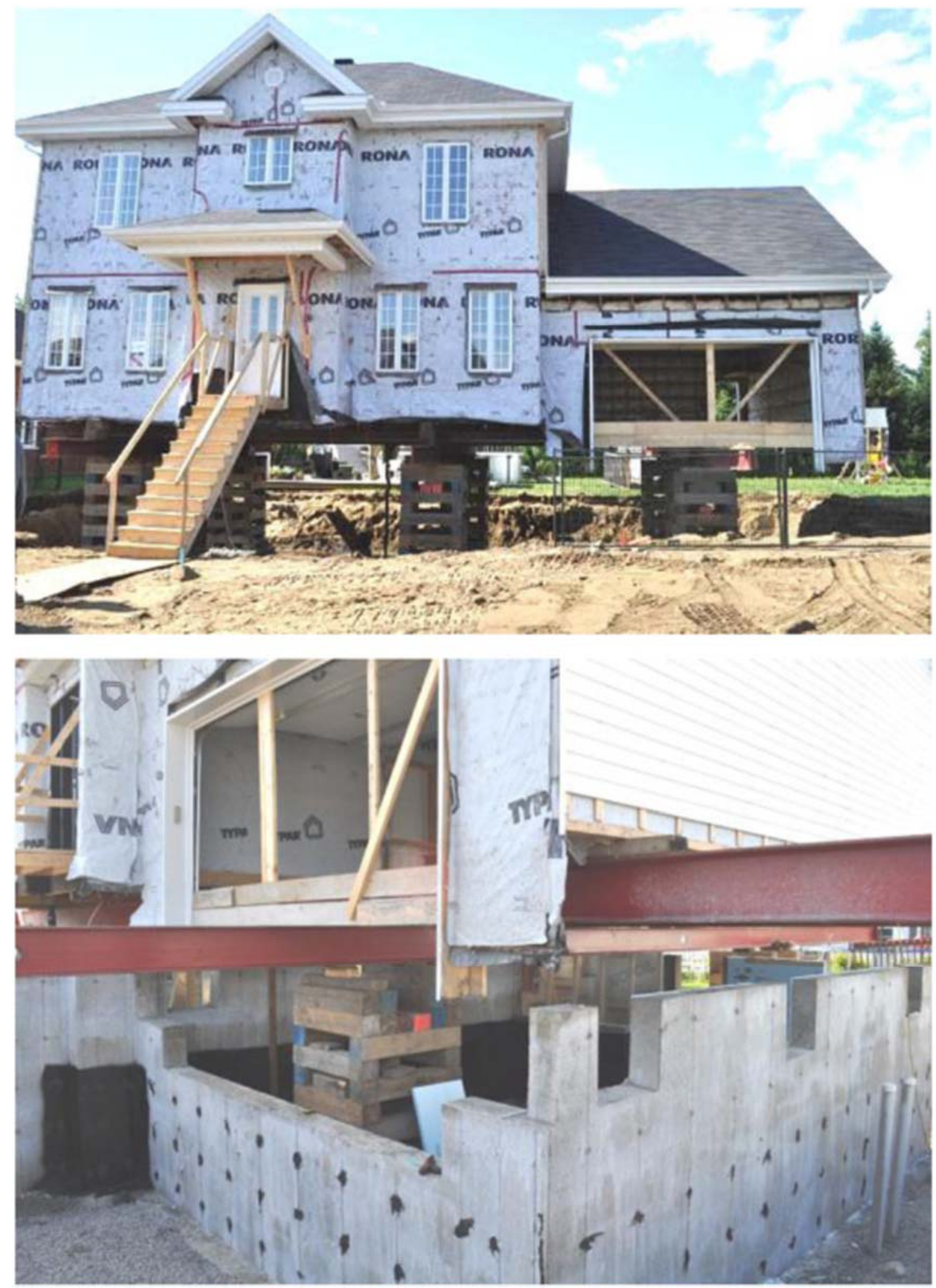

Figure 1 - 3: Replacement procedures for the foundations and walls [2] 


\subsection{Objective and research significance}

This thesis was initiated following the case of Trois-Rivieres and focused on developing a new test methods and adopting existing tests to evaluate aggregates for their potential to cause damage in concrete due to oxidation of sulphide phases. Moreover, the applicability of existing tests on evaluating possible preventive measures is evaluated. For developing new test methods, emphases were placed on simplicity, practicality and cost of the proposed method. It should be noted that the sulphide minerals can be found in many places around the world, so the developed test methods and the understanding of the deterioration mechanisms are likely to have global positive impacts.

\subsection{Thesis Outline}

This thesis examines different tests used to evaluate the potential oxidation of aggregates from different sources. The goal is to propose a test method or test protocol to evaluate aggregates prior to being used in concrete. These tests are classified as: (i) aggregate tests, (ii) mortar bar tests, and (iii) concrete prism tests. Within each test, analytical techniques such as scanning electron microscopy, thermal analysis, and X-Ray diffraction are used to help explain the findings. Each of the above tests (including materials, experimental details, and analytical techniques) is presented in a separate chapter. 
The thesis ends with a summary and conclusion chapter to bring all of the findings together and provide recommendations for future research. The thesis chapters are organized as follows:

Chapter 1: Introduction

This chapter introduces the topic and provides historical background regarding the case that took place in the Trois-Rivieres region (Quebec, Canada) where more than 900 residential houses were affected by the oxidation of sulphide-bearing aggregates. Sulphide-bearing aggregates can cause severe deterioration in concrete structures when the aggregates oxidize. In addition, the oxidation product can generate sulphate ions, which react with the hydrated cement products to form gypsum, ettringite, and thaumasite. These phases are also responsible for extra expansion and severe cracking, causing damage to concrete elements. Understanding the oxidation mechanism is very important in order to evaluate the potential volume increase responsible for expansion and cracking. This damage can decrease the serviceability of concrete elements, leading to major economic losses.

Chapter 2: Literature Review

This chapter covers the literature pertaining to the oxidation of sulphide-bearing aggregates and sulphate attacks, as well as the properties and formation of other phases in concrete, such as Friedel's salt, as this phase was found in some of the samples that were tested. 


\section{Chapter 3: Aggregate Testing Program}

This chapter covers the development of a new screening test to investigate the potential oxidation of sulphide-bearing aggregates. The mineralogical composition of aggregates, their filed performance, and their total sulphur ( $\mathrm{Sr} \%)$ content was used to assess the test results.

\section{Chapter 4: Mortar Bar Tests}

This chapter covers the initial stage of adopting a new oxidation mortar bar test proposed by Rodrigues et al, [3]. In addition, the test was used in this thesis with a wide range of aggregates from Ontario and Quebec. The test was also used to evaluate possible preventive measures against the oxidation of sulphide-bearing aggregates and the subsequent sulphate attack.

\section{Chapter 5: Concrete Prism Tests}

This chapter presents attempts to develop a concrete prism test to evaluate the potential damage of sulphide-bearing aggregates. While none of the attempted testing regimes are recommended as a new concrete test, the information can shed light on new directions to be taken in this area of research. 
Chapter 6: Summary and Conclusions

This chapter brings together all of the results from different tests in an attempt to draw conclusions and pave the road for more research on this topic.

\section{Chapter 7: Recommendations}

This chapter gives a short overview of the proposed recommendations for future research. 


\section{Chapter 2}

\section{Literature Review}

\subsection{Background}

Concrete damage is a major issue faced by engineers in both the public and private sectors. The deterioration resulting from a disintegration mechanism decreases the durability of the concrete, reducing the serviceability of concrete buildings and leading to major economic loss. Damage to concrete can occur because of the combined effects of external deleterious factors such as de-icing salts, freezing and thawing, and sulphate attacks, or because of internal reactions caused by one or more of the concrete ingredients such as the alkali-aggregate reaction or the oxidation of sulphide-bearing aggregates [3].

Many years ago, engineers and researchers discovered that the use of sulphide-bearing aggregates in concrete mixing could cause serious deterioration of the concrete [3]. Since then, more studies have been conducted in order to investigate and understand the combined deleterious mechanisms, which are the oxidation of iron-bearing aggregates followed by sulphate attacks. Some studies [4] have attempted to create laboratory testing methods to establish the harmful effect of sulphide-bearing aggregates in concrete. The deleterious effects of a sulphate attack on concrete can be seen in several places around the world. The primary factor that causes a sulphate attack is the type and number of minerals in the sulphide-bearing aggregate. 
Berard et al. [5] used petrographic analysis to provide evidence of expansive minerals in the concrete foundations of several houses that experienced severe deterioration within two to four years after construction in a small community located north of Montreal (Canada). At the same time and in the same area, several concrete structures related to infrastructure (overpasses and bridges) began to deteriorate. These concrete structures were so badly damaged that significant parts of the structures fell. In 1969, Berard et al. [5] examined coarse grained gabbro found in the fragments of the destroyed concrete foundations. These fragments were collected from an area north of Montreal, Canada. The aggregates used in this concrete mixture contained traces of pyrite and pyrrhotite. Under the microscope, brownish powdery particles could be seen. The authors found that the reaction that caused the expansion and deterioration of the concrete structures was the oxidation of the pyrrhotite minerals, followed by sulphuric acid formation which in turn reacts with $\mathrm{Ca}(\mathrm{OH})_{2}$ portlandite to form gypsum. This gypsum reacted with the $\mathrm{C}_{3} \mathrm{~A}$ of the cement via monosulphoaluminte to form ettringite.

Oberholster and Kruger [6] found that South Africa does not have any standard specifications to limit the use of coarse and fine aggregates that contain iron sulphide minerals in concrete mixtures. This serious problem was highlighted in 1979 when they encountered severe cracking and deterioration in the concrete of houses in the Penge area. They reported that the aggregate which was used in the concrete mixture contained a carbonaceous and iron sulphide mineral. Petrographic examination revealed a white colour around the aggregate particles, and the SEM identified the white colour as thaumasite. The concrete samples made in the laboratory by the author with the same aggregates, which also displayed cracks and expansion, contained the 
crystal formation of ettringite. The authors explained that the deterioration occurred because of the oxidation of sulphide minerals in the aggregate, followed by sulphuric acid formation, and finally, thaumasite formation. There is concern in South Africa regarding the potential harmful effects of the iron sulphide-bearing aggregates in concrete.

Lugg and Probert [7] stated that throughout the period from 1900 to 1950, mundic rock was used as a coarse aggregate for concrete blocks in order to reduce the cost of construction in the Cornwall and Devon regions of England. Unfortunately, many engineers have since used this aggregate in concrete construction. This kind of aggregate was extracted for free or at a very low cost since it was readily available. This rock was identified as a sulphide mineral and subsequently oxidized, deteriorating the concrete blocks. Additionally, due to the high humidity in the occupied homes, the growth of spores was discovered on the inner surfaces of many of these buildings, posing a significant hazard to human health. The authors illustrated that pyrite was the most problematic sulphide mineral in mundic rock.

In their study, Schmidt et al, [4] examined two types of concrete. The first type came from a dam constructed in Switzerland during the 1970s, while the second was prepared in a laboratory and stored in water for five years at $60^{\circ} \mathrm{C}$. The laboratory made concrete contained a similar aggregate to the one used in the construction of the dam. The petrography analysis for the extracted aggregates confirmed that this kind of aggregate contained reactive iron sulphide minerals, which mainly consisted of pyrite and pyrrhotite. The authors explained that the oxidation process of both iron sulphide minerals started from the surface of the aggregate particles. Moreover, this oxidation 
led to the formation of a dark patterned layer, which was the main cause of the volume increase and expansion in the concrete. As a result, the degradation and displacement occurred in the upstream part of the dam. The petrographic analysis of the concrete samples prepared in the laboratory was performed after four years of testing under the previous conditions. The reaction of iron sulphide minerals in the laboratory specimens was much lower than the concrete from the dam. These results indicate that it is very hard to identify the right environments or testing regime to reproduce qualitative iron sulphide mineral disintegration in the laboratory. The authors also confirmed that the pyrrhotite sulphide-minerals react much faster than the pyrite sulphideminerals.

When sulphide minerals are exposed to water and oxygen they oxidize and cause the release of sulphate ions which react with water to produce sulphuric acid $\left(\mathrm{H}_{2} \mathrm{SO}_{4}\right)$. The sulphuric acid in turn reacts with $\mathrm{Ca}(\mathrm{OH})_{2}$, one of the hydrated cement products, to form gypsum [8]:

$$
\mathrm{Ca}(\mathrm{OH})_{2}+\mathrm{H}_{2} \mathrm{SO}_{4} \longrightarrow \mathrm{CaSO}_{4} \cdot 2 \mathrm{H}_{2} \mathrm{O} \text { (gypsum) }
$$

Gypsum reacts with cement paste causing different forms of sulphate attacks. If gypsum resulting from the oxidation of sulphide-bearing aggregates reacts with the aluminate phase of the hydration product of cement (or monosulphoaluminate), ettringite is produced as per the following equations $[9,10]$ :

$3 \mathrm{C} \mathrm{H}_{2}$ (gypsum) $+\mathrm{C}_{3} \mathrm{~A}+26 \mathrm{H}_{2} \mathrm{O} \longrightarrow \mathrm{C}_{6} \mathrm{AS}_{3} \mathrm{H}_{32}$ (ettringite) 
Thaumasite is another possible product of a sulphate attack and can have deleterious effects on concrete structures. Thaumasite is a calcium-silicate-sulphate-carbonate-hydrate, which forms at temperatures under $5^{\circ} \mathrm{C}$. The source of sulphate could be ettringite, where thaumasite uses the ettringite as a nucleation site, while calcium $(\mathrm{CaO})$ and silica $\left(\mathrm{SiO}_{2}\right)$ are usually derived from a calcium silicate hydrate $(\mathrm{C}-\mathrm{S}-\mathrm{H})$. The sources of carbonate could be the air, carbonate fillers used to produce Portland cement, or the aggregate itself.

Since aggregates represent about $70 \%$ of the total concrete volume, it is important to identify the proper aggregate to avoid any issues that might cause deterioration in concrete structures. Sulphide-bearing aggregates can cause deterioration in concrete structures when the sulphide minerals in the aggregate oxidize. In addition, this oxidation product can generate sulphate ions, which react with hydrated cement products to form gypsum, ettringite, and thaumasite. These phases are responsible for the extra expansion and severe cracking, causing damage to concrete elements.

Understanding the oxidation mechanism is critical in order to evaluate the potential volume increase, which leads to expansion and light or severe cracking in concrete containing sulphidebearing aggregates. There are many factors that affect this reaction, as will be seen in the following sections. 


\subsection{Sulphide Minerals}

Sulphide minerals are a combination of the element sulphur (atomic number 16) and various kinds of metals, such as iron. Sulphide minerals are reactive when exposed to air and humidity. Their surface chemistry, controlled by the $\mathrm{pH}$, can be studied using spectroscopic methods, especially X-rays, in order to identify the mechanism and reaction rates [11]. Figure 2 1 shows the different types of sulphide minerals.

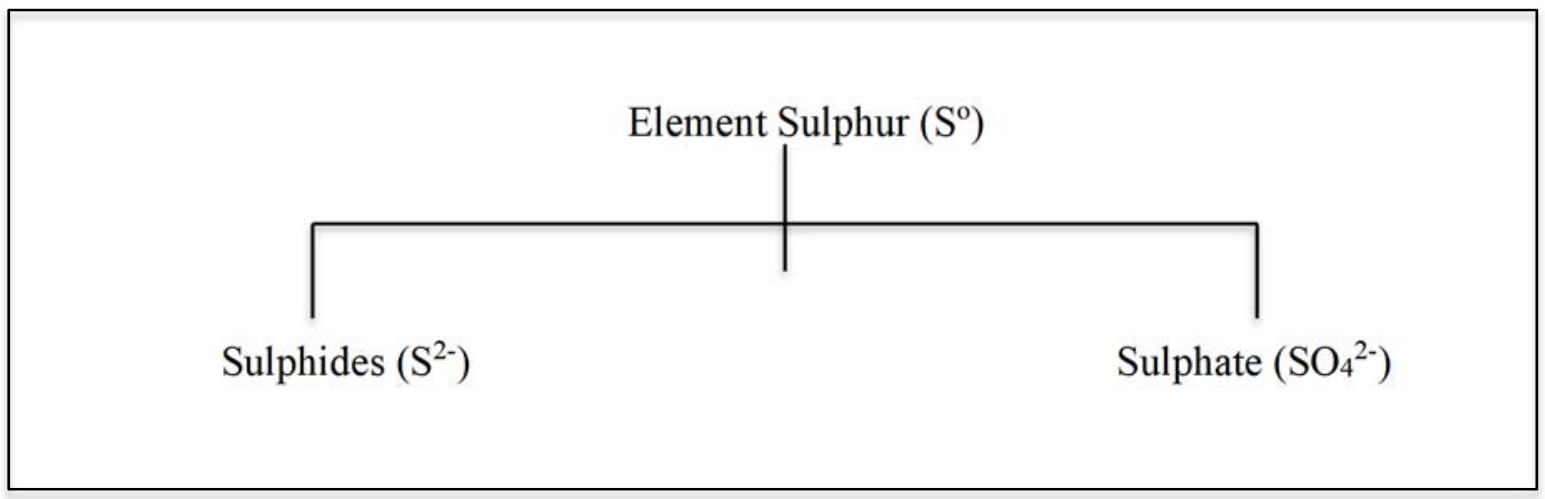

Figure 2 - 1: Types of Sulphide Minerals.

The crystal structures of sulphide minerals are well known and encompass many classical forms of crystal chemistry. For example, the pyrite structure is $\mathrm{FeS}_{2}$ and the pyrrhotite structure is $\mathrm{Fe}_{(1-\mathrm{x})} \mathrm{S}$. Pyrrhotite oxidizes in the presence of moisture and air and forms iron oxyhydroxides (rust). The aggregate that was used to construct the concrete foundations in the Trois-Rivieres region contained various proportions of pyrite and pyrrhotite. The overall ratio of sulphides to aggregate found in the area ranged from $5-7 \%$ of the total aggregate volume [12]. 
Damage to concrete can occur because of the internal reactions caused by the oxidation of sulphide- minerals. The sulphide phases are minor constituents in some rocks. Oxidation of these phases can have harmful effects on concrete if such rocks are used as aggregate. Steger [13] reported that the oxidation of sulphide-bearing aggregates occurs at a relative humidity of $37 \%$ $75 \%$. Several authors have reported the presence of sulphide-bearing aggregates in deteriorated concrete.

\subsection{Mechanisms of Sulphide Oxidation}

It is common knowledge that iron sulphide aggregates are unstable upon exposure to oxygen and air. The iron sulphide aggregate will oxidize and cause acidic formation, after which the oxidation of ferrous products produces ferric which can then form ferric hydroxide (rust) in accordance with the following equations [14]:

$$
\begin{aligned}
\mathrm{Fe}_{1-\mathrm{x}} \mathrm{S}+(2-\mathrm{x} / 2) \mathrm{O}_{2}+\mathrm{xH}_{2} \mathrm{O} & \longrightarrow(1-\mathrm{x}) \mathrm{Fe}^{2+}+\mathrm{SO}_{4}^{2-}+2 \mathrm{x} \mathrm{H}^{+} \\
\mathrm{Fe}^{2+}+1 / 4 \mathrm{O}_{2}+2 \mathrm{H}^{+} & \longrightarrow \mathrm{Fe}^{3+}+1 / 2 \mathrm{H}_{2} \mathrm{O} \\
\mathrm{Fe}^{3+}+3 \mathrm{H}_{2} \mathrm{O} & \longrightarrow \mathrm{Fe}(\mathrm{OH})_{3}+3 \mathrm{H}^{+}
\end{aligned}
$$

The sulphuric acid in turn reacts with one of the hydrated Portland cement paste products $\mathrm{Ca}(\mathrm{OH})_{2}$ to form gypsum, as previously mentioned. Shnorhokian [15] demonstrated that the 
factors that cause sulphide oxidation include new exposure of the surface area of the mineral, the presence of oxygen, moisture, and $\mathrm{pH}$.

\subsection{Iron Sulphide Aggregates}

As mentioned before, the iron rich aggregates are unstable when exposed to humidity and oxygen. This process can lead to rust formation associated with volume increase followed by a series of reactions that can cause severe concrete deterioration. Pyrrhotite dissolves faster during the oxidation process while pyrite dissolves slower $[16,17]$. In addition, the solubility of pyrrhotite is four times faster than pyrite $[4,18,19]$. Figure 2 - 2 shows the main common iron sulphide minerals.

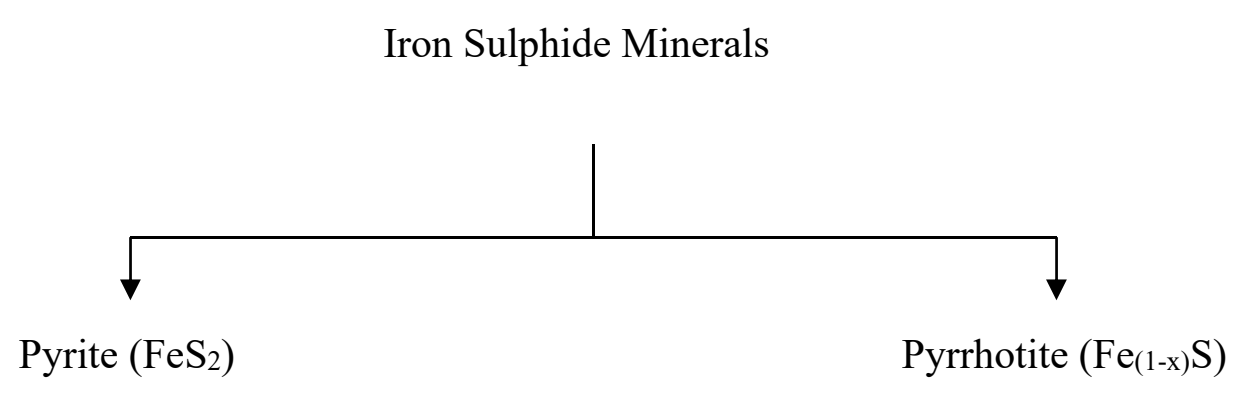

Dissolves slower with the oxidation process

Dissolves faster with the oxidation process

Figure 2 - 2: Properties of Pyrite and Pyrrhotite 
Schmidt [4] argues that the higher the $\mathrm{pH}$ and oxygen concentration and the smaller the particle size, the higher the disintegration of the iron sulphide aggregates. The kinetic reactions of the iron sulphide aggregates when used in concrete also rely on various parameters such as moisture content, and porosity conditions [20].

\subsection{Pyrite $\left(\mathrm{FeS}_{2}\right)$}

Pyrite is a mineral in stone and produces sulphuric acid when it oxidizes upon exposure to water and oxygen. This phenomenon can cause cracking and heaving in the concrete. Pyrite is also defined as a ferrous sulphide (iron sulphide); it is categorized as a sulphide mineral and carries the nickname fool's gold due to its resemblance to gold. Its chemical compound is generally written as $\mathrm{FeS}_{2}$. The mechanism of concrete deterioration when the coarse aggregate used in concrete mixing contains pyrite grains is as follows.

When pyrite grains are exposed to water, oxygen and an alkaline pore water solution of concrete, the exposed surface grains of pyrite will consume water and oxygen, causing the oxidation of iron sulphate and sulphuric acid. Both mechanisms (rust stains and sulphuric acid) cause expansion, and the deterioration of concrete. This internal force can cause cracking, popouts, and micro-cracking in the paste. The latter mechanism causes the internal sulphate attack due to the release of sulphate ions associated with the formation of sulphuric acid. Figure 2 - 3 shows the main product of pyrite grains when expose to oxygen and water. 


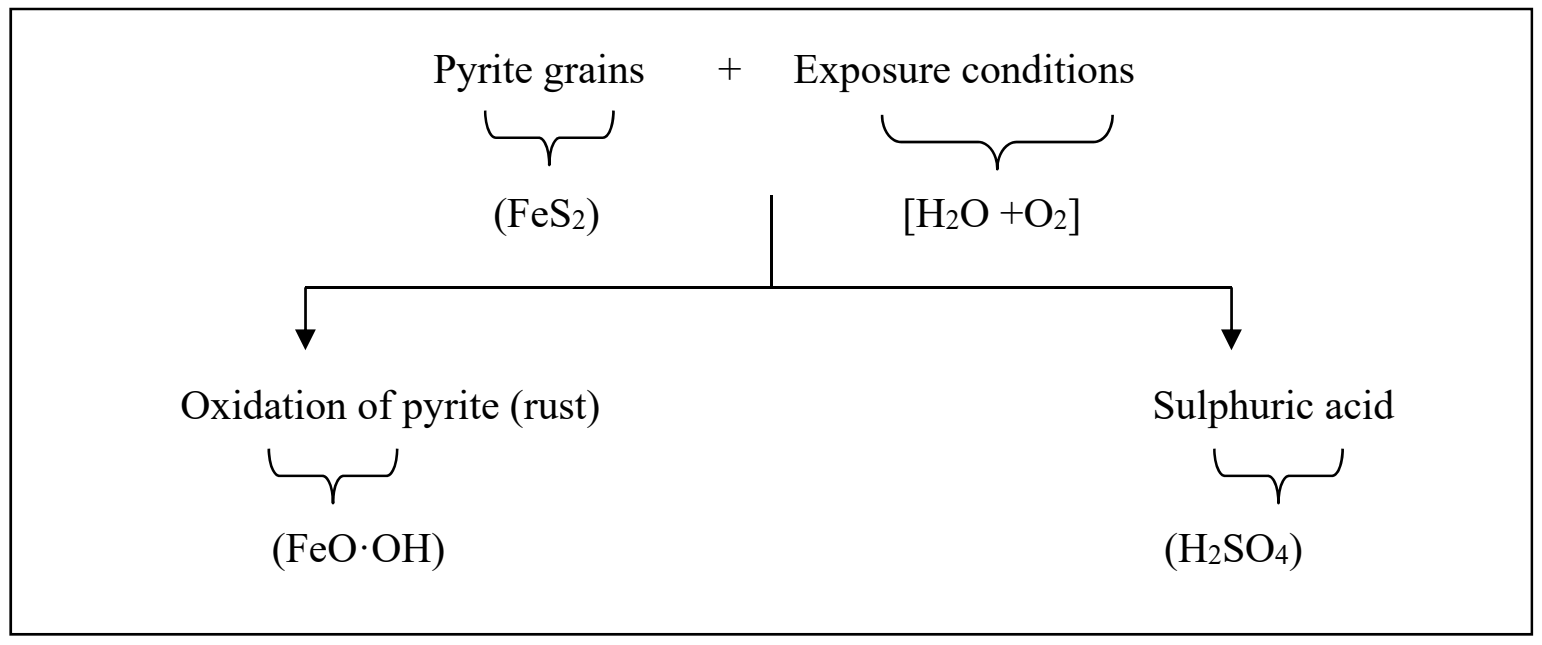

Figure 2 - 3: Products of Pyrite upon Exposure to the Atmosphere.

Shayan [8] examined floor slabs for ten years using X-ray diffraction and a scanning electron microscope (SEM) and found that severe blistering and deterioration of a concrete slab was due to the oxidation of pyrite $(<5 \%)$ found in the coarse aggregates.

\subsection{Pyrrhotite $\left(\mathrm{Fe}_{1-\mathrm{x}} \mathrm{S}\right)$}

Pyrrhotite is an iron sulphide mineral, that when exposed to (i) open air and (ii) moisture conditions for a long time, will develop widespread surface oxidation, which may lead to the formation of a thin overlying layer of ferric (iron III) oxide/hydroxide [21]. This layer is a brown bronze-yellow colour. Over the duration of two years, Tagnit-Hamou et al. [22] examined building foundations using X-ray diffraction and a scanning electron microscope. They found that severe deterioration in the concrete was due to the oxidation of the pyrrhotite grains found in the coarse 
aggregates used to produce the concrete. Figure 2 - 4 shows the main product of pyrrhotite grains when expose to oxygen and water.

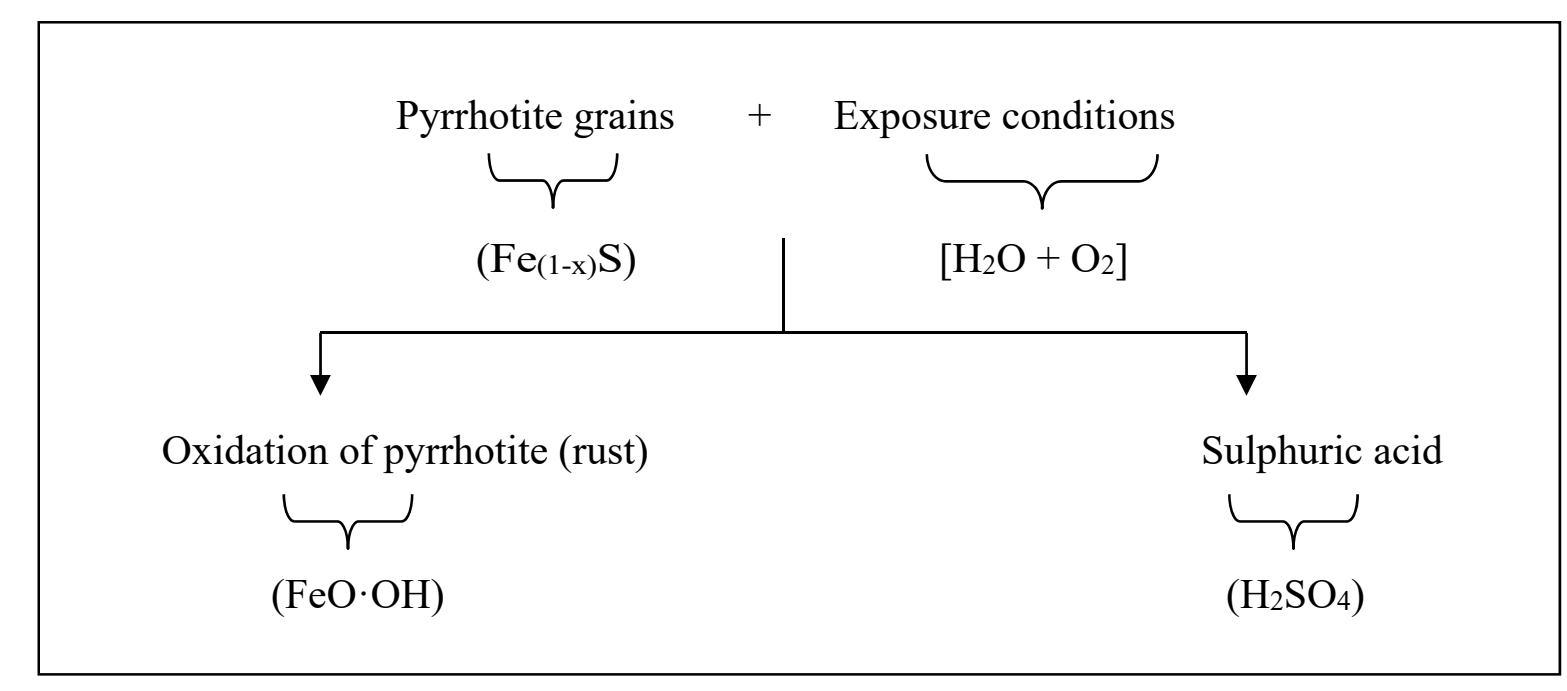

Figure 2 - 4: Products of Pyrrhotite and Exposure to the Atmosphere.

Schmidt et al. [4] found that approximately $30-40 \%$ of the pyrrhotite grains found in the aggregates used to produce old dam concrete were actively reacting. Furthermore, Chinchon et al. [23] reported that throughout the period from 1970 to 1972, some public works and buildings near Barcelona were deteriorated and the concrete used for these buildings was comprised of coarse aggregates with high pyrrhotite grain content. Pyrrhotite is the most prevalent sulphur-rich aggregate in nature after pyrite and can be found in many places around the world, especially Canada, Russia, Australia and China.

There are many factors that can affect the oxidation rate. The first factor is temperature; the higher the temperature the higher the oxidation of pyrrhotite grains. The second factor is the 18 
specific surface area $\left(\right.$ surface area/volume $\mathrm{or}^{2} / \mathrm{m}^{3}$ ). Research has shown that the specific surface (crystal structure) of crystalline pyrrhotite is 2 - 10 times bigger than the crystalline pyrite and this difference could explain why pyrrhotite grains are more reactive and susceptible to faster rates of oxidation process [14]. Janzen et al. [24] noted that the chemical formula of pyrrhotite is $\mathrm{Fe}(1-\mathrm{x}) \mathrm{S}$, with $\mathrm{x}$ ranging from $0(\mathrm{FeS})$ to $0.125\left(\mathrm{Fe}_{7} \mathrm{~S}_{8}\right)$, and that the $\mathrm{Fe}_{7} \mathrm{~S}_{8}$ crystal has a monoclinic structure while $\mathrm{FeS}$ and $\mathrm{Fe}(1-\mathrm{x}) \mathrm{S}$ crystals have orthorhombic and hexagonal structures, respectively. Orlova et al. [25] demonstrated that the hexagonal crystal is much more reactive than the monoclinic structure. Nevertheless, pyrrhotite generally exists as a mixture of mineral phases (hexagonal and monoclinic) and is rarely found as a pure mineral phase.

The main difference between pyrite and pyrrhotite can be summarized in the following paragraphs as follows:

- Pyrite is one of the most common iron sulphides. Chinchon-Paya et al. [16] reported that pyrite particles are composed of $49.03 \% \mathrm{~S}$ and $46.37 \% \mathrm{Fe}$, and that XRD analysis for pyrite produces a sharp single peak at about $33^{\circ}, 2 \theta$. The Vickers hardness number (VHN) for pyrite is between 1505 and 1620, as reported by Craig et al, [26]. Pyrite therefore deforms less readily than other iron sulphides.

- Pyrrhotite is composed of $35.18 \% \mathrm{~S}$ and $61.12 \% \mathrm{Fe}$, Chinchon-Paya et al. [16]. The XRD analysis for pyrrhotite produces a sharp single peak at about $45^{\circ}, 2 \theta$. The same results were obtained by Arnold [27] and Graham [28]. The results obtained by Chinchon-Paya et al. 
[16] show that the degradation of pyrrhotite is much faster than the degradation of pyrite. Pyrrhotite particles generated a larger amount of $\mathrm{SO}_{4}{ }^{2-}$ and $\mathrm{Fe}^{2+}$ than pyrite grains when both aggregates were soaked in a water solution with a constant oxygen flow for almost two months. The results prove that pyrrhotite grains are very harmful to concrete. Moreover, Craig et al. [26] found that the VHN of pyrrhotite is between 230 and 318, which indicates that pyrrhotite is much weaker than pyrite.

\subsection{Sulphate Attack}

The term sulphate attack is generally used to describe the damage that might occur to concrete through the effect of sulphate ions $[29,30]$. Sulphate attack is defined as one of the physical and chemical mechanisms that can attack the concrete. When sulphate ions react with the calcium hydroxide hydrated cement product, gypsum formation occurs, followed by ettringite and thaumasite formation. All of these final products can cause expansion followed by severe cracking in the concrete structure.

Sulphate attack is a complex process and its mechanism depends on several parameters including the nature of the aggregates, the Earth's atmosphere (e.g. sulphate release from ground water table or fertilizers in the soil), the cement composition, environmental issues (e.g. wet/dry cycles), mix proportioning and the water to cement ratio (w/c). Numerous studies have explained how sulphate ions are formed, negatively impacting the sustainability and service life of the concrete constructions [31 - 35]. 
As previously mentioned, sulphate attack is the main reason for the formation of ettringite [36]. The same author reported that the concrete can expand when exposed to sulphate water or sulphate ion concentrations of at least 1000 ppm sulphate. Neville [37] identified the difference between the physical and chemical attack. The physical attack involves salt crystallization, while the chemical attack involves sulphate ion reacting with cement phases.

\subsubsection{Types of Sulphate Attack}

Figure 2 - 5 shows the main types of sulphate attack. This study focuses on the mechanisms and reasons for the chemical sulphate attack, especially the internal sources of sulphate attack. In other words, this study focuses on the deleterious effects of sulphide minerals in aggregates.

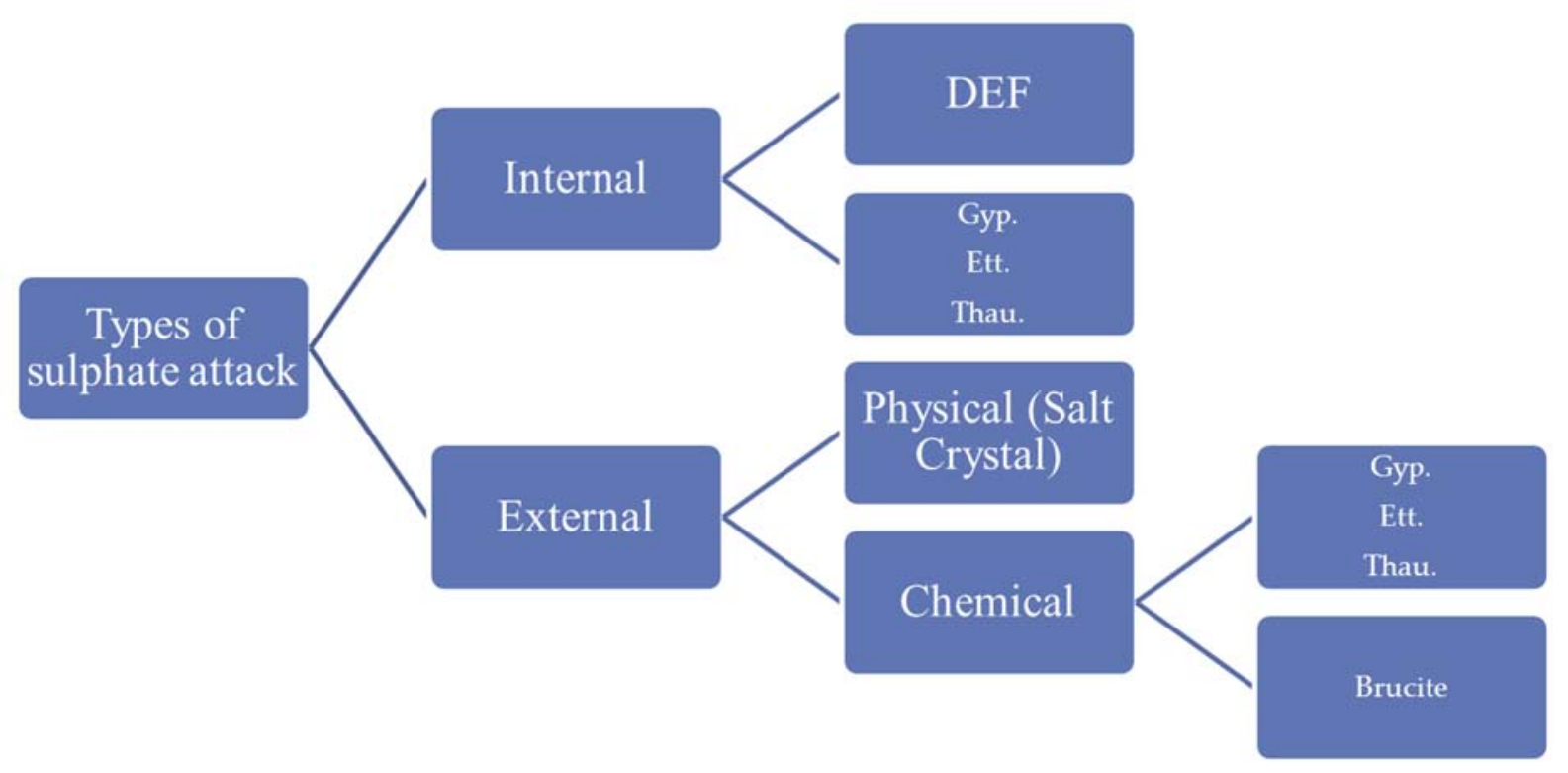

Figure 2 - 5: Breakdown of possible types of sulphate attack. 


\section{- External Sulphate Attack}

Sulphate ions may attack concrete when reacting with hydrated cement products. These reactions cause enough internal pressure to damage the cement paste, causing severe deterioration of the concrete [38].

- Calcium sulphate $\left(\mathrm{CaSO}_{4}\right)$ reacts with calcium aluminate hydrate to form ettringite $\left(\mathrm{C}_{6}-\mathrm{A}-\mathrm{S}_{3}-\mathrm{H}_{32}\right)$

- The physical sulphate attack occurred when, sodium sulphate $\left(\mathrm{Na}_{2} \mathrm{SO}_{4}\right)$ reacts with calcium aluminate hydrate to form ettringite $\left(\mathrm{C}_{6}-\mathrm{A}-\mathrm{S}_{3}-\mathrm{H}_{32}\right)$ and gypsum $\left(\mathrm{CaSO}_{4} \cdot 2 \mathrm{H}_{2} \mathrm{O}\right.$

- Magnesium sulphate $\left(\mathrm{MgSO}_{4}\right)$ when reacting with calcium aluminate hydrate will cause ettringite $\left(\mathrm{C}_{6}-\mathrm{A}-\mathrm{S}_{3}-\mathrm{H}_{32}\right)$, gypsum $\left(\mathrm{CaSO}_{4} \cdot 2 \mathrm{H}_{2} \mathrm{O}\right)$ and brucite $\left[\mathrm{Mg}(\mathrm{OH})_{2}\right]$ formation.

- Thaumasite can form from direct route or woodfordite route as will explained lateer.

\section{- Internal Sulphate Attack}

The formation of sulphate phases such as gypsum, ettringite and thaumasite is a process that leads to severe damage in concrete constructions. These sulphate phases can result in the 
softening, cracking, and the complete disintegration of the concrete [39]. Sulphate attacks on cementing materials may lead to the formation of new phases that have negative effects on the sustainability and life span of concrete constructions. Figure $2-6$ shows the main products of internal sulphate attack.

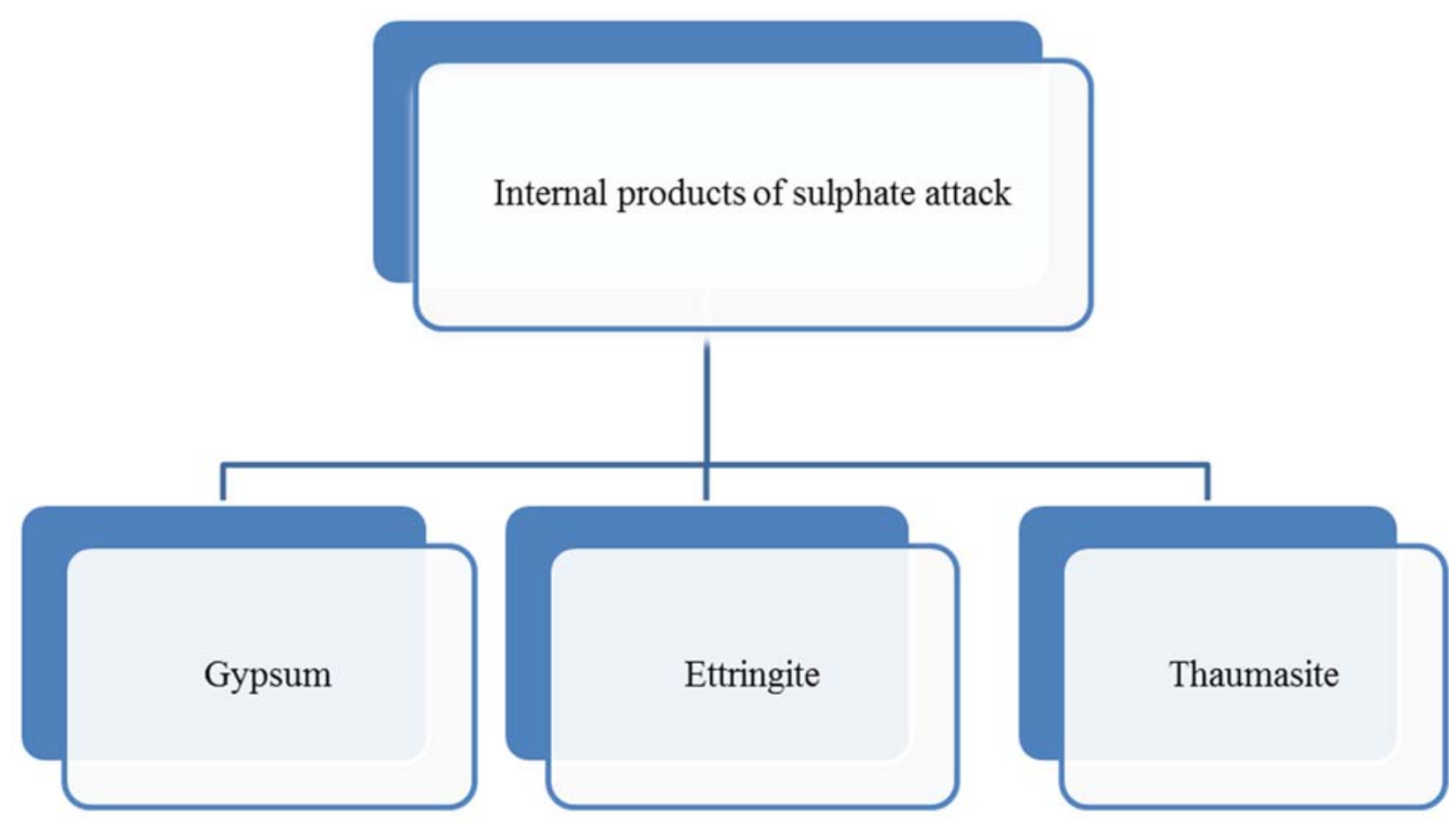

Figure 2 - 6: Internal Products of a Sulphate Attack.

\subsection{The Mechanism of an Internal Sulphate Attack}

When sulphide-bearing, aggregates oxidize, sulphate ions may be released. The sulphate ions react with calcium hydroxide (one of the hydrated cement paste products) to form calcium 
sulfate hydrate (gypsum). This calcium sulphate hydrate can subsequently react with tri-calcium aluminate $\left(\mathrm{C}_{3} \mathrm{~A}\right)$, through the formation of monosulphoaluminate, to form ettringite. At a temperature of under $5^{\circ} \mathrm{C}$ and in the presence of carbon dioxide and a high concentration of sulphate ions, thaumasite can form.

\section{- Gypsum Formation $\left(\mathrm{CaSO}_{4} \cdot \mathrm{H}_{2} \mathrm{O}\right)$}

Herrero et al. [40] illustrated that the chemical formula of gypsum is $\mathrm{CaSO}_{4} \cdot 2 \mathrm{H}_{2} \mathrm{O}$. Gypsum is considered the largest cause of sulphate attacks, along with ettringite and thaumasite. All three of these phases of sulphate attack might cause expansion in the concrete. The formation of these different phases can arise from two main sulphate reactions:

- When gypsum is added to the clinker during the manufacturing of Portland cement in the cooling phase. This process is necessary to regulate the initial setting time for the concrete and the first ettringite crystals may form afterwards.

- When sulphate ions are found in the pore water solution of concrete and react with $\mathrm{CH}_{2}$ (one of the cement hydration products) to form gypsum, which in turn reacts with monosulphate to initiate secondary ettringite formation. 


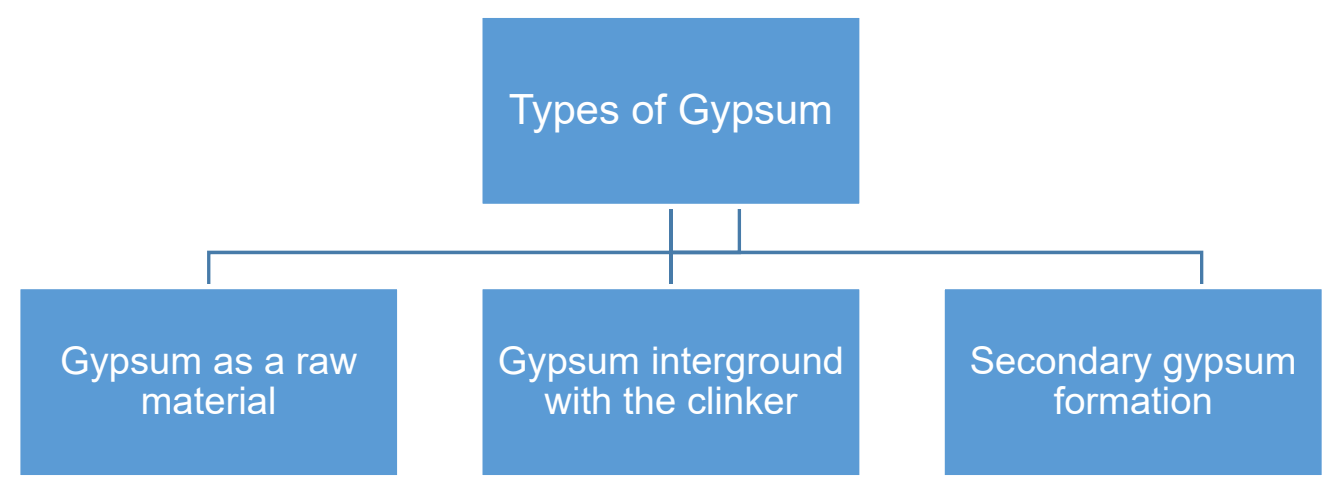

Found in many soils To control the flash set Diff. views for gypsum formation

Figure 2 - 7: Different types of gypsum formation.

There are two different schools of thought regarding the damage mechanism of gypsum. Authors in the first school [41 - 46] report that gypsum may cause disruptive expansion when it forms. Meanwhile, authors in the second school [47 - 50] do not believe that gypsum formation can cause expansion. Crammond [51] illustrated that the peak of 2 theta value is (11.69) for gypsum under the X-Ray diffraction analysis. Gypsum can be found as a raw material in many soils or as a rock constituent [40]. Crammond [51] also reported that when gypsum is heated to a temperature greater than $105^{\circ} \mathrm{C}$, it will become dehydrated gypsum with the chemical composition $\mathrm{CaSO}_{4}$. Figure 2 - 7 displays the different types of gypsum. 


\section{- Ettringite Formation $\left(\mathrm{C}_{6}-\mathrm{A}-\underline{\mathrm{S}}_{3}-\mathrm{H}_{32}\right)$}

There are two types of ettringite formation: positive and negative. Mehta [36] notes that there are two types of ettringite. The first one is called cementitious ettringite, which forms during the hydration process (mainly during the first 14 hours). This ettringite may gradually convert into monosulphualuminate if a high concentration of alumina ions is present. The second type of ettringite formation is expansive. This occurs when monosulphualuminate becomes unstable in the aqueous conditions of a high sulphate ion concentration, where sulphate ions can penetrate the paste within the pore water solution and cause secondary ettringite formation (harmful ettringite). Phase 1 ettringite crystals are long $(10-100 \mu \mathrm{m})[36]$.

Brueckner [52] pointed out in his literature review that damage in concrete caused by sulphate attack was discovered in 1877. The author cited certain studies in which the water enriched compound was found in the damaged matrix and designated as $3 \mathrm{CaO} \cdot \mathrm{Al}_{2} \mathrm{O}_{3} \cdot 3 \mathrm{CaSO}_{4} \cdot 30 \mathrm{H}_{2} \mathrm{O}$ and this formation of salt was called 'cement bacillus, currently known as ettringite. Since that time several studies have focused on the effects caused by ettringite crystals. Ettringite is the crystal form of calcium sulphate aluminate and is found in cement paste [53].

This primary ettringite can dissolve and recrystallize in any open microcracks or voids. Under the SEM, small white crystals, typically 20 to $30 \mu \mathrm{m}$ long, are often observed in cracks, especially in samples taken from old concrete structures. When gypsum is consumed, the 
remaining $\mathrm{C}_{3} \mathrm{~A}$ will continue to react with the primary ettringite to form calcium monosulphoaluminate $\left(3 \mathrm{CaO} \cdot \mathrm{Al}_{2} \mathrm{O}_{3} \cdot \mathrm{CaSO}_{4} \cdot 12 \mathrm{H}_{2} \mathrm{O}\right)$. This monosulphoaluminate is a solid crystal unless additional sulphate ions become available in the cement paste, at which point the sulphate can then combine with monosulphoaluminate to reform ettringite, but in an expansive phase.

Wille and Zhong [54] illustrated that the secondary ettringite formation and thaumasite could cause expansion, resulting in micro-cracking and a volume increase in the concrete matrix. It is well known that primary ettringite formation usually occurs within the first few days of cement matrix development.

\section{- Thaumasite Formation}

The first person to discover thaumasite was Nordenskiold from Sweden in 1878. The word thaumasite is derived from the Greek word (thumazein), which means 'to be surprised'. This refers to thumasite's unusual structure with sulphate, carbonate and hexahydroxysilicate anions [55]. Thaumasite is a calcium carbonate-silicate sulphate hydrate with the following formula [56]:

$$
\mathrm{Ca}_{6}\left[\mathrm{Si}(\mathrm{OH})_{6}\right]_{2}\left(\mathrm{CO}_{3}\right)_{2}\left(\mathrm{SO}_{4}\right)_{2} \cdot 24 \mathrm{H}_{2} \mathrm{O} \quad \text { or } \quad \mathrm{CaSiO}_{3} \cdot \mathrm{CaCO}_{3} \cdot \mathrm{CaSO}_{4} \cdot 15 \mathrm{H}_{2} \mathrm{O} \text {. }
$$

Thaumasite crystals are very similar to ettringite crystals, and present as a needle with a hexagonal structure [56]. Thaumasite crystals have a hardness of 3.5 , a specific gravity of 1.9 , and are usually white in colour [57]. Crammond [58] points out that the deterioration of concrete 
buildings due to the effect of thaumasite formation has been reported in a great number of countries all over the world, including Canada, UK, USA, France, South Africa, Norway, Germany, Switzerland, Slovenia, China and Italy [52]. In 1965, thaumasite was identified as one of the sulphate attack phases in the USA [59]. Macphee and Diamond [60] state that the special form of thaumasite is mentioned in most papers and that around 60 papers were discussed at the first International Conference on Cementitious Materials to discover the main paths of thaumasite formation. Crammond [58] confirmed that there are two main thaumasite formation paths as shown in Figure 2 - 8:

- Thaumasite form of sulphate attack (TSA): The most critical case of this thaumasite formation encountered was in the Canadian Arctic [61]. This type of formation is characterized by apparent damage in concrete structures where the concrete matrix becomes totally or partially replaced by thaumasite and the affected concrete is transformed into mush. In this case, TSA causes softening of the concrete members.

- Thaumasite Formation (TF): In this case, thaumasite can form in cracks and voids without causing any disturbance to the concrete structure, leaving no apparent trace of a sulphate attack. Macphee and Diamond [60] confirmed that not all forms of thaumasite are destructive. 


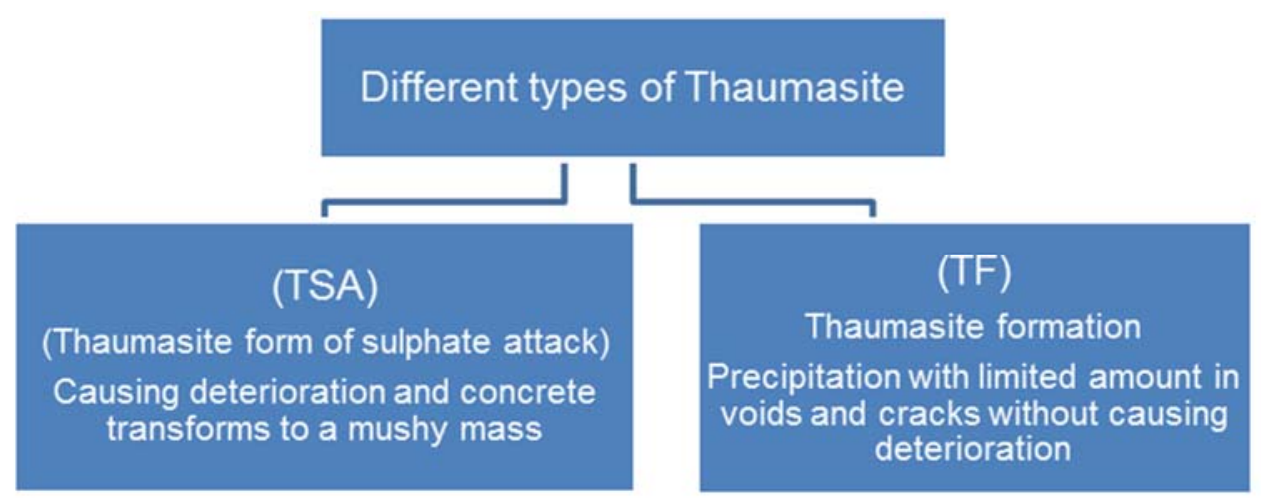

Figure 2 - 8: Possible Consequences of Thaumasite Presence.

Bensted [56] proposed two different routes of thaumasite formation as shown in Figure $2-9$

- The direct route of thaumasite formation: Thaumasite forms due to the reaction of sulphate ions with carbonate, silicate and calcium ions in the presence of water. In other words, the formation occurs directly from the pore water solution in the concrete matrix. This reaction is slow and general reactants contain mainly gypsum, calcium silicate hydrate (C-S-H) and calcite $\left(\mathrm{CaCO}_{3}\right)$.

- The woodfordite route: Thaumasite is formed due to a reaction between silicate (mainly C$\mathrm{S}-\mathrm{H})$, ettringite, carbonate and an excess amount of water. The formation occurs due to the decomposition of ettringite, and thaumasite use the ettringite as an initial nucleation to form. This reaction is also very slow. 


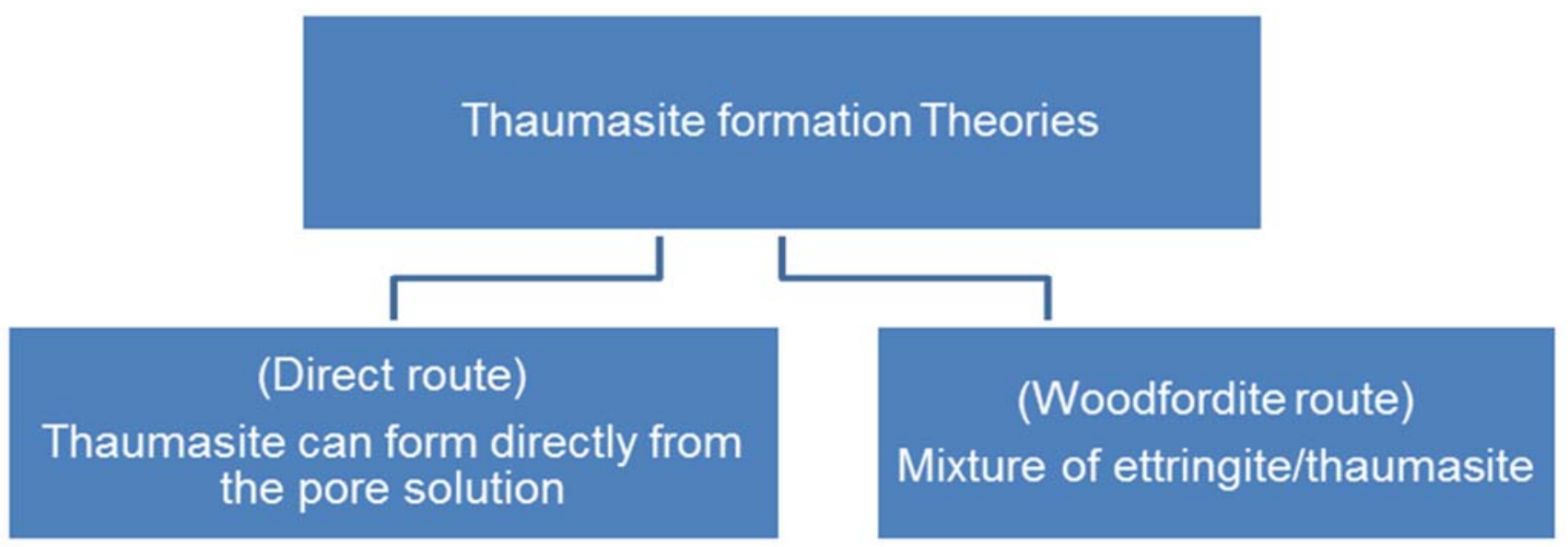

Figure 2 - 9: Theories of Thaumasite Formation.

Woodfordite route vs. direct route: Bensted [56] demonstrated that the direct route is relatively slower than the woodfordite route. The key difference is that ettringite can be used as an initial source for the woodfordite route.

\section{- Factors promoting thaumasite formation}

Thaumasite formation is dependent upon multiple factors as shown in Figure 2 - 10 including:

- $\mathrm{pH}$ : Gaze and Crammond [62] observed that thaumasite can form between a $\mathrm{pH}$ range of 10.5 and 13. Crammond [58] noted that thaumasite becomes much less stable at a $\mathrm{pH}$ lower than 7. Sahu et al. [63] reported that thaumasite formation in a concrete matrix occurs 
between a $\mathrm{pH}$ range of 10 and11.

- Temperature: The Thaumasite Expert Group (TEG) [55] emphasized that TSA takes place at low temperatures, mainly less than $15^{\circ} \mathrm{C}$, while the conventional sulphate attack (with gypsum and/or ettringite) takes place at temperatures greater than $15^{\circ} \mathrm{C}$. Brueckner [52] explained that the main reason for faster formation of thaumasite at lower temperatures is the solubility of carbon dioxide; the solubility of $\mathrm{CO}_{2}$ increases to double the amount in a solution kept at $0^{\circ} \mathrm{C}$ compared to a solution kept at $25^{\circ} \mathrm{C}$. It should be noted that the solubility of portlandite also increases at low temperatures. Koehler et al., Collett et al., and Crammond $[58,64,65]$ demonstrated that the deterioration rate in concrete matrices increased at lower temperatures. Bensted $[56,66]$ stated that thaumasite can form by the direct route at temperatures below $15^{\circ} \mathrm{C}$ (preferably $0-5^{\circ} \mathrm{C}$ ). Thaumasite can form by the woodfordite route at temperatures below $15^{\circ} \mathrm{C}$. A few studies $[60,67]$ have proposed that the thaumasite form of sulphate attack might occur at temperatures greater than $20^{\circ} \mathrm{C}$.

- Source of silicate: The principle source is calcium silicate hydrate (C-S-H), which is one of the hardened cement products. It is the main glue in all Portland cement materials.

- Source of sulphate: The main source for external sulphate attack in the form of TSA, as postulated by the Thaumasite Expert Group [55], is the groundwater and sulphide-bearing soils that are found in vast areas around England. 
- Source of carbonate: Carbonate ions are essential for the formation of thaumasite and can be derived from the aggregate (calcareous limestone or dolomitic limestone aggregate) [52, 58] or from cement filler. This source can also be present in water in the form of bicarbonate or carbonate ions, or in the atmosphere in the form of $\mathrm{CO}_{2}$.

- Source of water: Most of the free water sources naturally come from the ground.

- Additional factors that can play an important role in reducing the deleterious effect of the concrete matrix include $\mathrm{W} / \mathrm{C}$ ratio, curing and compaction, quantity of the filler and type of Portland cement [52]. Thaumasite has received attention [58, 63, 68 - 71] because of its deteriorative reaction with the $\mathrm{C}-\mathrm{S}-\mathrm{H}$, resulting in its decomposition.

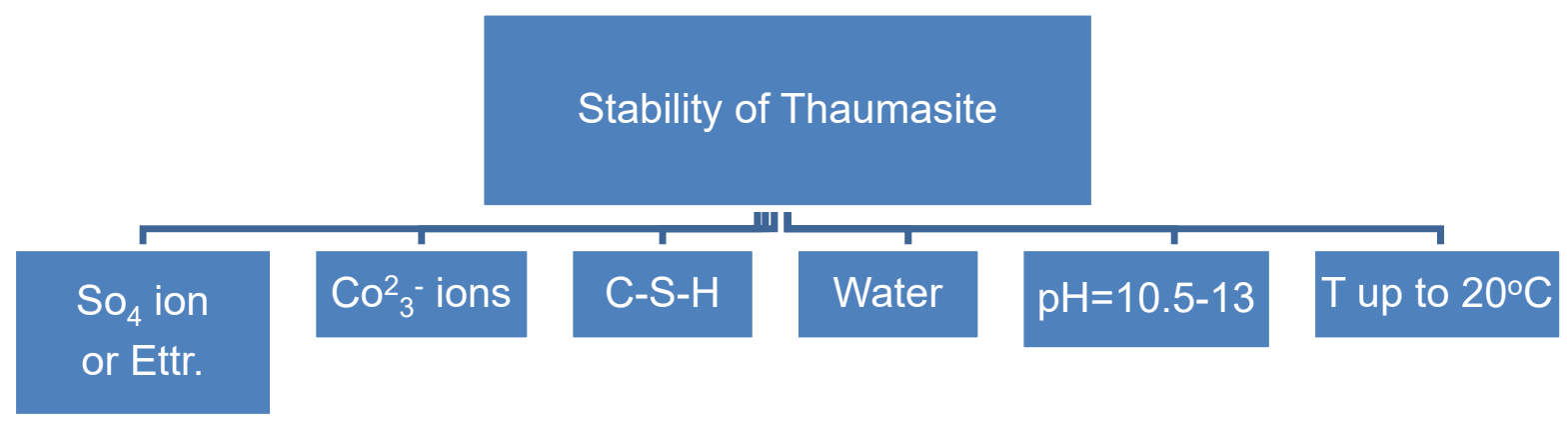

Figure 2 - 10: Factors promoting thaumasite formation 


\subsection{Chlorides in Concrete}

Chloride ions interact with concrete hydration products through chemical or adsorption processes. Both produces new phases in concrete as explained below.

\subsubsection{Chloride Binding}

The expression 'bound chlorides' indicates that the chloride ions cannot move freely in the pore water or solution of concrete. Chloride binding processes are classified as physical or chemical.

Chemical binding describes the process in which the chemical reactions between the aluminate content in the paste and chlorides result in the formation of secondary products (e.g. Friedel's salt [72] or Kuzel's salt. Physical binding describes the process in which absorption arises and leads to the binding of chloride ions to the hydrated products, for instance, the calcium-silicatehydrate $(\mathrm{C}-\mathrm{S}-\mathrm{H})$ in the microstructure of the cement paste [73 - 75]. Physical binding is described as the result of the physical absorption of chlorides on the surface of the C-S-H hydrates.

This process consists of the adsorption of $\mathrm{Cl}^{-}$ions directly into the calcium silicate hydrate C-S-H sheets through Van der Waals forces within the C-S-H interlayer spaces [74]. This occurs because C-S-H sheets contain positive charges which have the ability to promote the absorption of $\mathrm{Cl}^{-}$ions. 
The release of sulphate ions that may already be present in the cement is the most important factor affecting concrete matrices. When the concentration of sulphate ions increases, the binding capability of chloride is reduced due to the formation of AFm group (ettringite or monosulphoaluminate) minerals rather than Friedel's salt [74, 75].

\section{- Friedel's and Kuzel's Salts Mechanism}

As previously mentioned, chemical binding is the result of chemical reactions between cement phases and chlorides, which cause the binding of chloride ions. When the $\mathrm{C}_{3} \mathrm{~A}$ in cement reacts with chloride ions, calcium chloroaluminate hydrate, commonly known as Friedel's salt $\left(\mathrm{C}_{3} \mathrm{~A} \cdot \mathrm{CaCl}_{2} \cdot 10 \mathrm{H}_{2} \mathrm{O}\right)$, is formed. The presence of sulphates in the cement paste creates a strong competition between the chloride and sulphate ions for the existing $\mathrm{C}_{3} \mathrm{~A}$. It is thought that $\mathrm{C}_{3} \mathrm{~A}$ preferentially reacts with sulphates.

During the hydration process of Portland cement in the presence of chlorides, ettringite formed first until all of the sulphate was consumed. Friedel's salt began to form afterwards. In other words, the Friedel's salt formed after all of the sulphate was consumed because the $\mathrm{Al}$ ions have an affinity for sulphate ions [75].

The chemical binding of high chloride concentrations in solutions is mostly attributed to the Friedel's salt formation $\left(\mathrm{C}_{3} \mathrm{~A} \cdot \mathrm{CaCl}_{2} \cdot 10 \mathrm{H}_{2} \mathrm{O}\right)$. In summary, Friedel's salt is defined as the formation of calcium chloroaluminate when chlorides react with the tricalcium aluminate $\left(\mathrm{C}_{3} \mathrm{~A}\right)$. 
Brown \& Bothe [76] observed that the existence of sulphates in cement paste can cause the formation of both ettringite and monosulphate. These stages can subsequently bind chlorides through the development of Kuzel's salt $\left(3 \mathrm{CaO} \cdot \mathrm{Al}_{2} \mathrm{O}_{3} \cdot 1 / 2 \mathrm{CaSO}_{4} \cdot 1 / 2 \mathrm{CaCl}_{2} \cdot 10 \mathrm{H}_{2} \mathrm{O}\right)$ or $\left(\mathrm{C}_{3} \mathrm{~A} \cdot\left(0.5 \mathrm{CaCl}_{2}\right)\left(0.5 \mathrm{CaSO}_{4}\right) \cdot 12 \mathrm{H}_{2} \mathrm{O}\right)$ at high chloride capacities.

Suraneni et al. [77] verified that a portion of the $\mathrm{Cl}^{-}$ions may react with the aluminate phases in the cement paste, forming Kuzel`s and Friedel`s salts. Brown and Doerr [78] found that the ingress of chloride ions led to the formation of Friedel's salts phase. Wu et al. [79] studied the effect of two different types of chloride de-icing on the salt-scaling damage of concrete. They demonstrated that the Friedel`s salts, which formed due to the chemical reaction between calcium aluminate hydrates and either $\mathrm{CaCl}_{2}$ or $\mathrm{NaCl}$, could cause damage to the concrete.

$\mathrm{Wu}$ et al. [79] explained that the deterioration features found during the microstructural examination were cracking and surface spalling. They pointed out that the concrete damage occurred as a result of the formation of Friedel`s salts and the frost damage actions.

Yee-Ching and Yuan et al. [74, 80] explain that the chemical binding between chloride ions and $\mathrm{C}_{3} \mathrm{~A}$ or $\mathrm{C}_{4} \mathrm{AF}$ in the cement matrix leads to the formation of either calcium chloroferrite $\left(\mathrm{C}_{3} \mathrm{~F} \cdot \mathrm{CaCl}_{2} \cdot 10 \mathrm{H}_{2} \mathrm{O}\right)$ or calcium chloroaluminate $\left(\mathrm{C}_{3} \mathrm{~A} \cdot \mathrm{CaCl}_{2} \cdot 10 \mathrm{H}_{2} \mathrm{O}\right)$, also known as Friedel's salt. They confirmed that calcium chloroferrite is a form of Friedel's salt, which contains iron ion instead of alumina ions [81]. Zibara [75] illustrated that the formation of calcium chloroferrite and Friedel's salt is reliant on the total amounts of $\mathrm{C}_{4} \mathrm{AF}$ and $\mathrm{C}_{3} \mathrm{~A}$ in the cement 
composition.

Farnam et al. [82] demonstrated that the interaction between the cementitious matrix and the de-icing salts might cause deterioration in the concrete. This could occur due to the formation of Friedel's salt and Kuzel's salt. He used the following two equations to illustrate the mechanism of Friedel`s salt formation, in the presence of $\mathrm{CaCl}_{2}$ :

$$
\begin{array}{ccc}
\mathrm{CaCl}_{2}+\mathrm{C}_{3} \mathrm{~A}+10 \mathrm{H}_{2} \mathrm{O} & \longrightarrow \mathrm{C}_{3} \mathrm{~A} \cdot \mathrm{CaCl}_{2} \cdot 10 \mathrm{H}_{2} \mathrm{O} \text { (Friedel's salt) } \\
\mathrm{CaCl}_{2}+\mathrm{C}_{4} \mathrm{ASH}_{12} & \longrightarrow & \mathrm{C}_{3} \mathrm{~A} \cdot \mathrm{CaCl}_{2} \cdot 10 \mathrm{H}_{2} \mathrm{O}+\mathrm{CS}_{2} \\
\text { (Monosulphoaluminate) } & \text { (Friedel's salt) (Gypsum) }
\end{array}
$$

Zibara [75] used the following two equations to illustrate the mechanism of Friedel's salt formation in the presence of $\mathrm{NaCl}$ :

$$
\begin{aligned}
& \mathrm{Ca}(\mathrm{OH})_{2}+2 \mathrm{NaCl} \longrightarrow \mathrm{CaCl}_{2}+2 \mathrm{Na}+2 \mathrm{OH} \\
& \mathrm{C}_{3} \mathrm{~A}+\mathrm{CaCl}_{2}+10 \mathrm{H}_{2} \mathrm{O} \longrightarrow \mathrm{C}_{3} \mathrm{~A} \cdot \mathrm{CaCl}_{2} \cdot 10 \mathrm{H}_{2} \mathrm{O}
\end{aligned}
$$

Shayan et al. [83] confirmed that microstructural examination on concrete samples revealed evidence of $\left(\mathrm{C}_{3} \mathrm{~A} \cdot \mathrm{CaCl}_{2} \cdot 10 \mathrm{H}_{2} \mathrm{O}\right)$ calcium chloroaluminate or Friedel's salt formation. This evidence was found within the cracks of samples (with dimensions $75 * 75 * 285 \mathrm{~mm}$ ) which 
were stored at $60^{\circ} \mathrm{C}$ and $100 \% \mathrm{RH}$. These samples were composed of aggregates containing different alkali contents. They demonstrated that the expansion found in these samples could be attributed to the formation of ettringite crystals and Friedel's salt. The same researchers $[83,84]$ demonstrated that the expansion occurred in concrete samples stored in $\mathrm{NaCl}$. It should be noted that the micro-cracks might have been caused by other mechanisms such as ASR, freezing and thawing, sulphate attack phases, dry and wet cycles or the thermal volume change.

It should be noted that many studies have either theoretically or physically proven the formation of Friedel's salts, which they explained through the use of different formation mechanisms with different chloride sources; however, none of these studies could determine whether or not the presence of Friedel`s salts alone in the cement matrices contributed to the expansion. 


\subsection{Supplementary Cementing Materials (SCMs) and their Effect on Concrete}

Supplementary cementitious material (SCM) can be used to replace various percentages of the Portland cement in concrete mixtures. These materials, combined with the Portland cement, will contribute to the hardening of the matrix through pozzolanic activity. These materials are sometimes called mineral admixtures. In general, a pozzolan is an aluminosiliceous or siliceous material that reacts chemically with $\mathrm{CH}$ in the presence of water to form calcium silicate hydrate CSH.

SCMs are material by-products from other natural materials or other industrial processes that are used to improve the durability of concrete, for example, in the form of a substance used to mitigate the effect of a deleterious sulphate attack [85], alkali-aggregate reactivity [86], and a chemical resistant, due to its denser pore structure [87]. Kawabata et al. and Dyer [88, 89] demonstrated that the addition of supplementary cementitious materials in sufficient quantity could form a calcium silicate hydrate gel with a low $\mathrm{Ca} / \mathrm{Si}$ ratio. This low $\mathrm{Ca} / \mathrm{Si}$ ratio can reduce the availability of hydroxide ions into the pore water solution in the concrete matrix, mitigating the deleterious effects of ASR. Mindess et al. [90] explained the mechanism of pozzolanic reactions using the following equation:

\footnotetext{
$\mathrm{CH}($ Calcium hydroxide $)+\mathrm{Si}($ siliceous material $)+\mathrm{H}($ water $) \longrightarrow \mathrm{C}-\mathrm{S}-\mathrm{H}$ (calcium silicate hydrate)
} 
Many studies have demonstrated SCM's role in mitigating the deleterious effect of the external sulphate attack. Kunther et al. [91] found that a partial replacement of ordinary Portland cement (OPC) blended with SCM`s with slag, fly ash or silica fume leads to better resistance to a sulphate attack. The authors listed the following benefits of using SCM`s rich with silica: 1) a denser microstructure that results in low permeability of the matrix, 2) Reduce the portlandite $(\mathrm{CH})$ by the pozzolanic reactions., and produces $\mathrm{CSH}$ of low $\mathrm{Ca} / \mathrm{Si}$ ratio making it more stable.

Kunther et al. [91] investigated the influence of different $\mathrm{Ca} / \mathrm{Si}$ ratios on the calcium silicate hydrate gel and its relationship with sulphate ions. The authors tested mortar bars of blended Portland cement with different $\mathrm{Ca} / \mathrm{Si}$ ratios $(0.83,1.25$ and 1.5$)$ and soaked them in various sulphate solutions. The results revealed that the higher the $\mathrm{Ca} / \mathrm{Si}$ ratio, the higher the expansion observed in the mortar bars due to formation of ettringite. They explained that the ettringite forms due to the leaching of calcium from portlandite and $\mathrm{C}-\mathrm{S}-\mathrm{H}$ at a high $\mathrm{Ca} / \mathrm{Si}$ ratio, and the extra amount of calcium affects the pore water solution composition in the matrix, which can lead to the ettringite crystal formation.

The following paragraphs provide a summary of the common types of SCM used in concrete:

\subsubsection{Fly Ash Class F}

Fly ash class $\mathrm{F}$ is one of the by-products usually produced from coal-fired furnaces and 
possesses calcium content under $15 \%$ [92]. The mean particle size varies between 10 and $15 \mu \mathrm{m}$ and the particles possess a relative density between 1.9 and 2.8 with a surface area ranging from 300 to $500 \mathrm{~m}^{2} / \mathrm{kg}$, and is gray in colour. The chemical composition varies from one material to another; an example of the composition is $42 \% \mathrm{SiO}_{2}, 20 \% \mathrm{Al}_{2} \mathrm{O}_{3}, 5 \% \mathrm{CaO}$ and $1.6 \% \mathrm{Na}_{2} \mathrm{O}$ [93]. Irassar and Batic [94] illustrated that the fly ash class F has good pozzolan activity, which can improve sulphate resistance. The beneficial effects of fly ash are summarized as follows: 1) reacts with $\mathrm{CH}$ to form C-S-H gel, and 2) Decreases concrete porosity.

\subsubsection{Ground Granulated Blast Furnace Slag (GGBFS)}

Slag, GGBFS, is a by-product of iron production which can be used as an SCM. The ground granulated blast furnace is manufactured from the iron blast furnace; the content essentially consists of aluminosilicates and silicates. White in colour, the average slag particle size varies between 10 and $20 \mu \mathrm{m}$ with a relative density between 2.85 and 2.95 , and a surface area ranging between 400 and $600 \mathrm{~m}^{2} / \mathrm{kg}$. a typical oxide composition is $40 \% \mathrm{SiO}_{2}, 10 \% \mathrm{Al}_{2} \mathrm{O}_{3}, 34 \% \mathrm{CaO}$, $0.8 \% \mathrm{Na}_{2} \mathrm{O}$ [93]. Bekir and Turhan [95] demonstrated that the use of slag as an SCM can increase the durability of concrete and play an effective role in decreasing the sulphate-inducing damage.

\subsubsection{Metakaolin}

Metakaolin (MK) is a by-product of high purity kaolin clay obtained through lowtemperature calcination and is used when a very high degree of impermeability is required. It is a 
special calcined clay with a mean particle size varying between 1 and $2 \mu \mathrm{m}$ and can normally use at a range of $8 \%$ to $12 \%$ by mass of the cementing materials. Its relative density is around 2.5 and the surface area is $19,000 \mathrm{~m}^{2} / \mathrm{kg}$. A typical oxide composition is $53 \% \mathrm{SiO}_{2}, 143 \% \mathrm{Al}_{2} \mathrm{O}_{3}, 0.1 \%$ $\mathrm{CaO}, 0.05 \% \mathrm{Na}_{2} \mathrm{O}[96]$.

Al-Akhras [97] investigated the effect of metakaolin in regards to resisting the effects of sulphate attacks in concrete using a 5\%,10\% and 15\% MK replacement. The results revealed that the external sulphate resistance in concrete specimens increased along with increases in the MK replacement.

\subsubsection{High Sulphate Resistance Cement}

High silica fume (HSF) cement is blended cement containing about $8 \%$ silica fume. Silica fume is a very fine powder with a particle size of approximately $1 \mu \mathrm{m}$ that is used when a very high degree of low permeability is required. Silica fume has a relative density between 2.2 and 2.25 and a surface area of $20,000 \mathrm{~m}^{2} / \mathrm{kg}$. It is a by-product of silicon or ferrosilicon. The typical oxides of silica fume are $90 \% \mathrm{SiO}_{2}, 0.4 \% \mathrm{Al}_{2} \mathrm{O}_{3}, 1.6 \% \mathrm{CaO}$, and $0.5 \% \mathrm{Na}_{2} \mathrm{O}$ [96].

Moon et al. [98] investigated the performance of four replacement ratios $0 \%, 5 \%, 10 \%$, $15 \%)$ of silica fume to cement. The samples were made from mortars and were soaked in $5 \%$ sodium sulphate. The results revealed that the mortars that were made with $15 \%$ silica fume showed a greater resistance to deterioration than the samples made with $0 \%$ silica fume. 


\subsection{Current Proposed Test Protocol to Evaluate Sulphide-Bearing aggregate}

The deteriorated concrete in Trois-Rivieres case showed a network of cracks in the foundations and walls $[2,39]$. Early investigations of the concrete from the houses suggested that sulphate attacks play a primary role in the concrete deterioration. This deterioration results from the oxidation of sulphide minerals such as pyrite $\left(\mathrm{FeS}_{2}\right)$ and pyrrhotite $(\mathrm{Fe}(1-\mathrm{x}) \mathrm{S})[39]$.

Following the case that took place in Trois-Rivieres, Quebec, a collaborative research work led by Laval University produced a number of test methods that later on form a proposed testing protocol [3, 99, 100]. Microscopic analysis [99] were examined under the SEM for several sulphide minerals with grain size from $2.5 \mathrm{~mm}$ to $5 \mathrm{~mm}$. These sulphide minerals were tested under different conditions as follows:

1. Three different temperatures $4^{\circ} \mathrm{C}, 38^{\circ} \mathrm{C}$ and $60^{\circ} \mathrm{C}$.

2. $60 \% \mathrm{RH}$ and $80 \%$.

3. Two soaking solutions (sodium hypochlorite and hydrogen peroxide)

The results for this work showed that all sulphide minerals were unstable under the oxidizing condition. The rate of oxidation in the sulphide minerals was increased when the temperature increased at $60^{\circ} \mathrm{C}$. Also, the results illustrated that house-hold bleach (or sodium hypochlorite) is a strong oxidizing agent. 
In the second study [3], an oxidation mortar bar test was developed in which mortar bars are soaked in $6 \%$ sodium hypochlorite solution as an oxidizing agent. The samples were tested under two phases of different exposure condition. In the first phase, 90 days, the samples were soaked for 3 hour in sodium hypochlorite followed by storage the samples in a fume hood at room temperature for additional 3 hours. Following this, the samples were transferred to an oven at $80^{\circ} \mathrm{C} / 80 \% \mathrm{RH}$. This cycle is repeated twice a week. The second phase, other 90 days, the samples were exposed exactly to the same condition as in phase 1 except that the samples stores in a fridge at $4{ }^{\circ} \mathrm{C} / 100 \% \mathrm{RH}$, instead of an oven. Under this testing condition, mortar bar samples made with the same aggregate used in the Trios Riveres case showed high expansion above $0.1 \%$ by the end of phase one, and $0.24 \%$ by the end of phase two. This test was carried out at four laboratories including Ryerson's concrete lab where similar expansion was obtained.

The two stages of the oxidation mortar address the oxidation of the sulphide-bearing aggregate (first stage) and the formation of new product resulting from sulphate attack, (gypsum, ettringite and thaumasite) in the second stage. These secondary products can cause volume change following by cracking and the disintegration to the concrete structures.

In addition to the above, an oxygen consumption test was developed [100] in which aggregates is crushed to a specific size and exposed to certain volume of air in a cell. The reduction in oxygen within a certain period of time (three hours) is taken as a measure of the potential oxidation of the aggregate under evaluation. This test was not investigated in this dissertation; however, it is one of the tests that form the suggested testing protocol. 
The suggested protocol is summarized in Figure $2-11$ [100]. The protocol consists of a chemical test to assess the total sulphur in aggregate, an oxidation test to evaluate the oxygen consumed by aggregate while compacted in a cell with limited volume of air, and an oxidation mortar bar test that involves testing mortar bars under conditions that promote aggregate oxidation and sulphate attack on the cement paste [99].

Based on the flow chart in Figure $2-11$ an aggregate with total sulphur content $<0.10 \%$ does not need further testing and is considered safe in terms of oxidizable sulphide content. Aggregates with total sulphur $>0.10 \%$ requires testing using, first, the oxygen consumption test. If the aggregate shows high oxygen consumption $(>5 \%)$, it is tested using the oxidation mortar bar test which is the last test to determine the aggregate's suitability for use in concrete. The limits specified for mortar bar test are currently under revisions based on more analysis that is also supported by the work carried out in this dissertation. 


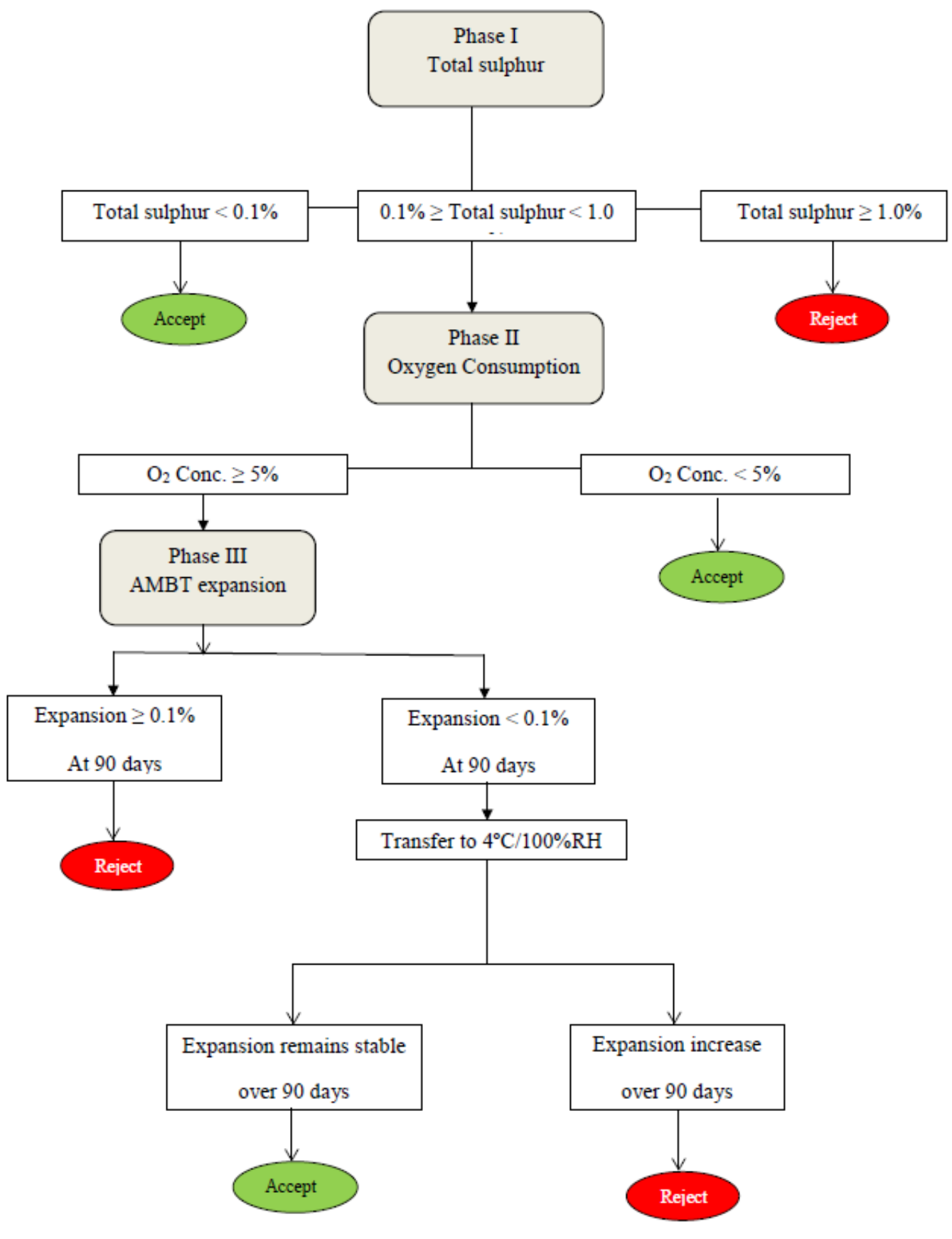

Figure 2 - 11: A test protocol proposed to assess the probable reactivity of sulphide-bearing aggregates [100]. 


\section{Chapter 3}

\section{Development of a Screening Test for Aggregates}

This Chapter focuses on developing a quick and simple screening test to evaluate whether or not an aggregate can contain oxidizable sulphide phases. Different aggregates from Quebec and Ontario were tested. The mineralogy and total sulphur content ( $\mathrm{Sr} \%)$ of each aggregate are listed in Table $3-1$. The investigation started by an attempt to use a modified version of the rock cylinder test developed to test alkali-carbonate reaction in aggregate; however, this initial investigation led to the development a new test that is based on exposing the aggregate to an oxidizing solution and measure the mass loss due to oxidation.

\subsection{Experimental Procedures and Materials}

\subsubsection{Rock Cylinder Test}

The rock cylinder test described in ASTM C586-11 [101] is used to assess the potential alkali-carbonate reactivity of aggregates by soaking small prisms $(40 \mathrm{~mm}$ length and $10 \times 10 \mathrm{~mm}$ cross section) in a $1 \mathrm{~N}$ sodium hydroxide solution. In this test, the samples were prepared from a sulphide-bearing aggregate with very high sulphide content, MW. The mineralogy and total sulphur content (Sr \%; determined by combustion) of this aggregate are listed in Table $3-1$. Following preparation, the aggregate prisms were soaked in sodium hypochlorite and limewater solutions. At the beginning of testing, the prisms shown in Figure 3 - 1 were dried in an oven for 
24 hours at $100^{\circ} \mathrm{C}$. The samples were then soaked at a temperature of $23^{\circ} \mathrm{C}$ for seven days and then dried in the oven at $100^{\circ} \mathrm{C}$ for another seven days. Once the soaking period concluded, the expansion in the samples was measured.

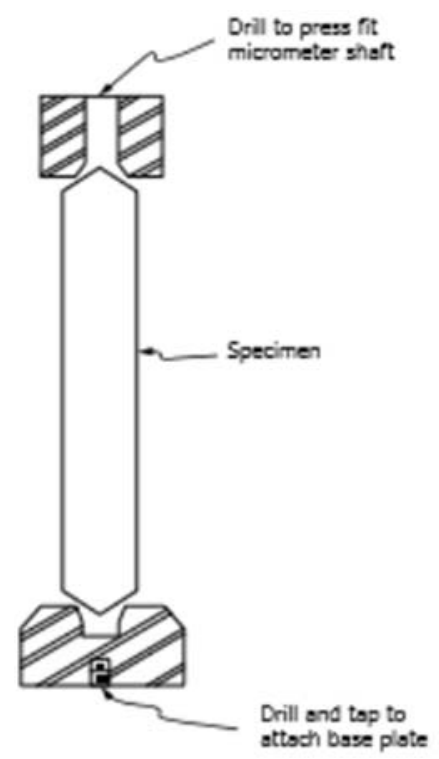

(a)

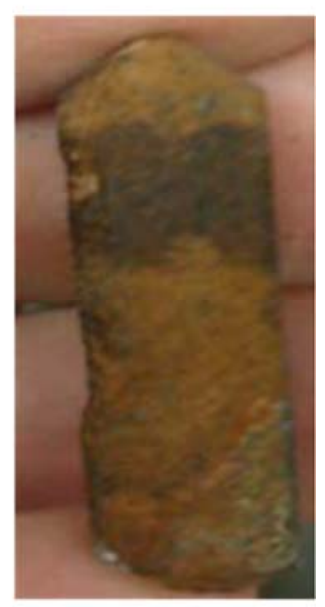

(b)

Figure 3 - 1: (a) Standard shape and size, (b) Rock cylinder sample prepared in the lab

Figure 3 - 2 shows the apparatus (length comparator) that was used for the length change measurements. The specimens were cut into square prisms with pointed ends and angles of $120^{\circ}$. 


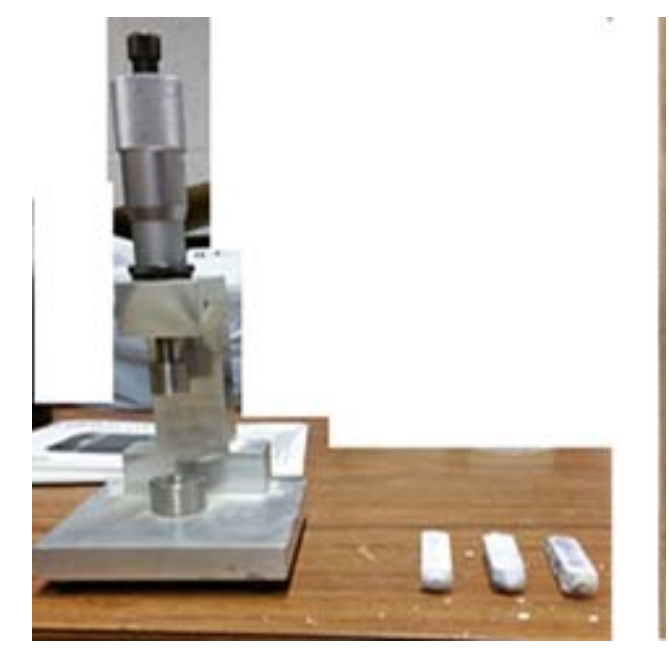

Figure 3 - 2: Apparatus for sample measurement

\subsubsection{Soaking Solutions}

A $6 \%$ sodium hypochlorite solution with a $\mathrm{pH}$ of 12.2 was used in this testing program as a strong oxidizing agent in order to investigate the oxidizing of sulphide-bearing aggregates. A limewater solution with a $\mathrm{pH}$ of 12.39 was used as a reference solution.

\subsection{Development of a new Screening Oxidation Test}

The aggregate samples were prepared following the processes described in ASTM D 75 [102] and ASTM C 702 [103]. The representative coarse aggregate sample was crushed to different sand-size fractions. From these fractions, $100 \mathrm{~g}$ was taken from either the fraction passing 4.75 $\mathrm{mm}$ and retained on $2.36 \mathrm{~mm}$ or the fraction passing $2.36 \mathrm{~mm}$ and retained on $1.18 \mathrm{~mm}$. For aggregates 23 and 46, two samples from the same source (23a and $23 \mathrm{~b}$ or $46 \mathrm{a}$ and 46b) were tested. 


\subsubsection{Test Procedures}

Thirty-one different types of coarse aggregates with different sulphur content were used in this study. The aggregate oxidation test used here involves soaking a certain mass of aggregates of a certain particle size in an oxidizing solution for a given period, followed by washing over a designated sieve and drying in an oven at $80^{\circ} \mathrm{C}$ for one day to determine the mass loss after each cycle of soaking/drying. A 6\% concentration sodium hypochlorite solution (household bleach) was used as the oxidizing solution. A representative $100 \mathrm{~g}$ of each aggregate was exposed to one litre of the sodium hypochlorite at a solid to liquid ratio of 1:10. This high ratio was chosen in order to accelerate the rate and level of oxidation.

The samples were tested in plastic bottles with a sealed lid in order to prevent evaporation when tested at $40^{\circ} \mathrm{C}$, and plastic household containers when tested at room temperature. During the first stage of this research study, the test was run at a temperature of $40^{\circ} \mathrm{C}$ based on Steger's report [13] that the oxidation rate increases with increasing temperature.

The aggregates were first washed and then dried in an oven at a temperature of $100^{\circ} \mathrm{C}$ for 24 hours. The samples were then allowed to cool down for 5 hours, and the initial or zero-mass reading, selected to be $100 \mathrm{~g}$, was then taken. The sample was then soaked in the oxidizing solution for 12 days at $40^{\circ} \mathrm{C}$. At the end of the soaking period, the samples were removed from the solution by draining and washed over a $600-\mu \mathrm{m}$ sieve. The remaining aggregates were then placed in an oven at $80^{\circ} \mathrm{C}$ for one day and then cooled for 5 hours at room temperature. The retained mass was 
measured following the last stage of the cycle (final sieving). Following mass loss determination, the sample was kept at room temperature out of the solution for one day prior to starting the next cycle. This resulted in a total cycle of 14 days or 2 weeks. The mass loss of the aggregates $\Delta \mathrm{m}$ (\%) after $\mathrm{n}$ wetting-drying cycles was calculated as follows:

$$
\Delta \mathrm{m}(\%)=\left[\left(\mathrm{m}_{0}-\mathrm{m}_{\mathrm{n}}\right) / \mathrm{m}_{0}\right] \times 100 \%
$$

Where: $\mathrm{m}_{0}(\mathrm{~g})=$ original or zero mass of the aggregate at 0 cycles $\mathrm{m}_{\mathrm{n}}(\mathrm{g})=$ mass of aggregate after $\mathrm{n}$ wetting-drying cycles.

The aggregate B \& B was used to evaluate the effect of particle size on mass loss. The aggregate MW was tested once in bleach and once in water to assess whether or not oxidation can take place without an oxidizing solution (bleach). Three different B \& B particle sizes were tested: (i) $9.5 \mathrm{~mm}$ to $4.75 \mathrm{~mm}$, (ii) $4.75 \mathrm{~mm}$ to $2.36 \mathrm{~mm}$, and (iii) $1.18 \mathrm{~mm}$ to $0.600 \mathrm{~mm}$. After testing, particle sizes from $4.75 \mathrm{~mm}$ to $2.36 \mathrm{~mm}$ were selected. In addition to measuring mass loss, selected testing solutions were tested for total iron $(\mathrm{Fe})$ and sulphate $\left(\mathrm{SO}_{4}{ }^{2-}\right)$ ions in solution after the first cycle (two weeks) of the test using spectrophotometry. The solution samples were diluted at 1:100 to meet the detection limit of the instrument for $\mathrm{SO}_{4}{ }^{2-}$, which ranges from 0 to $70 \mathrm{mg} / \mathrm{L}$. For the detection of total iron ions, the samples were diluted at 1:500, to bring the concentration to the detection limit of the instrument, which ranges from 0 to $3 \mathrm{mg} / \mathrm{L}$. According to the United States Environmental Protection Agency, the instrument used in this study is acceptable for water, wastewater and seawater analysis. 
After running the test at $40{ }^{\circ} \mathrm{C}$ and obtaining promising results, the research team thought that it might be possible to shorten the testing period. This was investigated using B \& B aggregates between $4.75 \mathrm{~mm}$ to $2.36 \mathrm{~mm}$ at three different temperatures: $23^{\circ} \mathrm{C}, 40^{\circ} \mathrm{C}$, and $80^{\circ} \mathrm{C}$. A shorter cycle consisting of 5 days of soaking at $23^{\circ} \mathrm{C}$ was investigated. The drying and preparation periods remained the same. Once the results were obtained, the same thirty aggregates were re-tested at $23^{\circ} \mathrm{C}$ using the shorter cycle (one week). A smaller participle size $-2.36 \mathrm{~mm}$ to $1.18 \mathrm{~mm}$ - was also adopted to accelerate the results. The washing was carried out using $300-\mu \mathrm{m}$ sieve. Selected solutions were examined for total iron ( $\mathrm{Fe})$ and sulphate $\left(\mathrm{SO}_{4}{ }^{2-}\right)$ ions after the first cycle (one week) of the test using spectrophotometry.

Finally, the same aggregates were tested without crushing. The representative coarse aggregate sample was taken from different size fractions as follows:

$\begin{array}{ll}\text { Size } & \text { Mass (g) } \\ 19.0-13.2 \mathrm{~mm} & 1500 \\ 13.2-9.5 \mathrm{~mm} & 1000 \\ 9.5-4.75 \mathrm{~mm} & 500\end{array}$

This test was run at $40^{\circ} \mathrm{C}, 23^{\circ} \mathrm{C}$, and $5^{\circ} \mathrm{C}$ for aggregates MAS and $\mathrm{C} 2$ to test the effect of temperature, where testing at $5^{\circ} \mathrm{C}$ was found to produce larger mass loss. After that, all the remaining aggregates were tested at $5^{\circ} \mathrm{C}$.

The length of the cycle was 2 weeks in this test, the solid to solution (sodium hypochlorite) ratio was 1: 2 . The aggregates were tested in rectangular plastic containers, with airtight lids for two weeks. During the two-week period, the solution was replaced twice by draining the solution 
and rinsing the aggregate with water over $2.36 \mathrm{~mm}$-sieve. Hence, the aggregates remained in solution for three periods of 4 days each. After the last period, the aggregate was dried at $60{ }^{\circ} \mathrm{C}$ for 24 hours, cooled down for 2 hours, and screened over a sieve two sizes smaller than the minimum size of the tested fraction. The mass loss was determined for each tested fraction.

\subsubsection{Measuring the Ion Concentrations in Oxidizing Solution}

In this testing program, the DR/2010 Spectrophotometer was used for the chemical analysis of the total sulphate ion, total iron ion (as will be discussed later in the oxidation test result subsection), and silica ion (as discussed in the mortar bar section). This instrument was used to investigate the concentration of different dissolved ions in sodium hypochlorite solution after one soaking cycle.

This instrument was originally intended for water, wastewater and bio solid quality tests, especially for determining different minerals, metals and other parameters. The essential function of a spectrophotometer is to convert the percent transmittance into concentration $(\mathrm{mg} / \mathrm{L})$, after which it is finally possible to read out the converted signal to digital numbers and display it through an apparatus screen.

This apparatus was used as an attempt to solve some of the mysteries surrounding problematic aggregates, especially when these aggregates react with a strong agent like a sodium hypochlorite solution. 


\subsubsection{Aggregate Samples and Properties}

The mineralogy and total sulphur content $(\mathrm{Sr} \%)$, determined by combustion, are listed in Table 3 - 1. The aggregates are classified into three categories:

- Cat. 1: aggregates that are known to have high sulphide content or have caused deterioration when used in concrete

- Cat. 2: aggregates that are alkali-reactive

- Cat. 3: aggregates that have no known issues related to sulphide 
Table 3 - 1: Aggregates mineralogy and Total Sulphur ( $\left.\mathrm{S}_{\mathrm{r}} \%\right)$ content.

\begin{tabular}{|c|c|c|c|c|c|}
\hline $\begin{array}{l}\text { Cate- } \\
\text { gory \# }\end{array}$ & $\begin{array}{l}\text { Agg. } \\
\text { ID }\end{array}$ & $\begin{array}{l}\text { Primary } \\
\text { Rock type }\end{array}$ & $\begin{array}{l}\text { Composit- } \\
\text { ion* }\end{array}$ & $\begin{array}{l}\text { Iron sulphur } \\
\text { mineral }\end{array}$ & $\begin{array}{c}\text { Total } \\
\text { Sulphur } \\
\left(\mathrm{S}_{\mathrm{r}} \%\right)\end{array}$ \\
\hline 1 & Ore & Gabbro & $\begin{array}{l}\text { Entirely ore } \\
\text { mineral }\end{array}$ & $\begin{array}{l}\text { Pyrrhotite } \\
\text { Pyrite } \\
\text { Chalcopyrite } \\
\text { Pentlandite }\end{array}$ & 20 \\
\hline 1 & MW & Gabbro & $\begin{array}{l}\text { Entirely ore } \\
\text { mineral }\end{array}$ & $\begin{array}{l}\text { Pyrrhotite } \\
\text { Pyrite } \\
\text { Chalcopyrite } \\
\text { Pentlandite }\end{array}$ & 20 \\
\hline 1 & $52 \mathrm{a}$ & Quartz-biotite schist & $\begin{array}{c}\text { Quartz } \\
\text { Feldspar } \\
\text { Biotite } \\
\text { Muscovite }\end{array}$ & $\begin{array}{c}\text { Pyrrhotite } \\
\text { Pyrite } \\
\text { Jarosite } \\
\text { Limonite }\end{array}$ & 1.50 \\
\hline 1 & $52 b$ & $\begin{array}{l}\text { Same as } 52 \text { a from different } \\
\text { location within the quarry }\end{array}$ & & & 0.54 \\
\hline 1 & $\begin{array}{l}\text { MAS } \\
{[104]}\end{array}$ & Gabbro & $\begin{array}{c}\text { Plagioclase } \\
\text { Biotite } \\
\text { Quartz }\end{array}$ & $\begin{array}{l}\text { Pyrrhotite } \\
\text { Pyrite } \\
\text { Chalcopyrite } \\
\text { Pentlandite }\end{array}$ & $\begin{array}{c}0.73- \\
1.28\end{array}$ \\
\hline 1 & $\begin{array}{l}\text { B\&B } \\
{[104]}\end{array}$ & Gabbro & $\begin{array}{l}\text { Plagioclase } \\
\text { Biotite } \\
\text { Quartz } \\
\text { K-Feldspar }\end{array}$ & $\begin{array}{l}\text { Pyrrhotite } \\
\text { Pyrite } \\
\text { Chalcopyrite }\end{array}$ & $\begin{array}{l}2.13- \\
4.22\end{array}$ \\
\hline 2 & Pitt & Dolomitic limestone & $\begin{array}{c}\text { Calcite } \\
\text { Dolomite }\end{array}$ & - & 0 \\
\hline 2 & Spr & Siliceous limestone & Calcite & - & $0.05-0.09$ \\
\hline
\end{tabular}




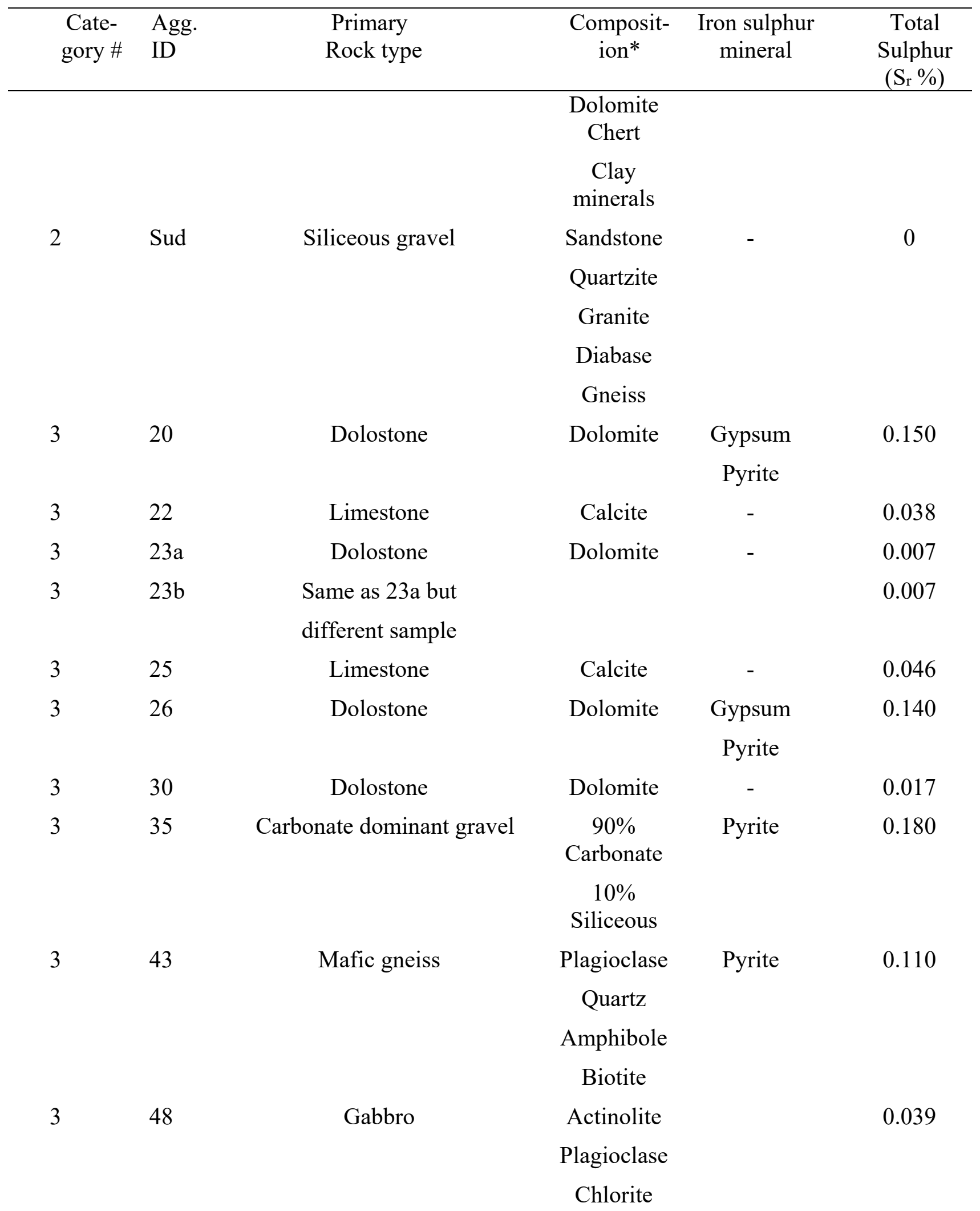




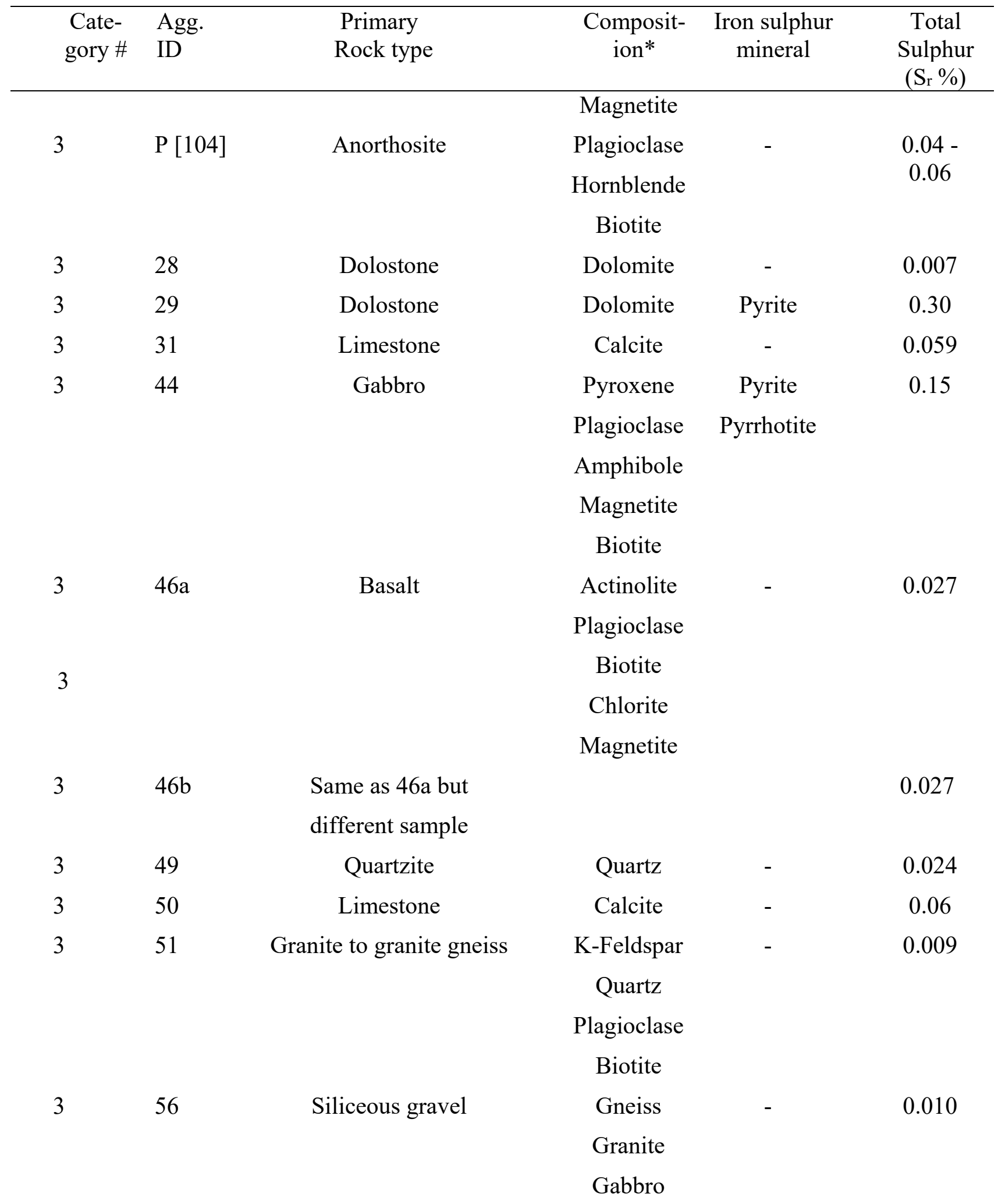




\begin{tabular}{cccccc}
\hline $\begin{array}{c}\text { Cate- } \\
\text { gory \# }\end{array}$ & $\begin{array}{l}\text { Agg. } \\
\text { ID }\end{array}$ & $\begin{array}{c}\text { Primary } \\
\text { Rock type }\end{array}$ & $\begin{array}{c}\text { Composit- } \\
\text { ion* }\end{array}$ & $\begin{array}{c}\text { Iron sulphur } \\
\text { mineral }\end{array}$ & $\begin{array}{c}\text { Total } \\
\text { Sulphur } \\
\left(\mathrm{S}_{\mathrm{r}} \%\right)\end{array}$ \\
\hline 3 & 57 & Siliceous gravel & $\begin{array}{c}\text { Mafic to } \\
\text { intermediat } \\
\text { e granite } \\
\text { gneiss }\end{array}$ \\
\end{tabular}

*Main rock and/or mineral compositions in decreasing order of abundance (listed most to least abundant)

\subsection{Results and Discussion}

\subsubsection{Rock Cylinder Test Results}

Figure 3 - 3 shows the expansion results for the MW aggregate when tested in two different soaking solutions (sodium hypochlorite and limewater). The testing program was only carried out for two cycles because the edges of the samples tested in sodium hypochlorite were disintegrated. As a result, the expansion measurements could not be taken.

Figure 3 - 4 shows the samples after only two cycles. The broken edges and oxidation are clear and it can also be seen that the disintegration of the rock is mainly in the form of material loss. The results indicate that although the sodium hypochlorite solution has a lower $\mathrm{pH}$ than the limewater solution, the expansion in the prisms soaked in sodium hypochlorite was much higher than that of the prisms soaked in limewater. Figure $3-4$ also shows the precipitation of very tiny brown particles (rust) which can easily be seen by the naked eye. 
It should be noted that this test was carried out for one type of rich sulphide aggregate due to the fact that it was very difficult to find large pieces for all the other aggregates.

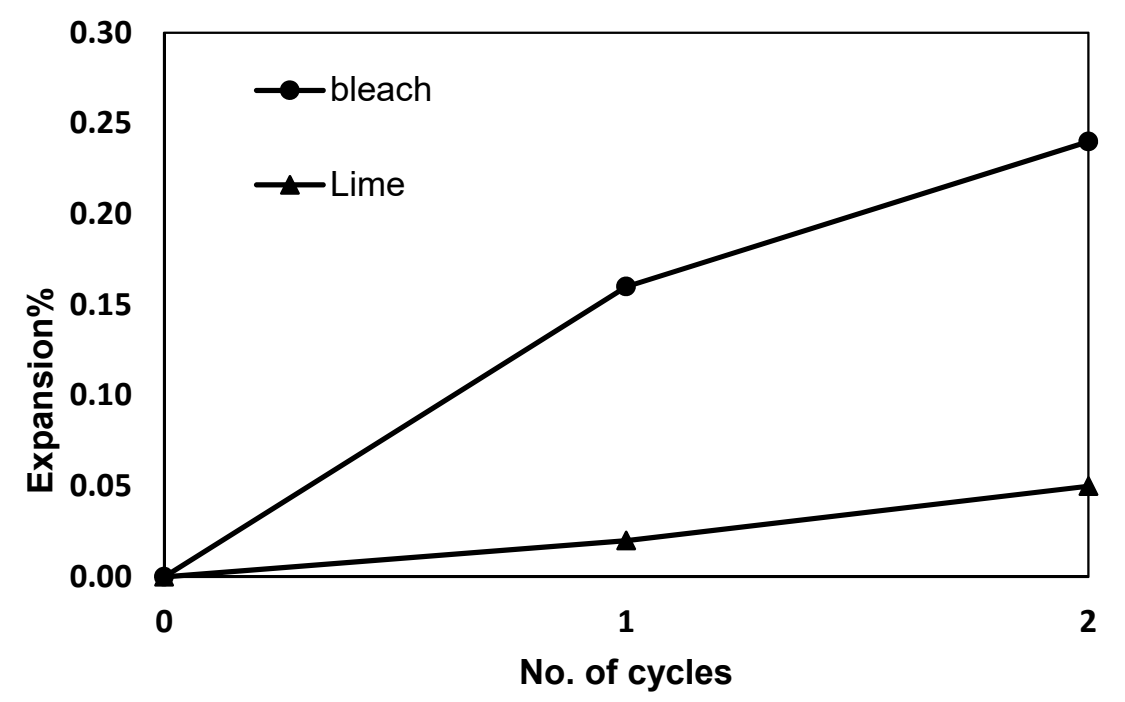

Figure 3 - 3: Expansion in the MW aggregate in two different solutions
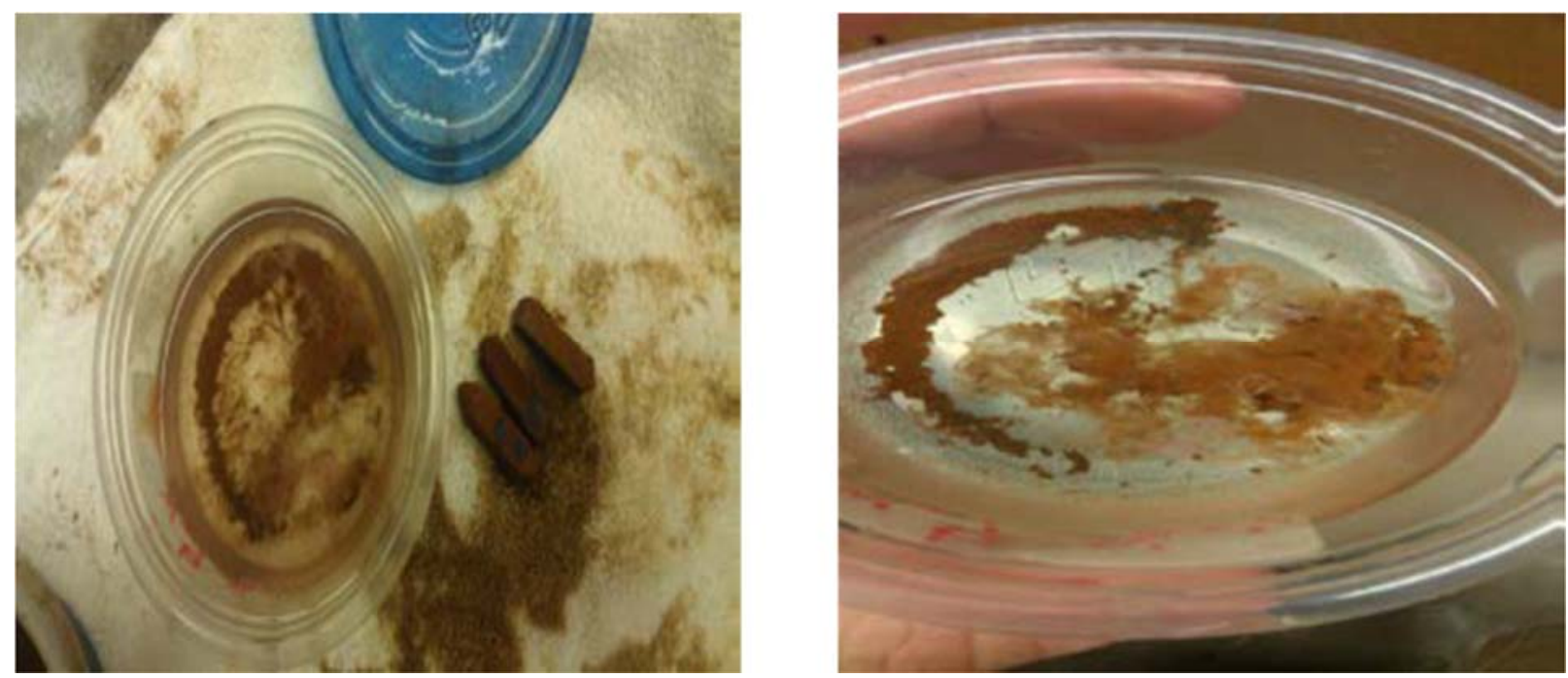

Figure 3 - 4: MW oxidized samples and some iron oxide precipitated onto the container 
It was clear from this test that the oxidation manifests itself better as a disintegration of the rock which can be measured as loss of mass from the original sample. This led to the development of the aggregate oxidation test described in the coming subsection.

\subsubsection{Aggregate Oxidation Test Results}

\subsubsection{Testing at $40^{\circ} \mathrm{C}$ Using Two-week Cycles}

As previously mentioned, the effect of particle size was evaluated using the B \& B aggregate. Two MW aggregate samples (size $4.75 \mathrm{~mm}-2.36 \mathrm{~mm}$ ) were tested in a sodium hypochlorite solution and water in order to investigate whether the wetting and drying cycle, without sodium hypochlorite, can promote oxidation.

Figure 3 - 5 shows that the finer the sample, the higher the oxidation rate, especially at early ages. However, the smallest size, $1.18 \mathrm{~mm}-0.600 \mathrm{~mm}$, was too hard to handle, sticking to the side of the bottles making it more difficult to drain. Based on that, the size $4.75 \mathrm{~mm}-2.36 \mathrm{~mm}$ was chosen. 


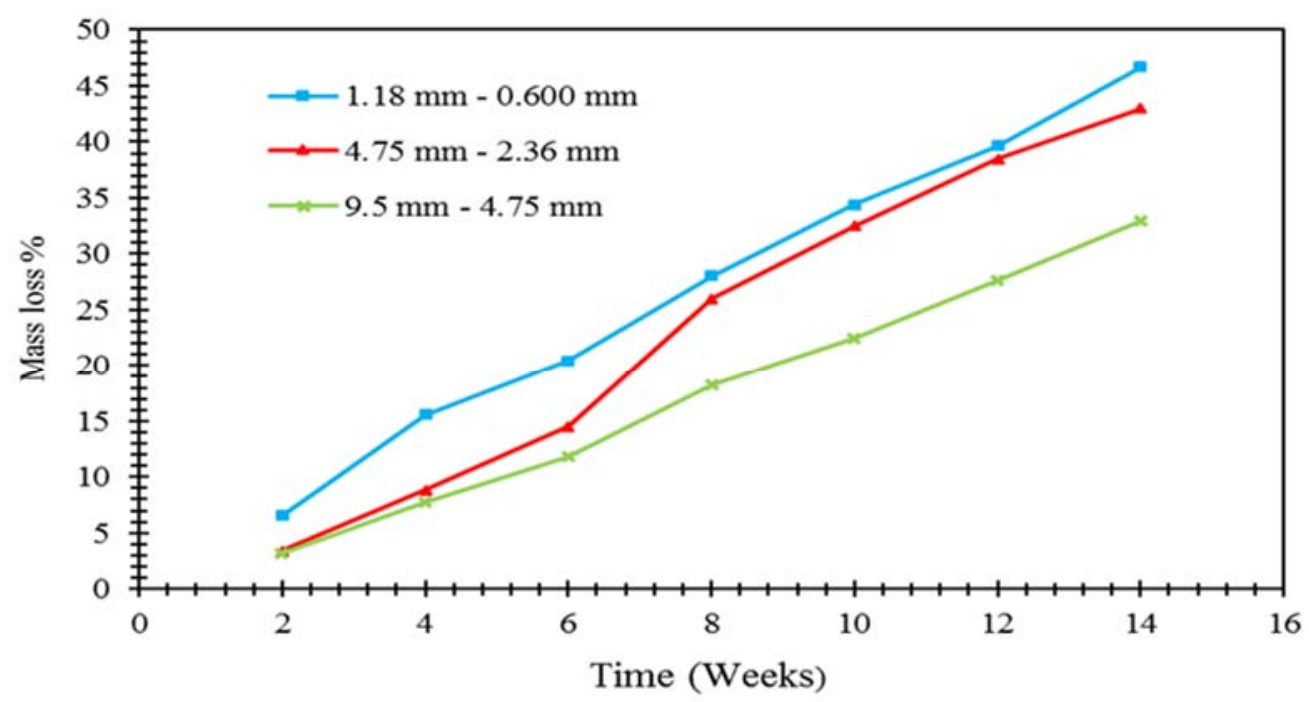

Figure 3 - 5: Effects of particle size on mass loss using the B \& B aggregate, tested using a 2week cycle at $40^{\circ} \mathrm{C}$

Figure 3 - 6 shows that running the test without the sodium hypochlorite solution (in water) does not produce considerable mass loss, even when an aggregate with very high level of oxidizable sulphide (B \& B) is used. 


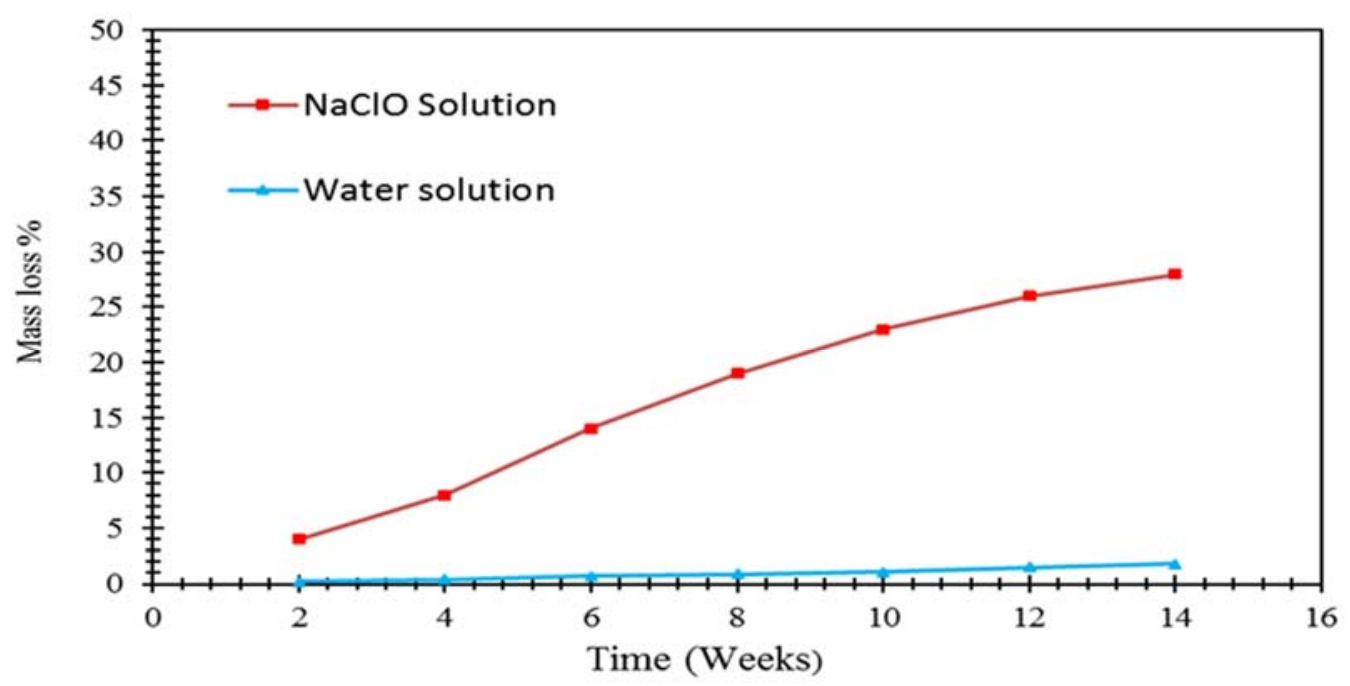

Figure 3 - 6: Effects of water and $\mathrm{NaClO}$ solution on mass loss of $\mathrm{MW}$ aggregate, tested using a 2-week cycle at $40^{\circ} \mathrm{C}$.

The mass loss $\%$ results for all thirty aggregates are listed in Table $3-2$. The aggregates were listed in descending order based on the total sulphur content. The mass loss $\%$ after two weeks (one cycle) ranged from $6.0 \%$ to $0.0 \%$. After 14 weeks (seven cycles), the mass loss $\%$ ranged from $32 \%$ to $0.1 \%$. Based on the results of the samples tested, a limit can be set to distinguish between aggregates that are known to have oxidizable sulphide and aggregates that do not. For instance, a limit of $1.0 \%$ can be used after one cycle or two weeks, or $3 \%$ at seven cycles or 14 weeks. The results reveal that a higher number of cycles increases the range of mass loss.

In addition to the mass loss, the colour change of the sodium hypochlorite solution provides a good indication of the presence of oxidizable sulphide, as shown in Figure 3 - 7. The brown colour is very clear in all aggregates that have a sulphur content $>0.54 \%$ and are known to have 
oxidizable sulphide minerals.

Table 3 - 2: Mass loss results and total Sulphur ( $\mathrm{Sr} \%)$ for aggregates tested at $40^{\circ} \mathrm{C}$ using particle size $4.75 \mathrm{~mm}$ to $2.36 \mathrm{~mm}$. Each cycle was two weeks, and the solid to solution ratio was 1:10.

\begin{tabular}{|c|c|c|c|c|c|c|}
\hline Cat. \# & Aggregate & $\begin{array}{c}\text { Total } \\
\text { sulphur } \\
\text { (Sr \%) }\end{array}$ & $\begin{array}{c}\text { Mass } \\
\text { loss } \% \\
\text { Cycle } \\
1 \\
\end{array}$ & $\begin{array}{c}\text { Mass } \\
\text { loss } \% \\
\text { Cycle } \\
2 \\
\end{array}$ & $\begin{array}{c}\text { Mass } \\
\text { loss } \% \\
\text { Cycle } \\
3 \\
\end{array}$ & $\begin{array}{c}\text { Mass } \\
\text { loss } \% \\
\text { Cycle } \\
7 \\
\end{array}$ \\
\hline 1 & Ore & 20.0 & 6.0 & 12.0 & 20.0 & 32.0 \\
\hline 1 & MW & 20.0 & 4.0 & 8.0 & 14.0 & 28.0 \\
\hline 1 & $52 \mathrm{a}$ & 1.50 & 5.0 & 9.0 & 12.0 & 14.0 \\
\hline 1 & MAS & 1.00 & 3.0 & 6.0 & 8.0 & 11.6 \\
\hline 1 & $52 \mathrm{~b}$ & 0.54 & 3.1 & 5.0 & 6.2 & 6.5 \\
\hline 3 & 29 & 0.30 & 0.2 & 0.4 & 0.7 & 1.8 \\
\hline 3 & 35 & 0.18 & 0 & 0 & 0.5 & 1.6 \\
\hline 3 & 20 & 0.15 & 0.5 & 0.5 & 0.9 & 1.2 \\
\hline 3 & 44 & 0.15 & 0 & 0.6 & 0.6 & 0.9 \\
\hline 3 & 26 & 0.14 & 0 & 0 & 0.5 & 1.5 \\
\hline 3 & 43 & 0.11 & 1.0 & 1.4 & 1.8 & 2.4 \\
\hline 3 & 50 & 0.06 & 0.2 & 0.2 & 0.2 & 1.2 \\
\hline 3 & 31 & 0.059 & 0 & 0 & 0 & 0.1 \\
\hline 3 & 57 & 0.050 & 1.2 & 1.2 & 2.0 & 1.0 \\
\hline 3 & 25 & 0.046 & 0 & 0 & 0 & 0.2 \\
\hline 3 & $\mathrm{P}$ & 0.04 & 0 & 0.3 & 0.3 & 1.8 \\
\hline 3 & 48 & 0.039 & 0 & 0 & 0 & 0.3 \\
\hline 3 & 22 & 0.038 & 0 & 0.1 & 0.2 & 0.4 \\
\hline 3 & $46 a$ & 0.027 & 0 & 0 & 0 & 0.2 \\
\hline 3 & $46 b$ & 0.027 & 0.3 & 0.5 & 0.8 & 1.2 \\
\hline 3 & 49 & 0.024 & 0 & 0 & 0 & 0.1 \\
\hline 3 & 30 & 0.017 & 0 & 0 & 0 & 0.1 \\
\hline 3 & 56 & 0.01 & 0 & 0 & 0 & 0.1 \\
\hline 3 & 51 & 0.009 & 0 & 0 & 0 & 0.2 \\
\hline 3 & $23 \mathrm{a}$ & 0.007 & 0 & 0 & 0 & 0.3 \\
\hline 3 & $23 b$ & 0.007 & 0 & 0 & 0.4 & 1.1 \\
\hline 3 & 28 & 0.007 & 0 & 0 & 0 & 0.2 \\
\hline 2 & Sud & 0 & 0 & 0 & 0 & 0.4 \\
\hline 2 & Pit & 0 & 0 & 0 & 0 & 1.5 \\
\hline 2 & Spr & 0 & 1.0 & 1.0 & 1.0 & 1.0 \\
\hline
\end{tabular}




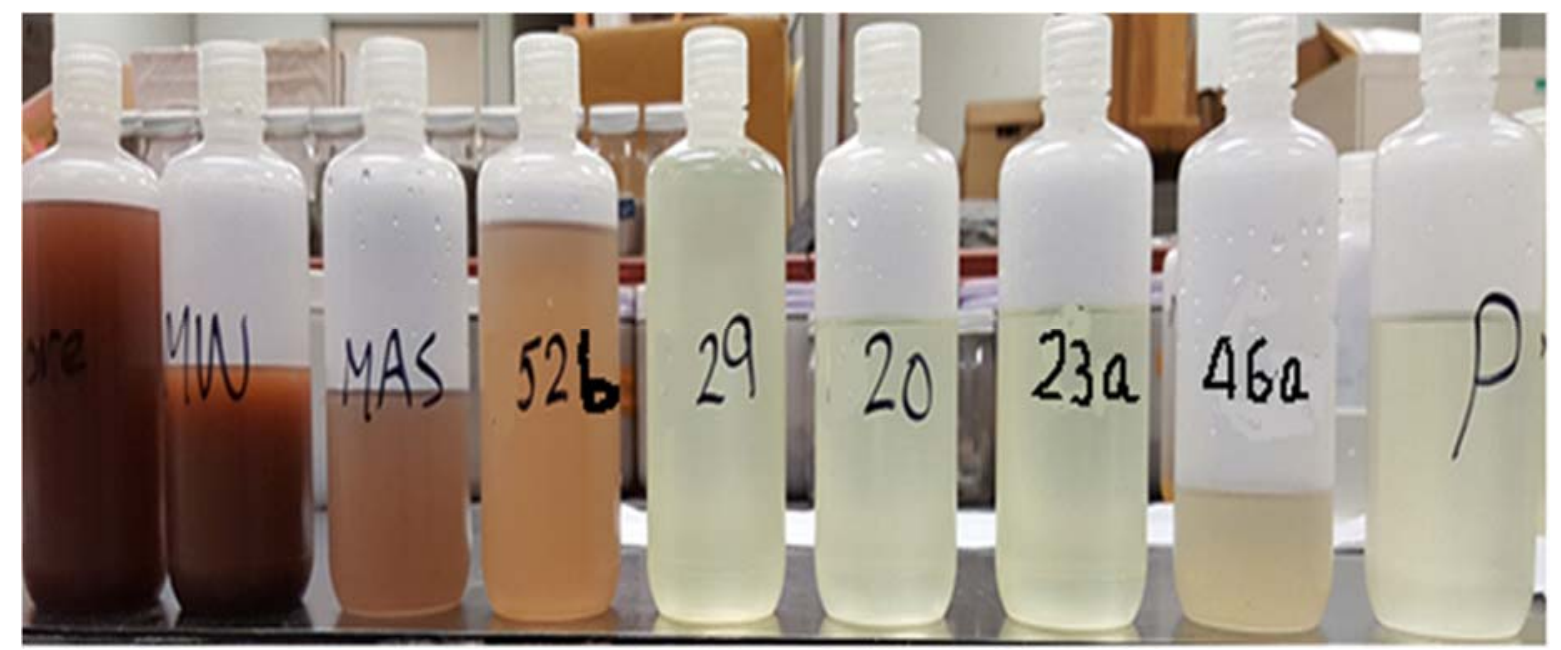

Figure 3 - 7: The colour of sodium hypochlorite solution after the first cycle (two-weeks) of the test.

The change in $\mathrm{pH}, \mathrm{Fe}$, and $\mathrm{SO}_{4}$ ions was also tested and the results are presented in table 3 - 3 .

Table 3 - 3: Change in $\mathrm{pH}$, sulphur, and iron in sodium hypochlorite solution after one cycle of 12 days soaking at $40^{\circ} \mathrm{C}$. Initial $\mathrm{pH}$ of the solution was 12.2 .

\begin{tabular}{cccccccccc}
\hline Aggregate & Ore & MW & MAS & $52 \mathrm{~b}$ & 29 & 20 & $46 \mathrm{a}$ & $23 \mathrm{a}$ & $\mathrm{P}$ \\
\hline $\begin{array}{c}\text { Mass loss after } \\
\text { cycle \#1 }\end{array}$ & 6.0 & 4.0 & 3.0 & 3.1 & 0.2 & 0.5 & 0 & 0 & 0 \\
$\begin{array}{c}\text { Total Sulphur } \\
\text { Sr\% }\end{array}$ & 20.0 & 20.0 & 1.0 & 0.54 & 0.30 & 0.15 & 0.027 & 0.007 & 0.04 \\
$\quad \mathrm{pH}$ & 8.0 & 8.5 & 11.9 & 12.0 & 12.1 & 12.1 & 12.1 & 12.0 & 12.0 \\
$\begin{array}{c}\text { Total iron ion } \\
\text { (Fe) (mg/L) }\end{array}$ & 600 & 525 & 75 & 29 & 10 & 4.5 & 3.0 & 1.0 & 0 \\
$\begin{array}{c}\text { Total sulphate } \\
\left.\text { ion (SO4 } 4^{2-}\right) \\
\quad(\mathrm{mg} / \mathrm{L})\end{array}$ & 5200 & 4500 & 700 & 310 & 160 & 400 & 0 & 0 & 0 \\
$\begin{array}{c}\text { Sulphate/Iron } \\
\text { (m) }\end{array}$ & 8.7 & 8.6 & 9.33 & 10.7 & 16 & 88.9 & & & \\
\hline
\end{tabular}


The results in Table 3 - 3 reveal that the $\mathrm{pH}$ of aggregates that are known to have a high level of sulphide content (i.e. Ore \& MW) dropped significantly. The decrease in the pH of MAS and 52b, which contain medium sulphide content, was not significant, suggesting that monitoring the $\mathrm{pH}$ alone is not suitable for most sulphide aggregates. This might be because the solid to solution ratio used in this test was 1:10 (a relatively high volume of solution) which requires a lot of oxidation products (sulphuric acid) to produce a significant reduction in the $\mathrm{pH}$.

The results demonstrate that the higher the mass loss, the higher the level of $\mathrm{SO}_{4}$ and iron ions in the solution. It is interesting to see that the ratio of sulphate-to-iron is in the range of 8 to 11 for the sulphide aggregates Ore, MW, MAS, and 52b. The ratio is different for aggregates with no sulphide. This ratio does not correspond to the expected mass ratio of S:Fe in pyrite or pyrrhotite. This is because the oxidation process produces a ferrous iron that oxides and precipitates in different forms, including ferric hydroxide or oxyhydroxides, such as ferrihydrite and goethite.

\section{- Repeatability of the test at $40^{\circ} \mathrm{C}$}

The repeatability of the oxidation test at $40^{\circ} \mathrm{C}$ was examined using two aggregates: MAS and C2 where MAS represents sulphide-bearing aggregate and C2 represents aggregate with no sulphide. The results are presented in Table $3-4$. 
Table 3 - 4: The standard deviation and coefficient of variation for MAS and C2 aggregates at $40^{\circ} \mathrm{C}$.

\begin{tabular}{lcc}
\hline \multicolumn{1}{c}{ Aggregate size } & MAS & $\mathrm{C} 2$ \\
\hline $.75 \mathrm{~mm}-2.36 \mathrm{~mm}$ at $40^{\circ} \mathrm{C}$ & 3.0 & 0 \\
Samples mass loss $(\%)$ & 3.1 & 0 \\
& 3.3 & 0 \\
Mean & 3.1 & 0 \\
Variance & 0.02 & 0 \\
Observation & 3 & 3 \\
Standard deviation & 0.13 & 0 \\
Coefficient of variation & 0.042 & 0 \\
\hline
\end{tabular}

The results showed very small variability between the three results for both MAS and C2 as reflected by the low standard deviation and coefficient of variation.

\subsubsection{Effects of Testing Temperature and Cycle Length}

The test successfully detected the presence of oxidizable sulphide when testing the aggregates at a temperature of $40^{\circ} \mathrm{C}$; however, it was thought that it would be useful to accelerate the test to obtain results in a shorter time. The effects of testing temperature and a shorter soaking cycle have been studied using the aggregate B \& B.

The effect of temperature is shown in Figure $3-8$. As the figure shows, the early mass loss was higher at $23^{\circ} \mathrm{C}$, and the late mass loss was slightly higher at $40^{\circ} \mathrm{C}$. The work of Frais can be used to explain why there wasn't higher mass loss at higher temperatures. Frais [105] illustrated that at high temperatures, hypochlorite anions might decompose into chlorine and chlorate, which are less efficient oxidizers than hypochlorite. Based on the obtained results, it was decided to run 
the test at room temperature $\left(23^{\circ} \mathrm{C}\right)$.

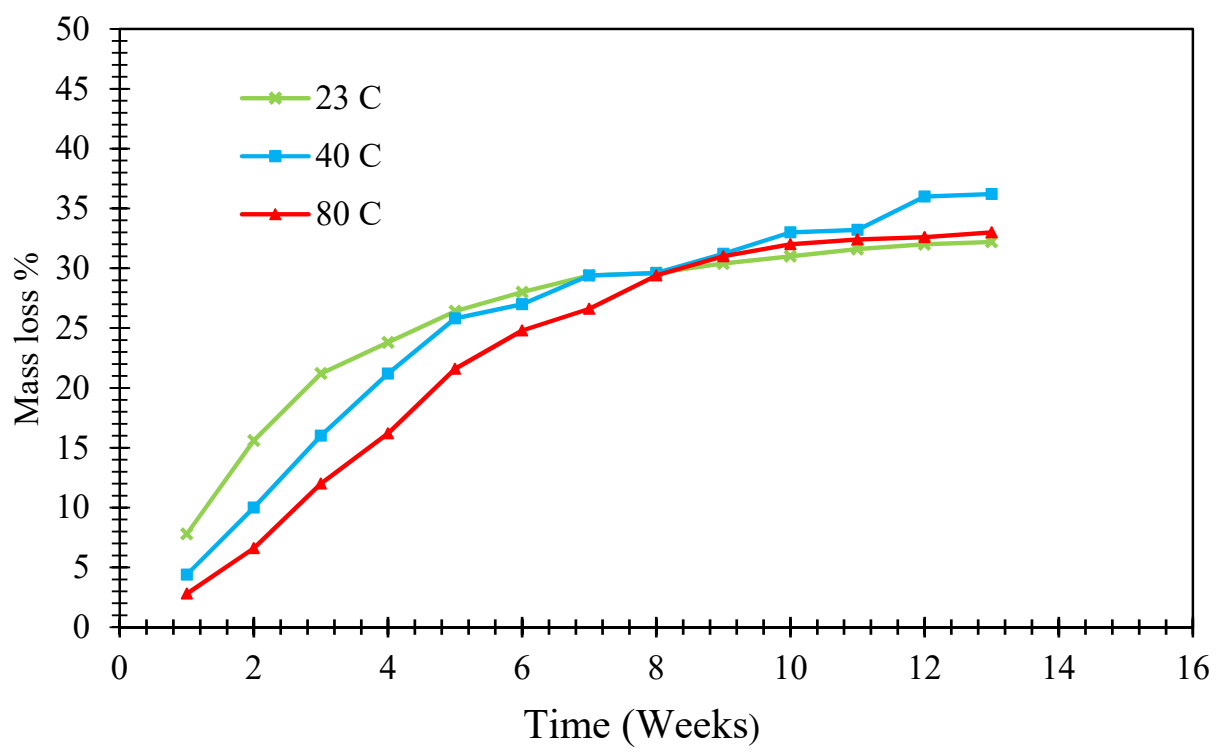

Figure 3 - 8: Effects of different temperatures on mass loss using B \& B aggregate size $4.75 \mathrm{~mm}$ to $2.36 \mathrm{~mm}$.

The effect of cycle length, shown in Figure 3 - 9 reveals that using a shorter cycle produces a higher mass loss. Two weeks on the x-axis of the graph represents one complete two-week cycle or two complete one-week cycles. Based on the obtained results, it was decided to test the samples using a one-week cycle at room temperature $\left(23^{\circ} \mathrm{C}\right)$. Additionally, a smaller aggregate, $2.36 \mathrm{~mm}-$ $1.18 \mathrm{~mm}$, was used to accelerate the results. 


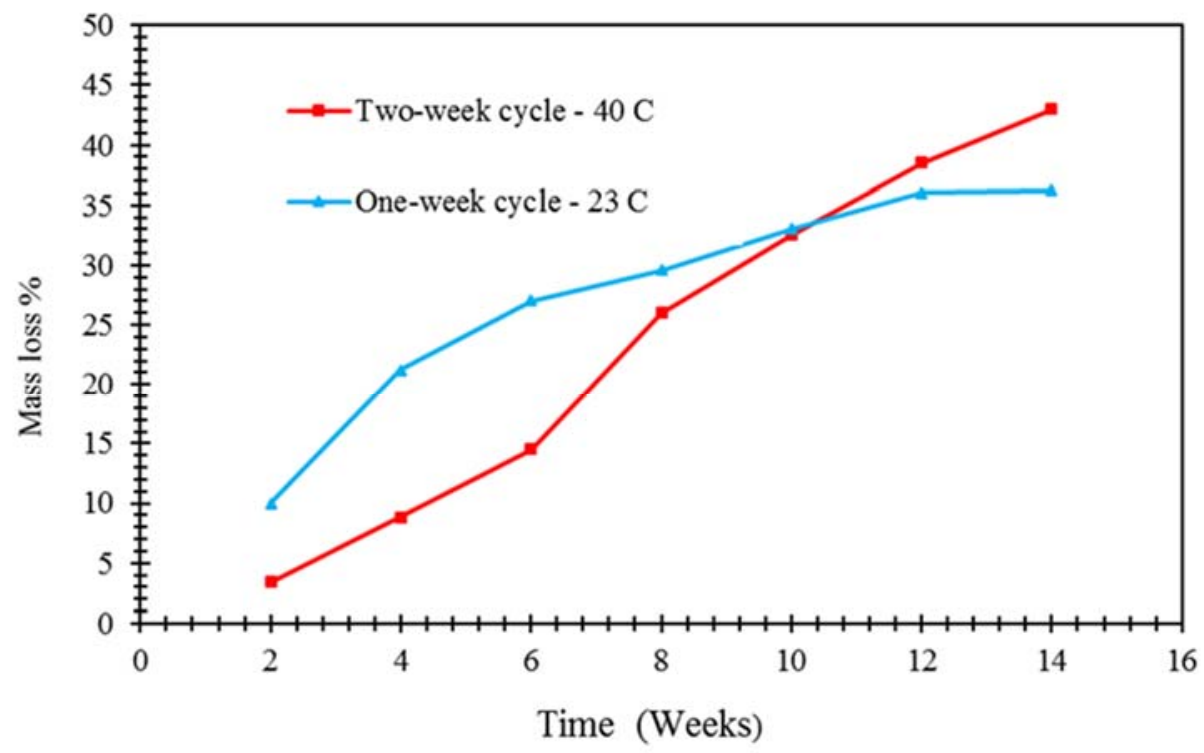

Figure 3 - 9: Effect of cycle length on mass loss using B \& B aggregate size 4.75 to $2.36 \mathrm{~mm}$

\subsubsection{Testing at $23{ }^{\circ} \mathrm{C}$ Using one-week Cycle}

The mass loss results are listed in Table $3-5$ and the sodium hypochlorite colour for aggregates with and without sulphide are shown in Figure 3 - 10. Finally, the dissolved sulphate and iron in the solution are listed in Table 3 - 6. The sulphate-to-iron ratio for aggregates with sulphide phases is the same when testing at $40^{\circ} \mathrm{C}$ using the larger size fraction $4.75 \mathrm{~mm}$ to 2.36 $\mathrm{mm}$. 
Table 3 - 5: Mass loss and total sulphur ( $\mathrm{Sr} \%$ ) results for aggregates tested at $23^{\circ} \mathrm{C}$ using particle size from $2.36 \mathrm{~mm}$ to $1.18 \mathrm{~mm}$ after cycles 1, 2, 4, 7. Each cycle was one week, and the solid to solution ratio was $1: 10$.

\begin{tabular}{|c|c|c|c|c|c|}
\hline Cat. \# & $\begin{array}{l}\text { Aggregate } \\
\text { ID }\end{array}$ & $\begin{array}{l}\text { Total } \\
\text { sulphur } \\
\text { Sr\% } \%\end{array}$ & $\begin{array}{l}\text { Mass } \\
\text { loss } \% \\
\text { Cycle } 1\end{array}$ & $\begin{array}{l}\text { Mass } \\
\text { loss } \% \\
\text { Cycle } 2\end{array}$ & $\begin{array}{l}\text { Mass } \\
\text { loss } \% \\
\text { Cycle } 3\end{array}$ \\
\hline 1 & Ore & 20.0 & 14 & 29.5 & 41.8 \\
\hline 1 & MW & 20.0 & 13 & 28 & 40.8 \\
\hline 1 & $52 \mathrm{a}$ & 1.50 & 5.3 & 9.1 & 12.4 \\
\hline 1 & MAS & 1.00 & 4.5 & 6.7 & 8.9 \\
\hline 1 & $52 \mathrm{~b}$ & 0.54 & 3.6 & 5.7 & 7.1 \\
\hline 3 & 29 & 0.30 & 0 & 0.2 & 0.2 \\
\hline 3 & 35 & 0.18 & 0 & 0 & 0 \\
\hline 3 & 20 & 0.15 & 0.8 & 1.0 & 1.3 \\
\hline 3 & 44 & 0.15 & 0.2 & 0.4 & 0.6 \\
\hline 3 & 26 & 0.14 & 0 & 0 & 0 \\
\hline 3 & 43 & 0.11 & 0.6 & 1.0 & 1.3 \\
\hline 3 & 50 & 0.06 & 0.1 & 0.2 & 0.3 \\
\hline 3 & 31 & 0.059 & 0 & 0 & 0.1 \\
\hline 3 & 57 & 0.05 & 0.4 & 0.8 & 1.2 \\
\hline 3 & 25 & 0.046 & 0 & 0 & 0 \\
\hline 3 & $\mathrm{P}$ & 0.040 & 0 & 0 & 0.1 \\
\hline 3 & 48 & 0.039 & 0 & 0.1 & 0.2 \\
\hline 3 & 22 & 0.038 & 0 & 0.2 & 0.3 \\
\hline 3 & $46 a$ & 0.027 & 0.2 & 0.2 & 0.7 \\
\hline 3 & $46 b$ & 0.027 & 0.4 & 0.6 & 1.6 \\
\hline 3 & 49 & 0.024 & 0 & 0 & 0 \\
\hline 3 & 30 & 0.017 & 0 & 0 & 0 \\
\hline 3 & 56 & 0.01 & 0 & 0 & 0 \\
\hline 3 & 51 & 0.009 & 0 & 0 & 0 \\
\hline 3 & $23 a$ & 0.007 & 0 & 0 & 0 \\
\hline 3 & $23 b$ & 0.01 & 0 & 0 & 0 \\
\hline 3 & 28 & 0.007 & 0 & 0 & 0 \\
\hline 2 & Sud & 0 & 0 & 0 & 0.2 \\
\hline 2 & Pit & 0 & 0 & 0 & 0.1 \\
\hline 2 & Spr & 0 & 0 & 0 & 0 \\
\hline
\end{tabular}



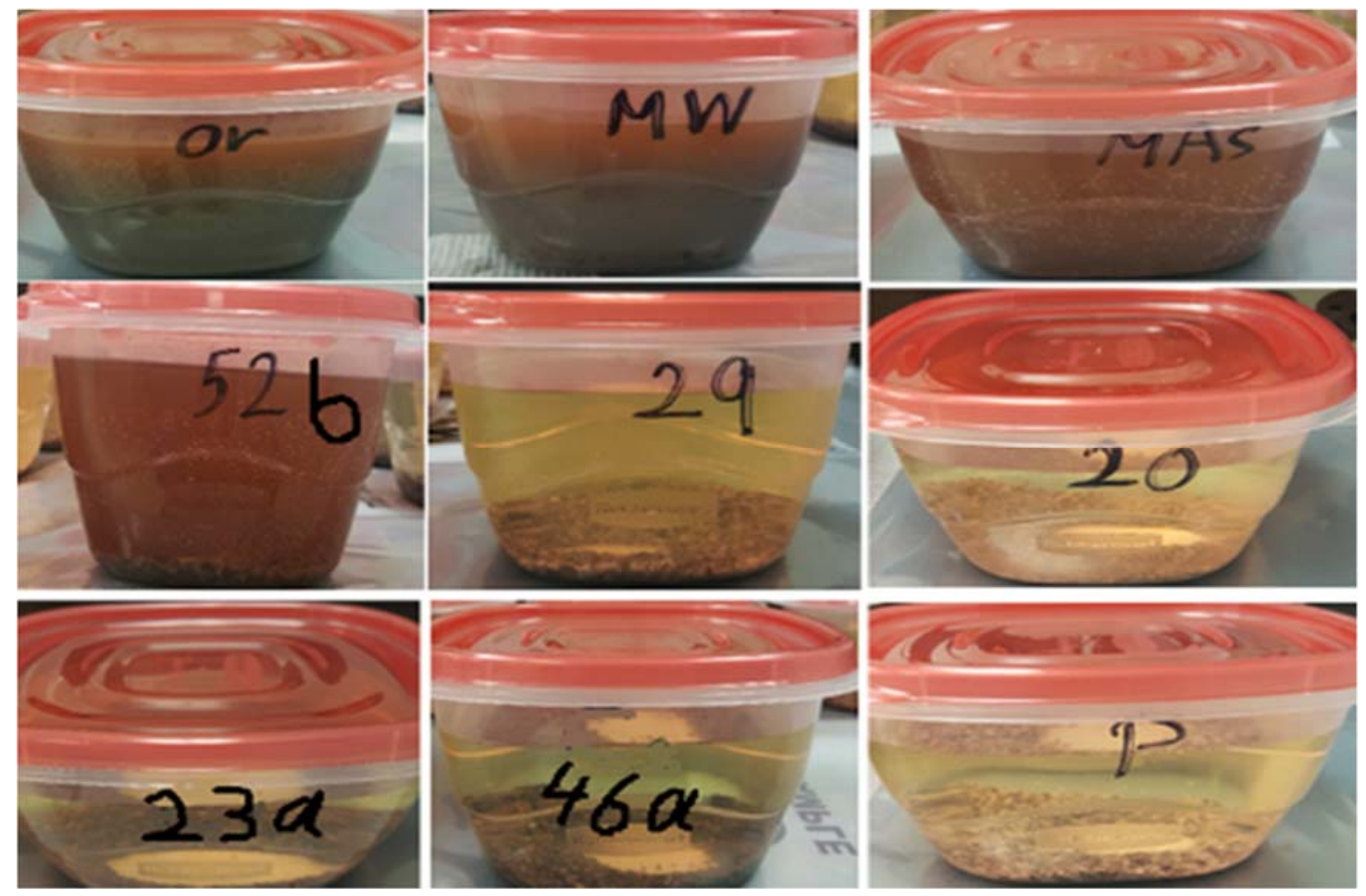

Figure 3 - 10: The colour of each container after the first cycle (one week) of the test

Table 3 - 6: Change in $\mathrm{pH}$, sulphur, and iron in bleach after one cycle of 5 days soaking at $23^{\circ} \mathrm{C}$. The cycle reported here is cycle \# 1. The initial pH of the solution was 12.4.

\begin{tabular}{|c|c|c|c|c|c|c|c|c|c|c|}
\hline Aggregate & Ore & MW & MAS & 52 & 29 & 20 & $46 a$ & $46 b$ & $23 a$ & $\mathrm{P}$ \\
\hline $\begin{array}{l}\text { Mass loss after } \\
\text { cycle } \# 1\end{array}$ & 14 & 13 & 4.5 & 3.6 & 0 & 0.8 & 0.2 & 0.4 & 0 & 0 \\
\hline $\mathrm{Sr} \%$ & 20.0 & 20.0 & 1.0 & 0.54 & 0.30 & 0.15 & 0.027 & 0.027 & 0.007 & 0.04 \\
\hline $\mathrm{pH}$ & 8.2 & 8.8 & 12.0 & 12.2 & 12.3 & 12.3 & 12.4 & 12.3 & 12.3 & 12.3 \\
\hline $\begin{array}{l}\text { Total iron ion } \\
(\mathrm{Fe})(\mathrm{mg} / \mathrm{L})\end{array}$ & 685 & 585 & 80.5 & 35 & 12 & 5 & 2 & 2.5 & 1.0 & 0 \\
\hline $\begin{array}{l}\text { Total } \\
\text { ion } \\
(\mathrm{mg} / \mathrm{L})\end{array}$ & 6300 & 5600 & 800 & 400 & 200 & 1000 & 100 & 200 & 0 & 0 \\
\hline Sulphate/Iron & 9.2 & 9.57 & 9.94 & 11.43 & 16.67 & 200 & 50 & 80 & & \\
\hline
\end{tabular}




\section{- Repeatability of the test at $23^{\circ} \mathrm{C}$}

The repeatability of the oxidation test at $23^{\circ} \mathrm{C}$ with two different aggregates MAS and $\mathrm{C} 2$ was carried out in order to validate the results. MAS aggregate represents a sulphide-bearing aggregates, while C2 aggregate represents control (non-sulphide aggregates). The results are presented in table 3 7 showing low standard deviation and coefficient of variation which suggest good repeatability of the test.

Table 3 - 7: The standard deviation and coefficient of variation for MAS and C2 aggregates at $23^{\circ} \mathrm{C}$.

\begin{tabular}{lcc}
\hline \multicolumn{1}{c}{ Aggregate size } & MAS & $\mathrm{C} 2$ \\
$4.75 \mathrm{~mm}-2.36 \mathrm{~mm}$ at $23^{\circ} \mathrm{C}$ & 4.5 & 0.1 \\
Samples mass loss $(\%)$ & 4.3 & 0.2 \\
& 4.6 & 0.1 \\
Mean & 4.5 & 0.1 \\
Variance & 0.02 & 0 \\
Observation & 3 & 3 \\
Standard deviation & 0.13 & 0 \\
Coefficient of variation & 0.029 & 0 \\
\hline
\end{tabular}

\subsubsection{Summary of results for the aggregate oxidation test}

The results revealed that testing at room temperature provided faster mass loss $\%$ compared to testing at $40^{\circ} \mathrm{C}$ using a coarser fraction. Figure $3-11$ and Figure $3-12$ represent a comparison between the long and short cycles. Where Figure $3-11$ shows the relationship between mass loss after 2 weeks of testing of the short cycle - representing 2 cycles - at $23^{\circ} \mathrm{C}$ using the size $2.36 \mathrm{~mm}$ 
$-1.18 \mathrm{~mm}$ versus 2 weeks of testing using the long cycle - representing one cycle - at $40^{\circ} \mathrm{C}$ using the size $4.75 \mathrm{~mm}-2.36 \mathrm{~mm}$.

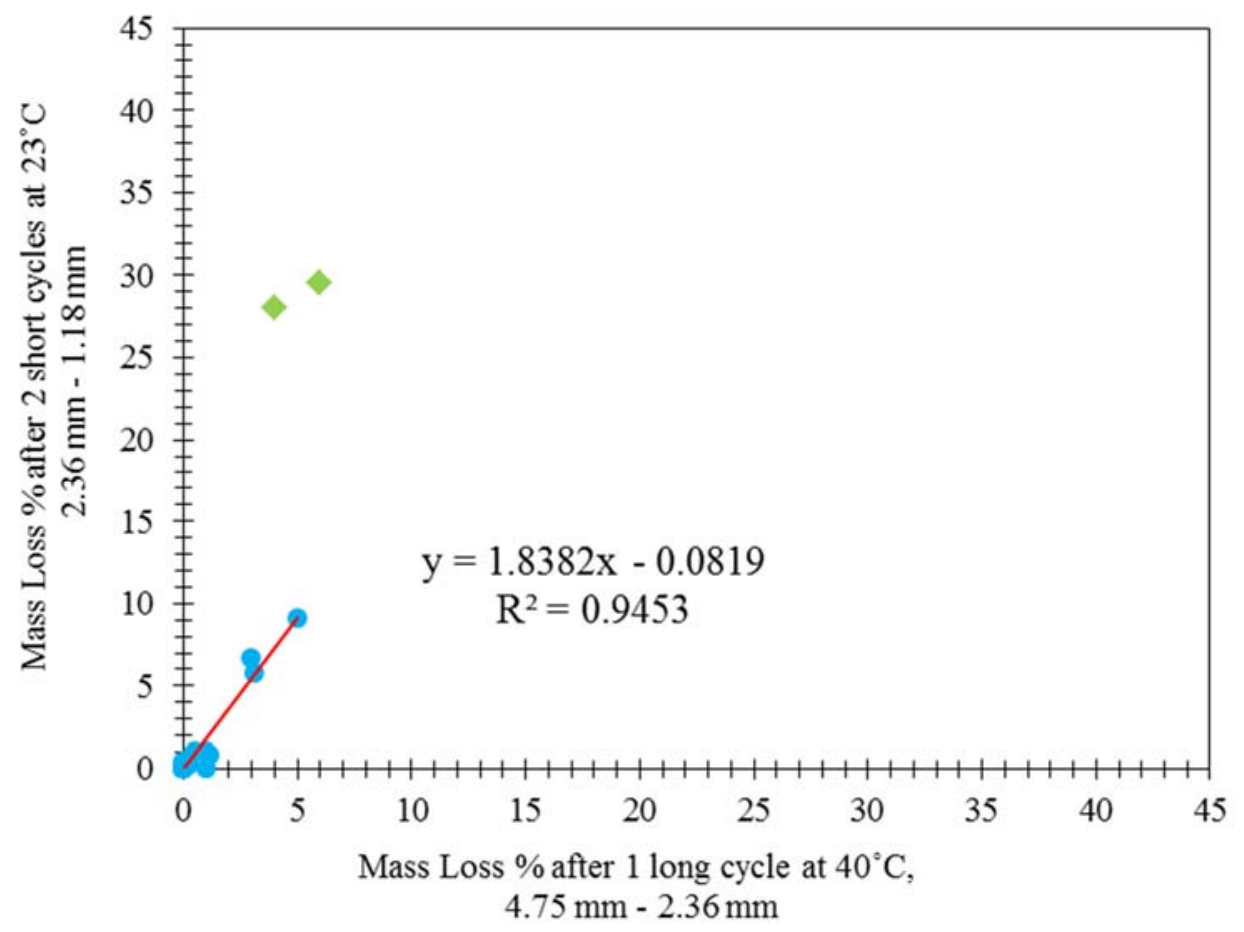

Figure 3 - 11: Comparison between mass loss using 1 long and 2 short cycles

The aggregates Ore and MW, which are high in sulphide minerals, showed a higher mass loss when tested using the short cycle at $23^{\circ} \mathrm{C}$ with the finer gradation compared to the longer cycle at $40^{\circ} \mathrm{C}$ with coarser gradation. The other aggregates followed a linear trend with a slope of 1.83 showing that two shorter cycles at room temperature using finer gradation produced almost double the mass loss obtained by testing the aggregates for one long cycle - two weeks - at $40^{\circ} \mathrm{C}$ using the coarser gradation. 
Figure $3-12$ shows the same trend observed in Figure 3 - 11. This graph compares the mass loss of the two testing regimes using the same number of cycles. The Ore and MW showed a much higher mass loss using three shorter cycles ( 3 weeks) at $23^{\circ} \mathrm{C}$ and finer gradation. For the other aggregates, the relationship followed a linear trend with a slope of almost 1.0, suggesting that the mass loss is the same in both testing regimes using the same number of cycles, regardless of the length of the cycles. The results show that testing the fraction from $2.36 \mathrm{~mm}$ to $1.18 \mathrm{~mm}$ at $23^{\circ} \mathrm{C}$ provides quicker results and produces more oxidation for materials with very high sulphide contents (such as Ore and MW).

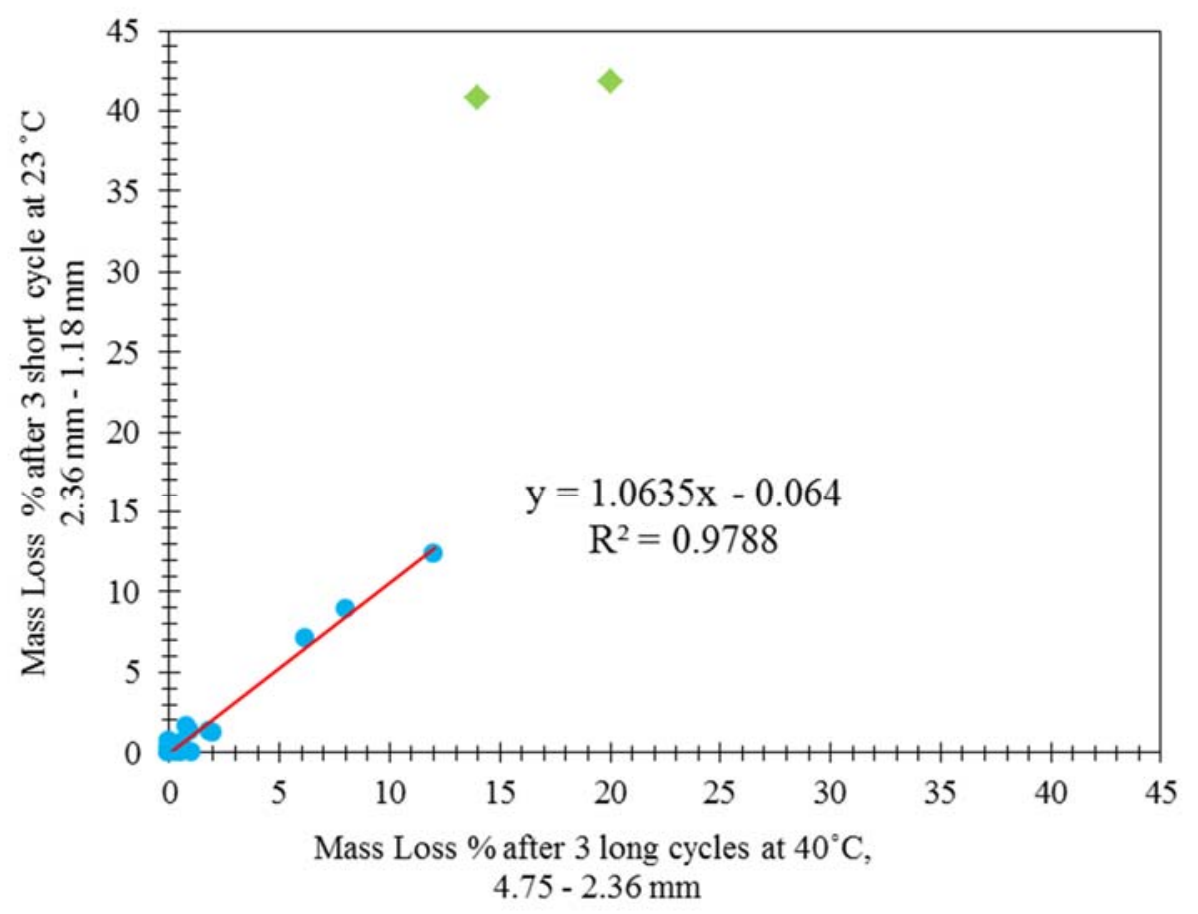

Figure 3 - 12: Comparison of mass loss using three long and three short cycles.

The results revealed that the test presented in this thesis was able to differentiate between aggregates with and without oxidizable sulphides, making it a useful test to screen aggregates for 
their potential to oxidize. Quicker results were obtained when the test was run at room temperature using a particle size of $2.36 \mathrm{~mm}$ to $1.18 \mathrm{~mm}$. The test was conducted using a sodium hypochlorite solution and containers with no observed overheating or issues related to safety. While it was successful, this method is open to more optimization. For example, testing larger aggregate sizes or testing different fractions of particle sizes and calculating the weighted average of mass loss. Testing a mass greater than $100 \mathrm{~g}$ may also provide better test result precision. In any case, the test in its current form provides an excellent indication of the aggregate's potential to contain oxidizable sulphide.

The test provides two main outputs that can be used together to evaluate aggregates:

(1) changes in the colour of the solution following the test, and (2) mass loss. The results of mass loss after one and three cycles of the test at $23^{\circ} \mathrm{C}$ using size $2.36 \mathrm{~mm}$ to $1.18 \mathrm{~mm}$ are shown in Figure 3 - 13 and Figure 3 - 14, respectively. The figures illustrate that a limit of $1.0 \%$ can be used for the mass loss after one cycle and $2.0 \%$ after three cycles. The third cycle can be used if an aggregate exceeds the $1.0 \%$ after the first cycle. These limits help differentiate between aggregates with and without sulphide. While the lowest mass loss obtained after one cycle for aggregates with known sulphide was 3.6\%, which is more than triple the suggested limit, the authors believe that a stricter limit can be adopted until more sulphide-bearing aggregates are tested. A limit of $0.5 \%$ or $1.0 \%$ after one and three cycles, are recommended. Using a limit of $0.5 \%$, only two aggregates out of 25 (which are known to have no sulphide) would fail. 
More detailed testing would be recommended for the aggregates that do not show changes in colour or mass loss, including looking at the sulphur and iron in the solution, petrographic examination, and quantitative determination of sulphide phases. Some forms of iron phases or clay minerals within the aggregate can cause mass loss and a change in colour. In such cases, the aggregate would be screened as "requires further testing". More detailed testing can be used to identify the cause of the mass loss and change in colour.

The iron and sulphate in the solution should be interpreted with caution. Although certain ratios of sulphate to iron were obtained for samples with oxidizable sulphide, this does not mean that this is always the case, especially since the ferrous iron produced during oxidation does not remain in the solution, as shown in the following two equations:

$$
\begin{aligned}
\mathrm{Fe}_{(1-\mathrm{x})} \mathrm{S}+(2-\mathrm{x} / 2) \mathrm{O}_{2}+\mathrm{xH}_{2} \mathrm{O} & \rightarrow(1-\mathrm{x}) \mathrm{Fe}^{2+}+\mathrm{SO}_{4}^{2-}+2 \mathrm{x} \mathrm{H}^{+} \\
\mathrm{Fe}^{3+}+3 \mathrm{H}_{2} \mathrm{O} & \rightarrow \quad \mathrm{Fe}(\mathrm{OH})_{3(\mathrm{~S})}+3 \mathrm{H}^{+}
\end{aligned}
$$

It should also be mentioned that high sulphate in solution could be due to the presence of another form of sulphate, such as gypsum. 


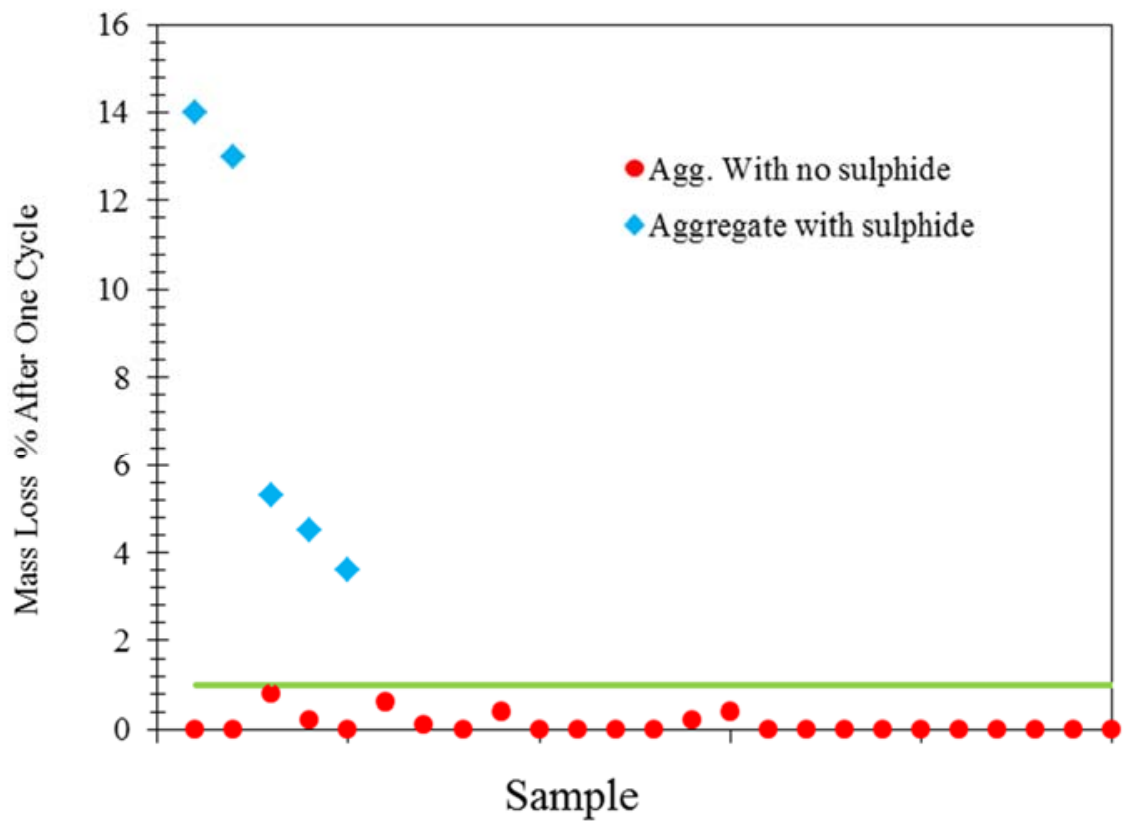

Figure 3 - 13: Mass loss of the 30 tested samples after one cycle of testing at $23{ }^{\circ} \mathrm{C}$ using size $2.36 \mathrm{~mm}-1.18 \mathrm{~mm}$

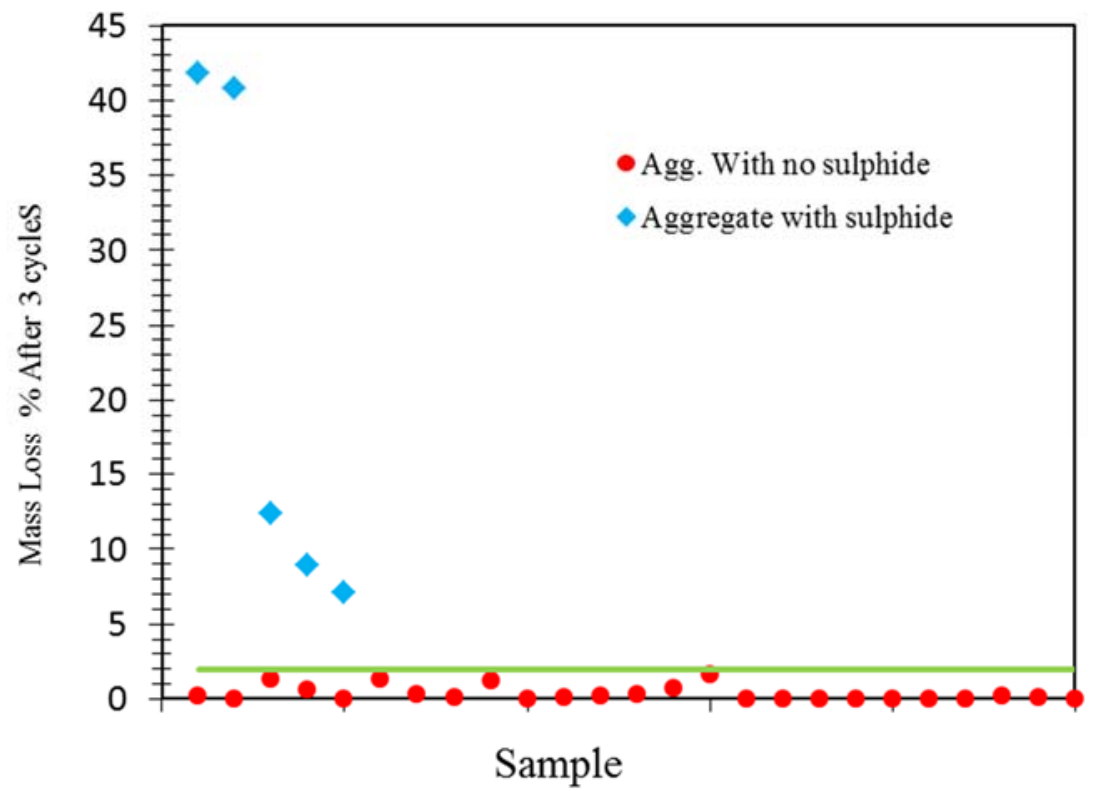

Figure 3 - 14: Mass loss of the 30 tested samples after 3 cycles of testing at $23{ }^{\circ} \mathrm{C}$ using 2.36 $\mathrm{mm}-1.18 \mathrm{~mm}$ aggregates. 
While a low level of total sulphur in aggregate has been suggested by some standards, e.g. 0.10\% as proposed by Annex P of CSA A23.1-2014 [106], aggregates with a sulphur content larger than this value can have little or no oxidizable sulphide. Six of the aggregates tested here with no known issues of oxidizable sulphide had a total sulphur $>0.10 \%$. Four of these aggregates met the $0.50 \%$ mass loss limit while the other two had a mass loss between $0.5 \%$ and $1.0 \%$. There was no direct relationship between mass loss and total sulphur. This shows the benefit of using the proposed test as a second step to total sulphur determination.

Aggregates $23 \mathrm{a}$ and $23 \mathrm{~b}$ and $46 \mathrm{a}$ and $46 \mathrm{~b}$ were tested in order to provide an indication of anticipated variability between different samples from the same source. Both samples $23 \mathrm{a}$ and $23 \mathrm{~b}$ showed zero mass loss; however, sample 46b showed a higher mass loss and higher sulphate and iron in the solution compared to 46a. It is not known if this difference is due to minor differences in sample compositions or due to the precision of the test method. However, the higher sulphate and iron in the solution and higher mass loss for sample $46 \mathrm{~b}$ suggests that there is a minor difference in the composition of the two samples. In any case, the difference in mass loss is not, large, particularly after the first cycle. Both samples had a mass loss $<0.5 \%$.

In summary, the aggregate oxidation presented here can serve as a screening test for coarse aggregates. Aggregates that do not change the colour of solution or show mass loss $<0.5 \%$ after one cycle when tested at room temperature for size $2.36 \mathrm{~mm}$ to $1.18 \mathrm{~mm}$ are likely to have no oxidizable sulphide content. 


\subsubsection{Application of the test to unprocessed coarse aggregate}

In this phase of the program, attempts were made to test coarse aggregate without processing to sand-size fractions. To examine the effect of temperature, the test was run at a temperature of $5^{\circ} \mathrm{C}, 23^{\circ} \mathrm{C}$ and $40^{\circ} \mathrm{C}$. The length of testing used in this part of the program was two weeks which included three cycles -4 days each - as explained in under the experimental program.

The results are presented in Table $3-8$ showing the mass loss for MAS and C2 aggregates with different sizes: $(19.0-13.2 \mathrm{~mm}, 13.2-9.5 \mathrm{~mm}$, and $9.5-4.75 \mathrm{~mm})$. The results showed that the smaller the aggregate size the higher the mass loss. In addition, the results confirmed that the mass loss for sulphide mineral aggregates (MAS) was much higher than the mass loss for aggregates with no sulphide. Finally, testing at $5^{\circ} \mathrm{C}$, showed a higher mass loss than the other two temperatures. This was thought to be attributable to higher dissolved oxygen at lower temperature [107]. 
Table 3 - 8: Mass loss for coarse-size MAS and C2 aggregates at different temperatures.

\begin{tabular}{|l|c|c|c|c|c|c|}
\hline \multicolumn{7}{|c|}{ Mass loss after two weeks (\%) } \\
\hline Aggregate & \multicolumn{7}{|c|}{ MAS } & \multicolumn{3}{c|}{ C } \\
\hline Size & $\begin{array}{c}19.0-13.2 \\
\mathrm{~mm}\end{array}$ & $\begin{array}{c}13.2-9.5 \\
\mathrm{~mm}\end{array}$ & $\begin{array}{c}9.5-4.75 \\
\mathrm{~mm}\end{array}$ & $\begin{array}{c}19.0-13.2 \\
\mathrm{~mm}\end{array}$ & $\begin{array}{c}13.2-9.5 \\
\mathrm{~mm}\end{array}$ & $\begin{array}{c}9.5-4.75 \\
\mathrm{~mm}\end{array}$ \\
\hline $40^{\circ} \mathrm{C}$ & 0.84 & 1.16 & 1.40 & 0.02 & 0.04 & 0.10 \\
\hline $23^{\circ} \mathrm{C}$ & 0.96 & 1.34 & 1.62 & 0.02 & 0.06 & 0.14 \\
\hline $5^{\circ} \mathrm{C}$ & 1.12 & 1.56 & 1.82 & 0.00 & 0.02 & 0.12 \\
\hline
\end{tabular}

The test was then carried out at $5^{\circ} \mathrm{C}$ for all aggregates. The results are listed in Table $3-9$. The results confirmed mass loss for only aggregates with sulphide phases. In addition, the results are in line with the results in table $3-2$ and table 3 - 5 for the same aggregate but crushed. 
Table 3 - 9: Mass loss and total sulphur $(\mathrm{Sr} \%)$ results for aggregates tested at $5^{\circ} \mathrm{C}$ using coarse aggregates without crushing after 1 cycles. The cycle was two weeks, and the solid to solution ratio was 1:2.

\begin{tabular}{|c|c|c|c|c|}
\hline $\begin{array}{l}\text { Aggregate } \\
\text { ID }\end{array}$ & $\begin{array}{l}\text { Total } \\
\text { sulphur } \\
\mathrm{Sr} \% \\
\end{array}$ & $\begin{array}{c}\text { Mass } \\
\text { loss } \% \\
19.0-13.2 \mathrm{~mm} \\
\end{array}$ & $\begin{array}{c}\text { Mass } \\
\text { loss } \% \\
13.2-9.0 \mathrm{~mm} \\
\end{array}$ & $\begin{array}{c}\text { Mass } \\
\text { loss } \% \\
9.5-4.75 \mathrm{~mm} \\
\end{array}$ \\
\hline Ore & 20.0 & N.A & N.A & N.A \\
\hline MW & 20.0 & 1.38 & 1.78 & 2.98 \\
\hline $52 \mathrm{a}$ & 1.50 & 2.11 & 2.42 & 3.02 \\
\hline MAS & 1.00 & 1.05 & 1.46 & 1.74 \\
\hline $52 \mathrm{~b}$ & 0.54 & 0.61 & 0.63 & 0.80 \\
\hline 29 & 0.30 & 0.13 & 0.11 & 0.18 \\
\hline 35 & 0.18 & 0.03 & 0.10 & 0.08 \\
\hline 20 & 0.15 & 0.01 & 0.38 & 0.46 \\
\hline 44 & 0.15 & 0.11 & 0.07 & 0.10 \\
\hline 26 & 0.14 & 0.01 & 0.12 & 0.32 \\
\hline 43 & 0.11 & 0.15 & 0.05 & 0.22 \\
\hline 50 & 0.06 & 0.12 & 0.06 & 0.08 \\
\hline 31 & 0.059 & 0.08 & 0.06 & 0.06 \\
\hline 57 & 0.05 & 0.14 & 0.13 & 0.28 \\
\hline 25 & 0.046 & 0.09 & 0.07 & 0.08 \\
\hline $\mathrm{P}$ & 0.040 & N.A & N.A & N.A \\
\hline 48 & 0.039 & 0.12 & 0.08 & 0.08 \\
\hline 22 & 0.038 & 0.16 & 0.10 & 00 \\
\hline $46 a$ & 0.027 & 0 & 0 & 0.10 \\
\hline $46 \mathrm{~b}$ & 0.027 & N.A & N.A & N.A \\
\hline 49 & 0.024 & 0 & 0.04 & 0.04 \\
\hline 30 & 0.017 & 0.11 & 0.13 & 0.02 \\
\hline 56 & 0.01 & 0.05 & 0.14 & 0.10 \\
\hline 51 & 0.009 & 0.11 & 0.08 & 0.06 \\
\hline $23 a$ & 0.007 & 0.04 & 0.01 & 0.04 \\
\hline $23 b$ & 0.01 & N.A & N.A & N.A \\
\hline 28 & 0.007 & 0.09 & 0.28 & 0.04 \\
\hline Sud & 0 & 0.11 & 0.09 & 0.22 \\
\hline Pit & 0 & 0 & 0.04 & 0.04 \\
\hline Spr & 0 & 0.09 & 0.28 & 0.04 \\
\hline
\end{tabular}




\section{- Repeatability of the test at $5^{\circ} \mathrm{C}$}

The repeatability of the oxidation test at $5^{\circ} \mathrm{C}$ was examined using MAS aggregate. The aggregate $\mathrm{C} 2$ did not show any mass loss. The results in table $3-10$ showed low coefficient of variation suggesting a good reputability of the test.

Table 3 - 10: Standard deviation and coefficient of variation for MAS aggregates at $5^{\circ} \mathrm{C}$ with different sizes.

\begin{tabular}{lccc}
\hline & \multicolumn{4}{c}{ MAS aggregate tested at $5^{\circ} \mathrm{C}$} & \\
Size & $19.0-13.2 \mathrm{~mm}$ & $13.2-9.5 \mathrm{~mm}$ & $9.5-4.75 \mathrm{~mm}$ \\
\hline & 1.05 & 1.46 & 1.74 \\
Samples mass loss (\%) & 1.12 & 1.56 & 1.82 \\
& 1.08 & 1.48 & 1.76 \\
Mean & 1.08 & 1.5 & 1.77 \\
Observation & 3 & 3 & 3 \\
Standard deviation & 0.035 & 0.053 & 0.042 \\
Coefficient of variation & 0.032 & 0.035 & 0.024 \\
\hline
\end{tabular}




\section{Chapter 4}

\section{Oxidation Mortar Bar Test}

In this chapter, an oxidation mortar bar test was introduced and used with different aggregates and cementing systems. The objective of the test is to evaluate the potential for oxidation and subsequent sulphate attacks in mortar bar samples cast with sulphide-bearing aggregates. The applicability of the test to different cementing systems was also investigated.

\subsection{Test Procedures}

Mortar bar samples with standard dimensions of $25 \mathrm{~mm}$ x $25 \mathrm{~mm}$ x $285 \mathrm{~mm}$ were used in this experiment. Sand-size aggregates were used for this test method of gradation similar to that used in the accelerated mortar bar test for evaluating alkali-silica reaction [108]. The processed aggregates were washed to remove any fine particles and adhering dust and dried in the oven at $80^{\circ} \mathrm{C}$ before casting the mortar bar samples.

This study used almost the same exposure condition and procedures employed by Rodrigues et al. $[3,100]$ except for one variation that will be described at the end of this subsection. The mortar bar samples were exposed to cycles that promote sulphide oxidation for 13 weeks, followed by another 13 weeks under conditions that promote thaumasite formation. The mix proportion was 1 part of Portland cement (PC) or cementing materials to 3 parts of aggregates. The water-to-cementing material ratio was kept at 0.65 in order to represent the damaged residential 
concrete in the Québec case.

After casting and demolding, the samples were cured for three days in a standard curing room at a relative humidity $(\mathrm{RH})>95 \%$ and temperature of $23^{\circ} \mathrm{C}$. The samples were then moved from the curing room and immediately soaked for 3 hours in a $6 \%$ sodium hypochlorite solution used as an oxidizing solution. After soaking, the samples were exposed to a temperature of $80^{\circ} \mathrm{C}$ and $\mathrm{RH}$ of $80 \%$ for three days. The relative humidity was achieved by storing the samples over a supersaturated solution of $\mathrm{NaCl}$. After the heating period, the samples were taken from the oven and allowed to cool down for half an hour at room temperature, before being soaked again for three hours in the oxidizing solution. This complete soaking/heating cycle was repeated twice a week; the length change measurements were taken only once per week following the 3 hours of soaking while the mortar bars were in a saturated surface dry condition. The same process was repeated for 13 weeks with a refrigeration period instead of a heating period; the samples were stored in a refrigerator at $5^{\circ} \mathrm{C}$ above water $(100 \% \mathrm{RH})$.

In Rodrigues et al, [3] samples were stored under fume hood for 3 hours at room temperature prior to being stored at $80^{\circ} \mathrm{C} / 80 \% \mathrm{RH}$. These 3 hours under fume hood was adopted initially assuming that it would help the samples achieving a $\mathrm{RH}$ of $80 \%$ in a shorter period of time when placed at $80^{\circ} \mathrm{C} / 80 \% \mathrm{RH}$. The reason for not following this process here was that samples were investigated with and without these three-hour periods under fume hood and it was found that more expansion was achieved without it, as will be presented later. It should be noted that in the method adopted here, the 3 hours cut from maintaining the samples at fume hood, were added to the storage at $80 \% \mathrm{RH}$ and $80{ }^{\circ} \mathrm{C}$. 


\subsection{Materials}

The materials investigated in this part of the research included cementing materials, different aggregates with various sulphide contents, and a $6 \%$ sodium hypochlorite solution (household bleach).

\subsubsection{Cementing Materials}

A general use (GU) Portland cement (PC) from Ontario, Canada, a low heat of hydration (LH) cement, and high sulphate resisting (HSF) cement were used. The HSF is blended cement containing approximately $8 \%$ silica fume. Three types of Supplementary Cementing Materials, low-calcium fly ash (FA), slag (S) and metakaolin (MK) were also used. The SCMs were used as a partial replacement of GU-Portland cement at $25 \%$ for FA, $30 \%$ for slag, and $10 \%$ for MK. The chemical and potential phase composition of the cementing materials are listed in Table $4-1$ as determined by X-ray fluorescence (XRF).

In addition, X-ray Diffraction (XRD) was carried out on powder samples. The internal wavelengths from anode material of Copper $(\mathrm{Cu})$ and generator settings of $40 \mathrm{~mA}$ and 45 $\mathrm{kV}$ were used in this study. 
Table 4 - 1: Chemical composition of the Portland cement and SCMs (mass \%) determined using $\mathrm{X}$-Ray Fluorescence (XRF).

\begin{tabular}{|c|c|c|c|c|c|c|}
\hline Material Type & PC-GU & PC-LH & PC-HSF & FA & $\mathrm{S}$ & MK \\
\hline LOI $\left(1000^{\circ} \mathrm{C}\right), \%$ & 2.71 & 2.10 & 6.89 & --- & --- & $-\cdots$ \\
\hline LOI $\left(750^{\circ} \mathrm{C}\right), \%$ & - & - - - & - & 2.78 & 2.90 & 1.82 \\
\hline $\mathrm{SiO}_{2}, \%$ & 19.33 & 20.20 & 23.38 & 47.36 & 37.58 & 63.10 \\
\hline $\mathrm{Al}_{2} \mathrm{O}_{3}, \%$ & 5.22 & 4.00 & 4.22 & 23.86 & 8.23 & 30.69 \\
\hline $\mathrm{Fe}_{2} \mathrm{O}_{3}, \%$ & 2.14 & 3.60 & 2.66 & 17.40 & 0.50 & 1.22 \\
\hline $\mathrm{CaO}, \%$ & 61.97 & 63.80 & 54.85 & 3.67 & 38.13 & 0.36 \\
\hline $\mathrm{MgO}, \%$ & 2.37 & 2.60 & 2.28 & 1.00 & 10.77 & 0.50 \\
\hline $\mathrm{SO}_{3}, \%$ & 3.91 & 2.90 & 3.48 & 0.40 & 2.72 & 0.05 \\
\hline $\mathrm{K}_{2} \mathrm{O}, \%$ & 1.14 & - & 0.86 & 1.84 & 0.52 & 1.77 \\
\hline $\mathrm{Na}_{2} \mathrm{O}, \%$ & 0.23 & 0.54 & 0.25 & 0.65 & 0.32 & 0.16 \\
\hline $\mathrm{TiO}_{2}, \%$ & 0.27 & - & 0.23 & 1.23 & 0.53 & 0.68 \\
\hline $\mathrm{SrO}, \%$ & 0.09 & -- & 0.22 & 0.13 & -- & 0.04 \\
\hline $\mathrm{P}_{2} \mathrm{O}_{5}, \%$ & 0.12 & - & 0.21 & 0.29 & 0.02 & 0.03 \\
\hline $\mathrm{Cl}, \%$ & 0.04 & - & 0.01 & - & 0.61 & -- \\
\hline $\mathrm{ZnO}, \%$ & 0.01 & -- & 0.06 & 0.02 & -- & 0.01 \\
\hline $\mathrm{Cr}_{2} \mathrm{O}_{3}, \%$ & 0.01 & -- & 0.01 & 0.03 & -- & 0.01 \\
\hline $\mathrm{Mn}_{2} \mathrm{O}_{3}, \%$ & 0.06 & -- & 0.07 & 0.04 & --- & 0.01 \\
\hline \multicolumn{7}{|c|}{ Potential phase compositions calculated using Bogue's equations } \\
\hline $\mathrm{C}_{3} \mathrm{~S}(\%)$ & 67 & 61 & & & & \\
\hline $\mathrm{C}_{2} \mathrm{~S}(\%)$ & 5 & 11 & & & & \\
\hline $\mathrm{C}_{3} \mathrm{~A}(\%)$ & 10 & 4 & & & & \\
\hline $\mathrm{C}_{4} \mathrm{AF}(\%)$ & 6 & 11 & & & & \\
\hline
\end{tabular}

\subsubsection{Aggregates}

All coarse aggregates were from Ontario and Quebec. The mineralogy and total sulphur content ( $\mathrm{Sr} \%)$ of each aggregate are listed in Table 4 - 2. 
Table 4 - 2: Mineralogy of aggregates and their total sulphur ( $\mathrm{Sr} \%)$ content

\begin{tabular}{|c|c|c|c|c|}
\hline $\begin{array}{l}\text { Agg. } \\
\text { ID }\end{array}$ & $\begin{array}{l}\text { Primary } \\
\text { Rock type }\end{array}$ & $\begin{array}{l}\text { Composit- } \\
\text { ion* }\end{array}$ & $\begin{array}{l}\text { Iron sulphur } \\
\text { mineral }\end{array}$ & $\begin{array}{l}\text { Total Sulphur } \\
\quad\left(\mathrm{S}_{\mathrm{T}} \%\right)\end{array}$ \\
\hline Ore & Gabbro & $\begin{array}{l}\text { Entirely ore } \\
\text { mineral }\end{array}$ & $\begin{array}{c}\text { Pyrrhotite } \\
\text { Pyrite } \\
\text { Chalcopyrite } \\
\text { Pentlandite }\end{array}$ & 20 \\
\hline MW & Gabbro & $\begin{array}{l}\text { Entirely ore } \\
\text { mineral }\end{array}$ & $\begin{array}{l}\text { Pyrrhotite } \\
\text { Pyrite } \\
\text { Chalcopyrite } \\
\text { Pentlandite }\end{array}$ & 20 \\
\hline $52 \mathrm{a}$ & Quartz-biotite schist & $\begin{array}{c}\text { Quartz } \\
\text { Feldspar } \\
\text { Biotite } \\
\text { Muscovite }\end{array}$ & $\begin{array}{c}\text { Pyrrhotite } \\
\text { Pyrite } \\
\text { Jarosite } \\
\text { Limonite }\end{array}$ & 1.50 \\
\hline 52 & $\begin{array}{l}\text { Same as } 52 \mathrm{a} \text { from different } \\
\text { location within the quarry }\end{array}$ & & & 0.54 \\
\hline $\begin{array}{l}\text { MAS } \\
{[104]}\end{array}$ & Gabbro & $\begin{array}{l}\text { Plagioclase } \\
\text { Biotite } \\
\text { Quartz }\end{array}$ & $\begin{array}{c}\text { Pyrrhotite } \\
\text { Pyrite } \\
\text { Chalcopyrite } \\
\text { Pentlandite }\end{array}$ & $0.73-1.28$ \\
\hline $\mathrm{G}[104]$ & $\begin{array}{c}\text { Granitic gneiss with } \\
\text { No presence of carbonate material }\end{array}$ & $\begin{array}{l}\text { Plagioclase } \\
\text { Quartz } \\
\text { Hornblende }\end{array}$ & $\begin{array}{l}\text { Pyrrhotite } \\
\text { Pyrite } \\
\text { Chalcopyrite }\end{array}$ & $0.21-0.26$ \\
\hline Sud & Siliceous gravel & $\begin{array}{c}\text { Sandstone } \\
\text { Quartzite } \\
\text { Granite } \\
\text { Diabase }\end{array}$ & - & 0 \\
\hline
\end{tabular}




\begin{tabular}{|c|c|c|c|c|}
\hline $\begin{array}{l}\text { Agg. } \\
\text { ID }\end{array}$ & $\begin{array}{l}\text { Primary } \\
\text { Rock type }\end{array}$ & $\begin{array}{c}\text { Composit- } \\
\text { ion* }\end{array}$ & $\begin{array}{c}\text { Iron sulphur } \\
\text { mineral }\end{array}$ & $\begin{array}{l}\text { Total Sulphur } \\
\quad\left(\mathrm{S}_{\mathrm{T}} \%\right)\end{array}$ \\
\hline & & Gneiss & & \\
\hline \multirow[t]{2}{*}{20} & Dolostone & Dolomite & Gypsum & 0.150 \\
\hline & & & Pyrite & \\
\hline $\mathrm{C} 1$ & Dolostone & Dolomite & - & 0.007 \\
\hline \multirow[t]{3}{*}{ P [104] } & Anorthosite & Plagioclase & - & $0.04-0.06$ \\
\hline & & Hornblende & & \\
\hline & & Biotite & & \\
\hline \multirow[t]{5}{*}{$\mathrm{C} 2$} & Basalt & Actinolite & - & 0.027 \\
\hline & & Plagioclase & & \\
\hline & & Biotite & & \\
\hline & & Chlorite & & \\
\hline & & Magnetite & & \\
\hline
\end{tabular}

\subsubsection{Sodium Hypochlorite Solution}

Sodium hypochlorite was used as an oxidizing solution to accelerate the oxidation of the sulphide-bearing aggregates. This solution possesses a specific gravity of 1.1 and a $\mathrm{pH}$ of 12.2 [109].

\subsection{Experimental Program}

Figure 4 - 1 shows the different stages that took place in this research in adopting the mortar bar testing programs. These experimental programs are designed to develop a thorough understanding of the factors that affect the results of the test. 


\section{Oxidation Mortar Bar Test}
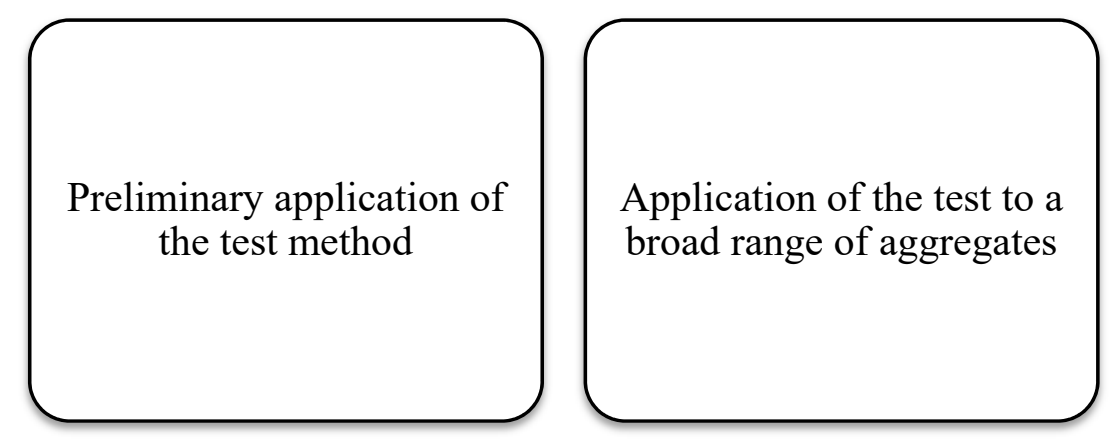

Investigating the ability of the test to evaluate the effects of mix parameters (w/c and SCMs)

Figure 4 - 1: Oxidation mortar bar testing programs

\subsubsection{Preliminary Application of the Test Method}

In the first part of the study, the test was initially implemented at four laboratories: Ryerson University, Laval University, Sherbrooke University, and IREQ (Robotics and Civil Engineering department, Hydro-Québec Research Institute). The objective was to find out the effects of sample preparation and the source of oxidizing agent on the results. Following the conclusion of the test, the group met to evaluate the results and discuss the factors that affect the obtained expansion, such as sample preparation and control of relative humidity. The results of this stage are presented in this chapter. 
In the second part of the study, the MAS aggregates were tested under different conditions. This testing program and the associated materials were prepared by Laval University (referred to as L) and Ryerson University (referred to as R), as explained in Figure 4 - 2. It should be noted that the P control aggregate used in this part of the study was prepared by Ryerson University. In this study, the mortar bar samples were moved to dry in the fume hood for 3 hours after the length measurements were taken.

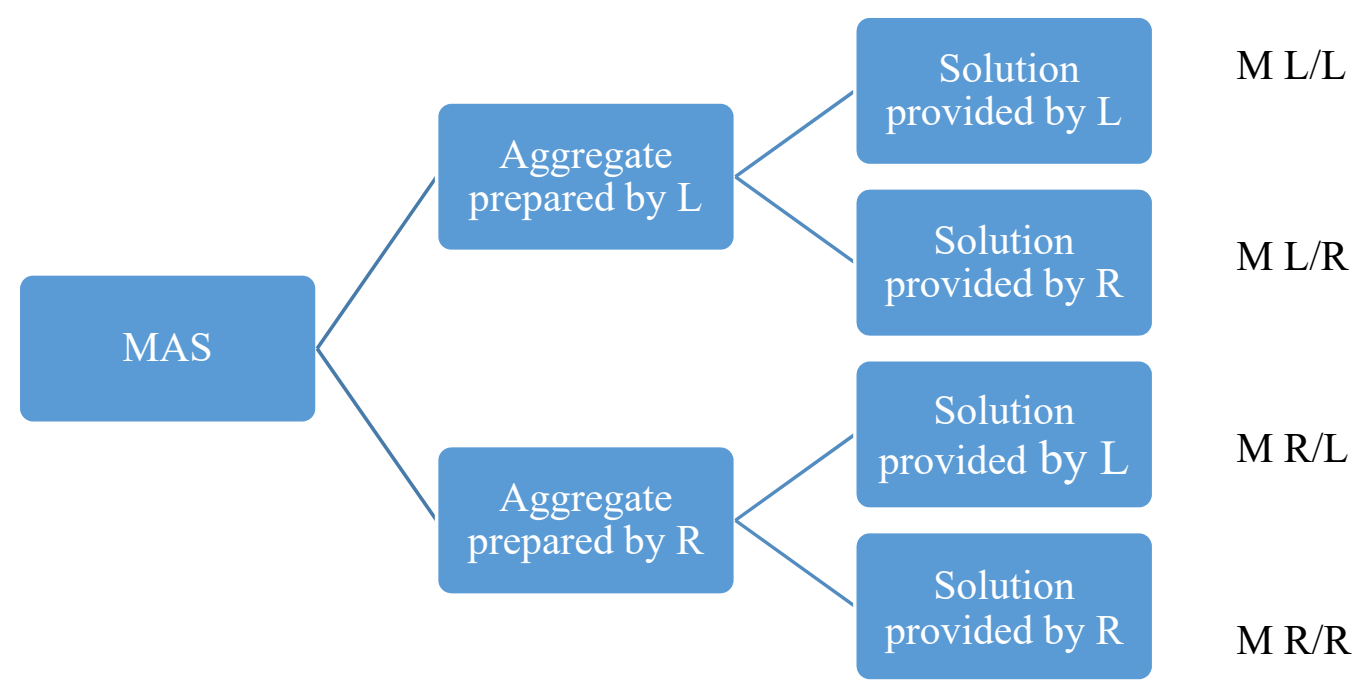

Figure 4 - 2: Preliminary tests for MAS

In another part of this dissertation, the effect of storing the mortar bar samples in the fume hood for 3 hours or half an hour at room temperature were tested. This took place to reach the most critical condition that would maximize the expansion of the mortar bar samples. 


\subsubsection{Application of the Test to Different Aggregates}

The scope of work in this testing regime focuses on the expansion of selected aggregates using a newly developed mortar bar test [3]. Results from the mortar bar tests are compared to those from the aggregate tests and attempts were made to explain the reasons for the lack of agreement between the test results. It should be noted that the mortar bar samples were cast with different aggregates and divided into two groups. The first group was prepared from aggregates that are known to have no sulphide content, C1, C2, P and Sud; The last aggregate, Sud, is an alkali-silica reactive aggregate. The second group consisted of sulphide-bearing aggregates. Five aggregates that contain different sulphide mineral contents were used: Ore, MW, MAS, 52 and 20. It should be noted that in this part of the study the mortar bar samples were left to dry at room temperature for half an hour after the length measurements were taken (after removing the samples from the solution and prior to being placed at $80^{\circ} \mathrm{C} / 80 \% \mathrm{RH}$ or $5^{\circ} \mathrm{C} / 100 \% \mathrm{RH}$ ).

\subsubsection{Investigating the ability of the test to evaluate the effects of mix parameters (SCM and W/C)}

This part of the study used the same exposure condition and procedures explained before. Also, in this study the mortar bar samples were moved to dry at room temperature for half an hour after 3 hours of soaking period. Two different parameters were examined in this testing program as follows: 


\section{- Effect of SCMs and Type of Portland Cement}

The applicability of the test to cementing systems containing supplementary cementing materials was evaluated. Three SCMs (low calcium fly ash, slag, and Metakaolin) as well as silica fume blended cement and a low tri-calcium aluminate $\left(\mathrm{C}_{3} \mathrm{~A}\right)$ cement were investigated. A test of the penetrability of the oxidizing solution was carried out in order to better understand how SCMs work.

Different sets of mortar bars cast with GU cement and different kind of SCMs and incorporating aggregates $\mathrm{C} 1, \mathrm{MAS}$ and $\mathrm{P}$ were tested to provide a baseline of expansion. The mortar bar test was run in the same manner as described before. In addition, samples of the same mixtures were tested another time using a longer soaking period of 24 hours. This longer soaking duration was used to examine if the SCMs have an effect on reducing the damaging expansion beyond that of reducing the penetration of the oxidizing solution, which was thought to be the main factor when using a soaking period of 3 hours.

\section{- Mass Gain and ion Penetrability of Mortar bar Samples with Different Cementing Systems}

In order to understand the factors that might lead to different expansions when different soaking periods are adopted, the mass gain and penetration of the solution into the mortar bars during the soaking period was monitored. For this investigation, mortar bar samples were cured for three days in a standard curing room at $\mathrm{RH}>95 \%$ and temperature of $23^{\circ} \mathrm{C}$. The samples were 
then moved from the curing room and exposed to one full cycle of soaking/heating ( 3 hours of soaking followed by three days in the oven at $\left.80^{\circ} \mathrm{C} / 80 \% \mathrm{RH}\right)$. After the heating period, the samples were taken out of the oven and allowed to cool down for half an hour at $23^{\circ} \mathrm{C}$. After that, the mass

of the samples was taken and used as the initial mass $\left(\mathrm{W}_{\mathrm{o}}\right)$. The samples were soaked for thirty hours in the oxidizing solution, and the mass gain of the samples $\Delta \mathrm{w}(\%)$ was calculated every one hour as follows:

$$
\Delta \mathrm{w}(\%)=\left[\left(\mathrm{w}_{\mathrm{n}}-\mathrm{w}_{0}\right) / \mathrm{w}_{0}\right] \times 100 \%
$$

Where: $\mathrm{w}_{0}(\mathrm{~g})=$ Initial mass of the mortar bars before starting the test.

$$
\mathrm{W}_{\mathrm{n}}(\mathrm{g})=\text { Mass of the mortar bars calculated each one hour for up to } 30 \text { hours. }
$$

The same test was repeated using a $20 \% \mathrm{CaCl}_{2}$ solution instead of the oxidizing solution to allow the detection of the depth of penetration using 0.10 molarity silver nitrate solution. This was done by breaking a part of the bars at different time intervals - 3, 6 , and 24 hours - and spraying the new cross-section with the 0.10 molarity silver nitrate solution [110].

\section{- Effect of the w/c Ratio}

In this part of the study, two separate groups of mortar bar samples were cast with MAS aggregate. The w/c ratio was 0.45 for the first group and 0.65 for the second group. 


\subsubsection{Paste Study to investigate phases produced under the testing conditions}

Paste samples were prepared using GU-Portland cement, GU + 25\% FA, and GU + 10\% MK. This study investigated the effects of the exposure conditions of the mortar bars test, mainly the second 13 weeks. The second 13 weeks of testing was chosen as some mortar bar samples only showed severe expansion in the second 13 weeks of the test.

The samples were prepared at a w/c of 0.50 as the 0.65 value used for the mortar bars would have produced a very liquid paste that would have suffered excessive segregation and bleeding. The paste samples were mixed in a high shear blender for 3 minutes of mixing, followed by two minutes of rest, then two minutes of mixing followed by two minutes of rest, and finally one minute of mixing. This results in a total mixing time and rest period of 10 minutes. The paste was poured into plastic cylinders (50 mm diameter by $100 \mathrm{~mm}$ height) and left to cure at $\mathrm{RH}>95 \%$ and a temperature of $23^{\circ} \mathrm{C}$ for three days. After the curing period, the samples were crushed to pieces passing sieve $9.50 \mathrm{~mm}$ and retained on sieve $4.75 \mathrm{~mm}$. The small pieces were then exposed to the same conditions used in the second 13-weeks of the mortar bar test method with the exception of a soaking period of one day rather than 3 hours. In other words, the samples were soaked in a $6 \%$ sodium hypochlorite solution for one day and then stored in a fridge at $5^{\circ} \mathrm{C}$ and $100 \% \mathrm{RH}$ (above water) for two days. These cycles were repeated twice per week. After six weeks, the samples were taken out and dried using the solvent replacement method (by exposing the samples to alcohol for three days and drying them in a desiccator at $40^{\circ} \mathrm{C}$ for one week). 
The samples were prepared for SEM analysis by impregnating them in epoxy followed by preparing polished sections. For thermal analysis and X-Ray Diffraction (XRD), the samples were ground to pass sieve $80 \mu \mathrm{m}$ and stored in an environment free of carbon dioxide and humidity until testing.

\subsection{Microscopy and Analytical Techniques}

\subsubsection{Microstructure Characterization}

Samples from the mortar bars and paste were cut, dried under a vacuum, impregnated with epoxy, and molded into a polished section for SEM examination. The samples were polished with a diamond grade of $0.3 \mu \mathrm{m}$. The polished specimens were sputtered with carbon using the Edwards Vacuum Coating System Model \# 306A. Polished sections were studied in a JEOL JSM6380 LV (SEM) operated at $20 \mathrm{kV}$ in backscattered electron imaging mode (BSE). The primary function of the SEM is to investigate the compounds developed in the samples under each testing condition.

\subsubsection{Differential Thermal Analysis (DTA)}

Differential Thermal Analysis (DTA) was carried out on paste samples containing GU PC, PC/FA and PC/MK using a Mettler Toledo DSC1 with a heating rate of $10 \mathrm{deg} / \mathrm{min}$ from $30^{\circ} \mathrm{C}$ to $700^{\circ} \mathrm{C}$ under grade 5.0 nitrogen. 


\subsubsection{X-ray Diffraction}

The XRD was carried out on the same paste samples tested using thermal analysis using an X-ray diffractometer. The internal wavelengths from anode material of Copper $(\mathrm{Cu})$ and generator settings of $40 \mathrm{~mA}$ and $45 \mathrm{kV}$ were used in this study.

\subsection{Results and Analysis}

\subsubsection{Phase composition of the raw SCM}

The X-ray diffraction of the raw materials and the XRD patterns and pattern list of fly ash, metakaolin and slag are shown in Figure 4-3 to Figure 4-5 suggests that the alumina in the fly ash sample used in this study is in the form of non-reactive mullite. This is in agreement with previous research that has shown that most of the alumina content of low calcium fly ash is in crystalline form; i.e. mullite $[111,112]$. 


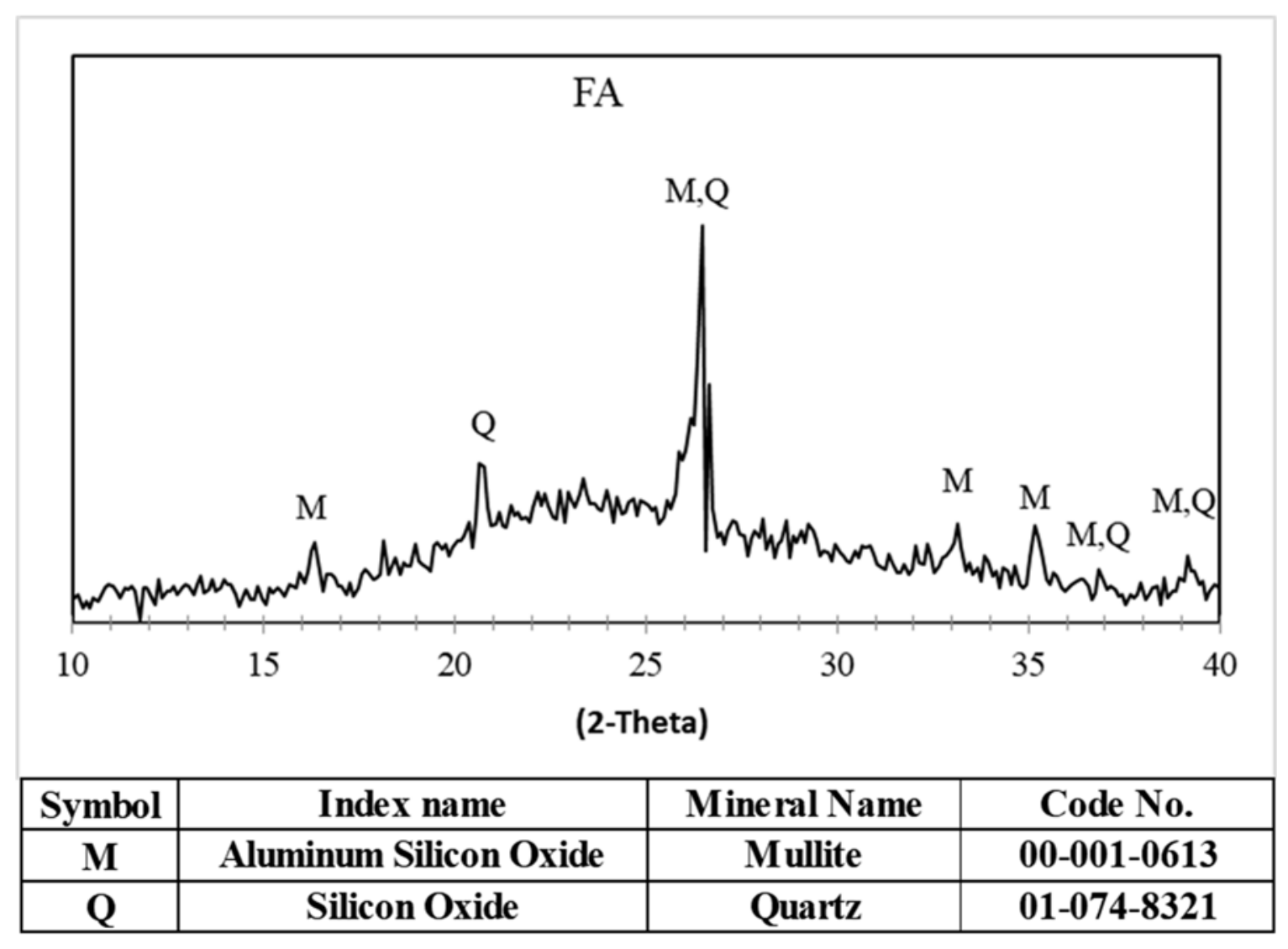

Figure 4 - 3: XRD patterns and pattern list of fly ash.

On the other hand, the MK sample shown in Figure 4-4 was characterized by a diffused amorphous phase between 2-theta that equals $20-30^{\circ}$, suggesting the presence of alkali-soluble silica and alumina [113]. Appendix A contains the list for each mineral used in the XRD Figures. 


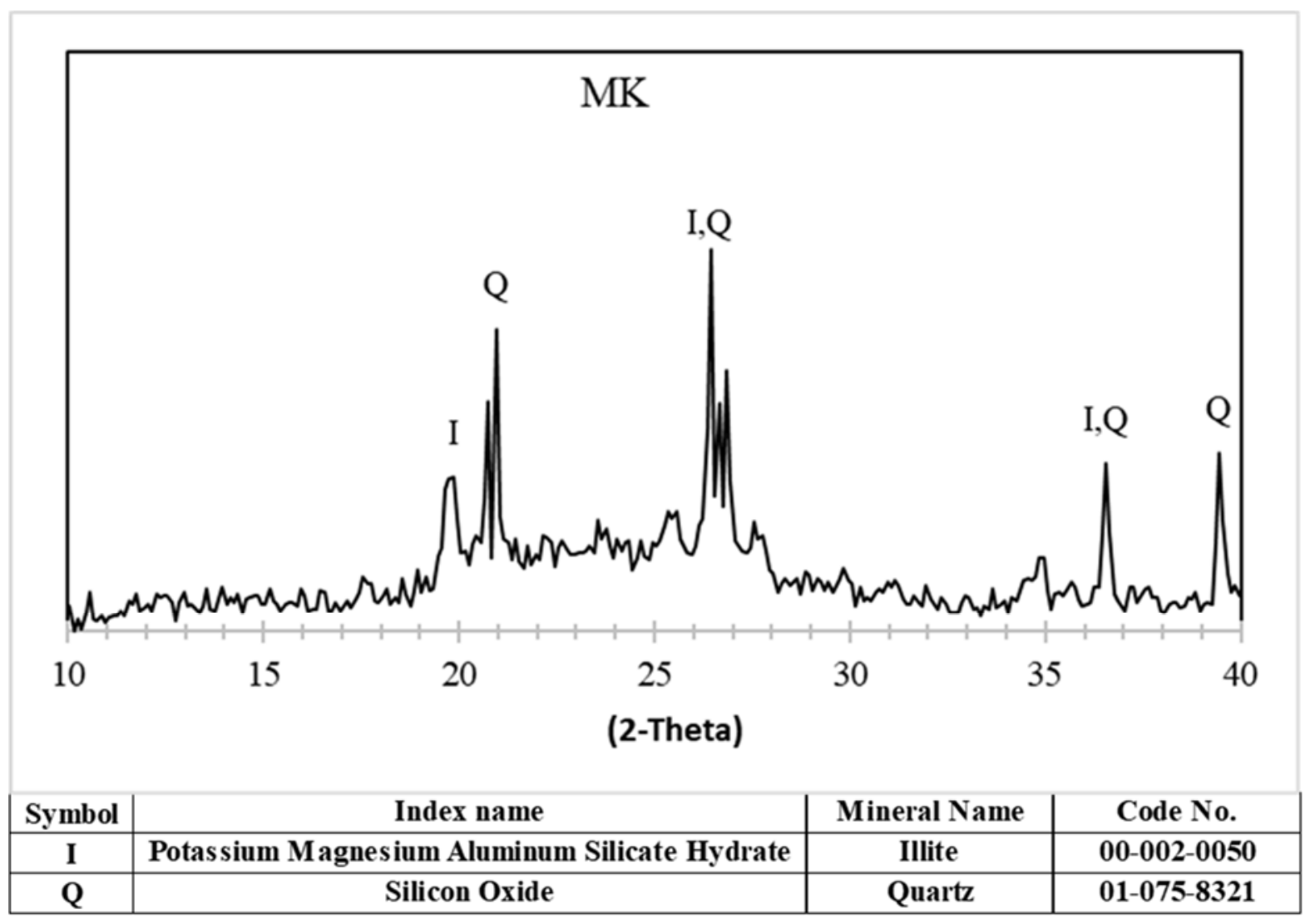

Figure 4 - 4: XRD patterns and pattern list of metakaolin 


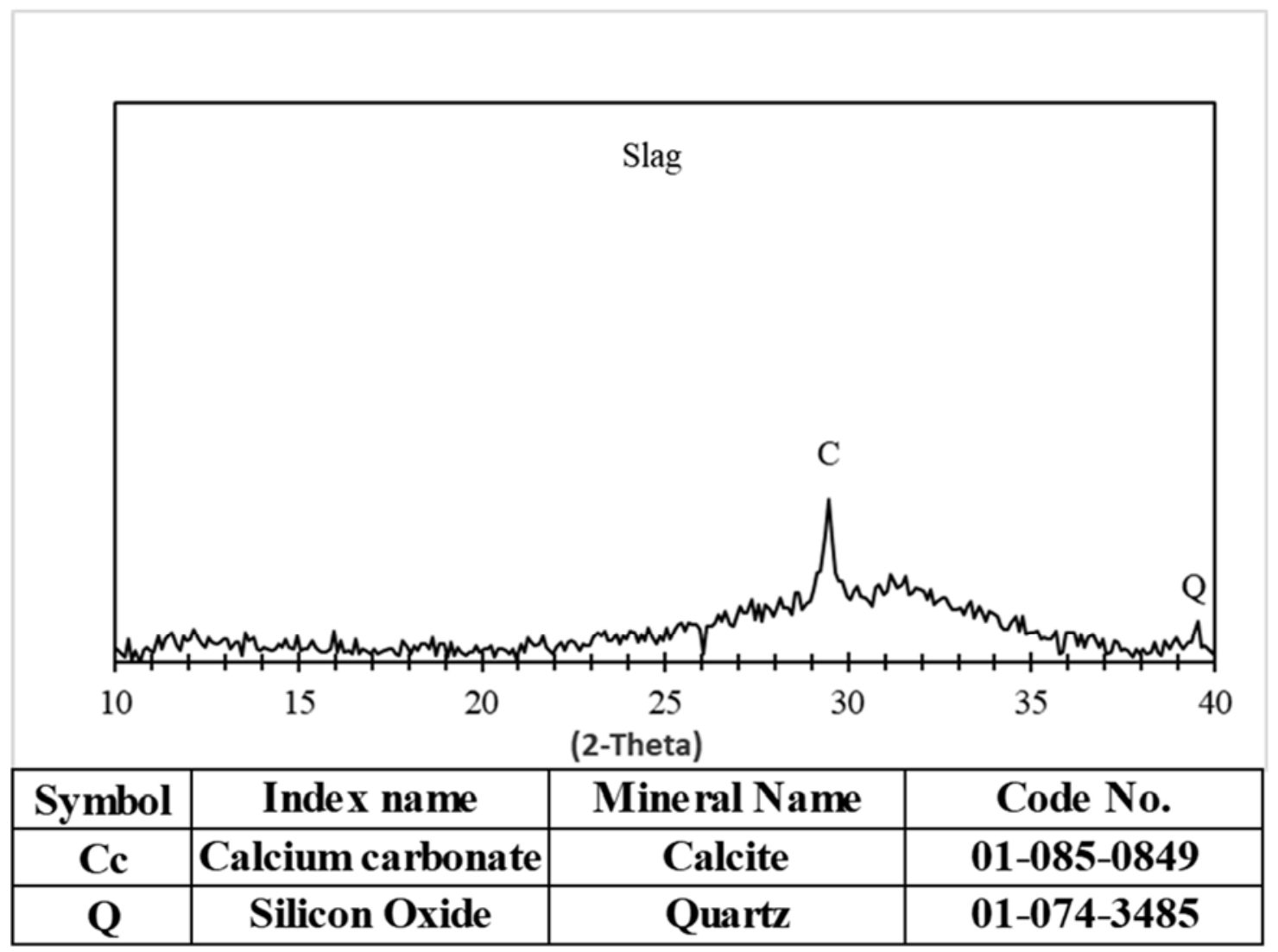

Figure 4 - 5: XRD patterns and pattern list of slag

\subsubsection{Preliminary Mortar Bar Testing}

In this part of the program, three different aggregates MAS, G, and P were tested using the same procedures described for the mortar bar test without controlling the relative humidity at $80 \%$. This was not done intentionally but it was found that the containers were improperly-sealed. The results are reported here to illustrate the effect of relative humidity on the expansion. Additional samples were tested using the same procedures, but the relative humidity was properly controlled at $80 \%$ when stored in the oven at $80^{\circ} \mathrm{C}$ during the first 13 weeks of the testing program. 


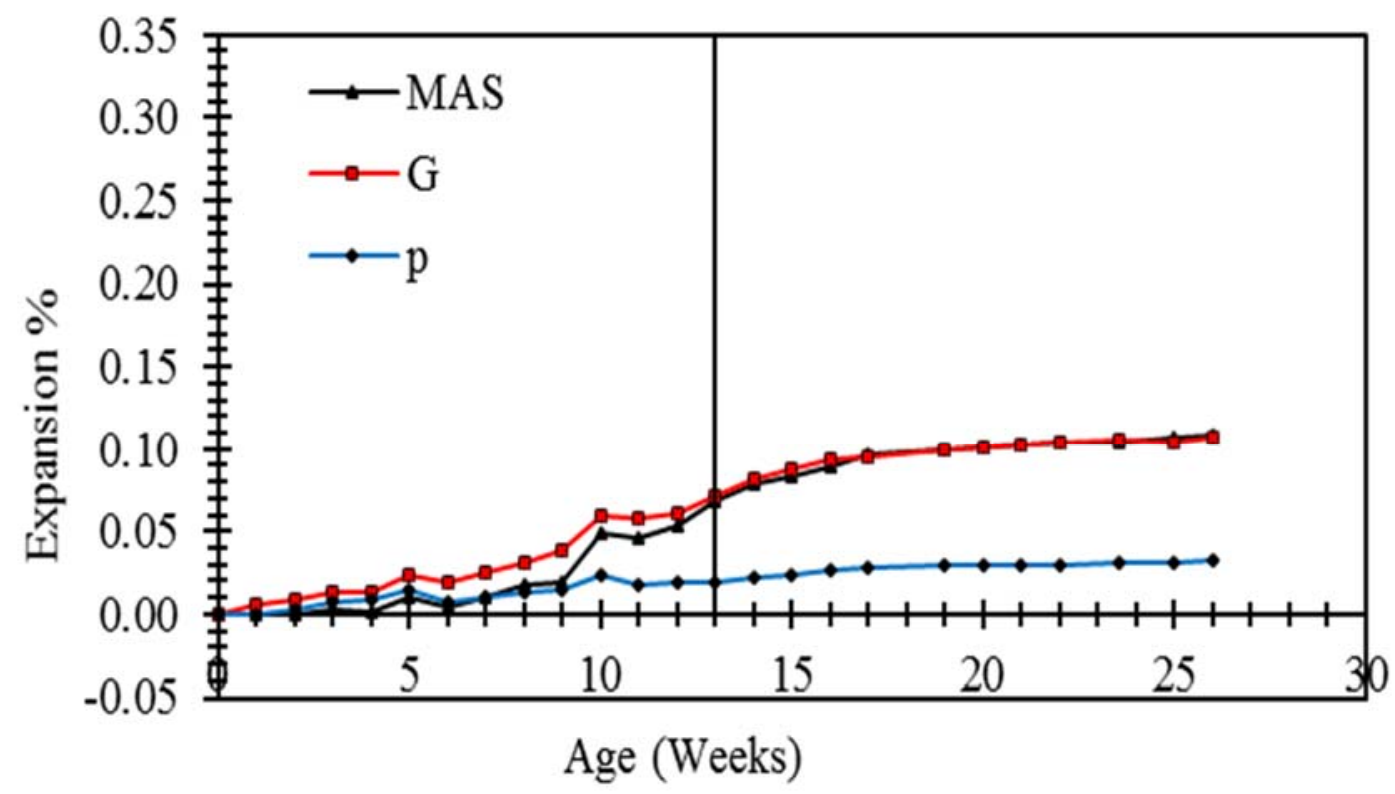

Figure 4 - 6: Expansion of mortar bar samples tested at $80^{\circ} \mathrm{C}$ with no control of RH in the first 13 weeks (improperly sealed container), followed by 13 weeks of testing at $5^{\circ} \mathrm{C}$ and $100 \% \mathrm{RH}$.

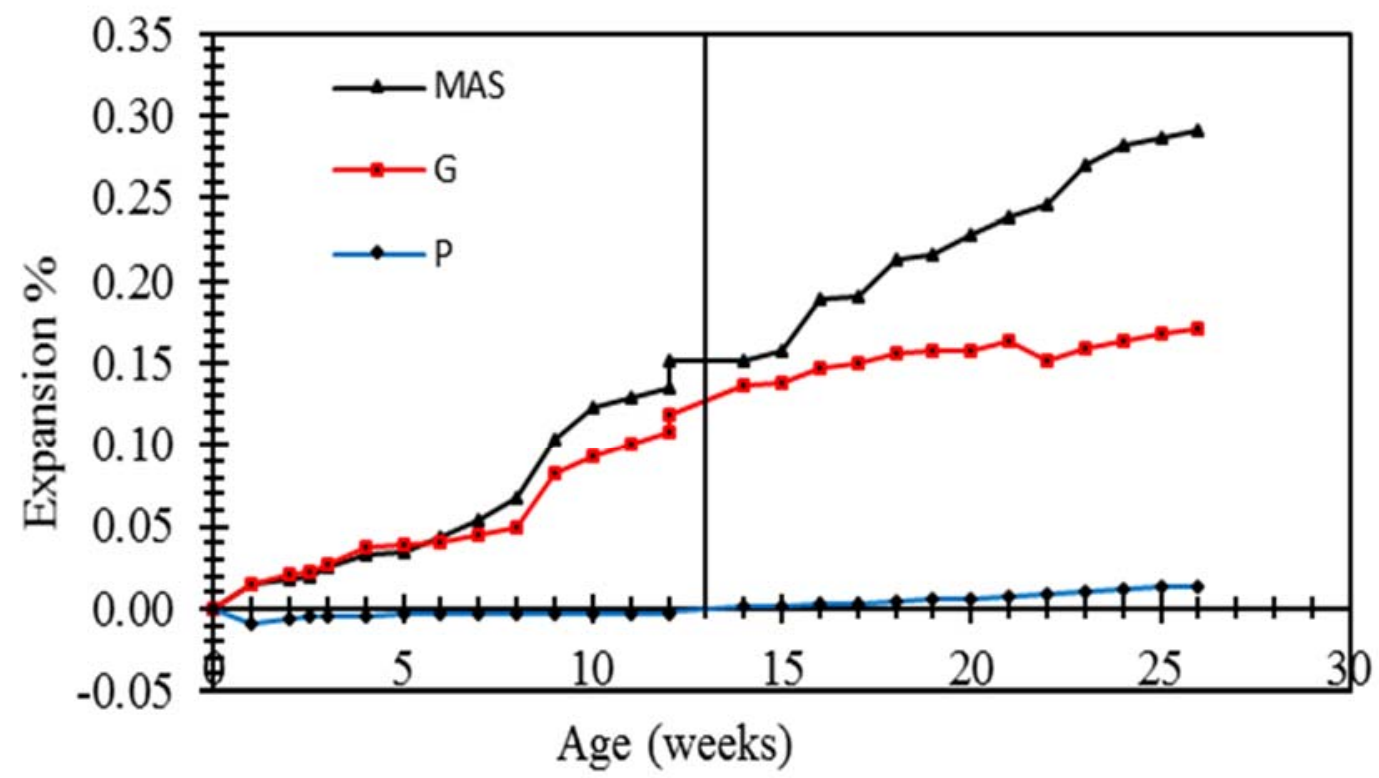

Figure 4 - 7: Expansion of mortar bar samples tested at $80^{\circ} \mathrm{C}$ and $80 \% \mathrm{RH}$ in the first 13 weeks, followed by 13 weeks of testing at $5^{\circ} \mathrm{C}$ and $100 \% \mathrm{RH}$. 
Figure $4-6$ and Figure $4-7$ show the expansion of the three aggregates after 26 weeks with uncontrolled and controlled humidity, respectively. This part of the testing program showed a higher expansion in the samples that were cast with sulphide-bearing aggregates and tested at $80^{\circ} \mathrm{C}$ and $80 \% \mathrm{RH}$, where the companion set of mortar bar samples incorporating the aggregate G presented an expansion similar to the expansion in mortar bar samples incorporating the MAS aggregate in the first 13 weeks under $80^{\circ} \mathrm{C}$ and $80 \% \mathrm{RH}$ condition. While the expansion in the second 13 weeks for the mortar bar samples cast with the $\mathrm{G}$ aggregate under $5^{\circ} \mathrm{C}$ and $100 \% \mathrm{RH}$ condition did not continue. It was very clear that the behavior of the expansion in the companion set of $\mathrm{G}$ bar was different than the mortar bar samples cast with MAS aggregate in the second 13 weeks. This suggests that the $\mathrm{G}$ aggregate does not contain in its composition any carbonate material. Figure $4-8$ shows the materials and equipment which were used to correct the problem and to modify the RH. Tightly sealed containers were used to maintain the $\mathrm{RH}$ at $80 \%$ using a high-quality lid and saran wrap Figure $4-8$ (a).

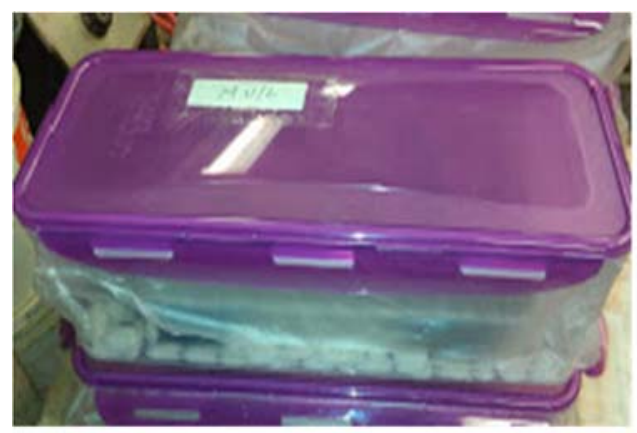

(a)

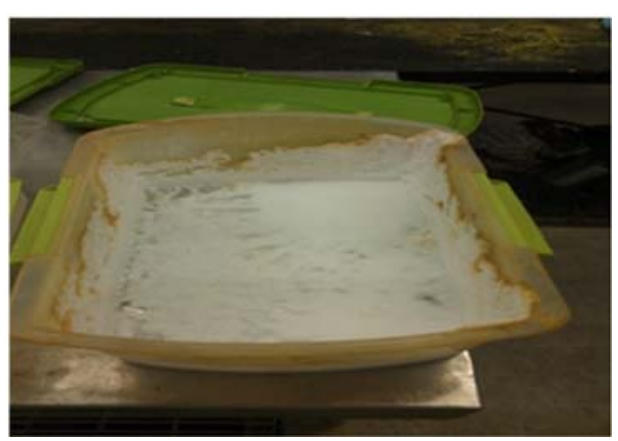

(b)

Figure 4 - 8: Containers used at $80^{\circ} \mathrm{C}$ and $80 \%$ RH (a) With proper seals and (b) With no control of RH 
Figure 4-9 shows the effects of bleach from different sources and aggregate processing on the expansion. It is clear that these have limited effects on the expansion of sulphide-bearing aggregates MAS. The figure shows very low expansion for all samples made with P (control), which contains almost zero sulphide content.

Figure 4 - 10 shows the mean expansion and standard deviation for the all mortar bar samples tested in Figure 4-9 and made with MAS aggregate. This figure reveals that the standard deviation for the expansion is very low, indicating that the source of bleach and sample preparation at different labs have minimal effects on the test results. It should be noted that each set of mortar bar samples consisted of three specimens. The average and standard deviation in Figure $4-10$ is for the MAS aggregate.

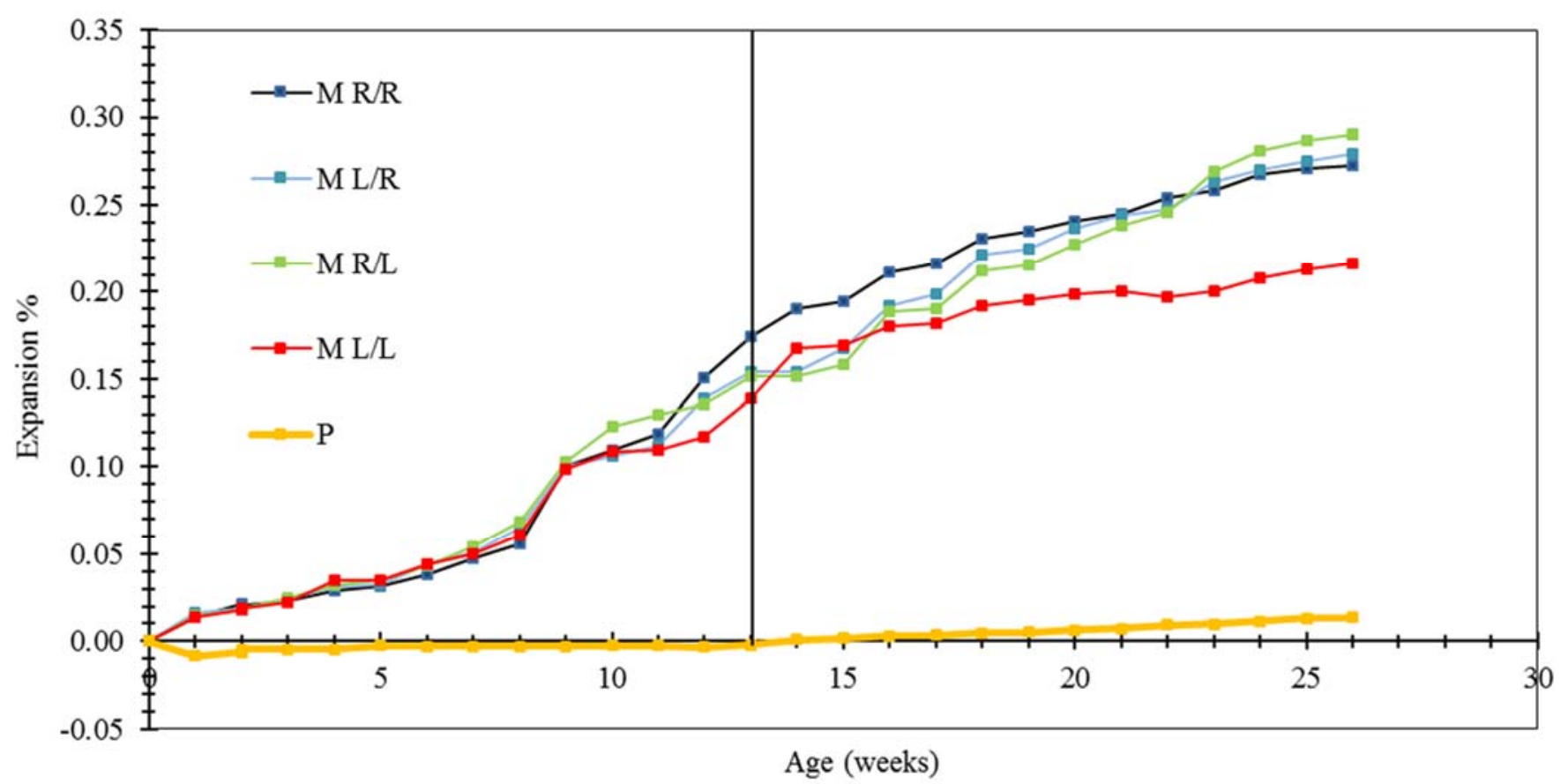

Figure 4 - 9: Expansion in mortar bar samples made with different sulphide mineral aggregates. 


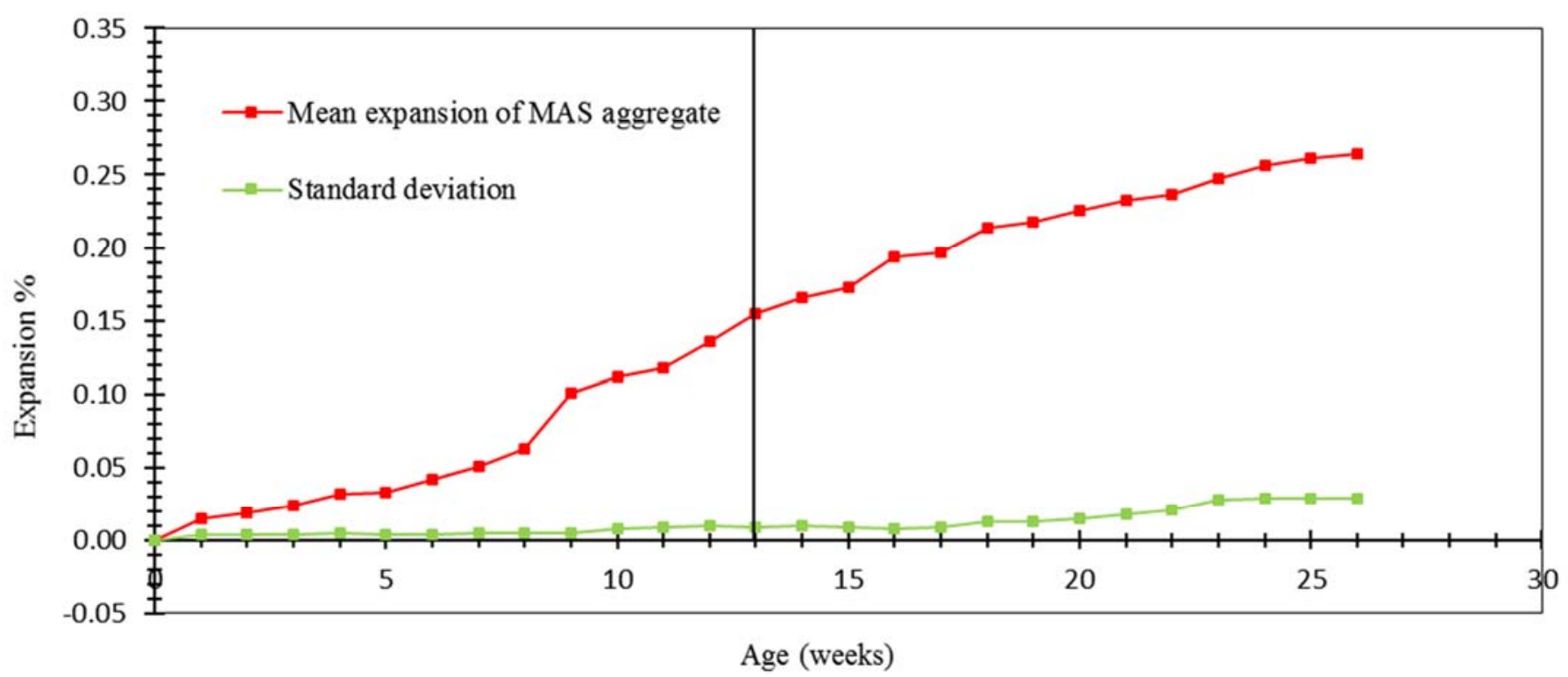

Figure 4 - 10: Standard deviation and the expansion mean and for all mortar bar sets made with MAS aggregate

In the last part of this section, Figure 4 - 11 shows that the expansion in mortar bar samples named (M n.f) was higher than the samples named ( $\mathrm{M} \mathrm{f).} \mathrm{It} \mathrm{should} \mathrm{be} \mathrm{noted} \mathrm{that} \mathrm{all} \mathrm{the} \mathrm{mortar} \mathrm{bar}$ samples were cast with MAS aggregate, and the companion set named (M n.f) were left in room temperature for a period of half an hour, while the set samples named ( $\mathrm{M} \mathrm{f}$ ) were left in a fume hood for a period of 3 hours after the samples were soaked in sodium hypochlorite solution for three hours. The higher expansion occurred in the M n.f mortar bar samples could be attributable to the longer storing time at $80 \mathrm{C} / 80 \% \mathrm{RH}$ and perhaps achieving an optimized $\mathrm{RH}$ for a longer duration compared to the other samples. Also, a longer duration at a temperature of $80^{\circ} \mathrm{C}$ and $\mathrm{RH}$ of $80 \%$ is required in order for oxidation to occur. Based on these results, it was decided to run the 
remainder of the testing without leaving the sample for three hours at room temperature under fume hood.

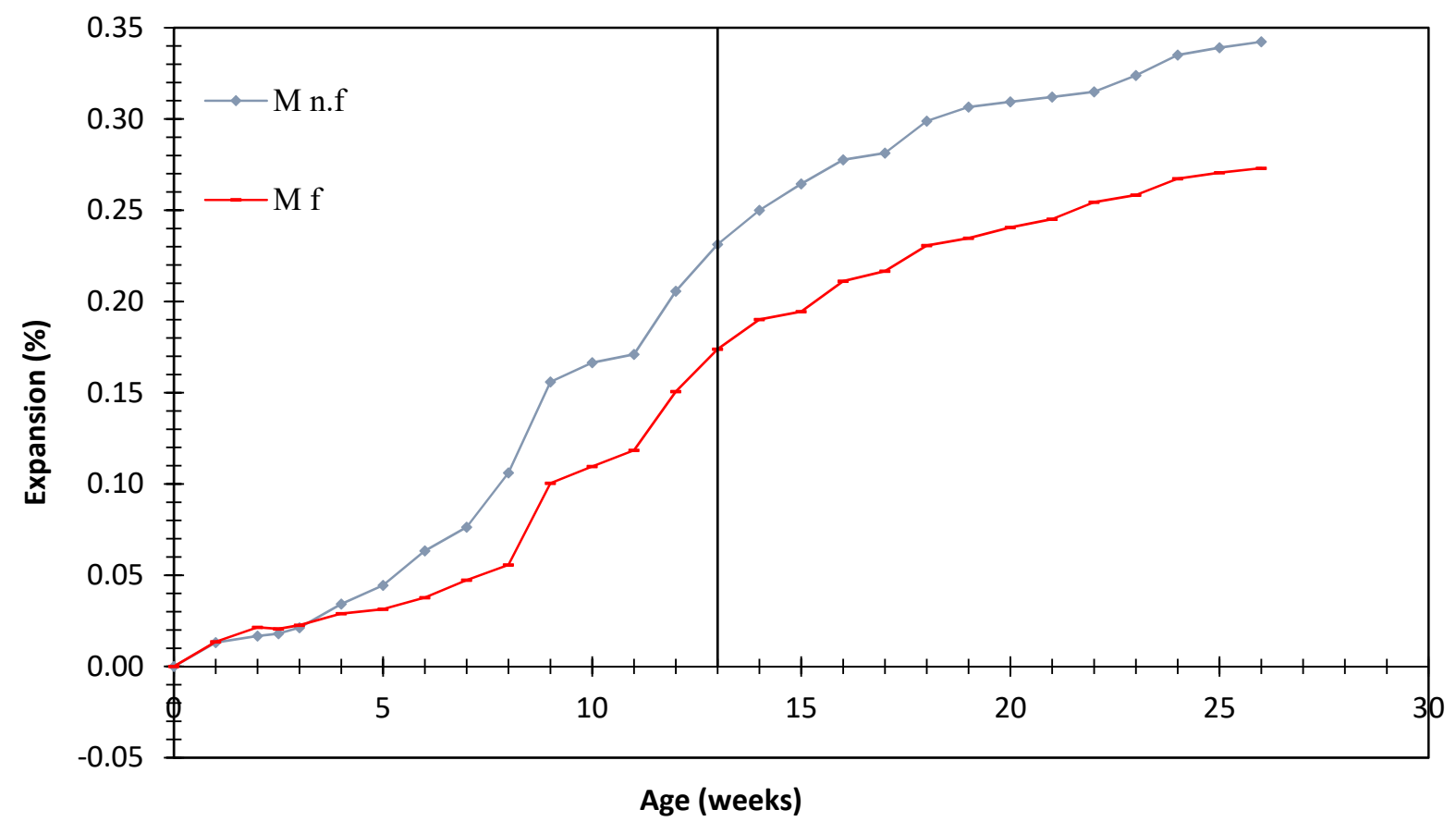

Figure 4 - 11: Expansion of MAS samples which placed in a fume hood for three hours ( $\mathrm{M} \mathrm{f}$ ) showing a slightly lower expansion than samples placed for half an hour in $23^{\circ} \mathrm{C}(\mathrm{M} \mathrm{n} . \mathrm{f})$

\subsubsection{Application of the Test to a Wide Range of Aggregates}

Figure 4 - 12 shows high expansion in all three sets that were cast with the $\mathrm{C} 2$ aggregate in the first 13 weeks. The samples only showed expansion in the first stage of the test with no subsequent expansion in the second 13 weeks when stored at $5^{\circ} \mathrm{C}$ and $100 \% \mathrm{RH}$. 
The same can be said for Sud, which showed a higher expansion rate in the first 13 weeks with a flat curve during the second stage. That is a characteristic of alkali-silica reactive aggregates when tested using this method, as previously reported [3]. The same figure shows that the expansion rate with the two control aggregates $\mathrm{C} 1$ and $\mathrm{P}$ was very low. It should be noted that the $\mathrm{C} 1, \mathrm{C} 2$ and $\mathrm{P}$ aggregates were tested three times to validate the results. The reason for the expansion in C2 aggregate is explained later in this Chapter.

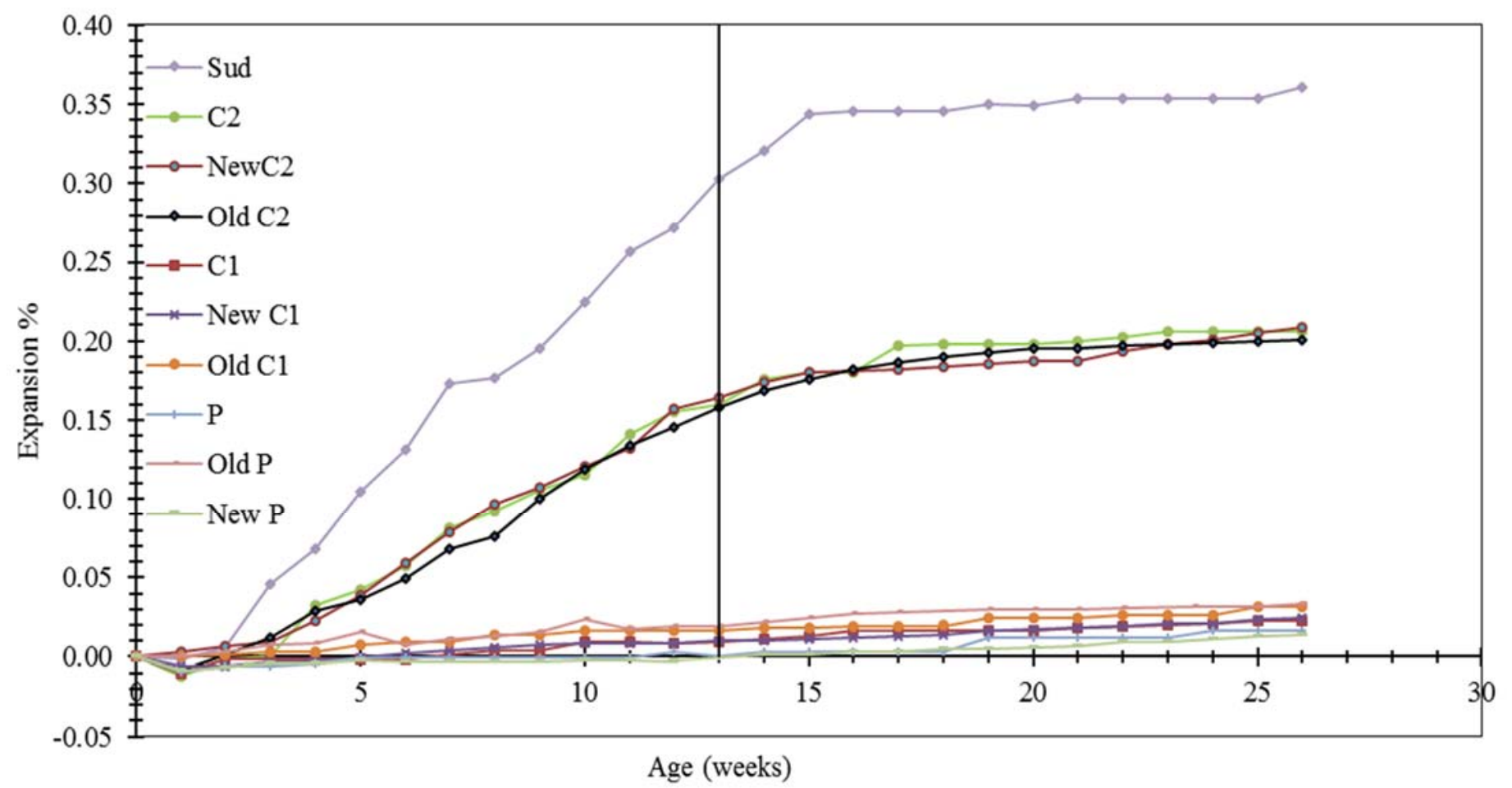

Figure 4 - 12: Expansion in all control and aggregates with total sulphur $<0.05 \%$

The curves in Figure 4 - 13 reveal a higher expansion for all sulphide aggregates in the first stage; this higher expansion is thought to be due to the oxidation process. Also, the curves revealed 
continued expansion during the second stage of the mortar bar sample test with the same aggregates; this is likely due to the thaumasite formation, which favorably forms at temperatures of about $5^{\circ} \mathrm{C}$ as previously confirmed [3].

The main difference between this group of aggregates in Figure $4-13$ and the aggregates in Figure $4-12$ is the expansion in the second stage of the test. The sulphide aggregates showed continued expansion in the second stage while the non-sulphide aggregates did not. This is the property that should be used to screen aggregate with oxidizable sulphide content from aggregate without.

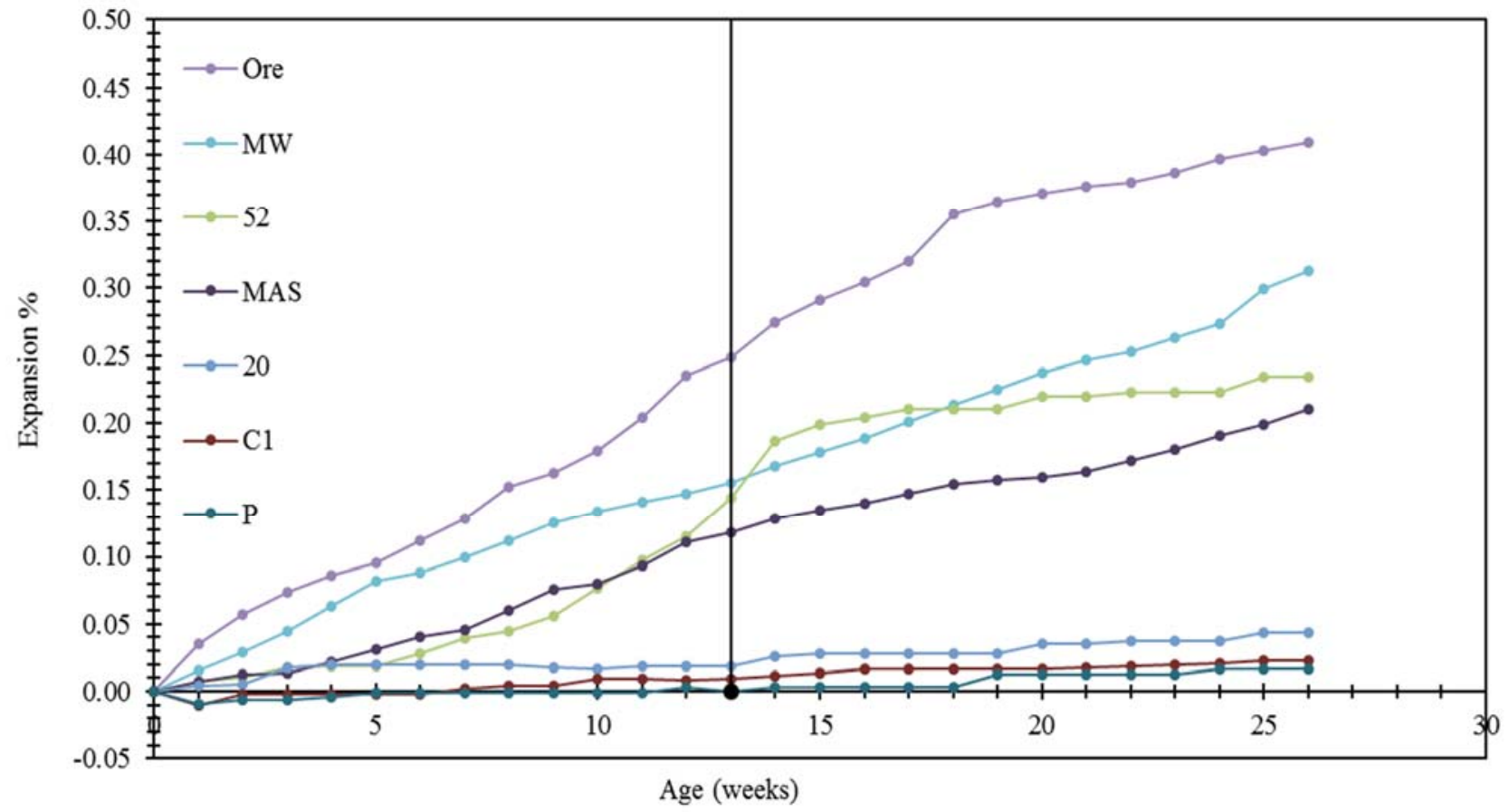

Figure 4 - 13: Expansion in samples with various sulphide contents. 


\section{- Microstructural Investigation of Aggregates}

The behaviour of aggregate C2 warranted further investigation. The behaviour of this aggregate under the effect of an oxidizing agent and in mortar bar was examined using SEM and EDS as well as by analyzing the chemical composition of the oxidizing solution after soaking the aggregate in it. For comparison, examination of the aggregate C1 was also carried out using SEM.

Figure $4-14$ reveals many white spots in a row $\mathrm{C} 1$ stone which are sulphide phases based on the EDS. The figure also shows the components of one of the magnified white spots containing iron sulphide. The low expansion of this sample suggests that the level of sulphide was not high enough to cause expansion or perhaps the sulphide is in a non-oxidizable form.

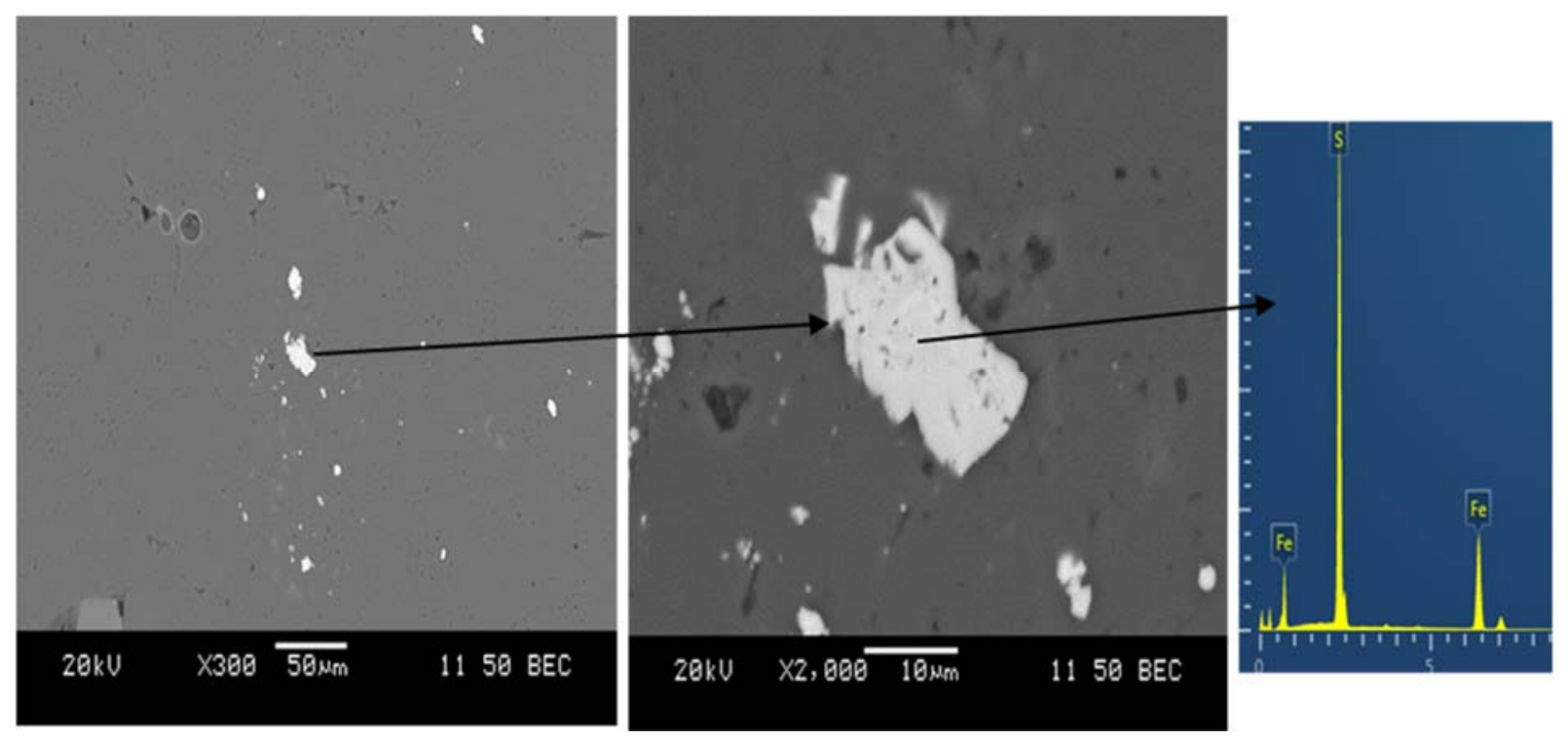

Figure 4 - 14: EDS analysis showing sulphide minerals in the $C 1$ aggregate. 
Figure 4-15 shows another type of white spots in the C2 stone under SEM, however, this iron is not in the form of sulphide as there is no detected sulphur peak; it is likely in one of the iron oxide forms.

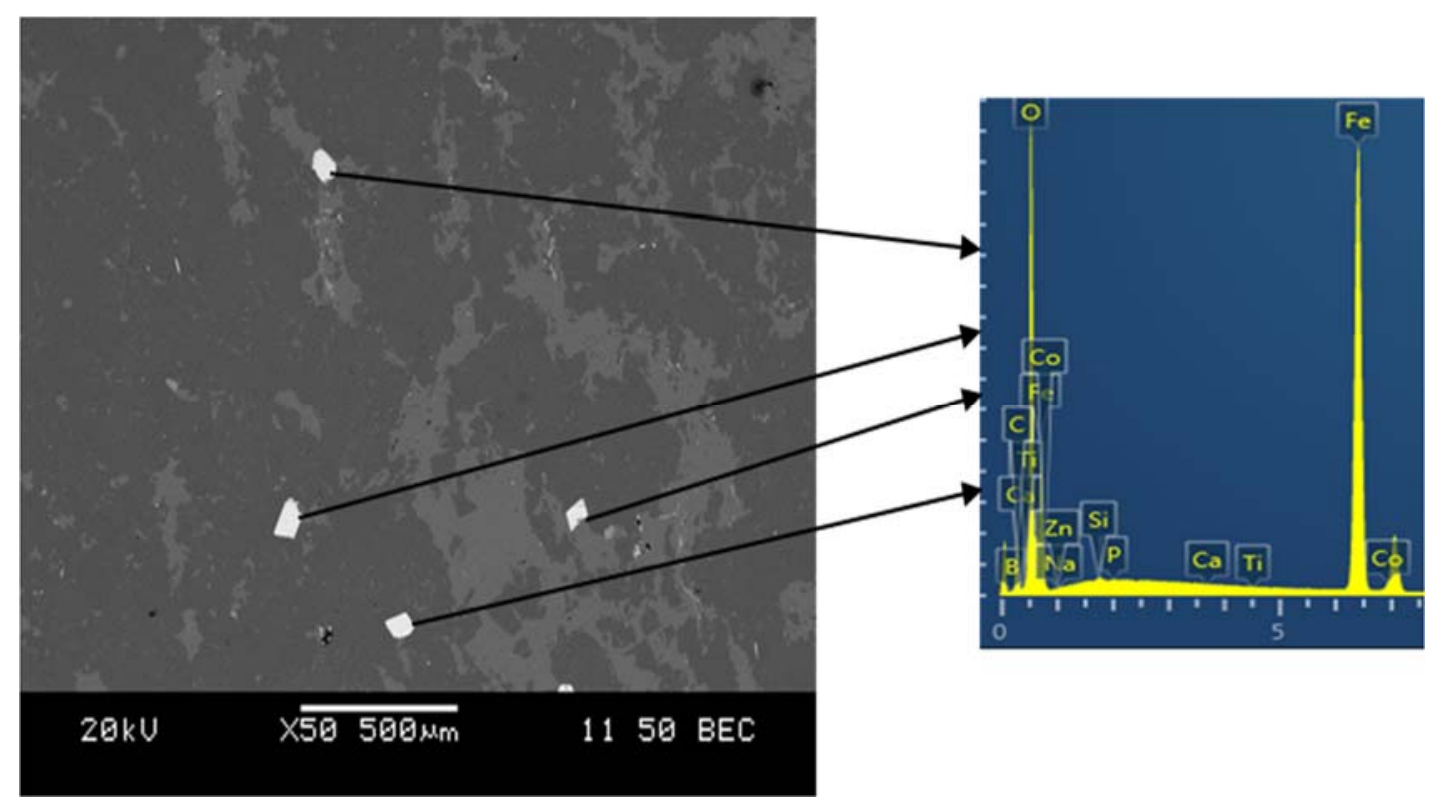

Figure 4 - 15: Evidence of a white spots in the C2 aggregate containing iron oxide.

Figure 4 - 16 shows the disintegration of the C2 aggregate fabric after the aggregate oxidation test (after being exposed to bleach or oxidizing agent). While there is no evidence of disintegration prior to the test, there is clear damage to the fabric after the test. It is possible that sodium hypochlorite could affect some aggregates like C2 through the dissolution of the silica ions. Indeed, this what was found when the oxidizing solutions were analysed for this aggregate and other selected aggregates as listed in Table 4 - 3. It is interesting to see that the expansion in 
the $\mathrm{C} 2$ and Sud aggregates is proportional to the amount of dissolved silica. As we can see in Table 4 - 3, the amount of dissolved silica in Sud was double in the amount of the silica dissolved in C2 and the expansion was proportional to it as shown in Figure 4 - 12. Also, the amount of Silica ion is low for both control aggregates $\mathrm{C} 1$ and $\mathrm{P}$. 

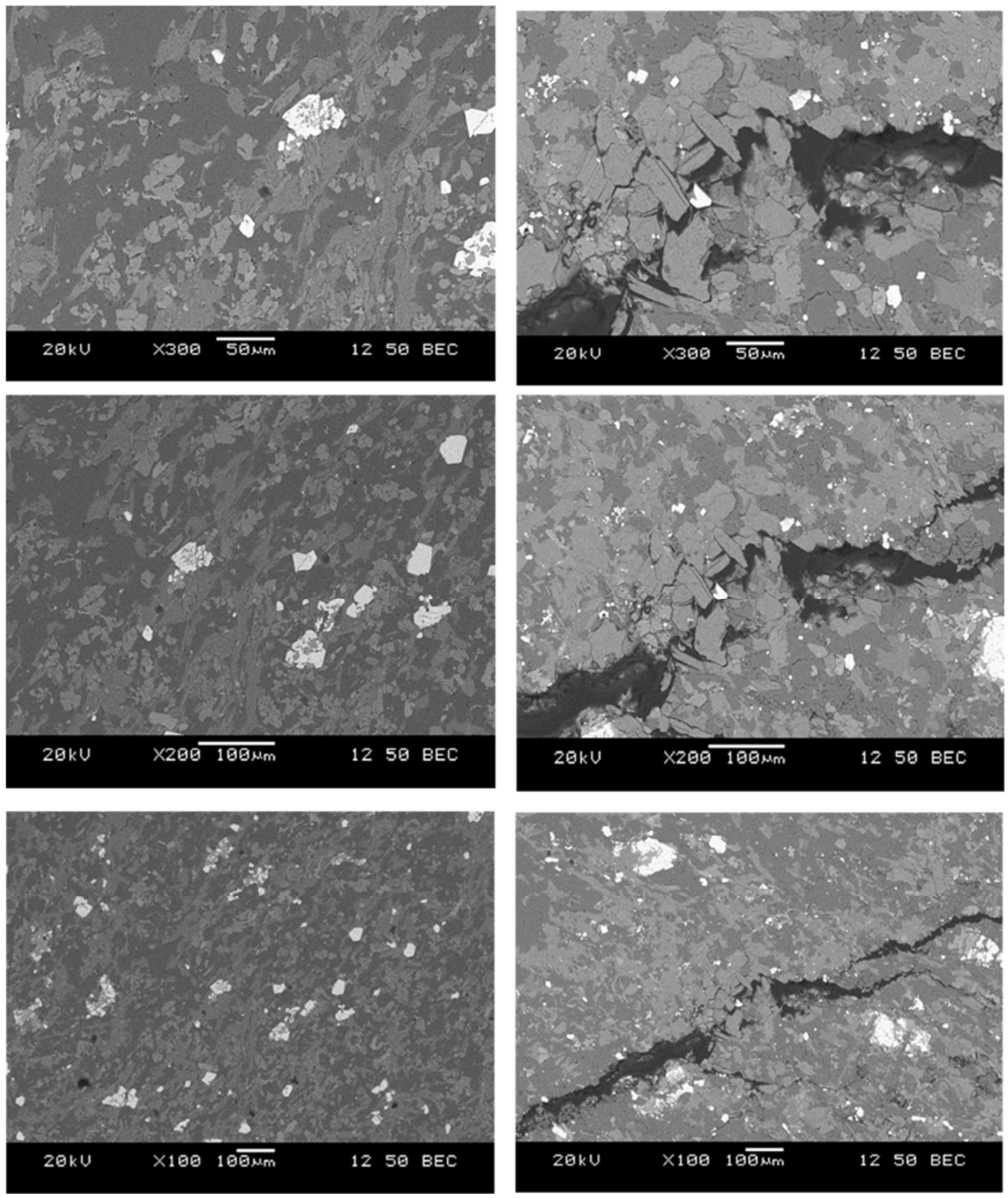

Before

After

Figure 4 - 16: C2 aggregate before \& after aggregate oxidation test 
Table 4 - 3: Silica ion concentration in solution under different temperatures.

\begin{tabular}{|c|c|c|c|c|}
\hline Aggregate & C2 & C1 & P & Sud \\
\hline Silica ion (mg/l) at $40^{\circ} \mathrm{C}$ & 3.6 & 0 & 0 & 3.8 \\
\hline Silica ion $(\mathrm{mg} / \mathrm{l})$ at $80^{\circ} \mathrm{C}$ & 14.4 & 2 & 4 & 28.7 \\
\hline
\end{tabular}

Figure 4-17 and Figure 4-18 show evidence of silica gel in the mortar bar samples with C2 and Sud aggregates, respectively when exposed to the sodium hypochlorite solution. The silica gel in both cases was form in an air void. The x-ray mapping in both figures show concentration of silicon, sodium and calcium which is a typical composition of alkali-silica gel. This gel is formed on the inside perimeter of the air void. 


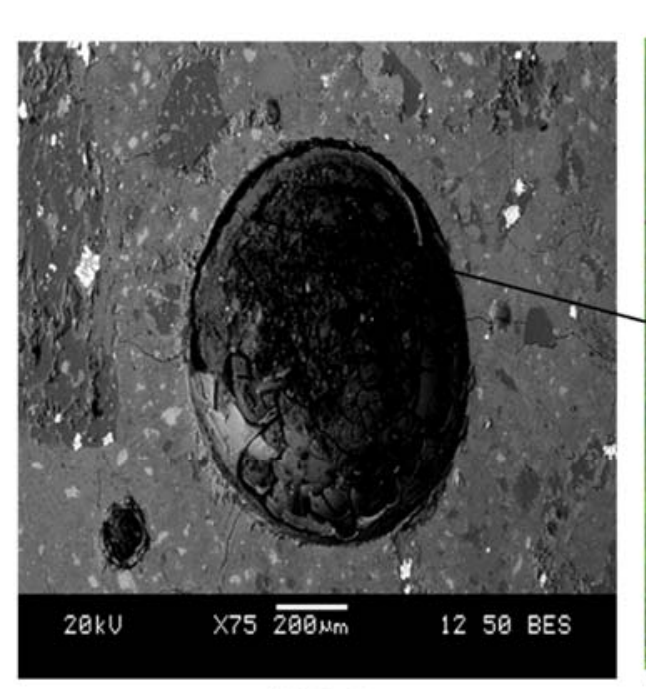

\section{Si K $\alpha 1$}
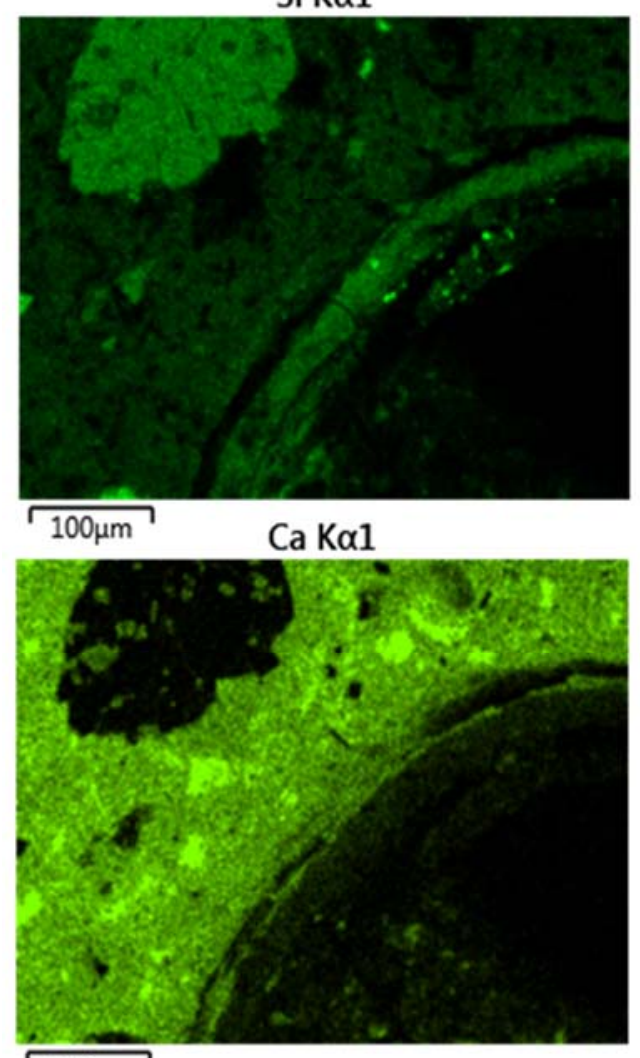

$\longdiv { 1 0 0 \mu \mathrm { m } }$

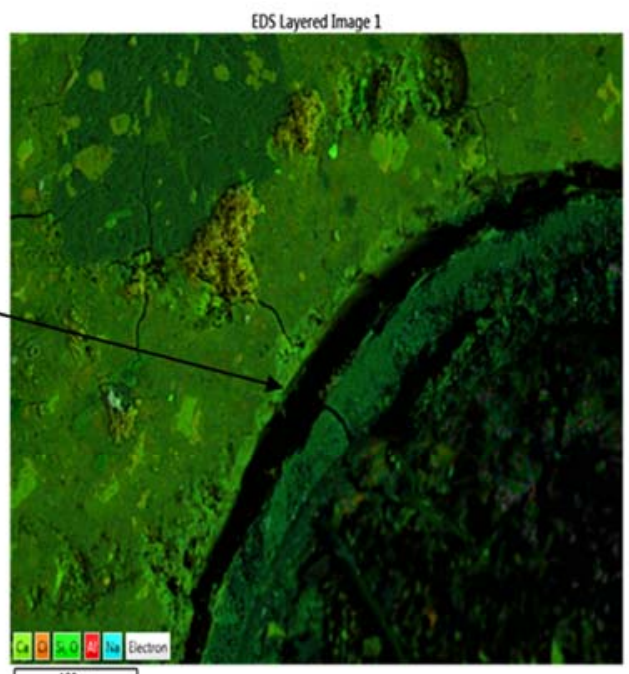

Na K $\alpha 1 \_2$
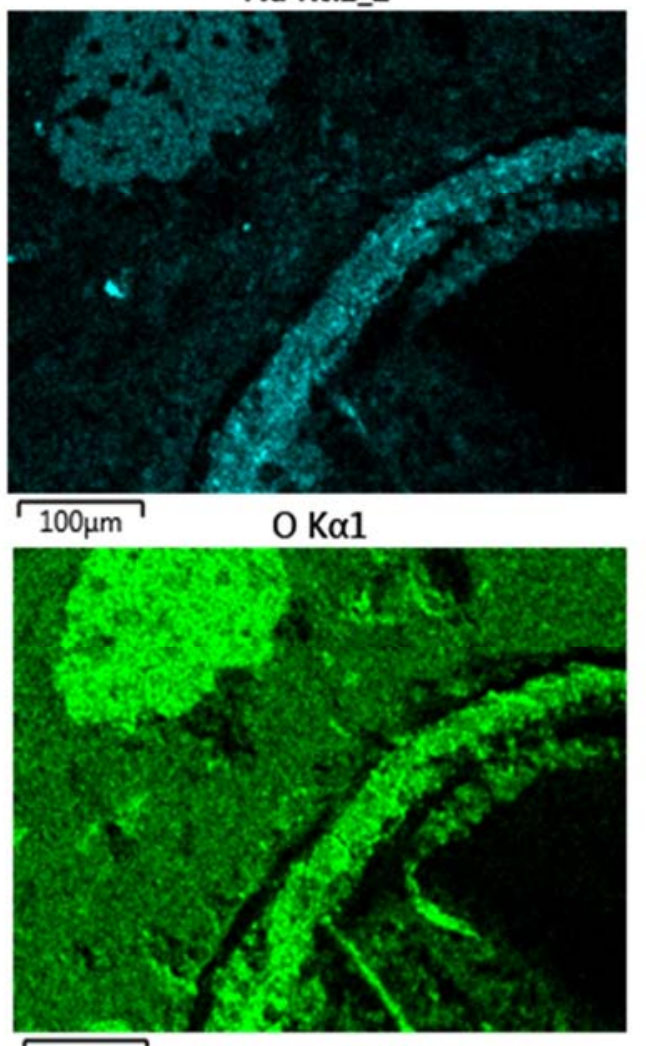

$\longdiv { 1 0 0 \mu \mathrm { m } }$

Figure 4 - 17: Evidence of ASR gel inside one of the air void in mortar bars with C2 aggregate 

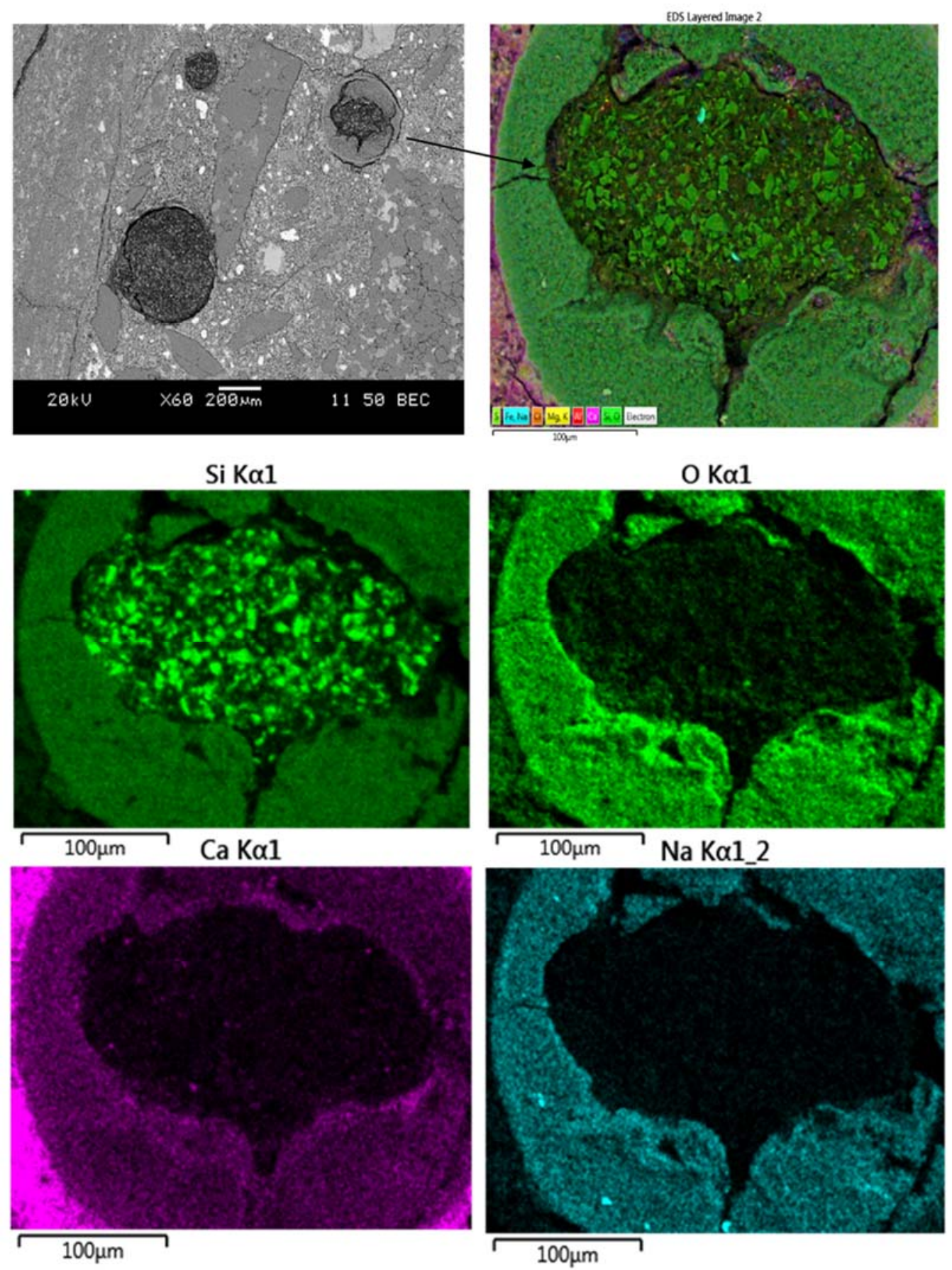

Figure 4 - 18: Evidence of ASR gel inside an air void in mortar bars containing Sud aggregates 
4.5.4 Investigating the ability of the test to evaluate the effects of mix parameters (SCM and w/c)

- Mass Gain and ion Penetrability of Mortar bar Samples with Different Cementing Systems

The mass gain versus soaking time for mortar bars with different cementing blends soaked in oxidizing solution is shown in Figure 4 - 19.

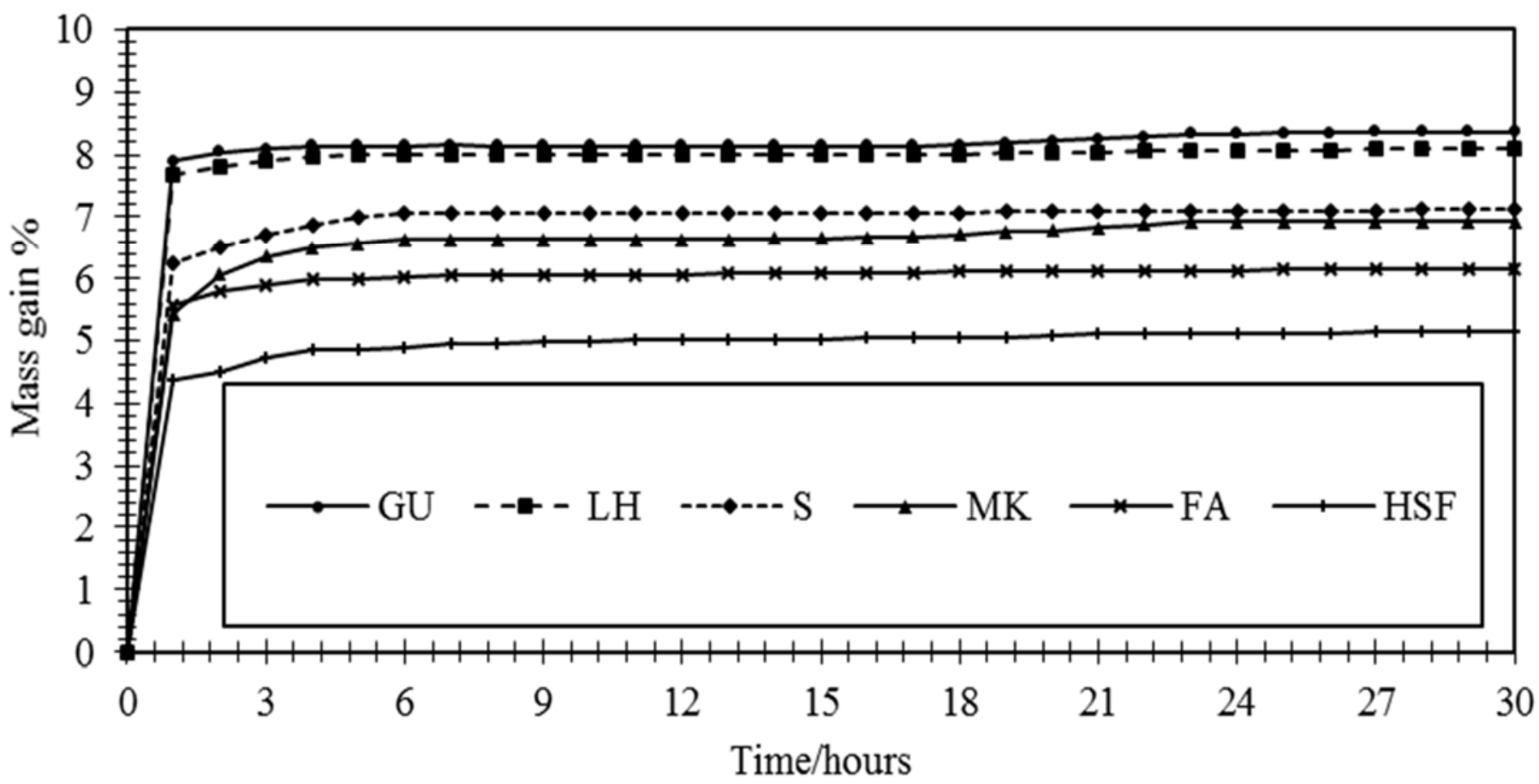

Figure 4 - 19: Mass gain of mortar bar samples made with $P$ aggregate soaked in 6\% sodium hypochlorite solution up to 30 hours.

Most of the mass gain was achieved within the first three hours for all samples. The samples tested using the $\mathrm{CaCl}_{2}$ solution presented the identical curve. However, the concentration of 
chloride ions within the samples was changed with time as shown in Figure 4- 20 especially for samples with SCM. This happens without a significant change in mass of the bars. This finding can be explained based on the conditioning of the samples. Initially, the samples were cured for three days in a curing room with $\mathrm{RH}$ of almost $100 \%$ at room temperature. By the end of the three days, the samples condition is expected to be close to saturation. After the three days, the bars were maintained at $80 \% \mathrm{RH}$ and $80^{\circ} \mathrm{C}$. This did not permit drying of the samples; rather, it allowed maintaining the $\mathrm{RH}$ at $80 \%$ or above inside the sample. Following this step, the samples were placed in the soaking solution. Hence, the mass gain represents how much soaking solution was able to penetrate the samples. The increase in ion concentration, without associated mass gain, is likely due to the ion diffusion within the sample while the sample is saturated.

Another possible explanation is that the cores of samples with SCM remain at relative humidity higher than $80 \%$ or close to saturation while in the oven due to enhanced pore structure of the samples. When placed in solution, the solution penetrates the outer part of the sample cross section, and the ions continue to diffuse within the water-saturated cores of the samples. The implication of this on the observed expansion will be discussed in the section below. 

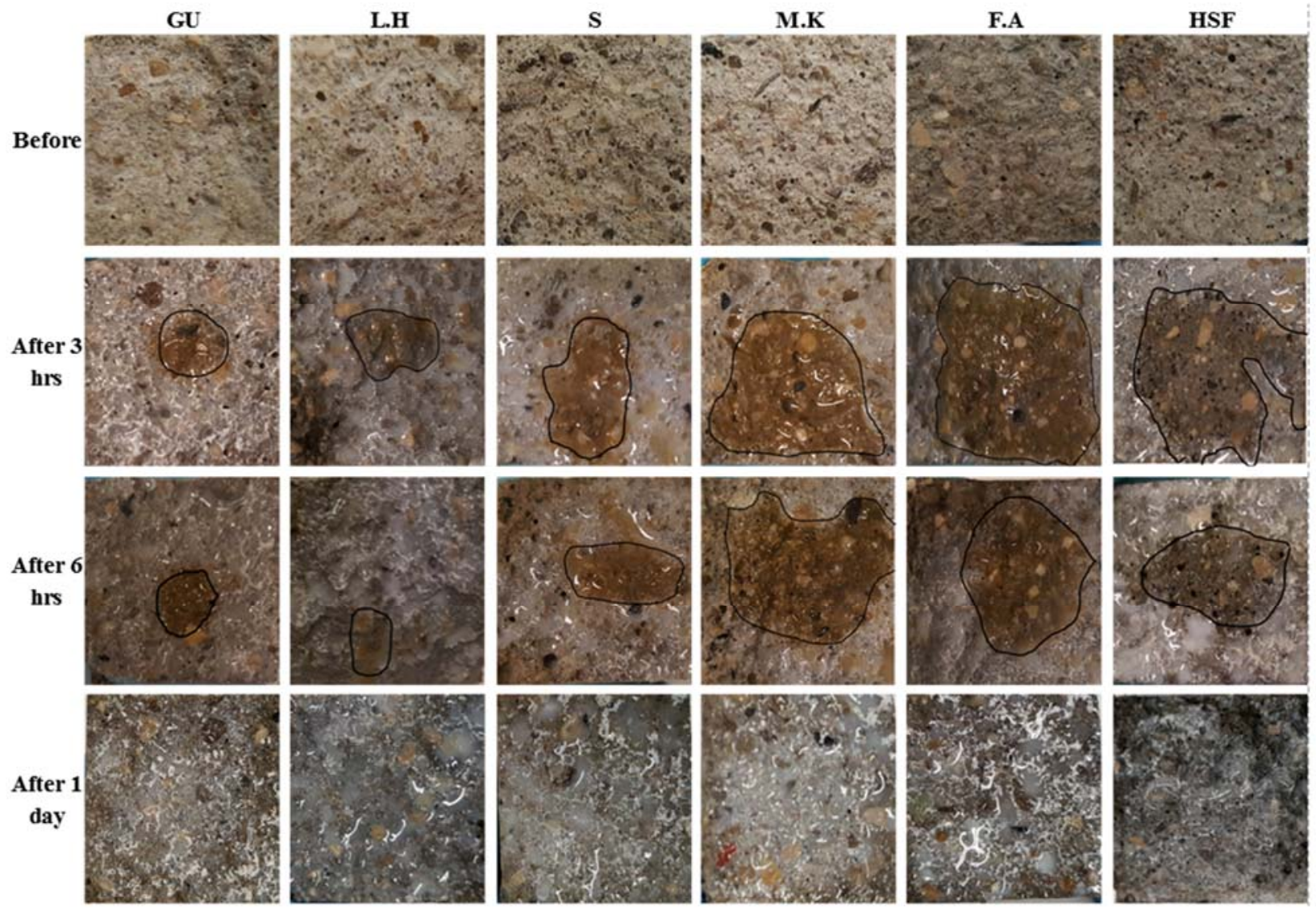

Figure 4 - 20: Migration of chloride ions into the mortar bar samples after different time of exposure.

\section{- Expansion of Mortar Bar Samples without SCM}

Figure $4-21$ (a) to (c) show the condition of the mortar bar samples that were cast with GU cement at the end of the testing period. 
These pictures will be used later on for comparison with samples containing metakaolin. Some of the bars were broken at the end of the tests in order to collect samples for SEM evaluation.

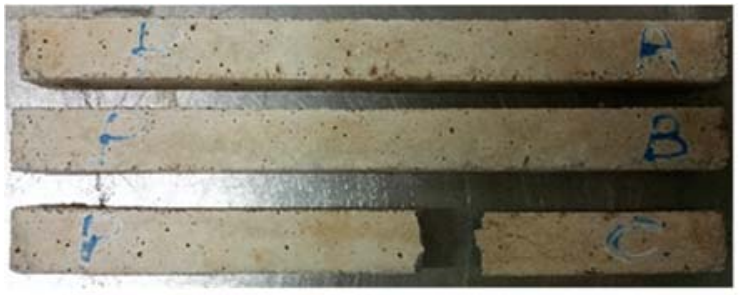

(a) Mortar bar samples cast with P aggregate

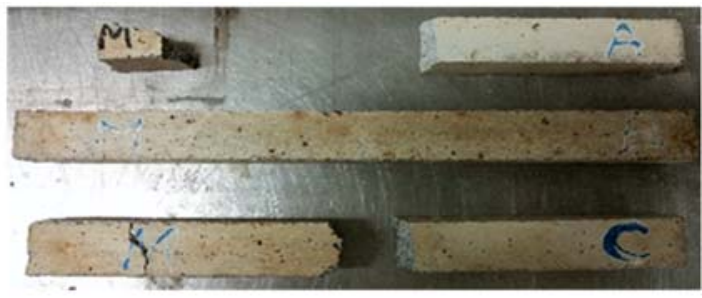

(b) Mortar bars cast with MAS aggregate

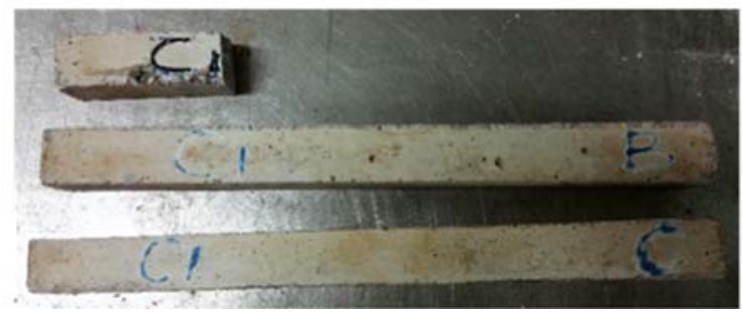

(c) Mortar bar samples cast with C1 aggregate

Figure 4 - 21: Condition of different mortar bar samples after 26 weeks with no visible cracks in the picture.

\section{- Testing Using a Soaking Period of 3 Hours}

The expansion of mortar bars incorporating aggregates $\mathrm{C} 1, \mathrm{MAS}$, and $\mathrm{P}$ is shown in Figure $4-22$ which provides a baseline of expansions of these aggregates when used without SCM. The expansion curves of these samples show high expansion in bars with MAS, and limited expansion in bars with the two non-sulphide bearing aggregates $\mathrm{C} 1$ and P. Figure $4-23$ to Figure $4-27$ show the expansion of mortar bars with three aggregates MAS, C1, and P when tested with the 
following cementing blends: low-heat (or low- $\mathrm{C}_{3} \mathrm{~A}$ ) PC, GU PC $+30 \%$ slag, PC $+25 \%$ lowcalcium fly ash, $\mathrm{PC}+10 \%$ metakaolin, high sulphate resisting (HSF) cement (PC blended with silica fume).

The low- $\mathrm{C}_{3} \mathrm{~A}$ reduced the expansion compared to samples with only GU PC, as shown in Figure $4-23$. As for SCM, all types and replacement levels reduced the expansion compared to the GU PC mix; however, the degree by which each of the SCM reduced the expansion varied from one SCM to another, with silica fume-blended cement $(8 \% \mathrm{SF})$ being the most efficient, slag (30\%) being the least effective, while low-calcium fly ash $(25 \%)$ was somewhere in the middle. The reduction in expansion was in the range of $50 \%$ to $85 \%$. The sample with $30 \%$ slag showed lower expansion than samples with GU but higher than samples with other SCM. This is in line with the results of the salt migration test illustrated in Figure $4-20$. The sample with slag has more migration of salt, representing more migration of oxidizing solution, within the cross section of the samples compared to samples with other SCMs, but less migration compared to the sample with only GU cement. 


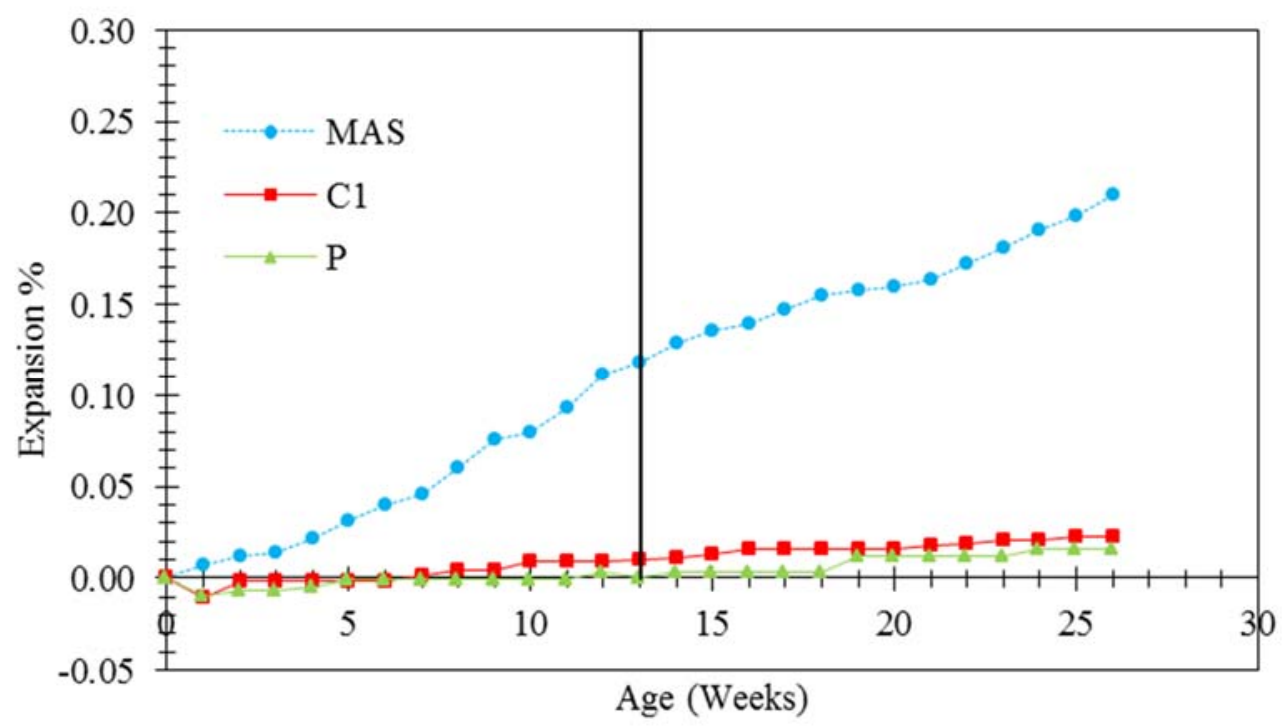

Figure 4 - 22: Expansion of mortar bar samples containing P, MAS, and C1 aggregates cast with GU cement and soaked 3 hours in a sodium hypochlorite solution.

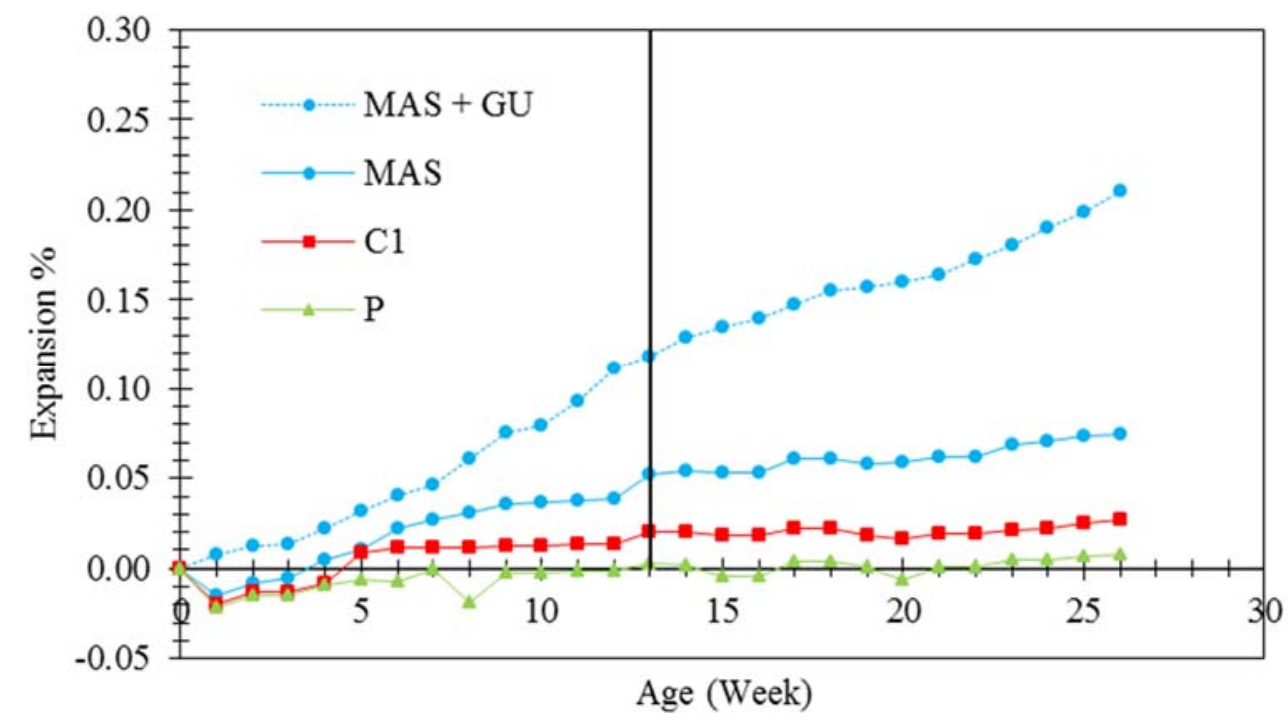

Figure 4 - 23: Expansion of mortar bar samples containing P, MAS and C1 aggregates cast with low heat hydration cement and soaked 3 hours in bleach. 


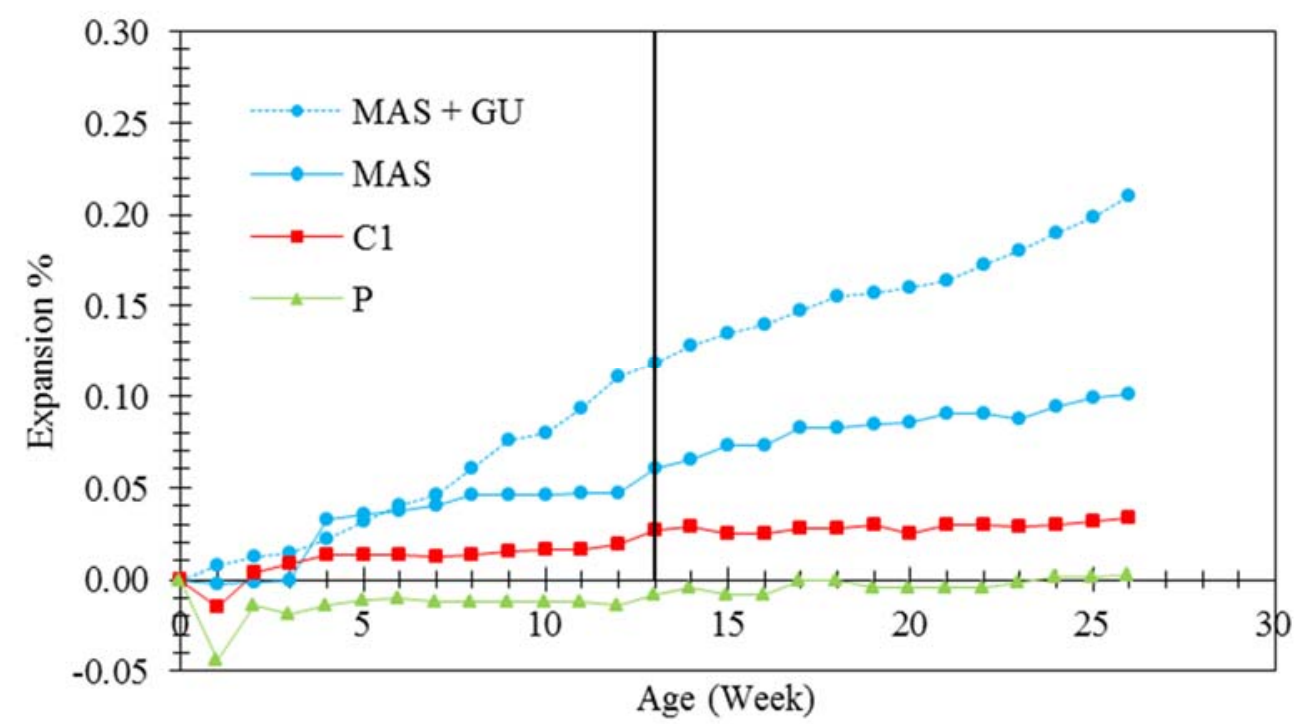

Figure 4 - 24: Expansion of mortar bar samples containing P, MAS, and C1 aggregates cast with slag and soaked 3 hours in a sodium hypochlorite solution.

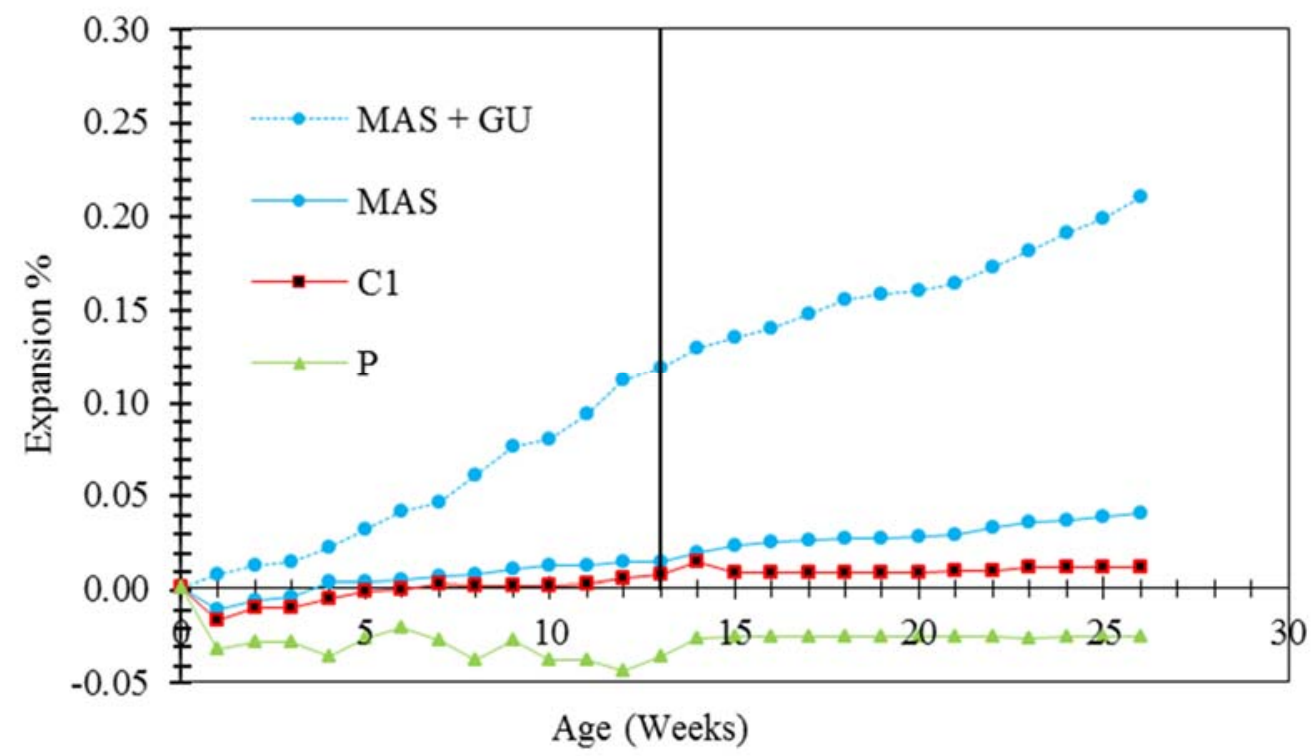

Figure 4 - 25: Expansion of mortar bar samples containing P, MAS, and C1 aggregates cast with fly ash and soaked 3 hours in a 6\% sodium hypochlorite solution. 


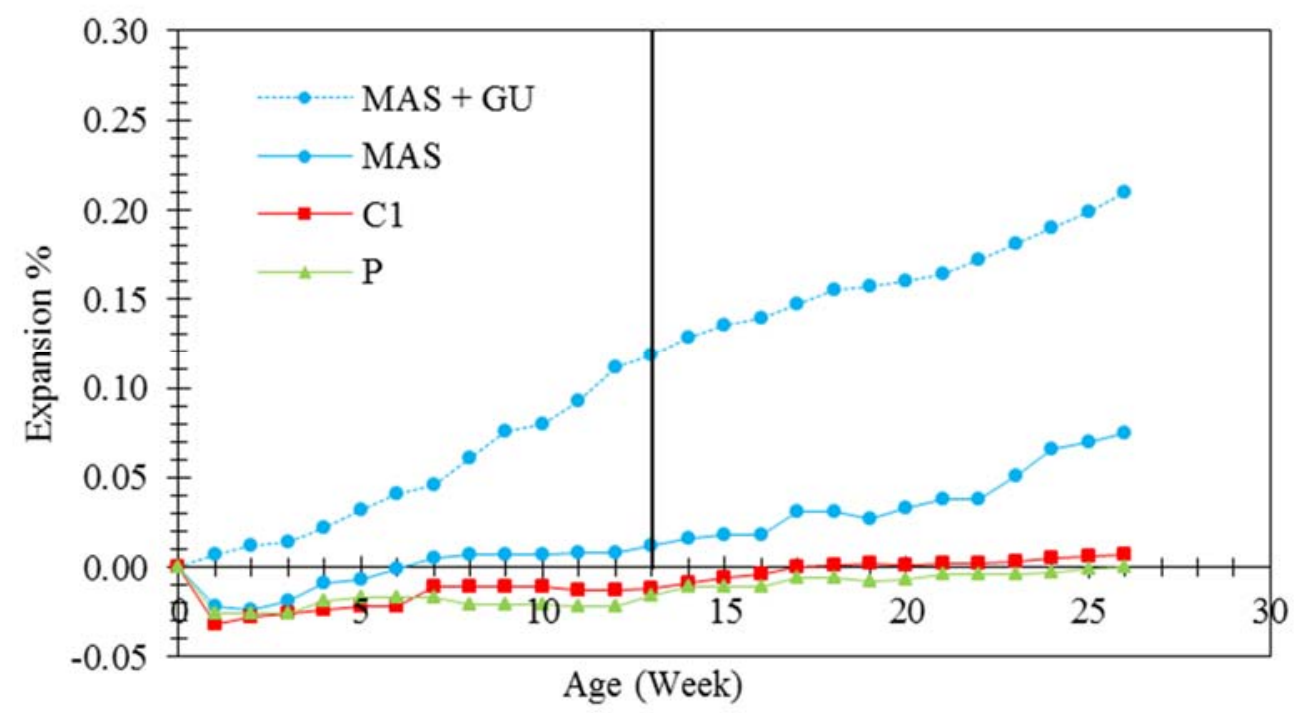

Figure 4 - 26: Expansion of mortar bar samples containing P, MAS, and C1 aggregates cast with metakaolin blended cement and soaked 3 hours in a sodium hypochlorite solution.

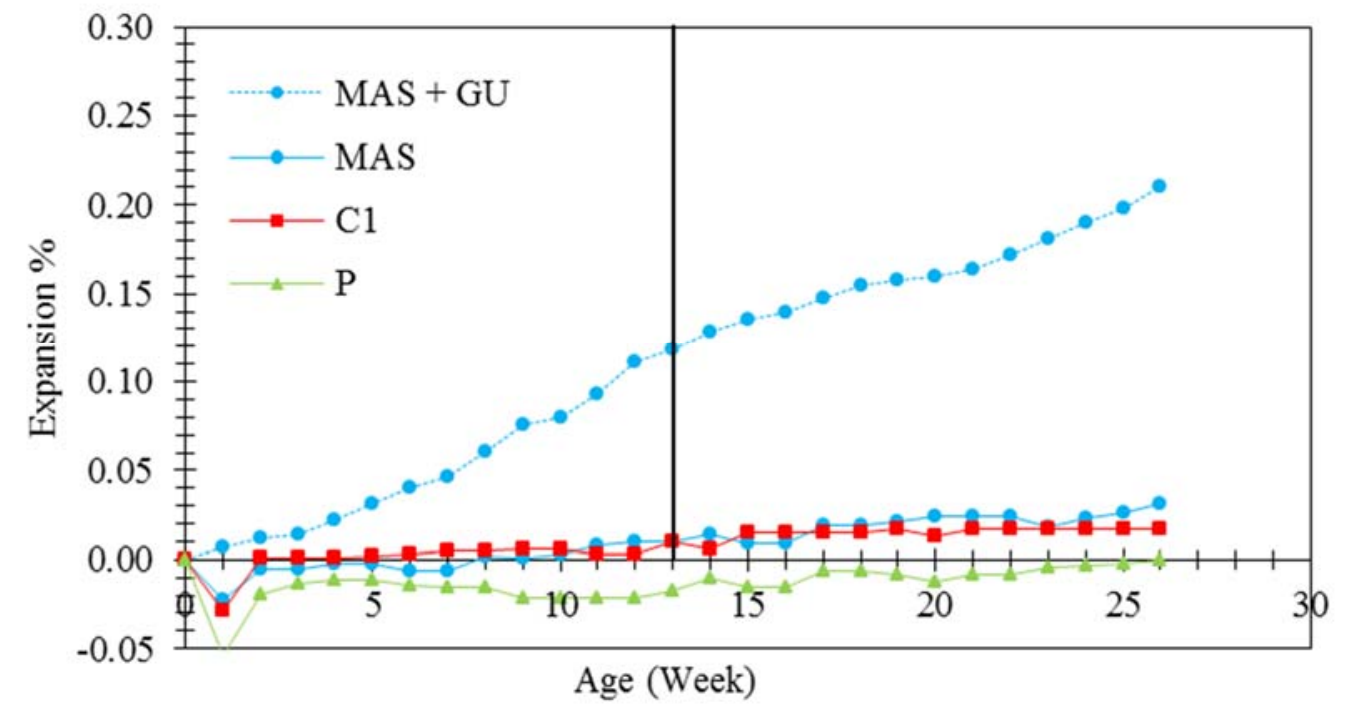

Figure 4 - 27: Expansion of mortar bar samples containing P, MAS, and C1 aggregates cast with high silica fume and soaked 3 hours in sodium hypochlorite. 
The sample with $10 \%$ MK showed an expansion that is higher than that obtained for samples with $25 \%$ fly ash or $8 \%$ silica fume, but lower than the expansion of the sample with $30 \%$ slag. It is also interesting to note that the expansion of this sample was close to zero in the first 13 weeks with a noticeable increase in the second 13 -week of the test where the samples were stored at $5^{\circ} \mathrm{C}$. Possible reasons for this trend will be described later.

It should be noted that when the mortar bar test was performed where the samples were soaked in the oxidizing solution for three hours, all tested SCM were able to reduce the expansion compared with the sample with sulphide-bearing aggregates and General Use Portland Cement (PC GU). The efficacy of SCM in reducing the expansion could likely be attributed to the reduced volume of oxidizing solution absorbed by the sample or diffused through it as shown in Figure 4 19 and Figure $4-20$ resulting in reduced rate of oxidation.

The reduced expansion of the samples with low- $\mathrm{C}_{3} \mathrm{~A}$ PC is not attributable to enhanced pores structure as both types of cement produced a similar mass gain and ion penetration when soaked in the testing solution as suggested by the results in Figure 4 - 19, Figure 4 - 20. It is likely that the limited amount of $\mathrm{C}_{3} \mathrm{~A}$ has reduced the formation of ettringite, thaumasite, or both. It should be noted that while the second stage of the test focuses mainly on promoting thaumasite formation, ettringite can also form at $5^{\circ} \mathrm{C}[114]$. Hence, the expansion in the mortar bars can be due to both ettringite and Thaumasite formation. Some research work suggested that ettringite is needed for the formation of thaumasite [58]. Following this view, the lower $\mathrm{C}_{3} \mathrm{~A}$ in the $\mathrm{LH} \mathrm{PC}$ could have reduced ettringite formation, resulting is less Thaumasite. On the other hand, other 
researchers suggested that thaumasite forms after all alumina is consumed and does not require ettringite as a base to form on top of it [115]. Following this view, the reduced expansion in bars with LH PC could be due to lower formation of ettringite and its associated expansive force.

\section{- Testing Using a Soaking Period of 24 Hours}

In this part of the study, the same three aggregates MAS, C1, and P and the PC GU were used, but only two types/levels of SCMs were examined: $25 \%$ FA and $10 \%$ MK. The mortar bars were subjected to the same testing condition as per the adopted test method [3] except that the soaking period was extended to 24 hours during both 13-week stages of the test. This was carried out to investigate the expansion when the sodium hypochlorite penetrates the whole cross section of samples with SCM, as it does with samples with only GU PC.

The results presented in Figure $4-28$ showed that the expansion of the mortar bars with GU-PC was much lower when the bars were soaked for 24 hours instead of 3 hours that is likely attributable to the shorter period at $80^{\circ} \mathrm{C}$ and $80 \% \mathrm{RH}$. Both procedures include two testing cycles per week, however, in the case of a soaking period of 24 hours, the samples were exposed to $80^{\circ} \mathrm{C}$ and $80 \%$ RH for two days instead of 3. Perhaps a longer duration at a temperature of $80^{\circ} \mathrm{C}$ and $\mathrm{RH}$ of $80 \%$ is required in order for oxidation to occur. 


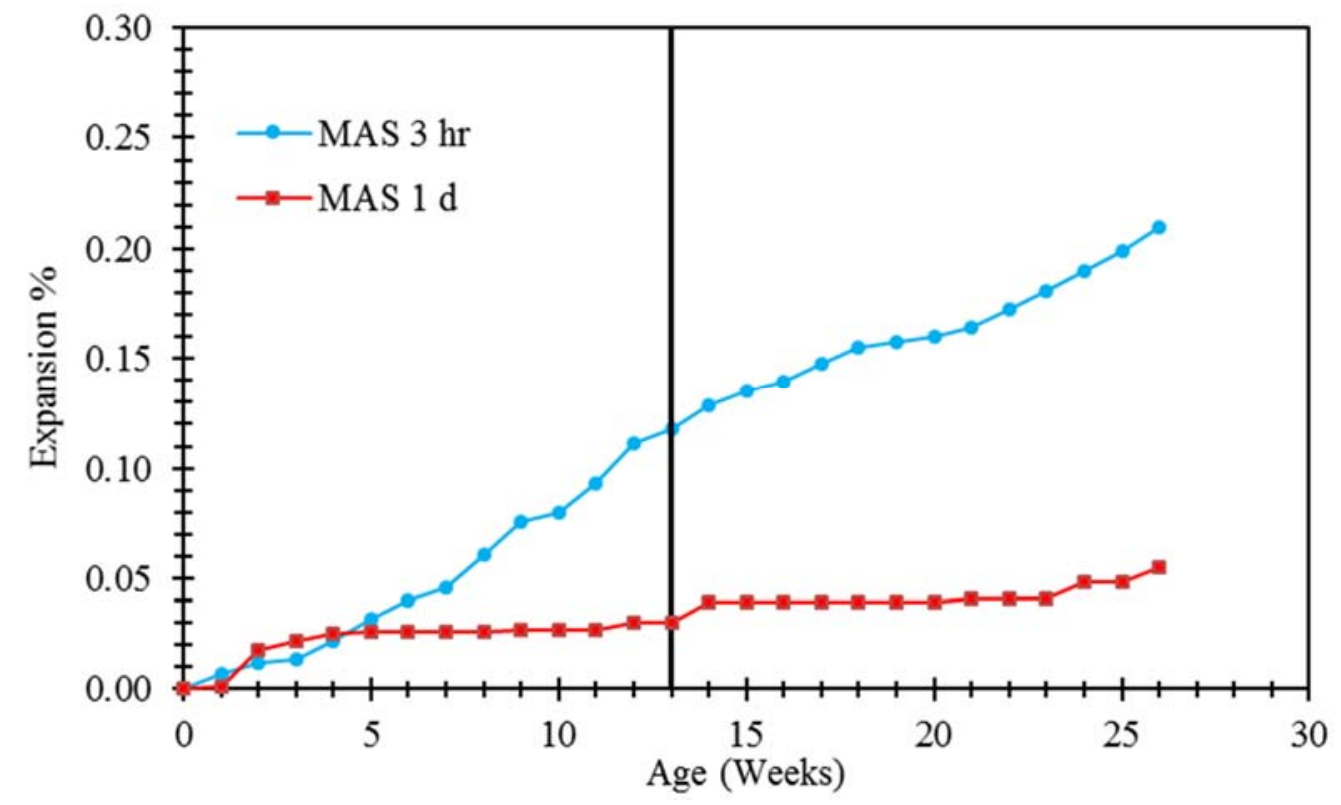

Figure 4 - 28: Expansions or mortar bar samples containing MAS aggregate and soaked for 3 hours or 24 hours in sodium hypochlorite solution

Figure $4-29$ to Figure $4-31$ show the expansion of the mortar bars with the three aggregates when tested with GU PC, PC $+25 \%$ low-calcium fly ash and PC $+10 \%$ metakaolin. As shown in Figure $4-30$ the expansion of the samples containing metakaolin showed a much different trend. There was no expansion in the first 13 weeks followed by severe expansion in the second 13-week. The expansion took place in samples with all aggregates including P and C1, which have no sulphide phases. 


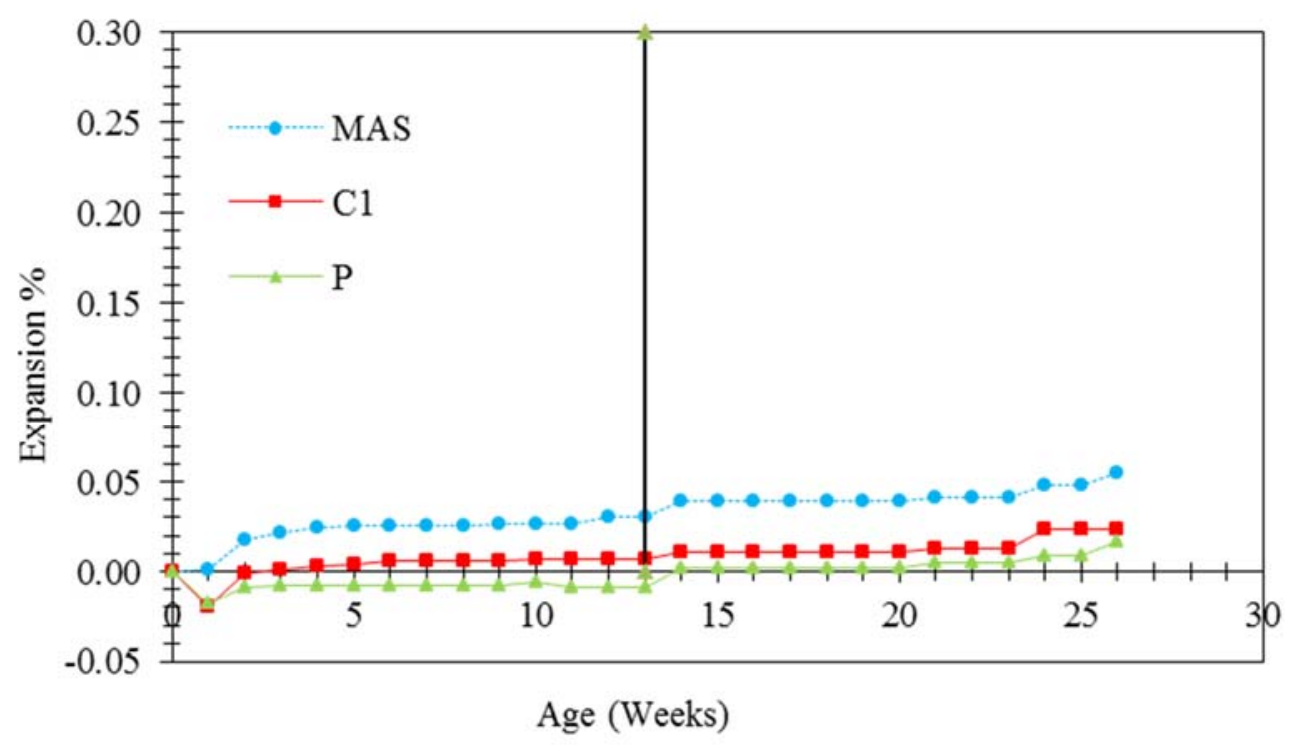

Figure 4 - 29: Expansion of mortar bar samples containing P, MAS, and C1 aggregates cast with GU cement and soaked for one day in sodium hypochlorite.

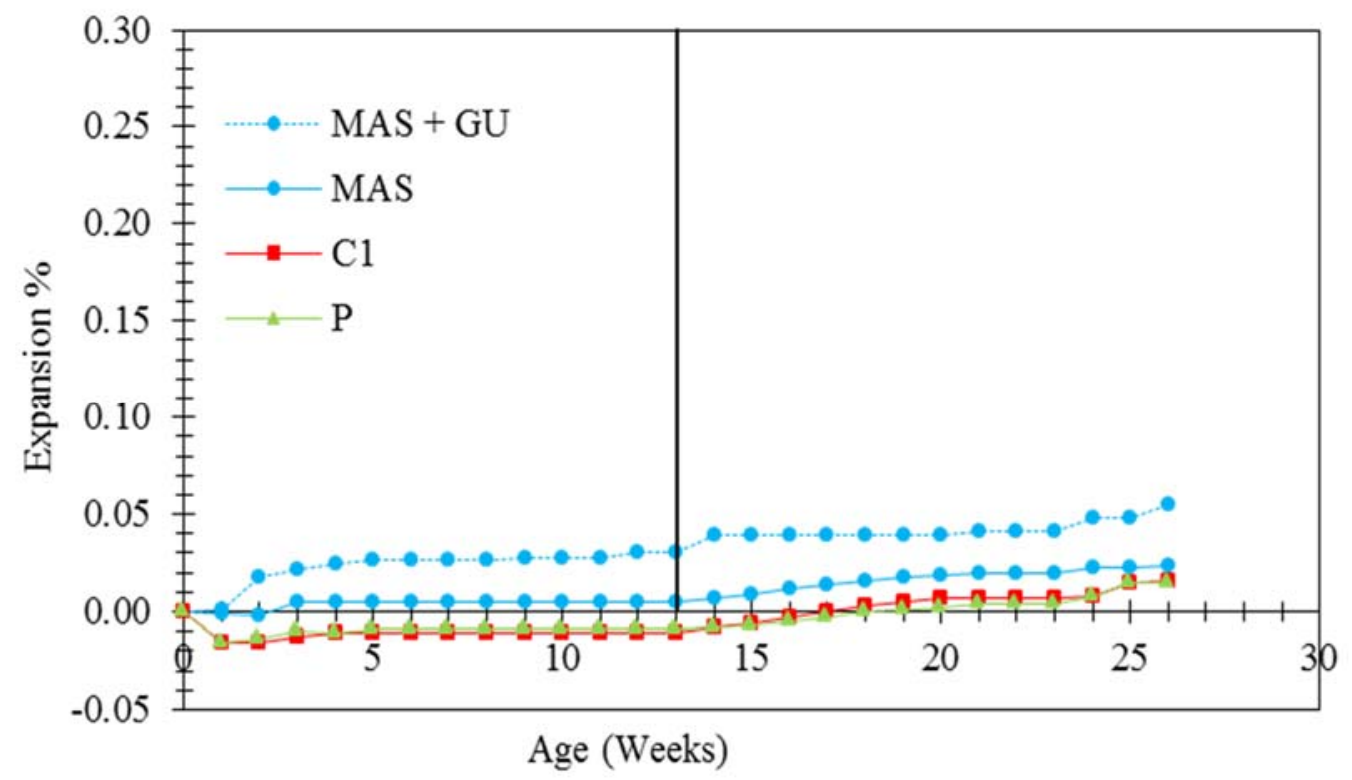

Figure 4 - 30: Expansion of mortar bar samples containing P, MAS, and C1 aggregates cast with fly ash and soaked for one day in sodium hypochlorite. 


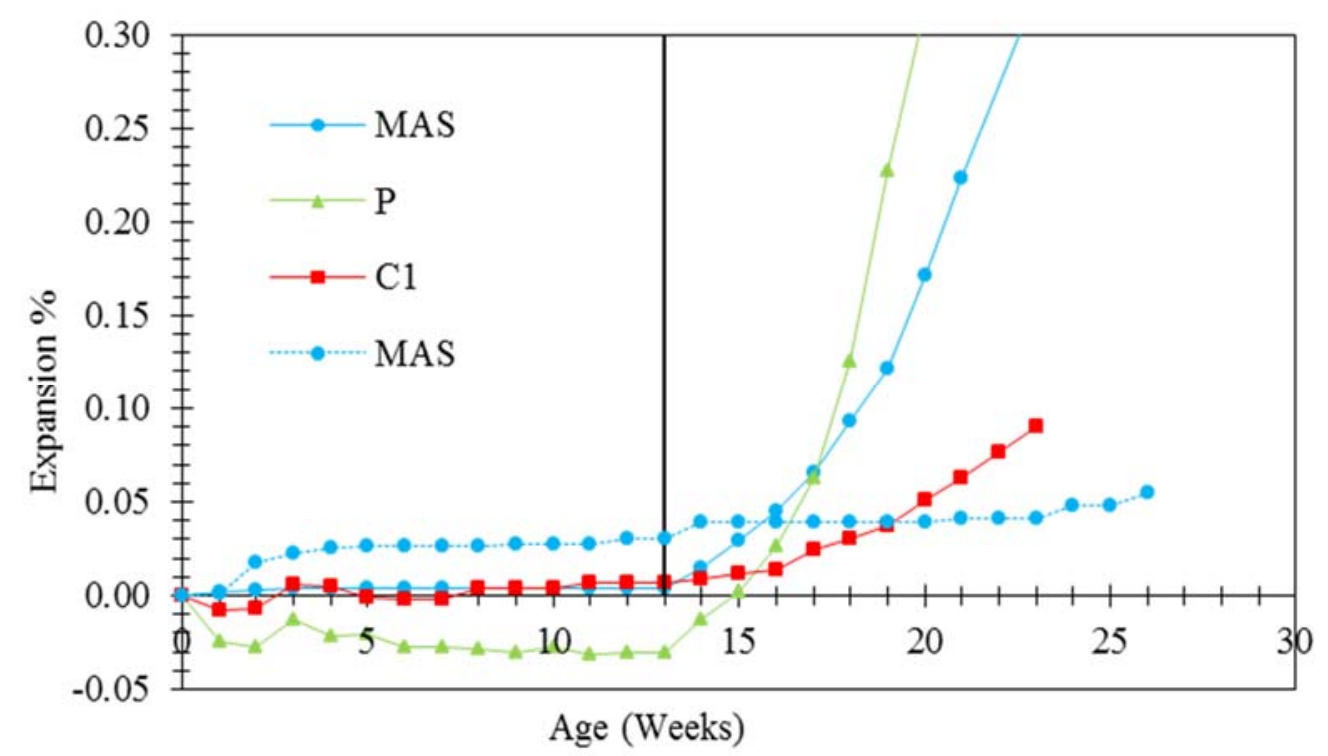

Figure 4 - 31: Expansion of mortar bar samples containing P, MAS, and C1 aggregates cast with metakaolin and soaked for one day in sodium hypochlorite.

Figure 4-32 shows pictures of the mortar bars after the completion of the test, reflecting the severe damage and cracking in samples with MAS and $\mathrm{P}$ aggregates ( $\mathrm{P}$ has no sulphide phases). The sample with the $\mathrm{C} 1$ aggregate did not reveal much damage as the expansion was not as high as it was for the other aggregates; however, the expansion was still much higher than the same aggregate when tested without MK. 


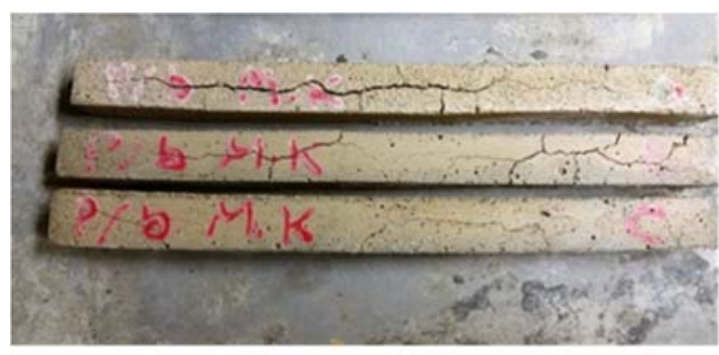

(a)

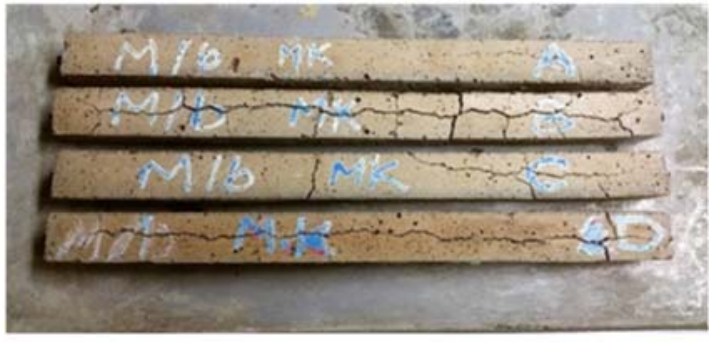

(b)

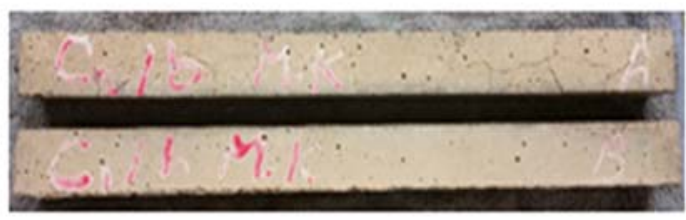

(c)

Figure 4 - 32: Condition of mortar bar samples containing 10\% MK after 26 weeks of testing with a soaking period of 24 hours: (a) P aggregate, (b) MAS aggregate, (c) C1 aggregate.

The results presented so far suggest that the expansion occurs under these two conditions: (a) longer soaking period - 24 hours - in the cases examined here, and (b) a system containing materials that supply a considerable amount of alumina, such as MK. It should be noted that the expansion in case of MK occurred in the second 13 weeks of the test, where samples were kept at $\mathrm{RH}$ of $100 \%$, either through soaking in for 24 hours at room temperature or stored at $5{ }^{\circ} \mathrm{C}$ above water. Much of the mechanistic testing (XRD, SEM and thermal analyses) focused on understanding why MK produced higher expansion under the testing condition of the mortar bars. The results are presented later on in this Chapter. 


\section{- Effect of W/C}

Two samples of w/c of 0.65 and 0.45 were tested using a soaking period of three hours. In addition to evaluating the effect of $w / c$, this study help determining if refining the pore structure of the cement matrix, without using SCM, can have an effect on the expansion. The expansions of these samples are shown in Figure 4 - 33. Indeed, the samples with w/c ratio of 0.45 showed much lower expansion. The relationship of this to samples under field investigation needs to be investigated. The results presented here suggest that the test in its current form may not be suitable for evaluating w/c. It is expected that samples with this aggregate would cause expansion or damage if used in concrete at lower w/c; however, the damage may take longer to occur.

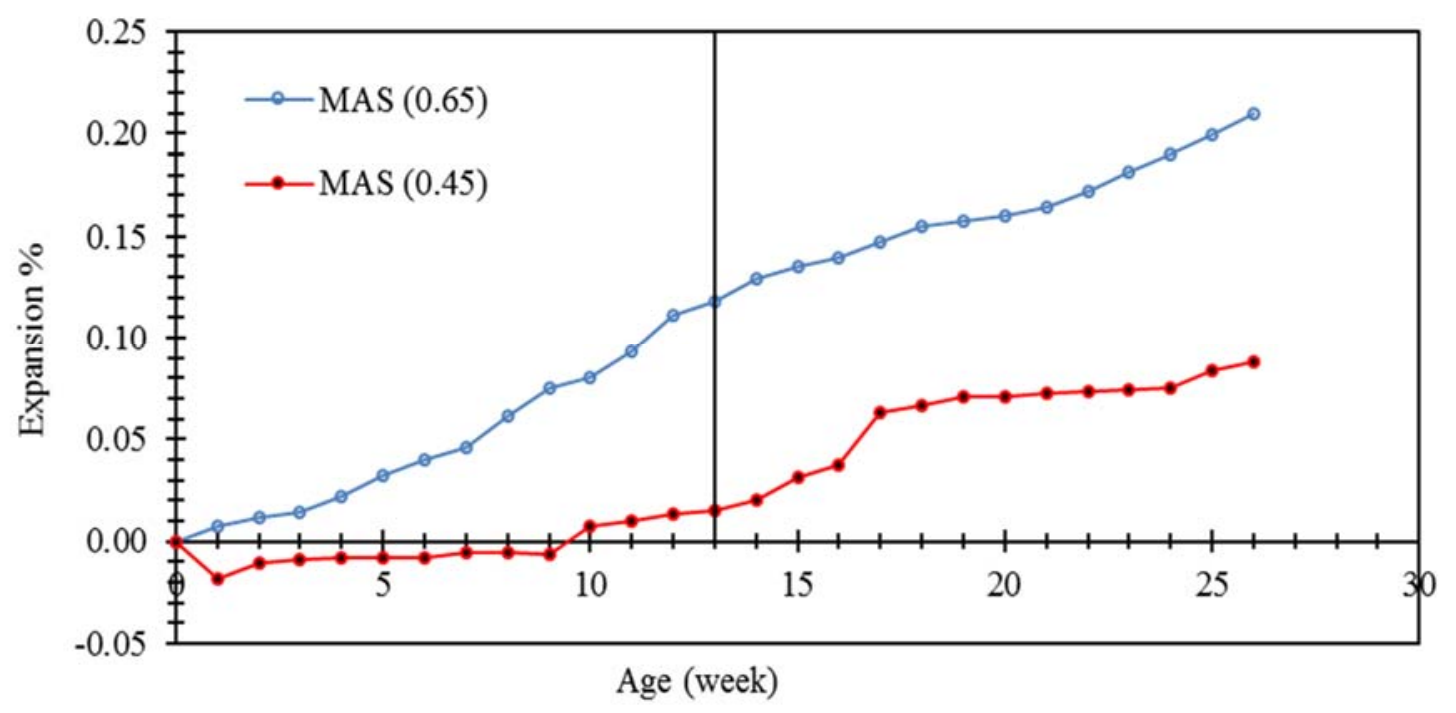

Figure 4 - 33: Expansion in mortar bar samples made with different $\mathrm{W} / \mathrm{C}$ ratios 


\subsection{Microscopy and Analytical Techniques for the Mortar bar Samples}

\subsubsection{Mortar Bars Soaked in Sodium Hypochlorite for 3 hours}

SEM examination of the mortar bar samples was carried out to identify the mechanisms that cause expansion. The samples were prepared using the mortar bar that contained no SCM. Figure 4 - 21 shows the expansions at the end of the 26-week testing period. Using Backscattered Electron (BSE) imaging and Energy Dispersive X-Ray Analysis (EDS), Figure 4 - 34 (a) shows deterioration in the paste around a MAS aggregate particle, while Figure 4 - 34 (b) shows part of a MAS aggregate particle with an iron sulphide inclusion. The oxidation of some areas of this

inclusion is reflected by the gray colour Figure 4 - 34 (d), while the non-oxidized area is represented by the white colour Figure 4 - 34 (c).

Element peaks obtained using EDS are shown on the same figure, identifying iron only in the oxidized region and iron and sulphur in the non-oxidized region of the aggregate. 

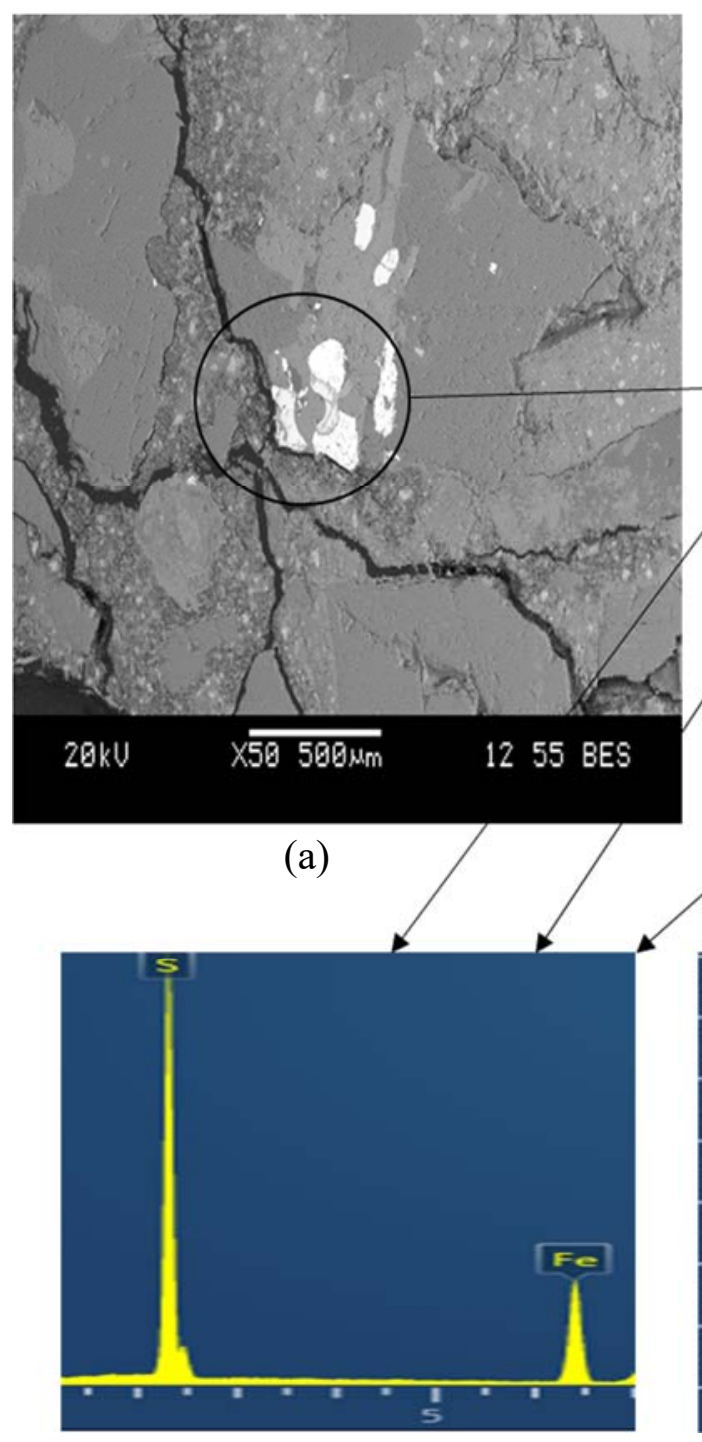

(c)

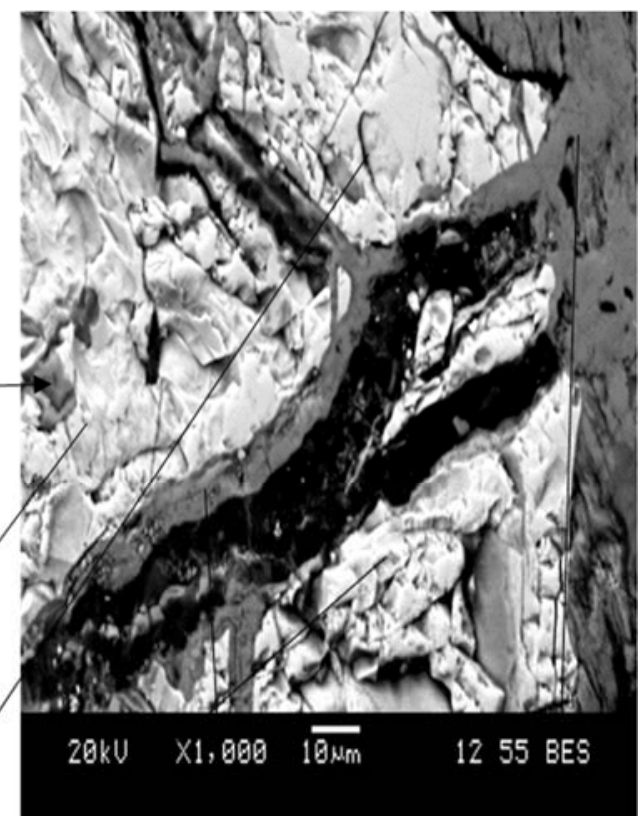

(b)
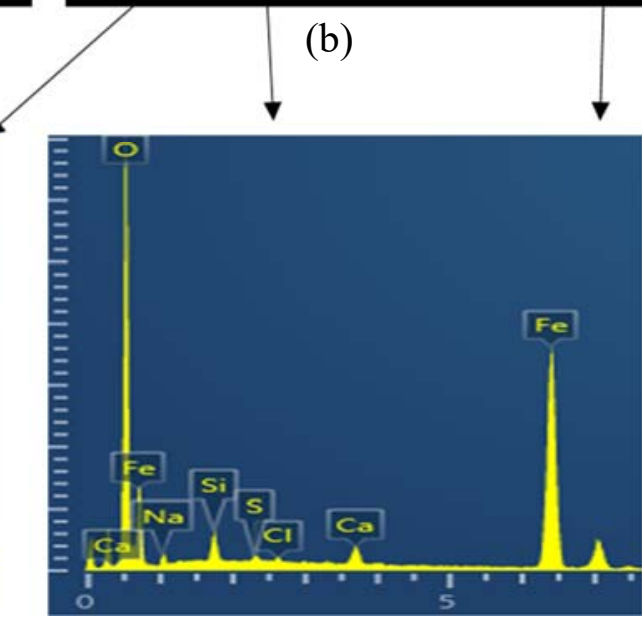

(d)

Figure 4 - 34: BSE image and EDS analysis.

Figure 4 - 34 showing: (a) deterioration of the paste around the MAS aggregate particles and (b) a sulphide phase at the edge of the aggregate with (c) un-oxidized part (white) and (d) oxidized part (dark gray).

The oxidation of sulphide minerals in the MAS aggregate is also illustrated in Figure 4 -

35, which reveals an elemental line mapping of oxidized sulphide inclusion in an MAS aggregate 
particle. The figure shows a similar concentration of iron elements along the line, while the concentration of sulphur and oxygen change when going through the oxidized region in the middle of the sample. The oxygen was zero in the non-oxidized region, but increases in the oxidized region. All of the sulphur elements disappeared in the oxidized region of the inclusion.
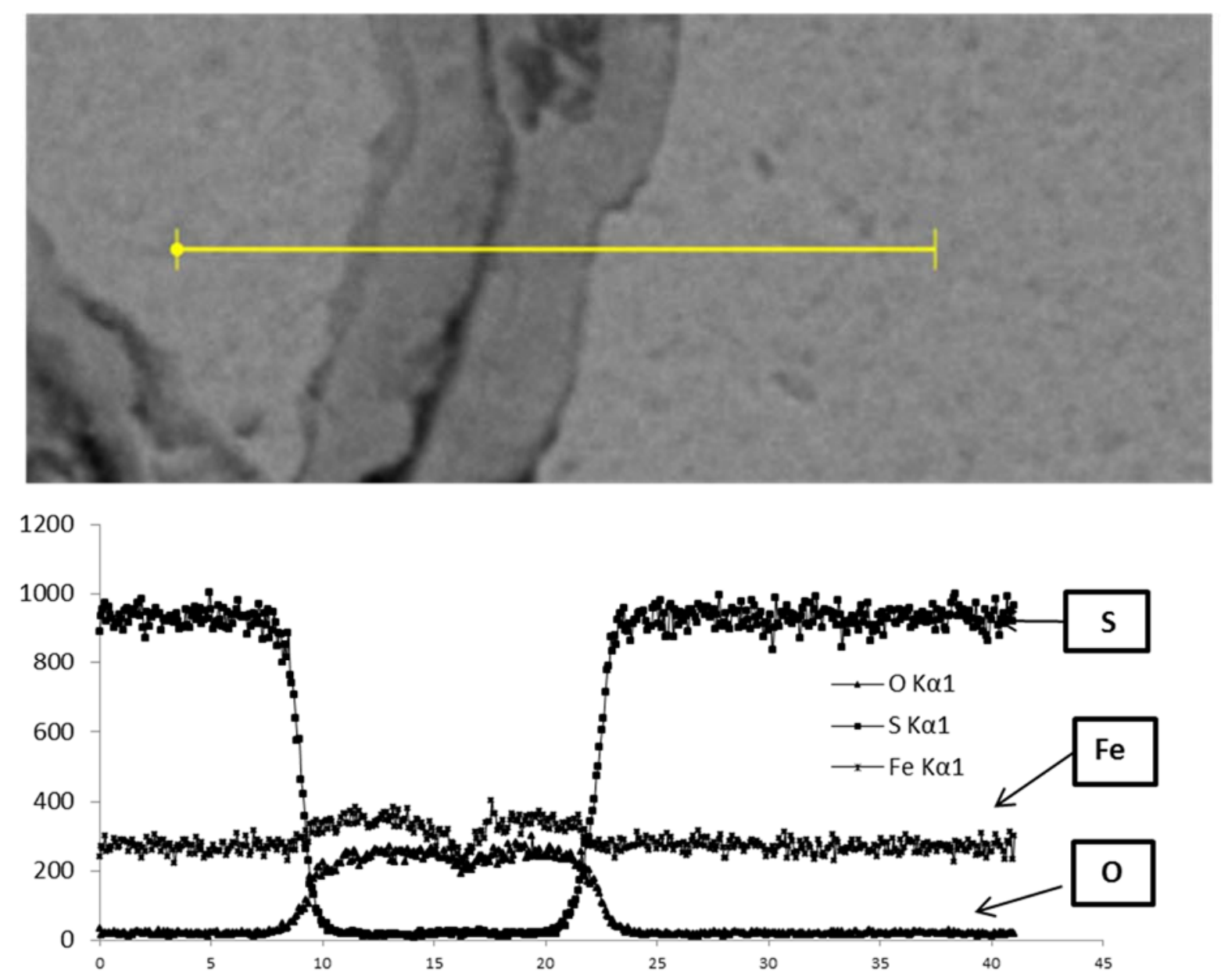

Figure 4 - 35: Elemental line scans of a sulphide phase intrusion in an MAS aggregate. 
Figure 4-36 shows BSE images and an EDS spectrum on the mortar bar sample with the MAS aggregate. It was not difficult to find the phase shown in the graph, which is believed to be a mixture of ettringite and thaumasite. This shows that the expansion in this sample is mainly due to a sulphate attack with a mixture formation of ettringite/thaumasite.

There is a possibility that the ettringite was formed during the first 13 weeks when the samples were cooled down and soaked in the sodium hypochlorite for three hours at room temperature. This ettringite would work as a nucleation site for the formation of thaumasite in the second 13-week period of the test when the samples were kept at $5^{\circ} \mathrm{C}$ and $100 \% \mathrm{RH}[58,64]$. The formation of ettringite could also have proceeded at $5^{\circ} \mathrm{C}$ but at a slower rate. Alternatively, both the ettringite and thaumasite could have formed together at a fine scale. Barnett et al. [70] and Lachowski et al. [68] showed that ettringite and thaumasite form through intergrowth at a very fine scale.

Figure 4 - 37 illustrates the damage in the paste of mortar bars with the sulphide-bearing aggregate MAS cast with 10\% metakaolin, in which both ettringite and Friedel's salt were detected. It is believed that the MK contributed to the formation of Friedel's salt, through providing alumina. As shown in

Figure 4-4 4-4 the XRD of raw MK samples shows presence of reactive aluminosilicate. 

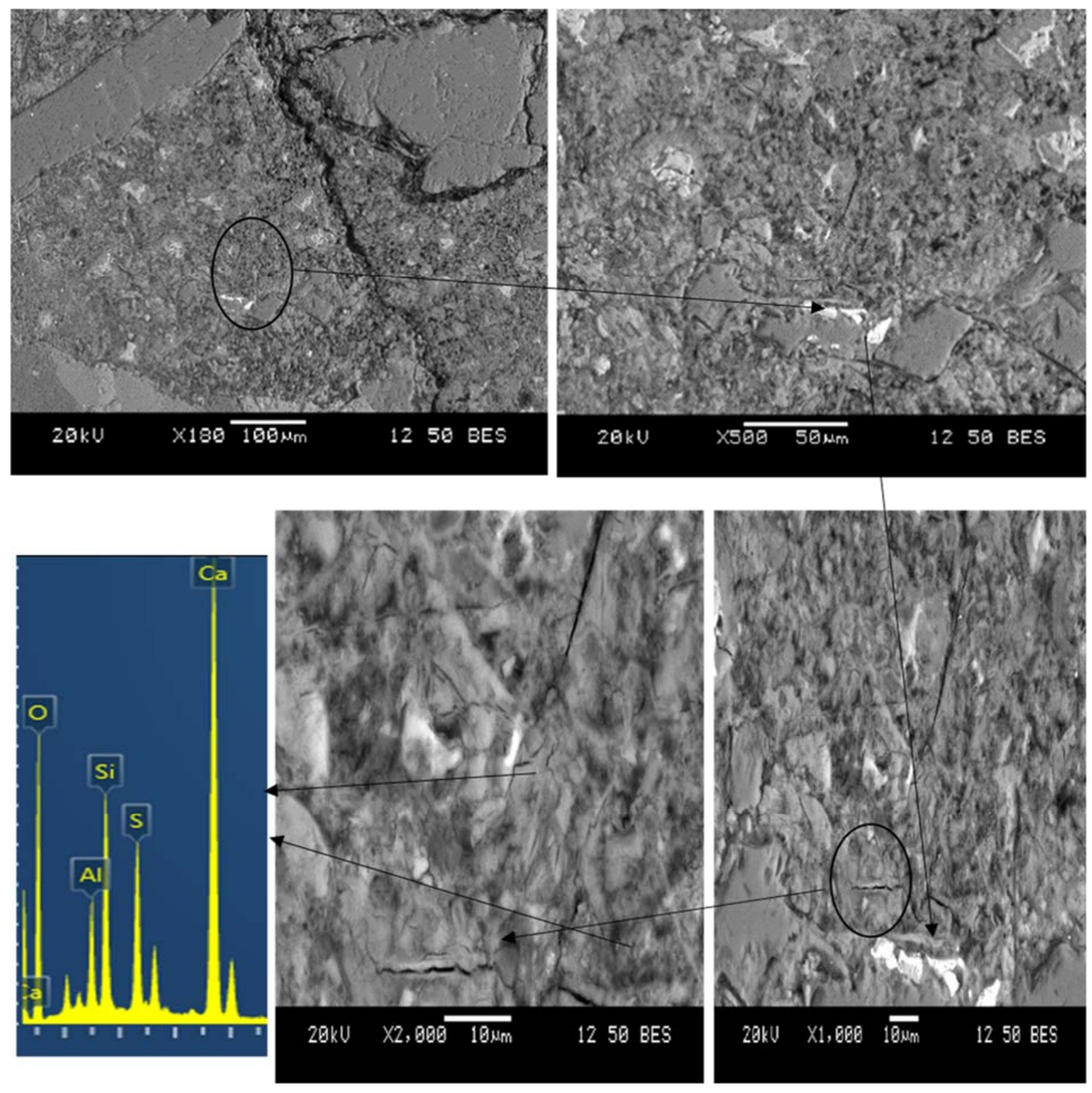

Figure 4 - 36: Ettringite/thaumasite formed in the paste of mortar bar samples with an MAS aggregate cast with GU-Portland cement. 


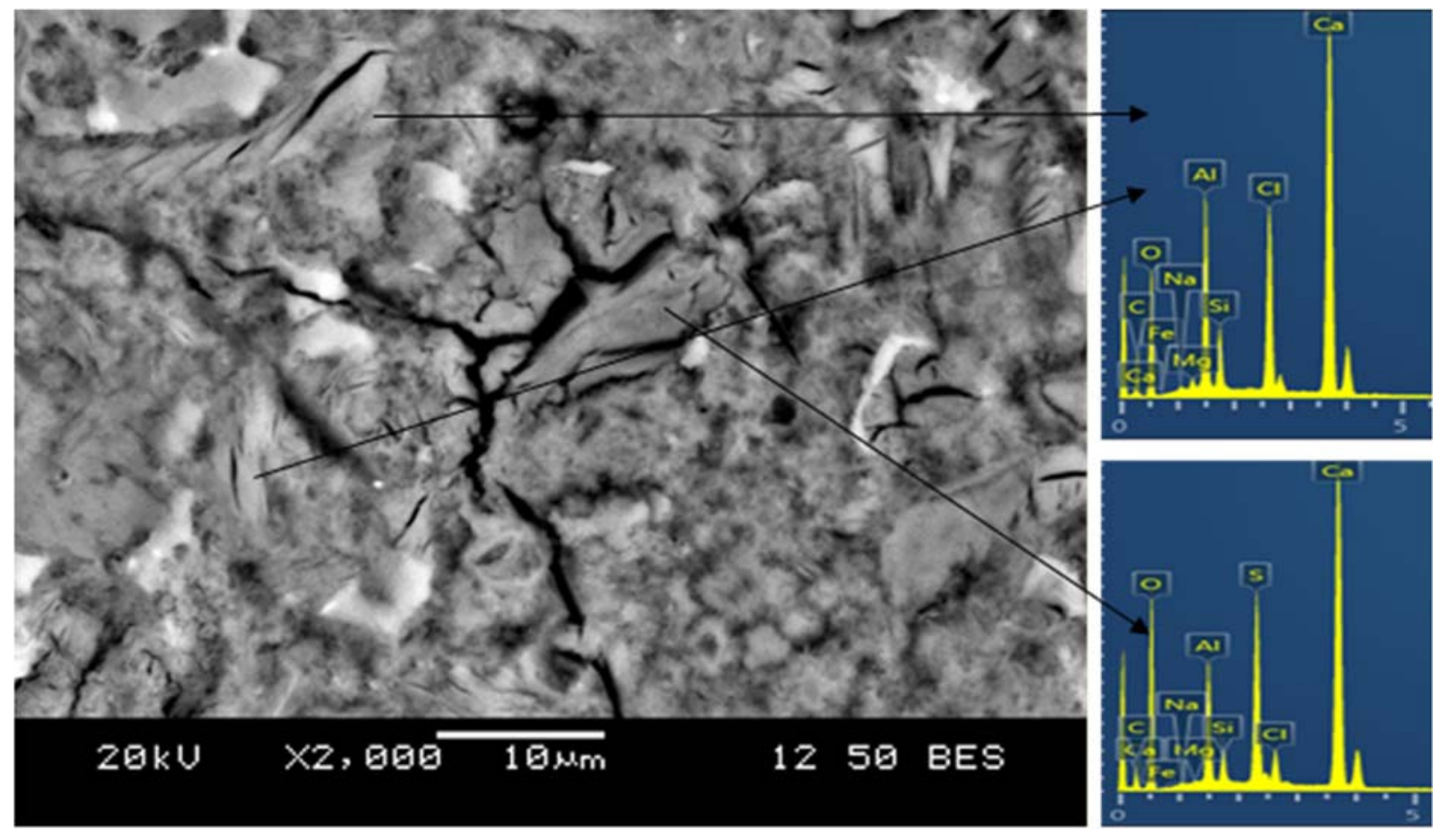

Figure 4 - 37: Damage of paste of mortar bars with MAS samples cast with $10 \%$ metakaolin showing the formation of ettringite and Friedel's salt.

\subsubsection{Mortar Bars Soaked in Sodium Hypochlorite for 24 Hours}

Figure $4-38$ to Figure $4-40$ show BSE images of mortar bar samples containing MK and MAS, P, and C1. All three of the samples showed severe expansion, leading to the belief that the expansion was caused by factors other than the oxidation of sulphide and a sulphate attack especially with the two control aggregates $\mathrm{C} 1$ and $\mathrm{P}$. It is very clear that there was no expansion in the first 13 weeks, followed by severe expansion in the second 13 weeks. The expansion took place in samples with all aggregates including P and C1, which have no sulphide phases. Friedel's salt was predominantly identified in all samples with evidence of ettringite formation in mortar 
bar samples cast with the MAS aggregate, which contains sulphide mineral phases. In some cases, the ettringite was mixed with chloride ions, forming what is known as Kuzel's salt [76, 109, 116].

The formation of Friedel's salt in the presence of MK is due to the extended period of exposure of the sample to chloride ions from the sodium hypochlorite when soaked for one day, rather than three hours as proposed in the accelerated mortar bar test method $[3,100]$. This high volume of chloride ions reacts with the high alumina from MK, forming Friedel's salt and causing severe cracking in all of the mortar bar samples with all aggregates. The chloride ions are available from the sodium hypochlorite solution as will be discussed later.

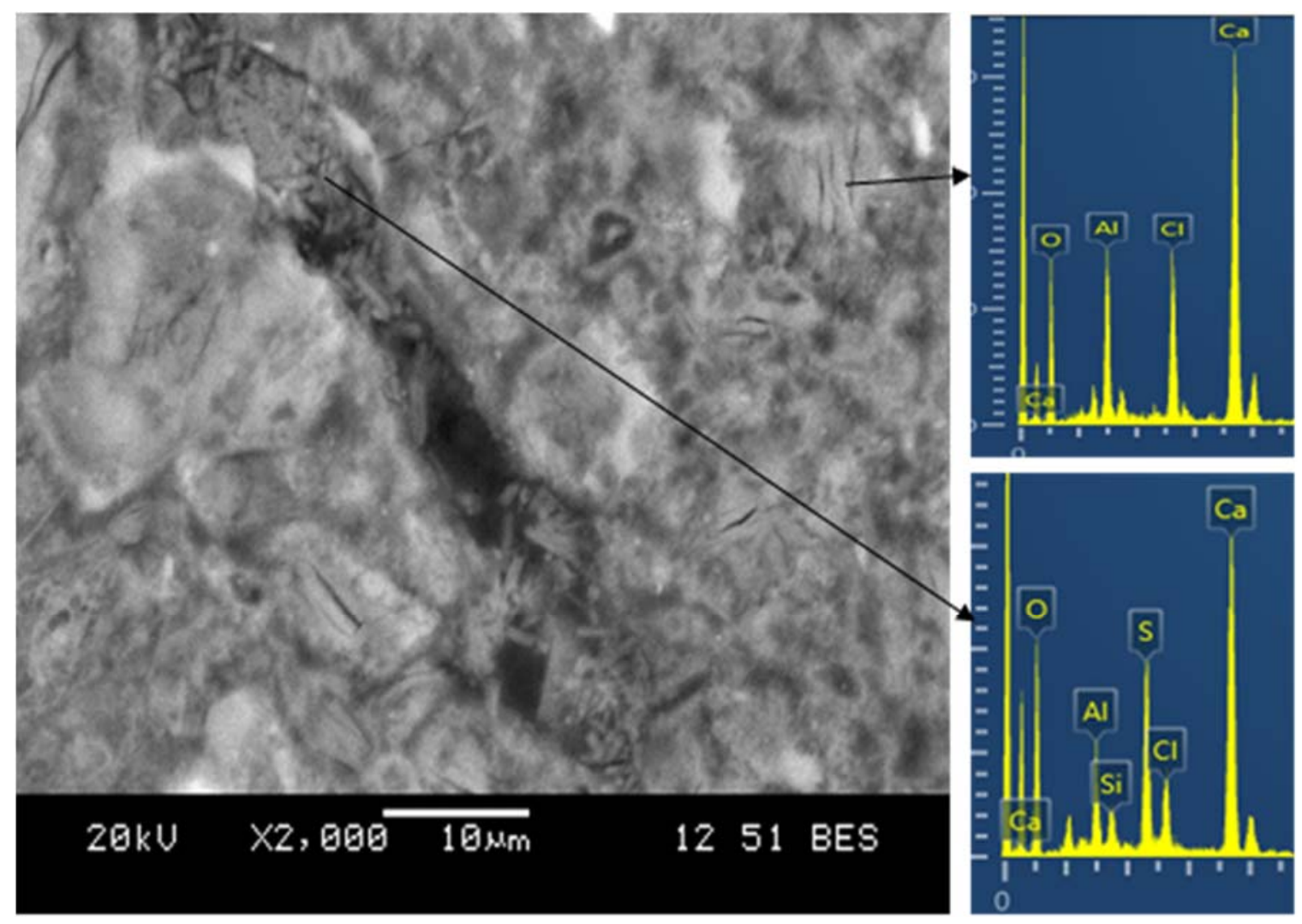

Figure 4 - 38: Damage in mortar bars with MAS aggregate cast with 10\% metakaolin. 

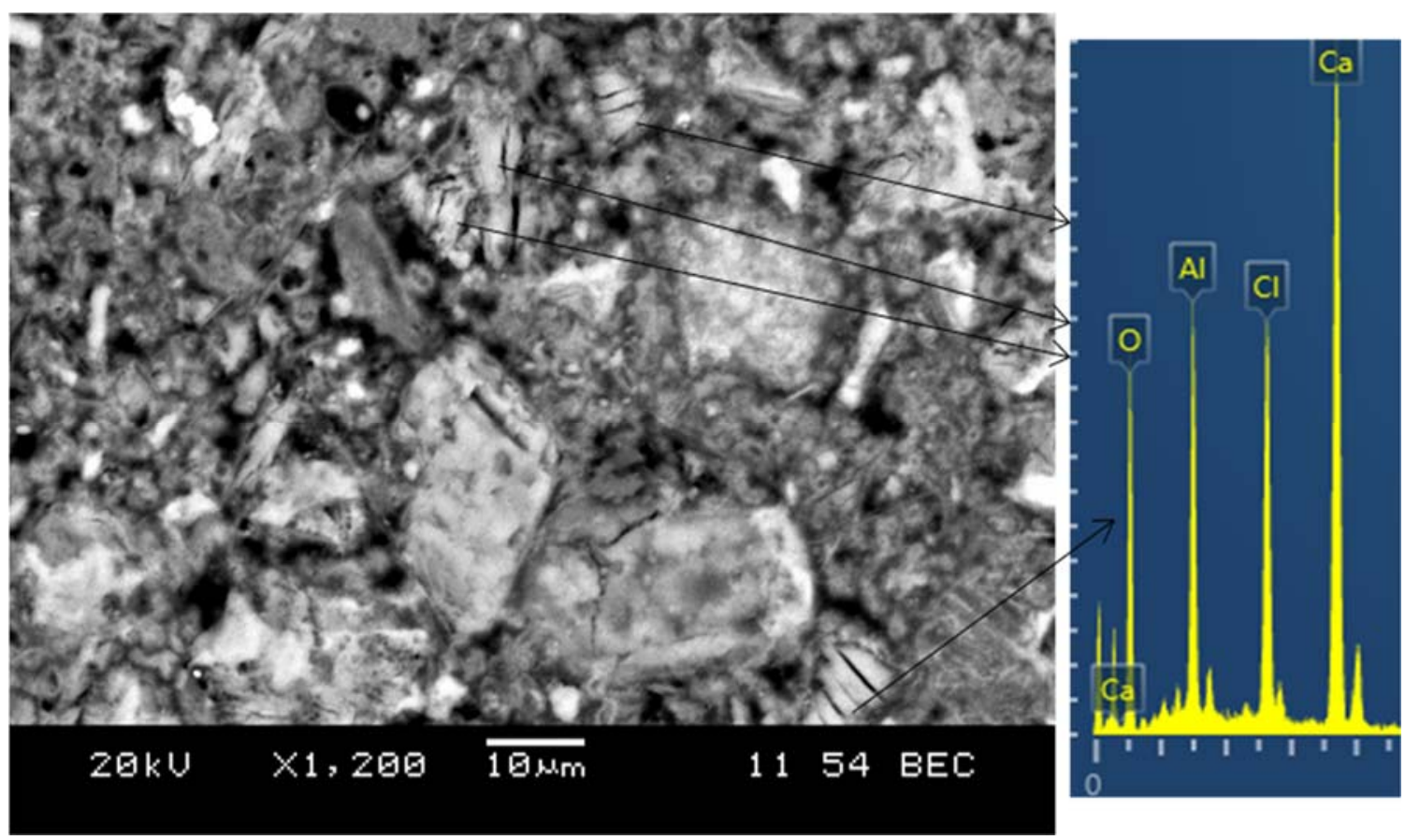

Figure 4 - 39: Formation of Friedel's salt in a mortar bar with P aggregates and 10\% metakaolin.

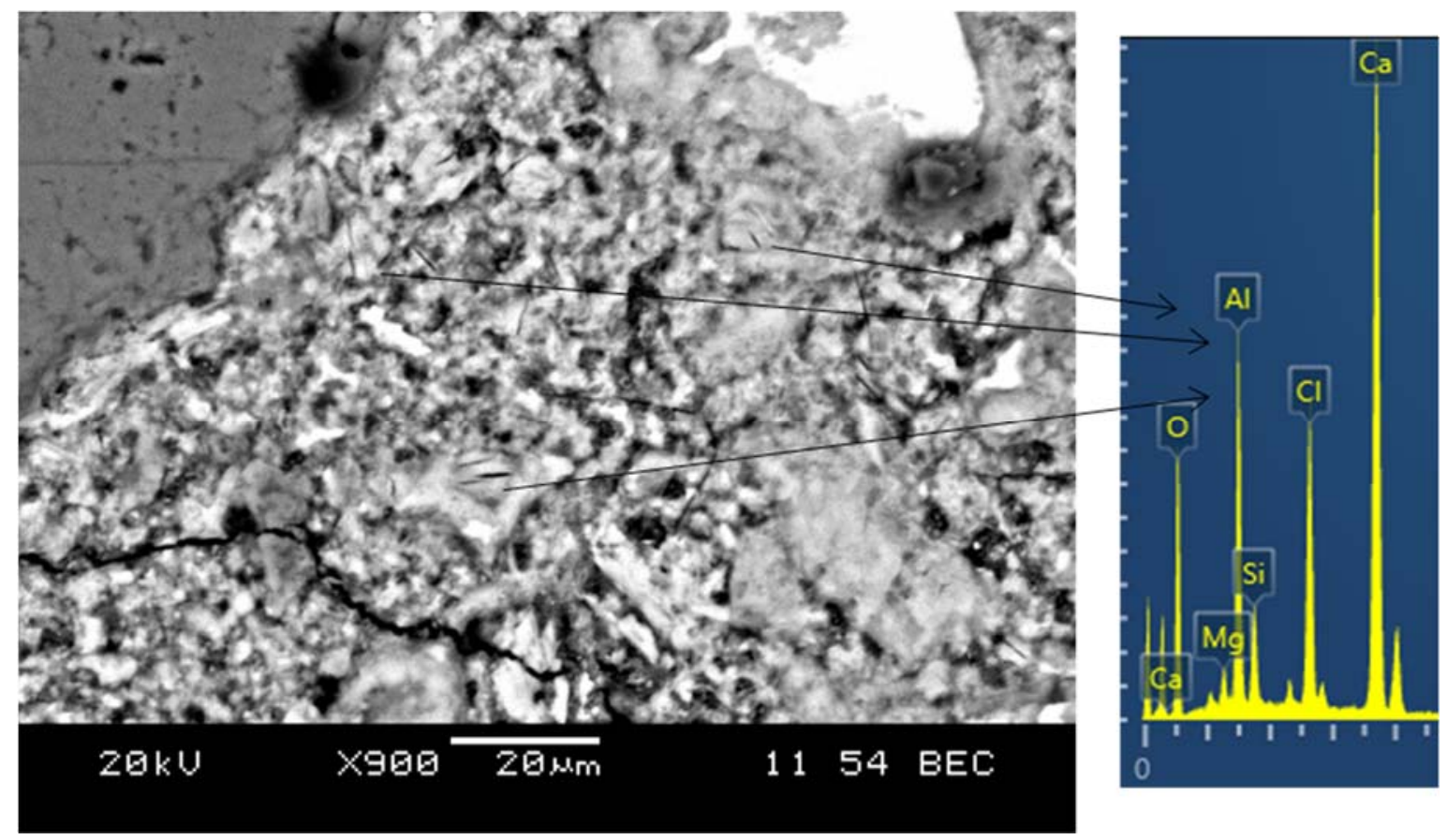

Figure 4 - 40: Damage in a mortar bar with $\mathrm{C} 1$ samples cast with 10\% metakaolin. 


\subsection{Microscopy and Analytical Techniques for the Paste Samples}

\subsubsection{SEM and EDS Analysis}

The SEM analysis was carried out on paste samples exposed to testing conditions similar to the second 13 -week testing period under $5^{\circ} \mathrm{C}$ and $100 \% \mathrm{RH}$ conditions where high expansion was observed for samples with MK. In the paste study, samples cast with 100\% PC-GU, PC with a $25 \%$ replacement of FA, and PC with a $10 \%$ replacement of MK were examined. Friedel's salt was clearly detected in the sample with MK, as illustrated in Figure 4 - 41. There was some evidence of Friedel's salt in the sample with FA, however, it was not abundantly available. The same can be said about the sample with GU cement. It should be noted that neither ettringite nor any other sulphate-bearing phases were observed as there is no source of additional sulphate in these samples. The purpose of this part was to investigate the effect of the sodium hypochlorite solution on the paste and to isolate that effect from sulphate attacks or the oxidation of sulphide in aggregates. 

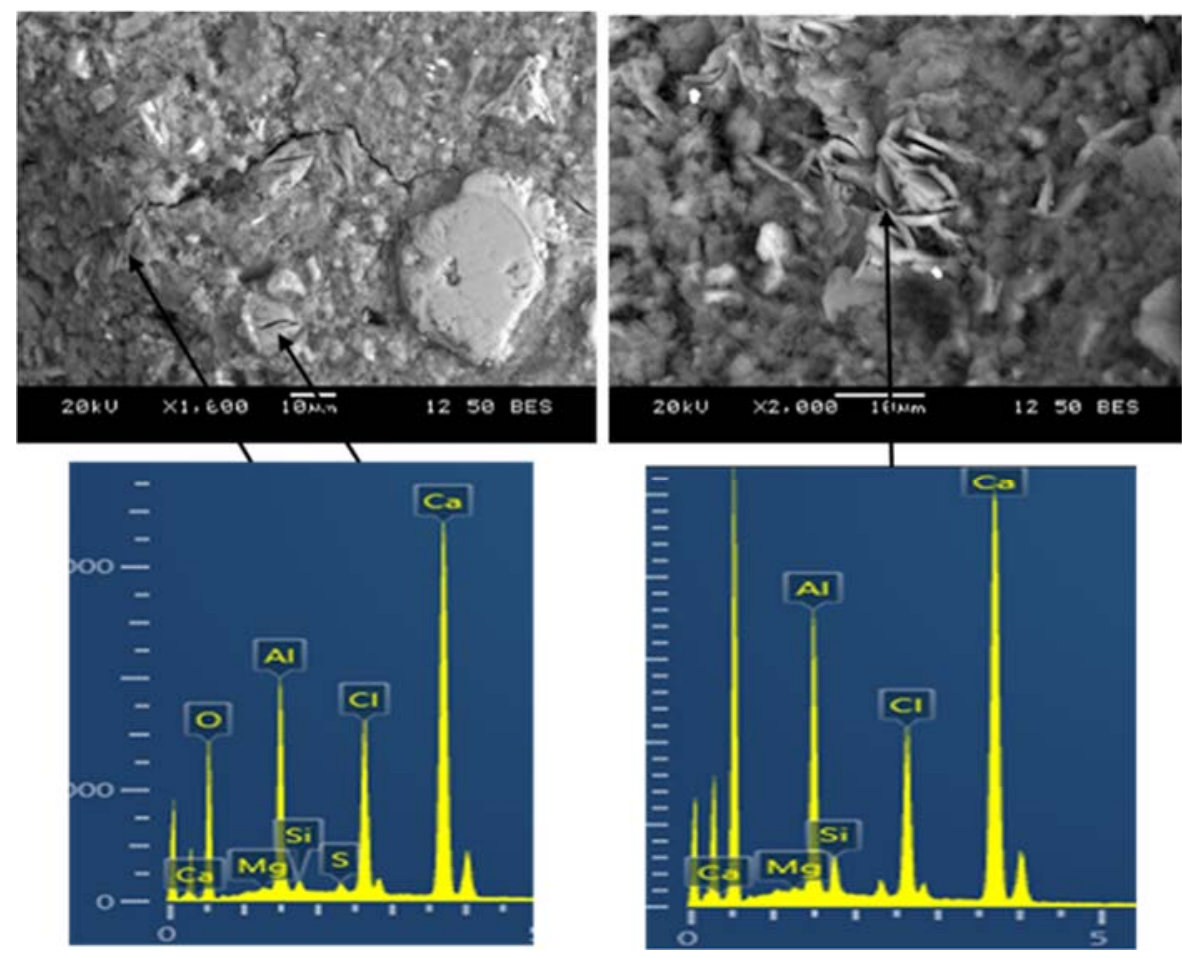

Figure 4 - 41: Friedel's salt formation in a large area in a MK paste sample exposed for 24 hours to a sodium hypochlorite solution.

\subsubsection{Thermal Analysis}

Differential thermal analysis (DTA) was carried out on samples cast with $100 \%$ PC GU, $\mathrm{PC}+25 \% \mathrm{FA}$ and $\mathrm{PC}+10 \% \mathrm{MK}$. The results are shown in Figure $4-42$. The endotherm peaks at a temperature of about $130^{\circ} \mathrm{C}$ and between $180^{\circ} \mathrm{C}$ and $190^{\circ} \mathrm{C}$ in the three samples could be due to the presence of C-S-H and ettringite, respectively $[119,120]$. The same two peaks can also be attributable to calcium aluminate hydrate $\left(\mathrm{C}_{4} \mathrm{AH}_{13}\right)$ or monosulphoaluminate [9], as both materials have the same peaks. 
It is clear that the two peaks are much higher in the samples with $10 \% \mathrm{MK}$ suggesting that the sample with MK has higher amounts of one or a combination of the phases ettringite, monosulphoaluminate or calcium aluminate hydrate.

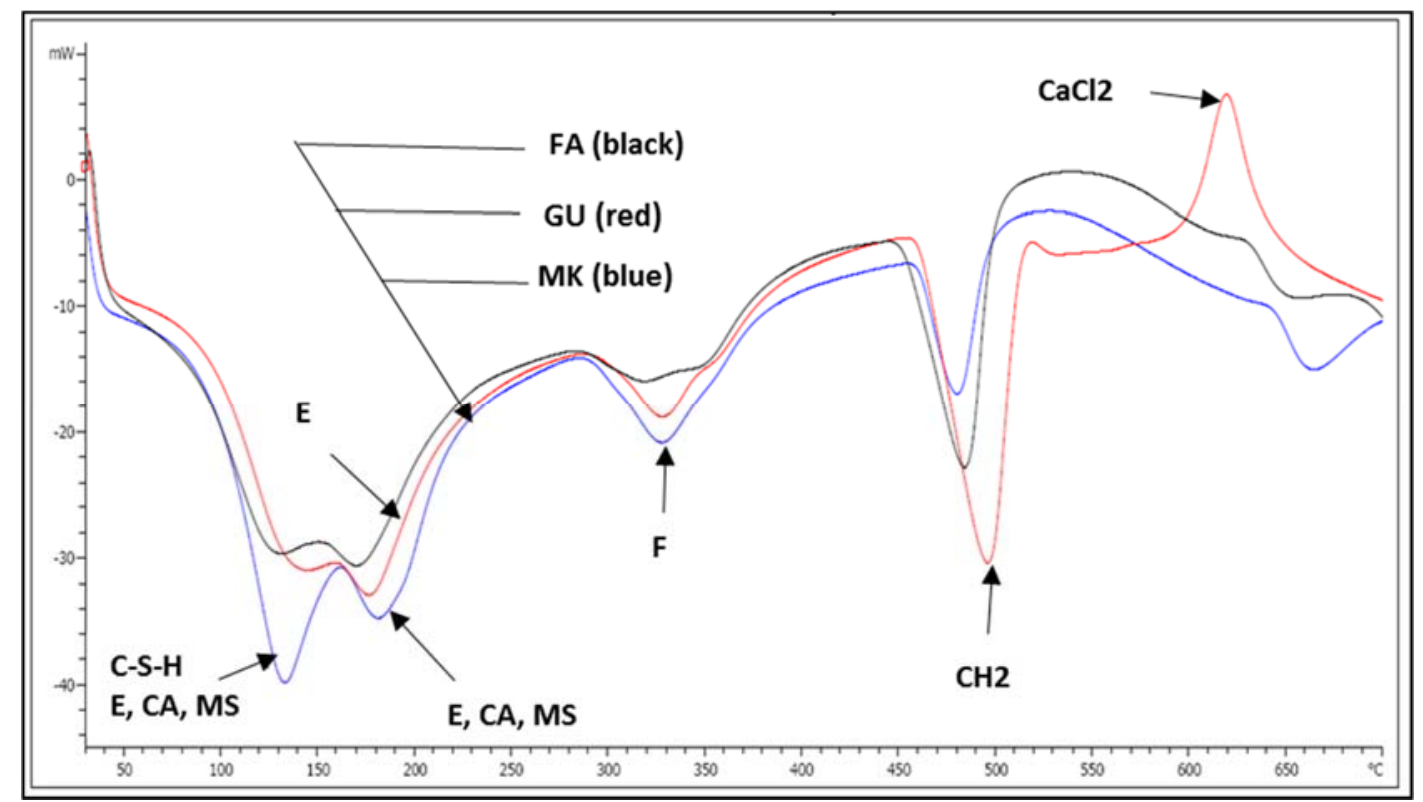

*E= Ettringite, $\mathbf{F}=$ Friedel's salt, $\mathbf{C A}=$ Calcium Aluminate Hydrate, $\mathrm{MS}=$ monosulphoaluminate

Figure 4 - 42: DTA for the three cement paste samples cast with GU - PC, PC + 25\% FA \& PC $+10 \% \mathrm{MK}$.

It is also noticeable that the samples with PC GU, FA and MK have a peak between 310$385^{\circ} \mathrm{C}$, which is attributable to Friedel's salt [121]. This peak is larger in the sample with MK confirming the findings from SEM carried out on mortar bars with MK. Friedel's salt can form from $\mathrm{C}_{4} \mathrm{AH}_{13}$ in the presence of chloride ions [81] or from monosulphoaluminate [110] as will be discussed later. 
Based on that and in addition to the larger peak of Friedel's salt in MK sample, the $\mathrm{C}_{4} \mathrm{AH}_{13}$ or monosulphoaluminate detected in the paste sample with MK have the potential of transforming to Friedel's salt, given enough chloride and time. The source of chloride ions would be the sodium hypochlorite. The formation of Friedel's salt in cementing system with MK has been reported in the literature [122].

While the oxide composition of the low calcium fly ash used in this study shows the presence of alumina, the DTA peaks in Figure 4 - 42 do not reflect the formation of an appreciable amount of $\mathrm{C}_{4} \mathrm{AH}_{13}$, monosulphoaluminate or Friedel's salt like the case with MK. This is in line with the mortar bar results that did not show significant expansion when fly ash was used. These observations could be due to the limited amount of reactive alumina or lower reactivity of alumina in fly ash compared to that in MK. The X-ray diffraction of the raw materials Figure 4 - 3 suggests that the alumina in the fly ash sample used in this study is in the form non-reactive mullite. This is in line with earlier works which showed low calcium fly ash to have most of its alumina content in a crystalline form; i.e. mullite $[111,112]$. On the other hand, the MK sample was characterized by a diffused amorphous phase between 2-theta equals $20-30^{\circ}$ suggesting the presence of alkalisoluble silica and alumina [113].

The high exothermal peak of the sample with $\mathrm{PC} \mathrm{GU}$ at $630^{\circ} \mathrm{C}$ could be attributable to calcium chloride [81, 122]. This phase could be formed due to the reaction between calcium hydroxide as one of Portland cement products of hydration and chloride ions [117] as mentioned before, where the source of chlorides would be the sodium hypochlorite. 
The presence of this peak only in the sample without SCM is not known, as traces of calcium chloride were found in XRD of all samples as will be presented later. Perhaps the DTA peak was not detected in the paste samples with MK and low-calcium fly ash due to the consumption of part of $\mathrm{Ca}(\mathrm{OH})_{2}$ during the pozzolanic reaction, reducing its availability for reacting with chloride ions. While Figure 4 - 42 shows $\mathrm{Ca}(\mathrm{OH})_{2}$ in all samples, the amount was higher in samples without SCM.

\subsubsection{X-ray Diffraction}

The x-ray diffraction carried out on hydrated samples exposed to only six weeks as per the second stage of the oxidation mortar bar is shown in Figure $4-43$ to Figure $4-45$. The results revealed the presences of aluminate-based phases in the sample containing MK. These phases include ettringite, thaumasite, monosulphoaluminate and Friedel's salt. There is evidence of the presences of the same phases in the GU sample, but the peaks are not as strong. The sample with fly ash had the least amount or weakest peaks for these phases. The results of XRD were in line with those obtained using differential thermal analysis. The pattern peaks for each phase are listed in Appendix A. 


\section{GUH}

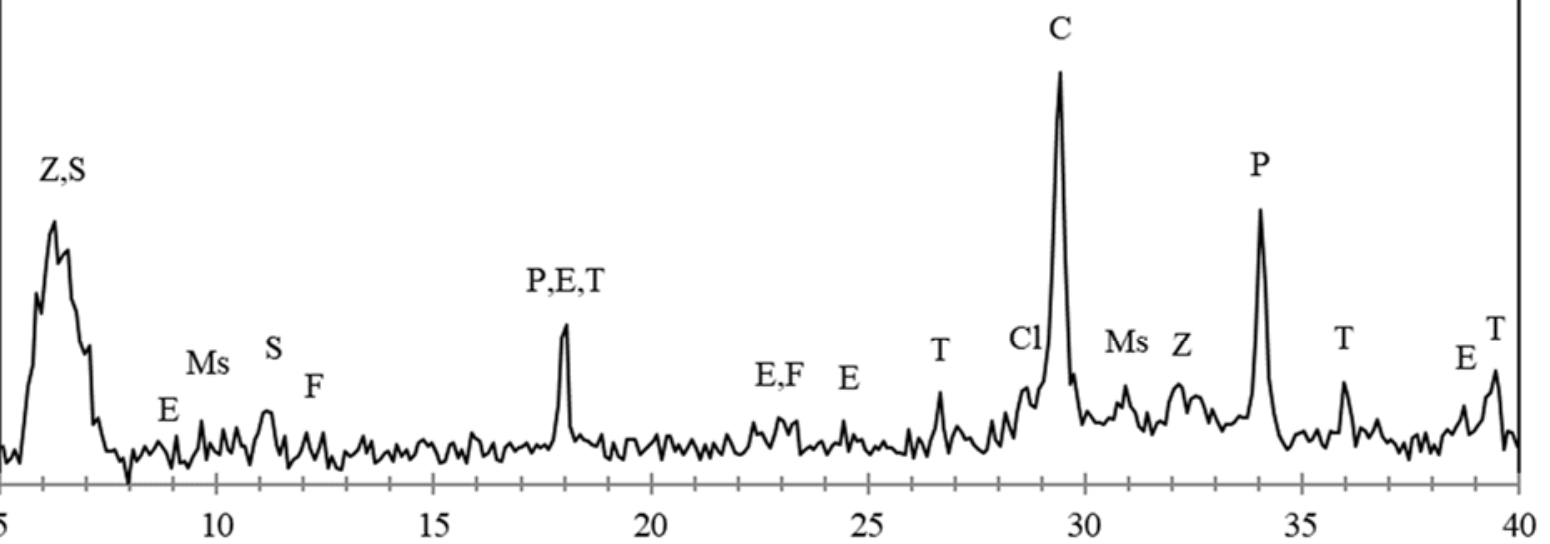

\begin{tabular}{|c|c|c|c|}
\hline Symbol & Index name & Mineral Name & Code No. \\
\hline $\mathrm{Z}$ & Silicon Oxide Hydrate & Zeolite & $01-073-7924$ \\
\hline $\mathrm{E}$ & Calcium Aluminum Sulphate Hydrate & Ettringite & $00-009-0414$ \\
\hline $\mathrm{Ms}$ & Calcium Aluminum Monosulphate Hydrate & Monosulphate & B. Lothenbach et al., 2008 [122] \\
\hline $\mathrm{S}$ & Silicon Oxide & Dealuminated & $01-075-3909$ \\
\hline $\mathrm{F}$ & Calcium Chloroaluminate Hydrate & Friedel's salt & M.D.A. Thomas et al., 2012. [73] \\
\hline $\mathrm{P}$ & Calcium Hydroxide & Portlandite & $00-004-0733$ \\
\hline $\mathrm{Cl}$ & Calcium Chloride & Calcium Chloride & $00-001-0338$ \\
\hline $\mathrm{T}$ & Calcium Carbonate Silicate Sulphate Hydrate & Thaumasite & $00-002-0061$ \\
\hline $\mathrm{C}$ & Calcium carbonate & Calcite & $01-085-0849$ \\
\hline
\end{tabular}

Figure 4 - 43: XRD patterns and pattern list of PC-GU hydrated 


\section{$\mathrm{FAH}$}

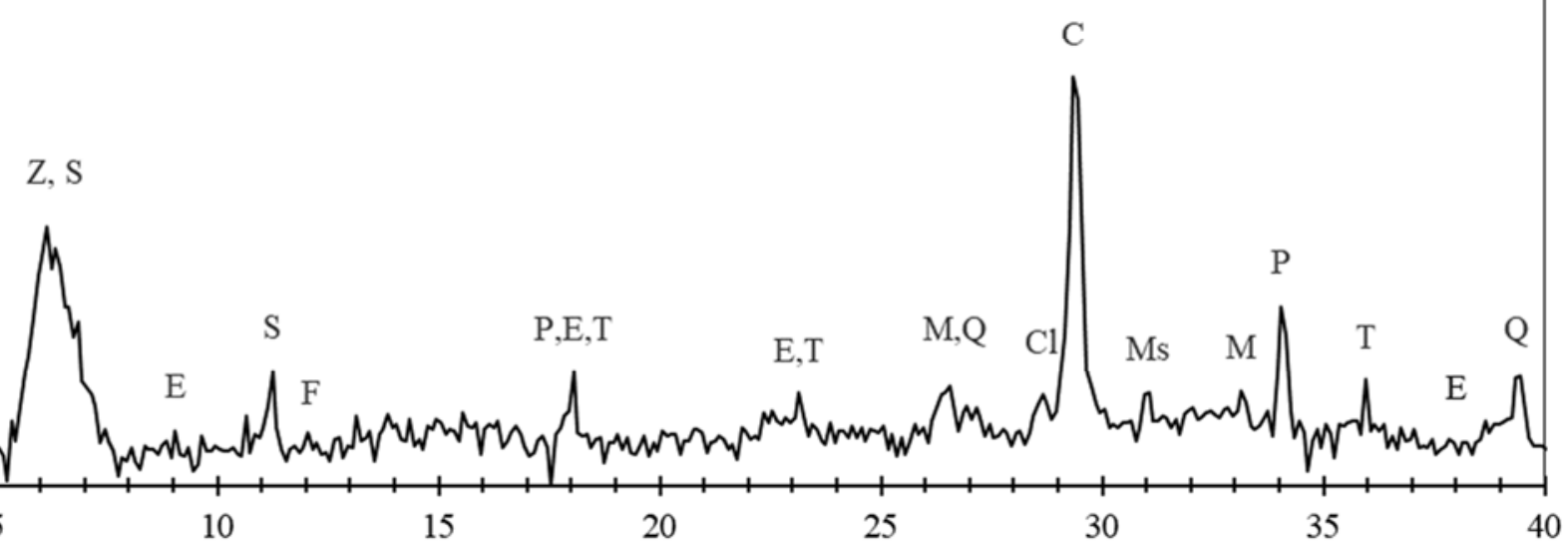

\begin{tabular}{|c|c|c|c|}
\hline Symbol & Index name & Mineral Name & Code No. \\
\hline Z & Silicon Oxide Hydrate & Zeolite & $01-073-7924$ \\
\hline E & Calcium Aluminum Sulphate Hydrate & Ettringite & $00-009-0414$ \\
\hline Ms & Calcium Aluminum Monosulphate Hydrate & Monosulphate & B. Lothenbach et al., 2008 [122] \\
\hline S & Silicon Oxide & Dealuminated & 01-075-3909 \\
\hline F & Calcium Chloroaluminate Hydrate & Friedel's salt & M.D.A. Thomas et al., 2012. [73] \\
\hline P & Calcium Hydroxide & Portlandite & 00-004-0733 \\
\hline Cl & Calcium Chloride & Calcium Chloride & $00-001-0338$ \\
\hline T & Calcium Carbonate Silicate Sulphate Hydrate & Thaumasite & $00-002-0061$ \\
\hline C & Calcium carbonate & Calcite & $01-085-0849$ \\
\hline M & Aluminum Silicon Oxide & Mullite & $00-001-0613$ \\
\hline Q & Silicon Oxide & Quartz & $01-075-8321$ \\
\hline
\end{tabular}

Figure 4 - 44: XRD patterns and pattern list of PC-GU $+25 \%$ fly ash hydrated 


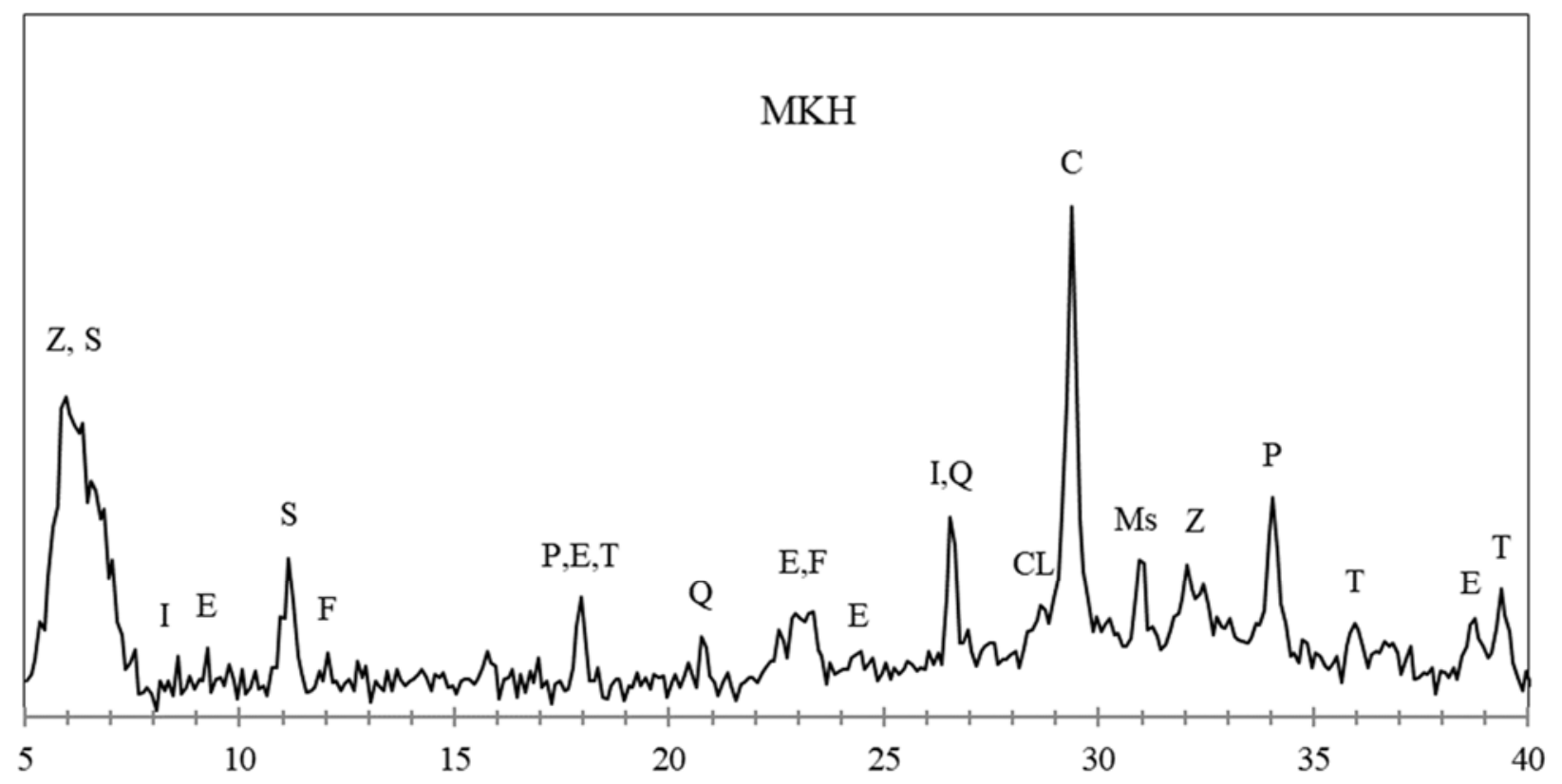

\begin{tabular}{|c|c|c|c|}
\hline Symbol & Indexname & Mineral Name & Code No. \\
\hline Z & Silicon Oxide Hydrate & Zeolite & $01-073-7924$ \\
\hline E & Calcium Aluminum Sulphate Hydrate & Ettringite & $00-009-0414$ \\
\hline Ms & Calcium Aluminum Monosulphate Hydrate & Monosulphate & B. Lothenbach et al., 2008 [122] \\
\hline S & Silicon Oxide & Dealuminated & 01-075-3909 \\
\hline F & Calcium Chloroaluminate Hydrate & Friedel's salt & M.D.A. Thomas et al., 2012. [73] \\
\hline P & Calcium Hydroxide & Portlandite & 00-004-0733 \\
\hline Cl & Calcium Chloride & Calcium Chloride & $00-001-0338$ \\
\hline T & Calcium Carbonate Silicate Sulphate Hydrate & Thaumasite & $00-002-0061$ \\
\hline C & Calcium carbonate & Calcite & $01-085-0849$ \\
\hline I & Potassium Magnesium Aluminum Silicate Hydrate & Mullite & $00-002-0050$ \\
\hline Q & Silicon Oxide & Quartz & $01-075-8321$ \\
\hline
\end{tabular}

Figure 4 - 45: XRD patterns and pattern list of PC-GU $+10 \%$ metakaolin hydrated 


\subsubsection{Analyses of the Mechanistic Tests Carried out on Paste samples}

Examining paste samples using SEM, thermal analysis, and XRD showed the presence of Friedel's salt and ettringite, monosulphoaluminate and calcium aluminate hydrates in excessive amounts in the sample with MK. The formation of Friedel's salt in the presence of MK is thought to be due to the extended period of exposure of the sample to chloride ions produced from the sodium hypochlorite when soaked for one day, rather than three hours. This high volume of chloride reacts with high aluminate phases formed due to the presence of reactive alumina from MK forming Friedel's salt. The process is explained in the coming paragraphs.

Initially, the chloride ions become available from the sodium hypochlorite solution following these reactions $[117,118]$ :

$$
\begin{aligned}
& \mathrm{NaClO}+\mathrm{H}_{2} \mathrm{O} \rightarrow \mathrm{HOCl} \text { (hypochlorous acid) }+\mathrm{NaOH} \text { (sodium hydroxide) } \\
& 2 \mathrm{HOCl} \text { (hypochlorous acid) } \rightarrow \quad 2 \mathrm{HCl} \text { (hydrochloric acid) }+\mathrm{O}_{2} \\
& 2 \mathrm{HCl} \text { (hydrochloric acid) }+\mathrm{Ca}(\mathrm{OH})_{2} \rightarrow \mathrm{CaCl}_{2}+2 \mathrm{H}_{2} \mathrm{O}
\end{aligned}
$$

When sodium hypochlorite is mixed with water, the reaction produces hypochlorous acid and sodium hydroxide [118]. 
The hypochlorous acid is then converted to hydrochloric acid and oxygen [118]; the hydrochloric acid reacts with calcium hydroxide as one of the hydrated Portland cement products to form calcium chloride and water [117]. In the case of cementing systems with high alumina content such as cementing blend with MK, the sulphur to alumina ratio is relatively low, which favors the formation of monosulphoaluminate (MS) rather than ettringite during hydration. In such systems, calcium aluminate hydrates also form. In the presence of $\mathrm{CaCl}_{2}$, Friedel's salt can form following the equations:

From Calcium aluminate hydrate:

$$
\mathrm{C}_{3} \mathrm{~A} \cdot \mathrm{Ca}(\mathrm{OH})_{2} .12 \mathrm{H}_{2} \mathrm{O}+\mathrm{CaCl}_{2} \rightarrow \mathrm{C}_{3} \mathrm{~A} \cdot \mathrm{CaCl}_{2} \cdot 10 \mathrm{H}_{2} \mathrm{O}+\mathrm{Ca}(\mathrm{OH})_{2}+\mathrm{H}_{2} \mathrm{O}[124]
$$

Or, from monosulphoaluminate:

$$
\mathrm{C}_{3} \mathrm{~A} \cdot \mathrm{CaSO}_{4} \cdot 12 \mathrm{H}_{2} \mathrm{O}+\mathrm{CaCl}_{2} \rightarrow \mathrm{C}_{3} \mathrm{~A} \cdot \mathrm{CaCl}_{2} \cdot 10 \mathrm{H}_{2} \mathrm{O}+\mathrm{CaSO}_{4} \cdot 2 \mathrm{H}_{2} \mathrm{O} \text { [124] }
$$

While Friedel's salt is not reported in the literature to cause expansion, its formation from monosulphoaluminate causes the release of sulphate as per in last equation. The produced sulphate competes with $\mathrm{CaCl}_{2}$ to react with the abundantly available monosulphoaluminate forming ettringite [125]. It should be stated that Ettringite was found to be stable at the moderate level of chloride so it could have formed in the presence of chloride ions [126]. 
The obtained expansion in samples with MK when soaked for 24 hours could be attributed to internal sulphate attack, where the sulphate would be released from the abundantly available monosulphoaluminate during the formation of Friedel's salt. The thermal analysis and XRD results suggested that the sample with MK has more Friedel's salt and possibility monosulphoaluminate, calcium aluminate hydrates, and ettringite compared with the other samples. Alternatively, the excessive amount of Friedel's salt could have caused swelling of the cementing system. This needs further investigation. 


\section{Chapter 5}

\section{Concrete Expansion Tests}

In this chapter, different concrete tests were conducted in order to examine their efficacy at evaluating the oxidation potential of sulphide-bearing aggregates. One advantage of these tests is that they incorporate coarse aggregates without any crushing.

\subsection{Experimental Program}

Different testing regimes were conducted. All of the samples used in this testing regime consisted of 3 specimens. The concrete prisms that were used in this investigation have standard dimensions of $76 \mathrm{~mm}$ x $76 \mathrm{~mm}$ x $285 \mathrm{~mm}$. In addition, each prism had two end studs made of platinum in order to resist rust. All of the concrete samples were prepared as per ASTM C192 [127]. The samples were exposed to different testing regimes that are listed in Table 5-1. It should be noted that the mineralogy and total sulphur content of each aggregates used in this testing were listed before in Table $4-2$. 
Table 5 - 1: Summary of concrete sample testing exposures

\begin{tabular}{|c|c|c|}
\hline Exposure \# & $\begin{array}{l}\text { Summary of the testing } \\
\text { cycles }\end{array}$ & Testing regime \\
\hline 1 & $\begin{array}{l}\text { - Samples stored in an } \\
\text { environmental chamber all } \\
\text { the time at } 60^{\circ} \mathrm{C} / 80 \% \text {. } \\
\text { - Measurements taken each } \\
\text { week at the same } \\
\text { temperature }\left(60^{\circ} \mathrm{C}\right) \text {. }\end{array}$ & $\begin{array}{l}\text { - After casting and demoulding, the samples were } \\
\text { cured in a standard curing room at humidity }>95 \% \\
\text { and room temperature for seven days; } \\
\text { - After the seven days, the samples were placed in the } \\
\text { environmental chamber for one day at } 60^{\circ} \mathrm{C} \\
\text { temperature, } 80 \% \mathrm{RH} \text {; } \\
\text { - After one day, the zero reading was immediately } \\
\text { taken once the samples were removed from the } \\
\text { chamber at a temperature of close to } 60^{\circ} \mathrm{C} \text {; } \\
\text { - Following this procedure, measurements were taken } \\
\text { every seven days as soon as the samples were } \\
\text { removed from the chamber. }\end{array}$ \\
\hline 2 & $\begin{array}{l}\text { - } 4 \text { days in sodium } \\
\text { hypochlorite solution. } \\
\text { - } 2 \text { days at } 80^{\circ} \mathrm{C} / 80 \% \mathrm{RH} \text { in } \\
\text { stage I. } \\
\text { - } 2 \text { days at } 5^{\circ} \mathrm{C} / 100 \% \mathrm{RH} \text { in } \\
\text { stage II. } \\
\text { - } 1 \text { day under a fume hood at } \\
\text { room temperature. }\end{array}$ & $\begin{array}{l}\text { - After casting and demoulding, the samples were } \\
\text { cured in a standard curing room at humidity }>95 \% \\
\text { and room temperature for seven days; } \\
\text { - The samples were kept in a sodium hypochlorite } \\
\text { solution at room temperature }\left(23^{\circ} \mathrm{C}\right) \text { for four days; } \\
\text { - The zero reading was taken while the sample was wet; } \\
\text { - The samples were kept in the oven at } 80^{\circ} \mathrm{C} / 80 \% \mathrm{RH} \\
\text { for } 2 \text { days in stage I up to } 13 \text { weeks; } \\
\text { - While, the samples were kept in the fridge at } \\
5^{\circ} \mathrm{C} / 100 \% \mathrm{RH} \text { for } 2 \text { days in stage II up to } 26 \text { weeks; } \\
\text { - The samples were kept in a fume hood for one day; } \\
\text { - The samples were put back into the solution for four } \\
\text { days of wet measurement; } \\
\text { - The cycle was repeated. }\end{array}$ \\
\hline 3 & $\begin{array}{l}\text { - } 1 \text { day in solution. } \\
\text { - } 5 \text { days in oven at } \\
60^{\circ} \mathrm{C} \text {. } \\
\text { - } 1 \text { day in a fume hood. }\end{array}$ & $\begin{array}{l}\text { - After casting and demoulding, the samples were } \\
\text { cured in a standard curing room at humidity }>95 \% \\
\text { and room temperature for seven days; } \\
\text { - The samples were kept for one day in solution at room } \\
\text { temperature }\left(23^{\circ} \mathrm{C}\right) \text {; } \\
\text { - The zero reading was taken while the sample was wet; } \\
\text { - The samples were kept in the oven for five days at } \\
60^{\circ} \mathrm{C} \text { with no control of relative humidity; } \\
\text { - The samples were kept in a fume hood for one day; } \\
\text { - The samples were placed back into the solution for } \\
\text { one day for wet measurement; } \\
\text { - The cycle was repeated. }\end{array}$ \\
\hline
\end{tabular}

*: Room temperature is maintained at $23^{\circ} \mathrm{C} \pm 2{ }^{\circ} \mathrm{C}$ 


\subsection{Samples Tested Under Different Exposures}

\subsubsection{Exposure 1}

The concrete samples were made with aggregates 52a, MW, MAS and C1. No oxidizing agent was used in this exposure. The samples were tested in an environmental chamber that automatically controls humidity and temperature. Measurements were taken every seven days without cooling (temperature close to $60^{\circ} \mathrm{C}$ ).

\subsubsection{Exposure 2}

Samples containing MAS, P, C1 and C2 aggregates were used in this exposure, which involved an oxidizing agent, as illustrated in Table 5-1.

\subsubsection{Exposure 3}

In addition to testing $100 \%$ sulphide-bearing aggregates and control aggregate with no sulphide phases, this exposure examined blends of sulphide- and non-sulphide aggregates. In addition, the effect of w/c was also examined. 
In the first part of the program, four samples consisting of different blends of non-sulphide and sulphide aggregates $\mathrm{C} 1$ and $\mathrm{MW}$ were used. The purpose of this test was to examine the sensitivity of the testing protocol to different sulphide levels. The first sample contained $100 \% \mathrm{MW}$, the second sample was cast with $90 \% \mathrm{C} 1+10 \% \mathrm{MW}$, the third sample was cast with $80 \% \mathrm{C} 1+20 \%$ MW, and the last sample was cast with $100 \% \mathrm{C} 1$. This exposure involves bleach as an oxidizing agent. The second part examined the effect of the $\mathrm{w} / \mathrm{c}$ ratio on expansion behaviour. Two different w/c ratios $(0.45$ and 0.65$)$ were investigated. Finally, the effect of $30 \%$ slag was also investigated. The samples were as follows:

Sample 1: containing aggregate 52a, sulphide aggregate, at a w/c of 0.65

Sample 2: containing aggregate $52 \mathrm{a}$ at a $\mathrm{w} / \mathrm{c}$ of 0.45

Sample 3: containing aggregate $52 \mathrm{a}$ and $30 \%$ slag at a w/c of 0.65

Sample 4: containing aggregate $\mathrm{C} 1$, non-sulphide aggregate, at a w/c of 0.65

\subsection{Results and Analysis}

\subsubsection{Exposure 1}

This exposure condition did not produce expansion, although some shrinkage recovery began to take place after 5 weeks, as illustrated in Figure 5 - 1. It should be noted that these samples were removed from a standard curing condition where the $\mathrm{RH}$ was above $95 \%$ and were placed at $80 \% \mathrm{RH}$ and $60^{\circ} \mathrm{C}$ after the curing time. 
This contributed to the observed shrinkage in the first few weeks. In fact, the shrinkage value for all samples after 1 day of placing in the chamber was about $-0.014 \%$; this value was taken as the zero reading since subsequent readings were taken at $60^{\circ} \mathrm{C}$. The results revealed that testing under this condition produces a very slow rate of expansion.

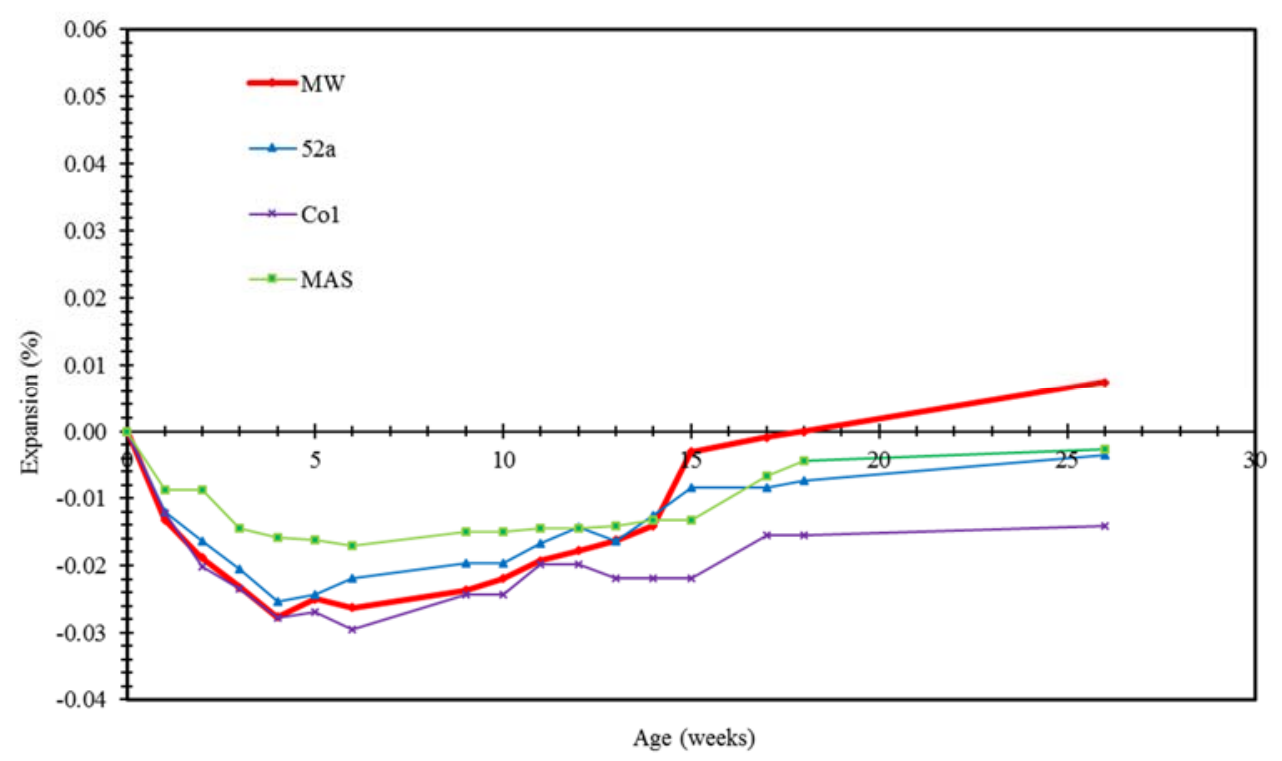

Figure 5 - 1: Volume change in concrete prisms containing different aggregates and kept at $60^{\circ} \mathrm{C}$ and $80 \% \mathrm{RH}$, using exposure 1 .

\subsubsection{Exposure 2}

Figure 5-2 shows very low expansion in the first stage up to 13 weeks, and in the second stage up to week 26; these results match with Mbonimpa et al. [128]. The author pointed out that high relative humidity (in the range of $>85 \%$ ) reduces the oxidation rate of sulphide minerals. The 
slow oxidation rate in the first stage may indicate that the samples were not kept in the oven for a sufficient period of time.

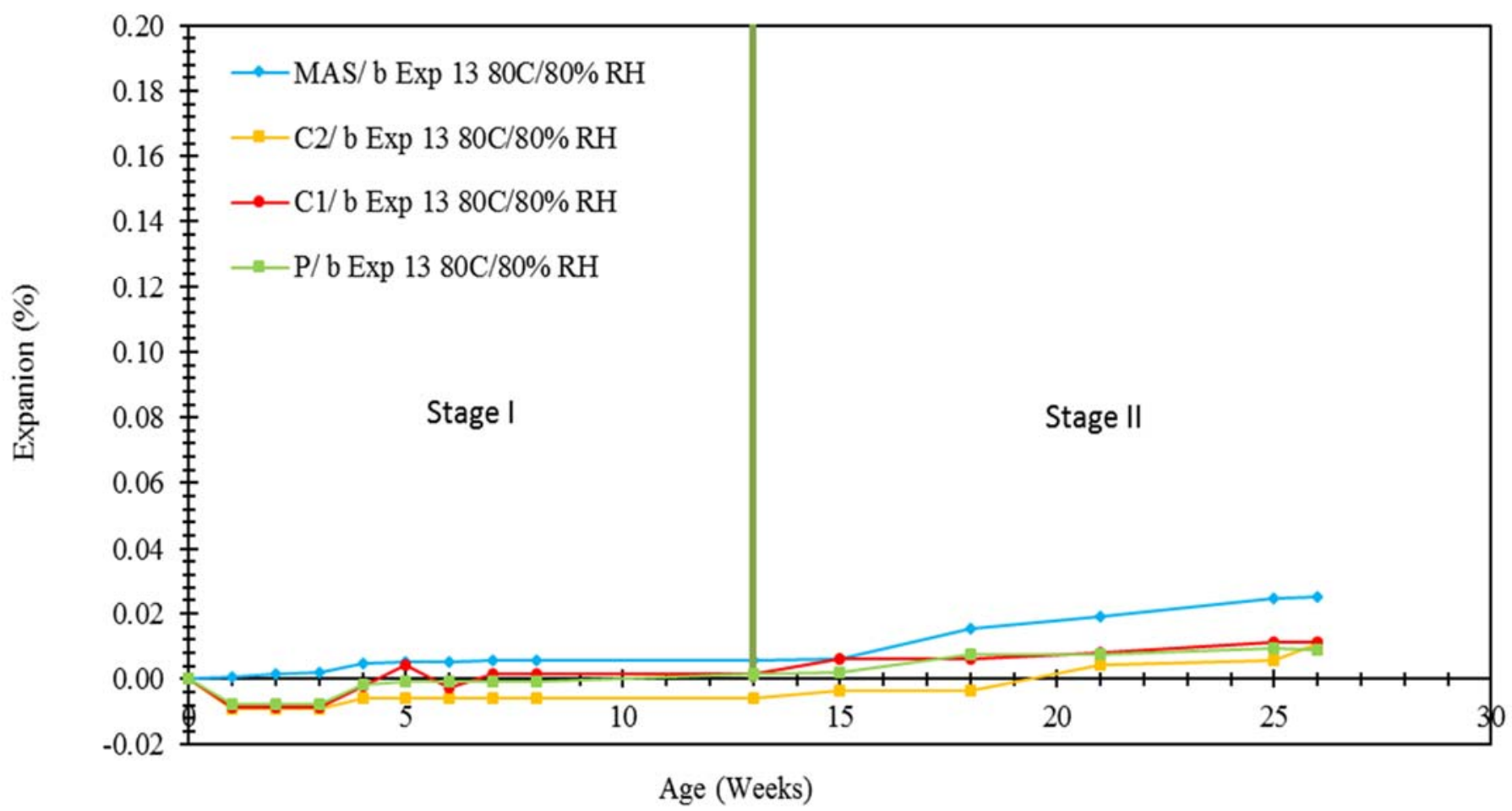

Figure 5 - 2: Expansion of concrete samples made with MAS, C2, C1 and P aggregates using exposure 2: 4-days soaking in a $6 \%$ sodium hypochlorite solution, 2 days in the oven at $60^{\circ} \mathrm{C}$.

\subsubsection{Exposure 3}

Although the expansion in all cases was low, there was a slightly higher expansion observed in the samples with $10 \%$ and $20 \%$ sulphide aggregates, as seen in Figure $5-3$. There was also a higher expansion with the concrete samples that contained $100 \% \mathrm{MW}$ (the rich sulphide 
minerals aggregate). It seems that this testing condition can lead to an expansion that is proportional to the level of sulphide in the aggregate.

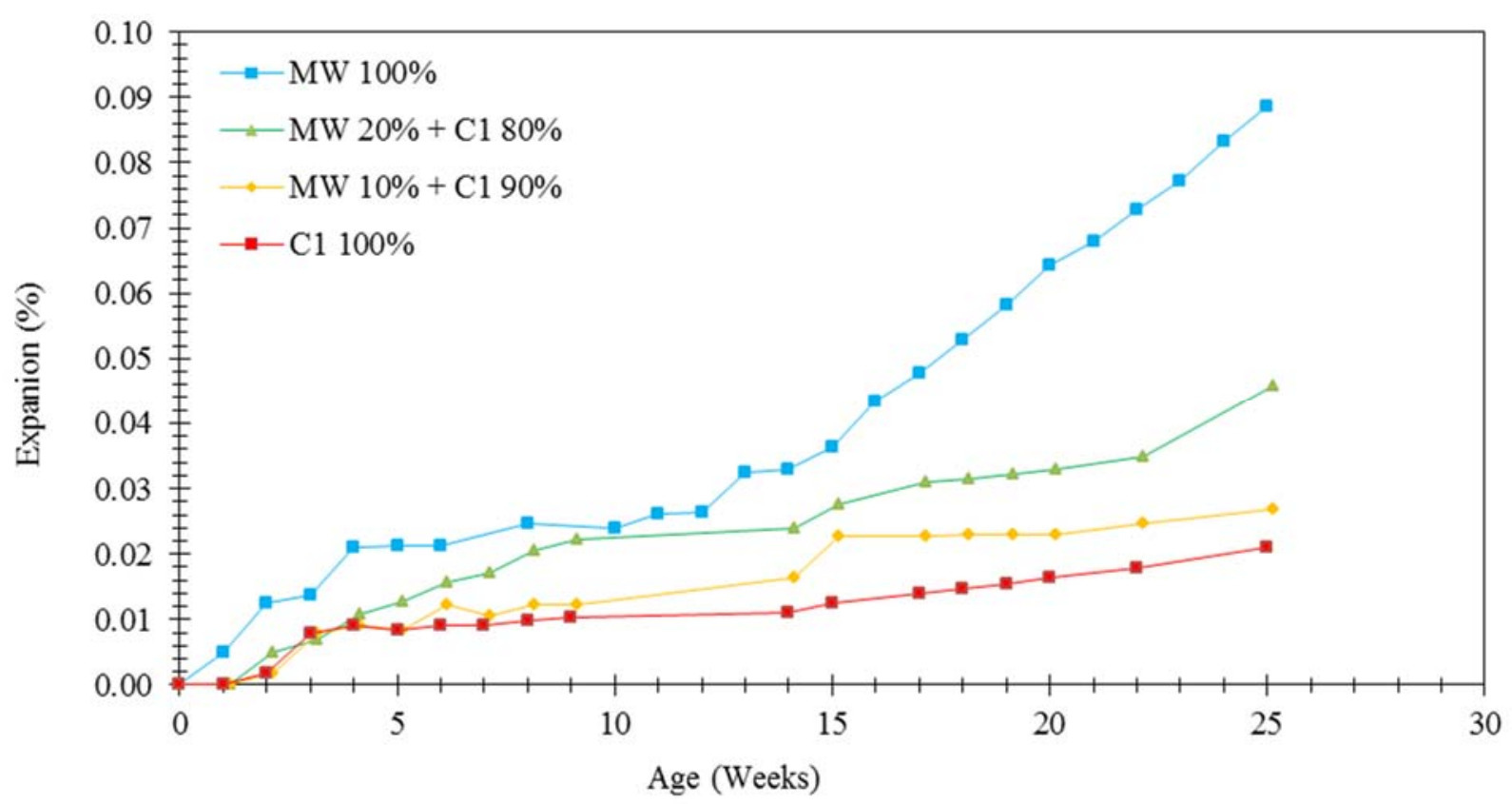

Figure 5 - 3: Expansion in MW and $\mathrm{C} 1$ aggregates with different replacement ratios using exposure 4: 1-day soaking in a 6\% sodium hypochlorite solution, 5 days in the oven at $60^{\circ} \mathrm{C}$.

Figure 5 - 4 shows the expansions in all of the samples. The figure is divided into four stages identified by vertical lines. Each stage represents a different testing condition. None of the concrete samples showed high expansion in stage 1. This might indicate that the oxidation of sulphide minerals does not cause much expansion. It is also possible that the condition did not lead to oxidation. In the second stage, all of the samples were placed in the shrinkage room at room temperature and $\mathrm{RH}$ of $50 \%$, to see if a lower $\mathrm{RH}$ leads to better oxidation. 
The expansion for all of the concrete samples decreased during the second stage up to week 65 , suggesting that:

a) The oxidation does not cause expansion, but instead produces oxidation products without the associated volume change, or:

b) The oxidation did not take place under these conditions.

The expansion was clear when the samples were moved to $100 \% \mathrm{RH}$ at room temperature. The concrete samples with the $52 \mathrm{a}$ aggregate at a $0.65 \mathrm{w} / \mathrm{c}$ showed a higher expansion in the third stage when the samples were stored at room temperature over water $(100 \% \mathrm{RH})$. This might be due to the ettringite formation, which requires a high $\mathrm{RH}$ to form. The concrete samples with the $\mathrm{C} 1$ and $52 \mathrm{a}$ aggregates with a $0.45 \mathrm{w} / \mathrm{c}$ ratio did not reach high expansion until week 78 .

The diagram also shows very high expansion in the last stage for concrete samples cast with the 52a aggregate with all different $w / \mathrm{c}$ ratios after week 78 , when the aggregate was tested under exposure 3. The reason for this behaviour was not thoroughly investigated in this study but more testing is being carried out in this direction. It is likely that oxidation took place during the period where the samples were stored at $50 \% \mathrm{RH}$. This oxidation produces sulfuric acid and possibly gypsum. When the humidity was raised in stage 3 , 
ettringitte formed and expansion was observed. It is interesting to note that the control $\mathrm{C} 1$ aggregate did not show high expansion in any of the stages.

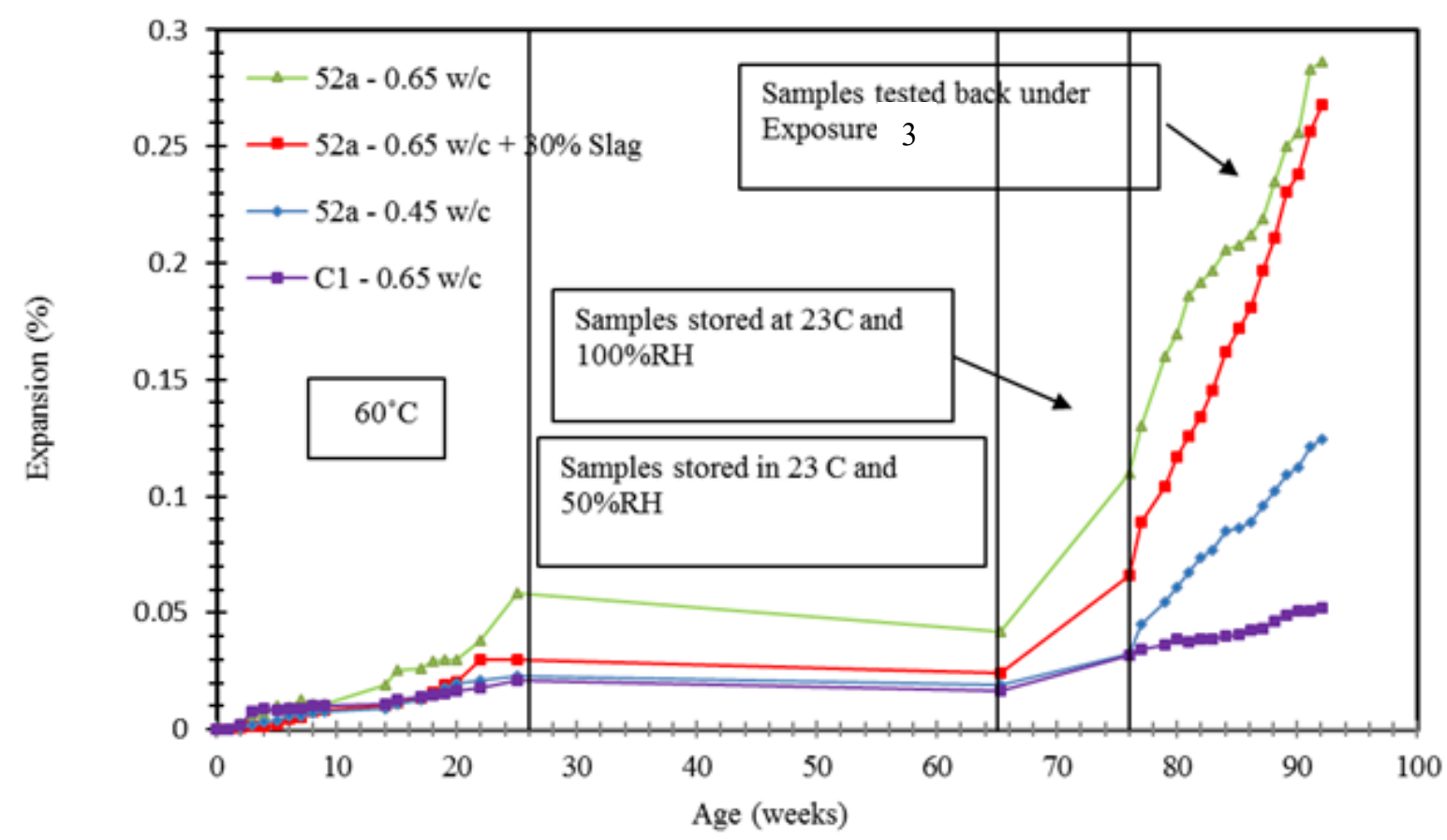

Figure 5 - 4: Expansion of concrete samples incorporating the 52a aggregate using exposure 3 one day soaking in a $6 \%$ sodium hypochlorite solution, 5 days in the oven at $60^{\circ} \mathrm{C}$. 


\section{Chapter 6}

\section{Summary and Conclusions}

\subsection{Summary}

This thesis presents a study into developing a new aggregate test and evaluating the recently developed oxidation mortar bar test for its efficacy to test different aggregate composition and cementing systems. In addition, attempts were made to a new concrete oxidation test. While these attempts did not yield a finalized test method, it paved the road for future research work by shedding light on the test conditions that are likely to produce oxidation and expansion in concrete samples. Based on a collaborative research project between Ryerson and three research institutions in Quebec, a test protocol was proposed [100] as shown in Figure 2-11.

In this thesis, the total sulphur content and the mortar bar test was carried out on a number of aggregates, mainly from Ontario. In addition, the mortar bar test was examined for its efficacy to test different cementing systems. The aggregate screening test is developed here to provide an additional test to the protocol to help screen aggregate and minimize the option of using the oxidation mortar bar test which requires 6 months to run. In addition, the aggregate oxidation test can replace the oxygen consumption test, if the repeatability, reproducibility and interlab study results prove its possibility for use as part of the protocol. 


\subsubsection{Aggregate Oxidation test}

In developing the screening test for aggregate, the focus was on having a simple test that can be carried out in a commercial lab without the need for a sophisticated test set up. The proposed test relies on one qualitative measure which is test solution color, and one quantitative measure which is the mass loss. The results were found to correlate well with aggregate composition or service record (field performance). In summary, coarse aggregate processed to size $2.36 \mathrm{~mm}$ to $1.18 \mathrm{~mm}$ and tested at room temperature for one week can be considered to contain no appreciable amount of oxidizable sulphide phases if it achieves mass loss $<0.5 \%$ and no change in solution color. A limit of $1.0 \%$ after three cycles can be used for aggregates failing the $0.5 \%$ limit at one cycle. Aggregates that fail such criteria should be exposed to more testing including the sulphide sulphur determined chemically, petrographic analysis, oxygen consumption test, or the oxidation mortar bar test. The limits specified here can be relaxed in the future after testing more aggregates of different geological composition. While testing coarse aggregates without crushing is more practical, the obtained mass loss is smaller, and may not be easy to distinguish aggregates with low sulphide content from aggregate with no sulphide. This requires further optimization.

\subsubsection{Oxidation Mortar Bar test}

The oxidation mortar bar was found to produce expansion in the first 13 weeks or first period of the test for aggregate with sulphide content and with some aggregates without sulphide content. This first period, phase I, involves soaking the mortar bar samples for 3 hour followed by 
storing the samples at $80^{\circ} \mathrm{C} / 80 \% \mathrm{RH}$ for three days. However, in the second stage of the test, only aggregates with sulphide minerals produces expansion.

This second period namely phase II, involves testing the samples under same soaking condition in phase I, but samples were stored at $5^{\circ} \mathrm{C} / 100 \% \mathrm{RH}$ for three days, instead of $80^{\circ} \mathrm{C}$ $180 \% \mathrm{RH}$ adopted in phase I.

The expansion in the first stage for aggregates with no sulphide content was found to be related to alkali-silica reaction in case of reactive aggregates and slow dissolution of silica and formation of alkali-silica products in aggregates with silica content. This was proven through studying the composition of the sodium hypochlorite solution in each aggregate was soaked. Dissolved silica was detected in the solution for aggregates with silica content.

In terms of the ability of the oxidation mortar bar test to investigate the effect of different cementing systems, the SCMs investigated here (25\% FA; $30 \%$ slag; $8 \%$ silica fume; $10 \%$ metakaolin) were able to reduce the expansion in mortar bars containing sulphide bearing aggregates by $50 \%$ to $85 \%$. It is likely that this is due to reduced volume of oxidizing solution penetrating the samples with SCM. Another interesting finding here is that extending the soaking period to one day instead of 3 hour produced less expansion, likely due to the shorter period during which the samples were placed in the oven at $80^{\circ} \mathrm{C}$ and $80 \%$ humidity. 
The significance of the results obtained in this dissertation in relation to actual in-field concrete needs to be examined. It can be argued that the way SCM reduces the amount or availability of an oxidizing agent in the mortar bar samples would be similar to the availability of oxygen to concrete under field conditions. In other words, the enhanced pore structure would reduce the availability of oxygen under field conditions. However, this needs validation through in situ testing of concrete. Until then the use of the oxidizing mortar bar test to evaluate SCM should be treated with caution. Changing the pore structure of the sample may alter the optimized conditions needed to promote oxidation in the lab samples using this test. The same change in microstructure of concrete under field conditions may not have the same reduction on the rate of oxidation.

\subsubsection{Concrete tests}

Different testing conditions were investigated and the main finding is that producing expansion in concrete requires longer time than producing expansion in mortar bars. However, one testing condition was found to produce expansion which requires soaking the concrete samples in oxidizing solution (sodium hypochlorite) for one day followed by storing the samples in an oven at $60^{\circ} \mathrm{C}$ for five days, then keeping the samples one day at room temperature under fume hood. However, it was evident from testing under this condition that a storing period at optimum relative humidity, likely lower than $80 \%$, might accelerate the oxidation process. Other conditions investigated here did not produce significant expansion in a relatively short period of time. 


\subsubsection{Suggested Aggregate Screening Flow Chart}

Based on the aggregate oxidation test developed in this thesis, the following testing flow chart as presented in Figure 6 - 1 is recommended to be adopted prior to applying the protocol described in Figure 2-11. The idea is to reduce the number of aggregates that need to be tested using the protocol in Figure 2-11 through using a simple, quick and economic test method.

The total sulphur test can be skipped as the aggregate oxidation test has the capacity to screen aggregate for its potential to oxidize; however, giving the low cost, short time and availability the total sulphur test, the author believe that the test provides an additional "safeguard" to the oxidation test. 


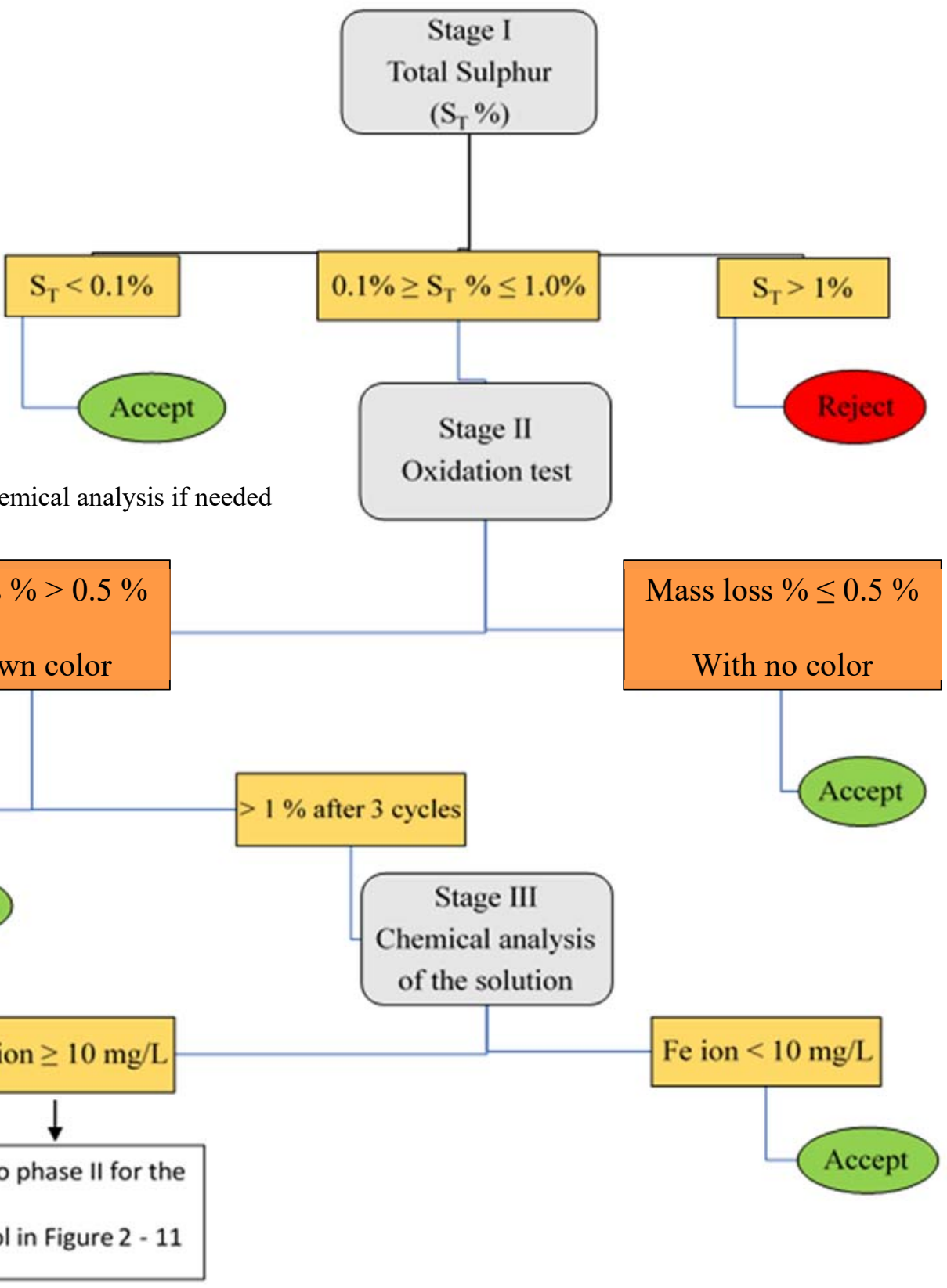

Figure 6-1: Suggested aggregate screening flow chart 


\subsection{Conclusions}

For the range of materials and based on the test conditions carried out in this dissertation, the following conclusions can be drawn:

1. An aggregate oxidation test was developed and found to be capable of screening aggregates with oxidizable sulphide phase from aggregates with no sulphide phases.

2. In the aggregate oxidation test, the finer the tested aggregate gradation the larger the mass loss within a certain period of time.

3. In its present form, the change in color of the test solution and the mass loss after one week of testing at room temperature can be used to screen aggregate for its use in concrete.

4. The aggregate oxidation test relies on measuring the mass loss after cycles of soaking in oxidizing solution $\left(6 \%\right.$ sodium hypochlorite), drying at $80^{\circ} \mathrm{C}$. A limit of $0.5 \%$ mass loss after one cycle of testing at $23^{\circ} \mathrm{C}$ using $2.36 \mathrm{~mm}-1.18 \mathrm{~mm}$ aggregates can be used, and $1.0 \%$ after three cycles, where the third cycle can be used in case of an aggregate exceeding the $0.5 \%$ after the first cycle. These limits are conservative based on the results of the investigation carried out here. Double these values can be used after more investigation particularly in terms of running the test at different labs. 
5. Testing at higher temperature did not accelerate the oxidation in the aggregate oxidation test. This is not related to the oxidation process but to a change in the chemical composition of the sodium hypochlorite used as an oxidizing agent at high temperature

6. Aggregate oxidation test can work as a screening test before the oxygen consumption test in the protocol as show in Figure $2-11$ or as replacement of the oxygen consumption and oxidation mortar bar tests. More work is needed to finalize this test and establish the repeatability and interlab variation.

7. Chemical analysis of the oxidizing solution used in the aggregate oxidation test showed the presence of sulphate and iron ions in solution for aggregates with oxidizable sulphide phases.

8. In the oxidation mortar bar test, some aggregates have dissolved silica when soaked in $6 \%$ sodium hypochlorite solution; however, for the materials tested here, this usually takes place only in the first 13 weeks of the testing.

9. For the materials tested in the developed mortar bar test, and according to the testing procedure, the results showed that the dissolved silica ion increase in solution at high temperature. 
10. The oxidation mortar bar test showed differences in expansions between samples with different cementing blends.

11. The low- $\mathrm{C}_{3} \mathrm{~A}$ PC and SCMs investigated here $30 \%$ slag, $25 \% \mathrm{FA} 8 \%$, silica fume, and $10 \%$ metakaolin and were able to reduce the expansion in mortar bars containing sulphide bearing aggregates by $50 \%$ to $85 \%$. One of the distinct mechanisms behind this finding is the enhanced pore structure of samples with SCMs and the reduced $\mathrm{C}_{3} \mathrm{~A}$ in samples with low- $\mathrm{C}_{3} \mathrm{~A}$ PC.

12. Mortar bars with low w/c showed lower expansion in the oxidation mortar bar test suggesting that the enhanced pore structure has an effect on the expansion. The relationship of this to concrete under field conditions needs to be investigated. In addition, the test might underestimate the damage if different mix properties are used such as lower w/c.

13. Soaking mortar bar samples in sodium hypochlorite solution can produce Friedel's salt; however, the amount is not large enough if the soaking period is only three hours. This Friedel's salt can release sulphate from monosulphoaluminte and lead to internal sulphate attack.

14. Expansion of concrete containing sulphide bearing aggregate could be produced in the lab; however, some testing exposures were more effective than others in accelerating the onset of expansion. One condition which involves one day of soaking in solution followed by 
five days in oven at $60^{\circ} \mathrm{C}$ was found to produce expansion. More work is needed to optimize the condition with wide range of aggregate. 


\section{Chapter 7}

\section{Recommendations for Future work}

Based on the findings of this thesis the following are recommendation for future studies:

1. Testing more aggregates with different geological composition are recommended to examine the applicability of the aggregate oxidation test to a wide range of aggregate and perhaps re-consider the proposed limits.

2. New screening test method is open to more optimization. For instance, testing larger aggregate size or testing different fractions of particle sizes and calculating the weighted average of mass loss are ideas that can be pursued.

3. The repeatability and the reproducibility of the new screening test in different laboratory are important to establish precision statement and proposed limits.

4. For the aggregate oxidation test, testing mass greater than $100 \mathrm{~g}$ may provide the better precision of the test results.

5. For the aggregate oxidation test, the reduction rate in $\mathrm{pH}$ was not significant in this study, so it is recommended to reduce the solid to solution ratio to $1: 2$ instead of $1: 10$. That might produce a measurable reduction in $\mathrm{pH}$ with a wide range of sulphide-bearing aggregates. 
6. Testing a wide range of aggregates with different size in oxygen consumption test is suggested to confirm the proposed limits.

7. Although, the higher temperature can promote the oxidation process. This higher temperature can cause the decomposition of ettringite crystal. So, using $70^{\circ} \mathrm{C}$ as the max temperature for future work might be helpful.

8. Considering the results of this work, chloride ion seems to be affecting the stability of ettringite, and promote the Friedel's salts formation. So, using any oxidizing agent that does not contain chlorides would prevent the complications arising when chlorides reacting with the different phases inside concrete.

9. The results obtained here using the mortar bar test needs to be validated using in-situ concrete with sulphide-bearing aggregates and SCMs.

10. Developing test method by using $60^{\circ} \mathrm{C}, 60 \% \mathrm{RH}$ and limewater as a soaking solution with the flow of oxygen gas might be helpful to promote the potential oxidation of sulphide minerals, and hence the expansion in mortar bars and concrete samples.

11. It is recommended to continue working on developing a test method for concrete. The results obtained in this dissertation can help the selection and optimization of future testing protocol that are likely to work. 
12. Although, both water and air are essential in order to increase the oxidation rate for sulphide minerals, the limited results in concrete samples suggested that the high $\mathrm{RH}$ at $80 \%$ might reduce the rate of reaction.

13. More experimental tests are needed to investigate the relation between ettringite, monosulphoaluminate, Kuzel's salt and Friedel's salt formation under the testing conditions used here.

14. More studies are highly recommended to investigate whether or not Friedel's salt formation can cause expansion in concrete. 


\section{Appendix A}

Table A-1: XRD Peak list [2 Theta \& Intensity (I \%)] for each mineral:

\begin{tabular}{|c|c|c|c|c|c|}
\hline Symbol & Mineral name & Ref. Code & Figure & 2 Theta & $\mathrm{I} \%$ \\
\hline $\mathrm{Z}$ & Zeolite & 01-073-7924 & $\begin{array}{l}\text { Fig. } 4-43 \\
\text { Fig. } 4-44 \\
\text { Fig. } 4-45\end{array}$ & 6.347 & 100 \\
\hline $\mathrm{E}$ & Ettringite & 00-009-0414 & $\begin{array}{l}\text { Fig. } 4-43 \\
\text { Fig. } 4-44 \\
\text { Fig. } 4-45\end{array}$ & 9.081 & 100 \\
\hline \multirow{3}{*}{$\mathrm{E}$} & \multirow{3}{*}{ Ettringite } & \multirow{3}{*}{$00-002-0059$} & $\begin{array}{l}\text { Fig. } 4-43 \\
\text { Fig. } 4-44 \\
\text { Fig. } 4-45\end{array}$ & 18.089 & 60 \\
\hline & & & $\begin{array}{l}\text { Fig. } 4-43 \\
\text { Fig. } 4-44 \\
\text { Fig. } 4-45\end{array}$ & 22.962 & 80 \\
\hline & & & $\begin{array}{l}\text { Fig. } 4-43 \\
\text { Fig. } 4-45\end{array}$ & 24.710 & 30 \\
\hline $\mathrm{S}$ & Silicon Oxide & 01-075-3909 & $\begin{array}{l}\text { Fig. } 4-43 \\
\text { Fig. } 4-44 \\
\text { Fig. } 4-45\end{array}$ & 6.088 & 100 \\
\hline $\mathrm{P}$ & Portlandite & $00-004-0733$ & $\begin{array}{l}\text { Fig. } 4-43 \\
\text { Fig. } 4-44 \\
\text { Fig. } 4-45\end{array}$ & $\begin{array}{l}18.089 \\
34.089\end{array}$ & $\begin{array}{l}74 \\
100\end{array}$ \\
\hline $\mathrm{Cl}$ & $\begin{array}{l}\text { Calcium } \\
\text { chloride }\end{array}$ & $00-001-0338$ & $\begin{array}{l}\text { Fig. } 4-43 \\
\text { Fig. } 4-44 \\
\text { Fig. } 4-45\end{array}$ & 29.258 & 80 \\
\hline \multirow[t]{2}{*}{$\mathrm{T}$} & \multirow[t]{2}{*}{ Thaumasite } & \multirow[t]{2}{*}{$00-002-0061$} & $\begin{array}{l}\text { Fig. } 4-43 \\
\text { Fig. } 4-44 \\
\text { Fig. } 4-45\end{array}$ & $\begin{array}{l}18.354 \\
36.191\end{array}$ & $\begin{array}{l}50 \\
80\end{array}$ \\
\hline & & & $\begin{array}{l}\text { Fig. } 4-43 \\
\text { Fig. } 4-45\end{array}$ & 39.673 & 40 \\
\hline $\mathrm{C}$ & $\begin{array}{l}\text { Calcium } \\
\text { carbonate }\end{array}$ & 01-085-0849 & $\begin{array}{l}\text { Fig. } 4-43 \\
\text { Fig. } 4-44 \\
\text { Fig. } 4-45\end{array}$ & 29.466 & 100 \\
\hline \multirow[t]{2}{*}{ M } & \multirow[t]{2}{*}{ Mullite } & \multirow[t]{2}{*}{$00-001-0613$} & Fig. 4 - 3 & $\begin{array}{l}16.372 \\
35.165 \\
33.280\end{array}$ & $\begin{array}{l}50 \\
83 \\
75 \\
\end{array}$ \\
\hline & & & $\begin{array}{c}\text { Fig. } 4-3 \\
\text { Fig. } 4-44 \\
\end{array}$ & 26.268 & 100 \\
\hline
\end{tabular}




\begin{tabular}{|c|c|c|c|c|c|}
\hline & & & $\begin{array}{l}\text { Fig. } 4-3 \\
\text { Fig. } 4-44\end{array}$ & 39.135 & 33 \\
\hline \multirow{3}{*}{ I } & \multirow{3}{*}{ Illite } & \multirow{3}{*}{$00-002-0050$} & Fig. $4-45$ & 8.836 & 100 \\
\hline & & & Fig. $4-4$ & $\begin{array}{l}19.891 \\
36.806 \\
\end{array}$ & $\begin{array}{l}100 \\
40\end{array}$ \\
\hline & & & $\begin{array}{l}\text { Fig. } 4-45 \\
\text { Fig. } 4-4\end{array}$ & 26.750 & 70 \\
\hline \multirow[t]{2}{*}{ Q } & \multirow[t]{2}{*}{ Quartz } & \multirow[t]{2}{*}{$01-075-8321$} & $\begin{array}{l}\text { Fig. } 4-44 \\
\text { Fig. } 4-45 \\
\text { Fig. } 4-3 \\
\text { Fig. } 4-4\end{array}$ & 26.621 & 100 \\
\hline & & & $\begin{array}{l}\text { Fig. } 4-45 \\
\text { Fig. } 4-3 \\
\text { Fig. } 4-4\end{array}$ & 20.840 & 21 \\
\hline
\end{tabular}




\section{Name and formula}

Reference code:

Common name:

PDF index name:

Empirical formula:

Chemical formula:

\section{1-073-7924}

\section{Zeolite $Y$}

Silicon Oxide Hydrate

$\mathrm{H}_{184} \mathrm{O}_{476} \mathrm{Si}_{192}$

$\mathrm{Si}_{192} \mathrm{O}_{384}\left(\mathrm{H}_{2} \mathrm{O}\right)_{92}$

\section{Crystallographic parameters}

Crystal system:

Space group:

Space group number:

$\mathrm{a}(\mathrm{A})$ :

b (A):

$c(A)$ :

Alpha ("):

Beta ("):

Gamma ():

Volume of cell $\left(10^{\wedge} 6 \mathrm{pm}^{\wedge} 3\right)$ :

Z:

RIR:
Cubic

$\mathrm{Fd}-3 \mathrm{~m}$

227

24.1010

24.1010

24.1010

90.0000

90.0000

90.0000

13999.26

1.00

11.57

\section{Status. subfiles and quality}

Status:

Subfiles:

Quality:

\section{Comments}

\section{ANX:}

Wyckoff Sequence:

Analysis:

Unit cell data source:

ICSD collection code:
Diffraction data collected at non ambient pressure Inorganic

Zeolite

ICSD Pattern

Blank (B)
A.48 $\times 119$

ihg 3 fe2 d(FD3-MZ).

$\mathrm{H} 1840476$ Si192. Formula from original source: Si192 $\mathrm{O} 384(\mathrm{H} 2 \mathrm{O}) 92$.

Powder Diffraction.

55481. Pressure of Datacollection: $4000 \mathrm{MPa}$. Minor Warning: Density calculated using chemical formula and refined composition differ by $1.5345 \%$. No R factors

reported/abstracted. Significant Warning: ICSD Warning on inter-atomic distances exist.

\section{$\underline{\text { References }}$}

Primary reference:

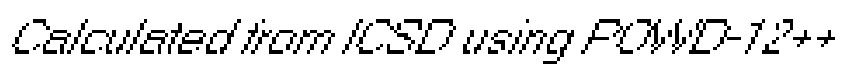

Structure:

Colligan, M., Forster. P.M., Cheetham, A.K., Lee Yong Jae, Vogt T., Hriljac, J.A., L/ $A m$. CYem. SaC, 126, 12015, (2004)

\section{Peak list}

No.

$\mathrm{h} \quad \mathrm{k} \quad \mathrm{l}$

d $[\mathrm{A}]$

2 Theta [deg] I [s 


\begin{tabular}{|c|c|c|c|c|c|c|}
\hline 1 & 1 & 1 & 1 & 13.91470 & 6.347 & 100.0 \\
\hline 2 & 2 & 2 & 0 & 8.52100 & 10.373 & 11.5 \\
\hline 3 & 3 & 1 & 1 & 7.26670 & 12.170 & 7.1 \\
\hline 4 & 2 & 2 & 2 & 6.95740 & 12.713 & 0.1 \\
\hline 5 & 4 & 0 & 0 & 6.02520 & 14.690 & 0.3 \\
\hline 6 & 3 & 3 & 1 & 5.52920 & 16.016 & 7.6 \\
\hline 7 & 4 & 2 & 2 & 4.91960 & 18.017 & 0.1 \\
\hline 8 & 5 & 1 & 1 & 4.63820 & 19.120 & 3.4 \\
\hline 9 & 4 & 4 & 0 & 4.26050 & 20.833 & 2.6 \\
\hline 10 & 5 & 3 & 1 & 4.07380 & 21.799 & 0.2 \\
\hline 11 & 4 & 4 & 2 & 4.01680 & 22.112 & 0.1 \\
\hline 12 & 6 & 2 & 0 & 3.81070 & 23.324 & 1.7 \\
\hline 13 & 5 & 3 & 3 & 3.67540 & 24.196 & 7.0 \\
\hline 14 & 4 & 4 & 4 & 3.47870 & 25.586 & 0.4 \\
\hline 15 & 7 & 1 & 1 & 3.37480 & 26.388 & 1.8 \\
\hline 16 & 6 & 4 & 2 & 3.22060 & 27.676 & 3.8 \\
\hline 17 & 7 & 3 & 1 & 3.13770 & 28.423 & 0.2 \\
\hline 18 & 8 & 0 & 0 & 3.01260 & 29.629 & 0.1 \\
\hline 19 & 7 & 3 & 3 & 2.94440 & 30.332 & 1.8 \\
\hline 20 & 6 & 4 & 4 & 2.92270 & 30.563 & 0.2 \\
\hline 21 & 8 & 2 & 2 & 2.84030 & 31.472 & 1.3 \\
\hline 22 & 7 & 5 & 1 & 2.78290 & 32.138 & 3.1 \\
\hline 23 & 8 & 4 & 0 & 2.69460 & 33.221 & 0.5 \\
\hline 24 & 9 & 1 & 1 & 2.64540 & 33.858 & 0.3 \\
\hline 25 & 8 & 4 & 2 & 2.62960 & 34.067 & 0.2 \\
\hline 26 & 6 & 6 & 4 & 2.56920 & 34.894 & 1.2 \\
\hline 27 & 9 & 3 & 1 & 2.52650 & 35.503 & 0.9 \\
\hline 28 & 8 & 4 & 4 & 2.45980 & 36.499 & 0.2 \\
\hline 29 & 7 & 5 & 5 & 2.42220 & 37.086 & 0.4 \\
\hline 30 & 10 & 2 & 0 & 2.36330 & 38.045 & 0.1 \\
\hline 31 & 9 & 5 & 1 & 2.32990 & 38.612 & 0.2 \\
\hline 32 & 10 & 2 & 2 & 2.31910 & 38.799 & 0.5 \\
\hline 33 & 8 & 6 & 4 & 2.23770 & 40.271 & 0.1 \\
\hline 34 & 10 & 4 & 2 & 2.20010 & 40.989 & 0.1 \\
\hline 35 & 11 & 1 & 1 & 2.17310 & 41.522 & 0.3 \\
\hline 36 & 8 & 8 & 0 & 2.13020 & 42.398 & 0.4 \\
\hline 37 & 9 & 7 & 1 & 2.10570 & 42.916 & 0.2 \\
\hline 38 & 10 & 4 & 4 & 2.09770 & 43.088 & 0.2 \\
\hline 39 & 10 & 6 & 0 & 2.06660 & 43.769 & 0.3 \\
\hline 40 & 11 & 3 & 3 & 2.04420 & 44.274 & 0.4 \\
\hline 41 & 10 & 6 & 2 & 2.03690 & 44.441 & 0.3 \\
\hline 42 & 12 & 0 & 0 & 2.00840 & 45.106 & 0.6 \\
\hline 43 & 11 & 5 & 1 & 1.98780 & 45.600 & 0.1 \\
\hline 44 & 12 & 2 & 2 & 1.95480 & 46.414 & 0.1 \\
\hline 45 & 11 & 5 & 3 & 1.93580 & 46.897 & 0.1 \\
\hline 46 & 12 & 4 & 0 & 1.90540 & 47.691 & 0.1 \\
\hline 47 & 9 & 9 & 1 & 1.88770 & 48.166 & 0.1 \\
\hline 48 & 12 & 4 & 2 & 1.88200 & 48.322 & 0.2 \\
\hline 49 & 10 & 8 & 2 & 1.85940 & 48.947 & 0.7 \\
\hline 50 & 11 & 7 & 1 & 1.84300 & 49.412 & 0.1 \\
\hline 51 & 10 & 6 & 6 & 1.83770 & 49.564 & 0.1 \\
\hline 52 & 12 & 4 & 4 & 1.81670 & 50.176 & 0.1 \\
\hline 53 & 9 & 7 & 7 & 1.80140 & 50.632 & 0.5 \\
\hline 54 & 10 & 8 & 4 & 1.79640 & 50.783 & 0.3 \\
\hline 5.5 & 12 & 6 & 2 & 1.77680 & 51.384 & 0.1 \\
\hline 56 & 13 & 3 & 3 & 1.76240 & 51.835 & 0.2 \\
\hline 57 & 8 & 8 & 8 & 1.73930 & 52.575 & 0.1 \\
\hline 58 & 13 & 5 & 1 & 1.72590 & 53.015 & 0.2 \\
\hline 59 & 12 & 6 & 4 & 1.72150 & 53.161 & 0.1 \\
\hline 60 & 10 & 10 & 0 & 1.70420 & 53.744 & 0.7 \\
\hline
\end{tabular}




\begin{tabular}{|c|c|c|c|c|c|c|}
\hline 61 & 13 & 5 & 3 & 1.69160 & 54.177 & 0.1 \\
\hline 62 & 14 & 2 & 2 & 1.68740 & 54.323 & 0.1 \\
\hline 63 & 12 & 8 & 0 & 1.67110 & 54.897 & 0.1 \\
\hline 64 & 11 & 9 & 3 & 1.65920 & 55.325 & 0.7 \\
\hline 65 & 12 & 8 & 2 & 1.65530 & 55.466 & 0.4 \\
\hline 66 & 12 & 6 & 6 & 1.63990 & 56.033 & 0.1 \\
\hline 67 & 11 & 7 & 7 & 1.62860 & 56.456 & 0.1 \\
\hline 68 & 12 & 8 & 4 & 1.61030 & 57.156 & 0.3 \\
\hline 69 & 13 & 7 & 3 & 1.59960 & 57.574 & 0.1 \\
\hline 70 & 14 & 4 & 4 & 1.59610 & 57.713 & 0.1 \\
\hline 71 & 14 & 6 & 0 & 1.58230 & 58.264 & 0.1 \\
\hline 72 & 15 & 3 & 1 & 1.57220 & 58.675 & 0.1 \\
\hline 73 & 14 & 6 & 2 & 1.56880 & 58.814 & 0.2 \\
\hline 74 & 11 & 11 & 1 & 1.54610 & 59.765 & 0.4 \\
\hline 75 & 12 & 8 & 6 & 1.54290 & 59.901 & 0.2 \\
\hline 76 & 14 & 6 & 4 & 1.53040 & 60.441 & 0.1 \\
\hline 77 & 15 & 5 & 1 & 1.52120 & 60.846 & 0.1 \\
\hline 78 & 16 & 0 & 0 & 1.50630 & 61.512 & 0.2 \\
\hline 79 & 15 & 5 & 3 & 1.49760 & 61.909 & 0.2 \\
\hline 80 & 12 & 10 & 4 & 1.49470 & 62.042 & 0.1 \\
\hline 81 & 10 & 10 & 8 & 1.48330 & 62.573 & 0.1 \\
\hline 82 & 11 & 11 & 5 & 1.47500 & 62.965 & 0.2 \\
\hline 83 & 14 & 6 & 6 & 1.47220 & 63.098 & 0.1 \\
\hline 84 & 16 & 4 & 0 & 1.46130 & 63.624 & 0.2 \\
\hline 85 & 15 & 5 & 5 & 1.45340 & 64.011 & 0.2 \\
\hline 86 & 16 & 4 & 2 & 1.45070 & 64.144 & 0.1 \\
\hline 87 & 12 & 10 & 6 & 1.44030 & 64.663 & 0.2 \\
\hline 88 & 11 & 9 & 9 & 1.43270 & 65.048 & 0.1 \\
\hline 89 & 12 & 12 & 0 & 1.42020 & 65.693 & 0.2 \\
\hline 90 & 17 & 1 & 1 & 1.41280 & 66.081 & 0.1 \\
\hline 91 & 12 & 12 & 2 & 1.41040 & 66.208 & 0.1 \\
\hline 92 & 14 & 10 & 0 & 1.40080 & 66.720 & 0.2 \\
\hline 93 & 13 & 9 & 7 & 1.39380 & 67.100 & 0.1 \\
\hline 94 & 14 & 10 & 2 & 1.39150 & 67.225 & 0.1 \\
\hline 95 & 12 & 12 & 4 & 1.38230 & 67.733 & 0.1 \\
\hline 96 & 15 & 9 & 1 & 1.37550 & 68.114 & 0.1 \\
\hline 97 & 16 & 6 & 4 & 1.37330 & 68.238 & 0.1 \\
\hline 98 & 14 & 10 & 4 & 1.36440 & 68.745 & 0.1 \\
\hline 99 & 17 & 5 & 1 & 1.35790 & 69.121 & 0.1 \\
\hline 100 & 16 & 8 & 0 & 1.34730 & 69.743 & 0.1 \\
\hline 101 & 15 & 7 & 7 & 1.34100 & 70.118 & 0.1 \\
\hline 102 & 16 & 8 & 2 & 1.33890 & 70.245 & 0.1 \\
\hline 103 & 18 & 2 & 0 & 1.33080 & 70.736 & 0.5 \\
\hline 104 & 13 & 9 & 9 & 1.32470 & 71.111 & 0.1 \\
\hline 105 & 18 & 2 & 2 & 1.32270 & 71.235 & 0.1 \\
\hline 106 & 16 & 8 & 4 & 1.31480 & 71.729 & 0.1 \\
\hline 107 & 17 & 5 & 5 & 1.30900 & 72.096 & 0.4 \\
\hline 108 & 14 & 12 & 2 & 1.29940 & 72.714 & 0.3 \\
\hline 109 & 13 & 13 & 3 & 1.29380 & 73.079 & 0.1 \\
\hline 110 & 12 & 12 & 8 & 1.28460 & 73.689 & 0.1 \\
\hline 111 & 15 & 11 & 3 & 1.27920 & 74.051 & 0.1 \\
\hline 112 & 16 & 10 & 2 & 1.27020 & 74.665 & 0.1 \\
\hline 113 & 17 & 7 & 5 & 1.26500 & 75.025 & 0.4 \\
\hline 114 & 15 & 11 & 5 & 1.25130 & 75.991 & 0.1 \\
\hline 115 & 18 & 6 & 4 & 1.24290 & 76.597 & 0.1 \\
\hline 116 & 17 & 9 & 3 & 1.23800 & 76.956 & 0.2 \\
\hline 117 & 16 & 8 & 8 & 1.22990 & 77.557 & 0.2 \\
\hline 118 & 17 & 7 & 7 & 1.22510 & 77.918 & 0.1 \\
\hline 119 & 12 & 12 & 10 & 1.22350 & 78.039 & 0.1 \\
\hline 120 & 14 & 14 & 0 & 1.21730 & 78.513 & 0.1 \\
\hline
\end{tabular}




\begin{tabular}{lrrrrrr}
\hline 121 & 19 & 5 & 3 & 1.21260 & 78.877 & 0.3 \\
122 & 16 & 12 & 0 & 1.20500 & 79.472 & 0.1 \\
123 & 14 & 12 & 8 & 1.19910 & 79.942 & 0.1 \\
124 & 20 & 2 & 2 & 1.19320 & 80.418 & 0.1 \\
125 & 13 & 11 & 11 & 1.18880 & 80.777 & 0.1 \\
126 & 20 & 4 & 0 & 1.18160 & 81.372 & 0.1
\end{tabular}

\section{Stick Pattern}

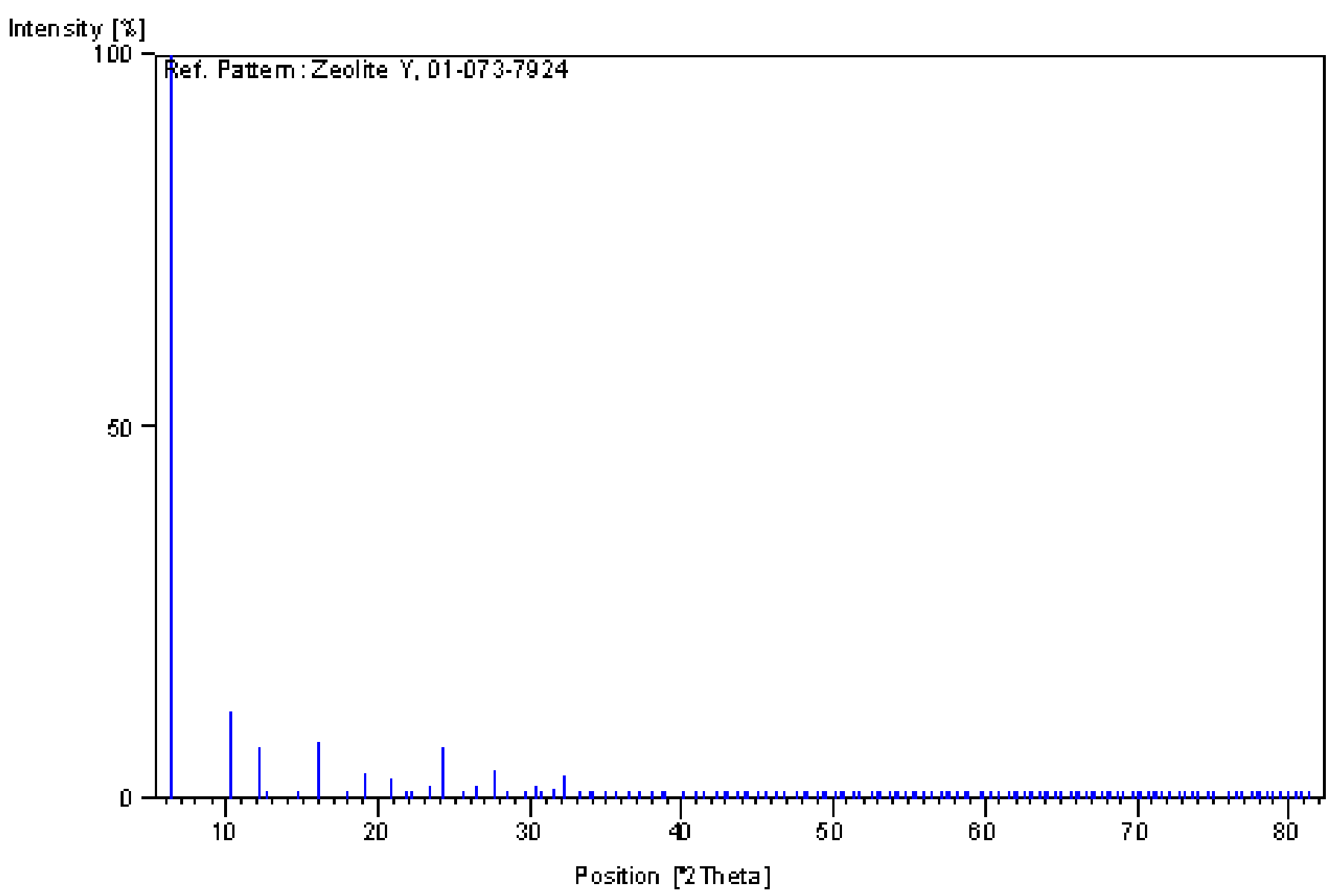




\section{Name and formula}

$\begin{array}{ll}\text { Reference code: } & 00-009-0414 \\ \text { Mineral name: } & \text { Ettringite, syn } \\ \text { PDF index name: } & \text { Calcium Aluminum Sulfate Hydroxide Hydrate } \\ \text { Empirical formula: } & \mathrm{Al}_{2} \mathrm{Ca}_{6} \mathrm{H}_{62} \mathrm{O}_{49} \mathrm{~S}_{3} \\ \text { Chemical formula: } & \mathrm{Ca}_{6} \mathrm{Al}_{2}\left(\mathrm{SO}_{4}\right)_{3}(\mathrm{OH})_{12}{ }_{25} \mathrm{H}_{2} \mathrm{O}\end{array}$

\section{Crystallographic parameters}

Crystal system:

Space group:

Space group number:

a $(A):$
b $(A):$
c $(A):$

Alpha (\%):

Beta ():

Gamma ():

Calculated density ( $\left.\mathrm{g} / \mathrm{cm}^{\wedge} 3\right)$ :

Measured density $\left(\mathrm{g} / \mathrm{cm}^{\wedge} 3\right)$ :

Volume of cell $\left(10^{\wedge} 6 \mathrm{pm}^{\wedge} 3\right)$ :

Z:

RIR:

\section{Hexagonal \\ $\mathrm{P} 63 / \mathrm{mmc}$ \\ 194}

11.2300

11.2300

21.4400

90.0000

90.0000

120.0000
1.75
1.77
2.00

2341.61

\section{Status, subfiles and quality}

Status:

Subfiles:

Quality:

\section{Comments}

Deleted by:

Color:

Sample source:

Sample preparation:

Analysis:

Unit cell data source:

Temperature:

\section{$\underline{\text { References }}$}

Primary reference:

Optical data:
Marked as deleted by ICDD

Inorganic

Mineral

NBS pattern

Indexed ()

\section{Peak list}

Deleted by 00-037-1476 and 00-041-1451.

Colorless, white.

Optical data specimen from Franklin. New Jersey, USA.

Sample prepared by the National Bureau of Standards.

Spectrographic analysis showed $0.1-1.0 \% \mathrm{Si}, \mathrm{Sr} ; 0.01-0.1 \% \mathrm{Ag}, \mathrm{Cr}, \mathrm{Cu}, \mathrm{Mg}, \mathrm{Na}, \mathrm{Pb}$; $0.001 \%-0.01 \%$ B, Ba, Cs, Fe, Mn, Ni, Sn, Zn, Zr.

Powder Diffraction.

Pattern taken at $298 \mathrm{~K}$.

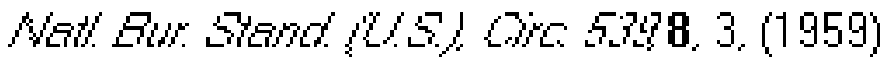

Hurlbut, Baum., Am Minera/ 45, 1137, (1960) 


\begin{tabular}{|c|c|c|c|c|c|c|}
\hline No. & $\mathrm{h}$ & $k$ & 1 & $\mathrm{~d} \quad \mathrm{i}]$ & 2 Theta [ deg] & I $\left[\frac{\hat{s}}{s}\right]$ \\
\hline 1 & 1 & 0 & 0 & 9.73000 & 9.081 & 100.0 \\
\hline 2 & 1 & 0 & 1 & 8.86000 & 9.975 & 14.0 \\
\hline 3 & 1 & 1 & 0 & 5.61000 & 15.784 & 80.0 \\
\hline 4 & 1 & 1 & 2 & 4.98000 & 17.796 & 25.0 \\
\hline 5 & 2 & 0 & 0 & 4.86000 & 18.239 & 8.0 \\
\hline 6 & 1 & 0 & 4 & 4.69000 & 18.907 & 35.0 \\
\hline 7 & 2 & 0 & 2 & 4.41000 & 20.119 & 4.0 \\
\hline 8 & 2 & 0 & 3 & 4.02000 & 22.094 & 2.0 \\
\hline 9 & 1 & 1 & 4 & 3.88000 & 22.902 & 50.0 \\
\hline 10 & 2 & 1 & 0 & 3.67000 & 24.232 & 8.0 \\
\hline 11 & 2 & 0 & 4 & 3.60000 & 24.710 & 16.0 \\
\hline 12 & 2 & 1 & 2 & 3.48000 & 25.577 & 30.0 \\
\hline 13 & 2 & 1 & 3 & 3.27000 & 27.250 & 6.0 \\
\hline 14 & 3 & 0 & 0 & 3.24000 & 27.507 & 20.0 \\
\hline 15 & 1 & 1 & 6 & 3.01600 & 29.595 & 8.0 \\
\hline 16 & 2 & 2 & 0 & 2.80600 & 31.867 & 8.0 \\
\hline 17 & 3 & 0 & 4 & 2.77300 & 32.256 & 40.0 \\
\hline 18 & 2 & 2 & 2 & 2.71400 & 32.977 & 8.0 \\
\hline 19 & 3 & 1 & 0 & 2.69700 & 33.191 & 14.0 \\
\hline 20 & 0 & 0 & 8 & 2.68000 & 33.408 & 8.0 \\
\hline 21 & 3 & 1 & 2 & 2.61600 & 34.250 & 20.0 \\
\hline 22 & 2 & 1 & 6 & 2.56400 & 34.967 & 45.0 \\
\hline 23 & 3 & 1 & 3 & 2.52400 & 35.539 & 6.0 \\
\hline 24 & 2 & 2 & 4 & 2.48700 & 36.086 & 4.0 \\
\hline 25 & 4 & 0 & 0 & 2.43400 & 36.900 & 4.0 \\
\hline 26 & 1 & 1 & 8 & 2.42200 & 37.089 & 4.0 \\
\hline 27 & 3 & 0 & 6 & 2.40100 & 37.426 & 12.0 \\
\hline 28 & 2 & 0 & 8 & 2.34700 & 38.320 & 6.0 \\
\hline 29 & 3 & 2 & 0 & 2.23000 & 40.416 & 20.0 \\
\hline 30 & 2 & 2 & 6 & 2.20900 & 40.817 & 45.0 \\
\hline 31 & 3 & 2 & 2 & 2.18500 & 41.286 & 10.0 \\
\hline 32 & 3 & 1 & 6 & 2.15400 & 41.907 & 25.0 \\
\hline 33 & 3 & 2 & 3 & 2.13000 & 42.402 & 4.0 \\
\hline 34 & 4 & 1 & 0 & 2.12400 & 42.528 & 6.0 \\
\hline 35 & 4 & 1 & 2 & 2.08100 & 43.451 & 6.0 \\
\hline 36 & 3 & 2 & 4 & 2.06200 & 43.872 & 6.0 \\
\hline 37 & 4 & 1 & 3 & 2.03300 & 44.531 & 2.0 \\
\hline 38 & 3 & 1 & 7 & 2.02700 & 44.670 & 2.0 \\
\hline 39 & 3 & 2 & 5 & 1.97900 & 45.814 & 4.0 \\
\hline 40 & 4 & 1 & 4 & 1.97500 & 45.912 & 3.0 \\
\hline 41 & 5 & 0 & 0 & 1.94600 & 46.636 & 30.0 \\
\hline 42 & 4 & 0 & 7 & 1.90500 & 47.702 & 30.0 \\
\hline 43 & 5 & 0 & 3 & 1.87500 & 48.514 & 30.0 \\
\hline 44 & 2 & 1 & 10 & 1.85300 & 49.127 & 40.0 \\
\hline 4.5 & 3 & 3 & 2 & 1.84500 & 49.355 & 40.0 \\
\hline 46 & 4 & 2 & 2 & 1.81200 & 50.315 & 10.0 \\
\hline 47 & 2 & 0 & 11 & 1.80900 & 50.405 & 10.0 \\
\hline 48 & 3 & 3 & 4 & 1.76800 & 51.658 & 40.0 \\
\hline
\end{tabular}

\section{Stick Pattern}




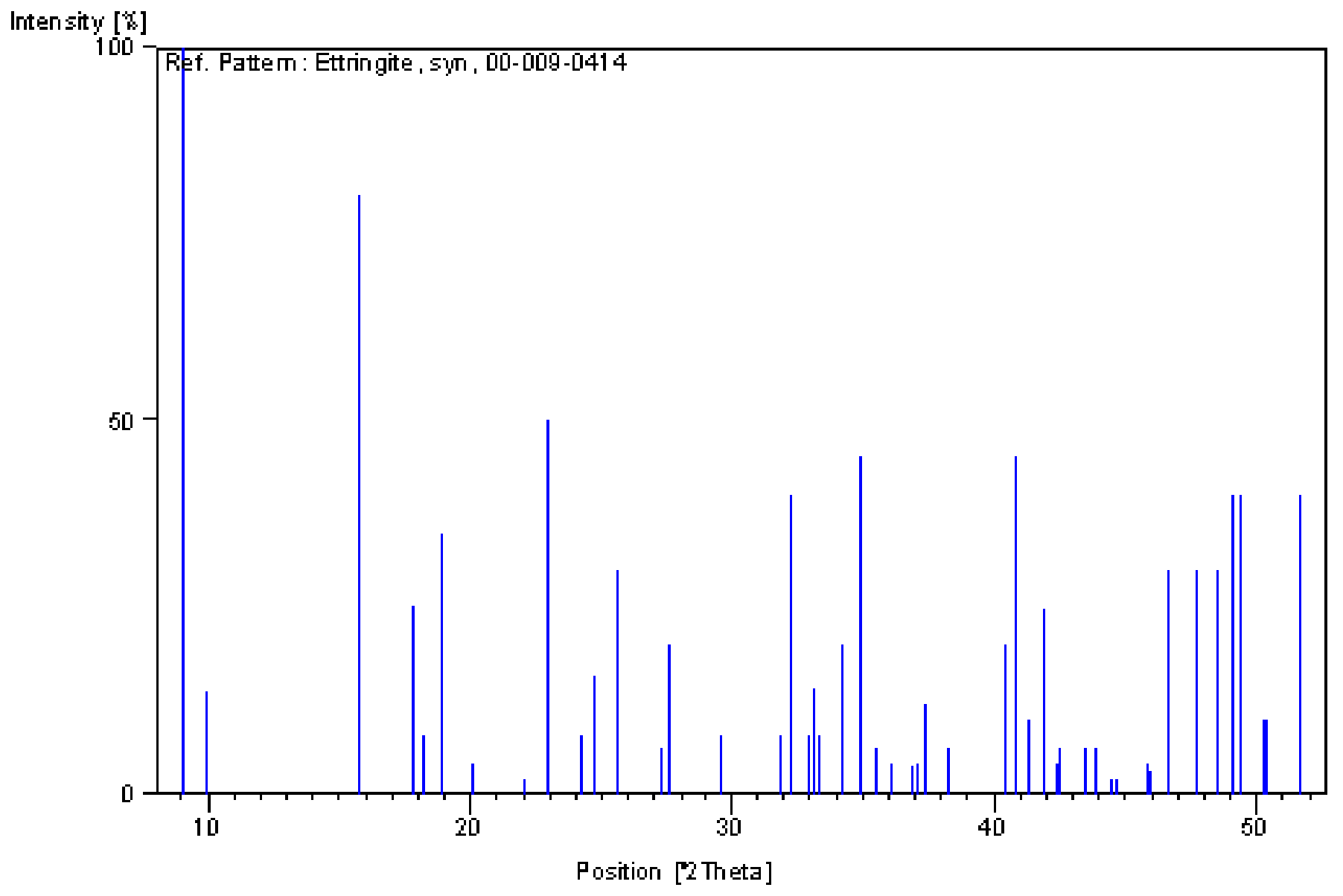




\section{Name and formula}

Reference code: $\quad$ 00-002-0059

$\begin{array}{ll}\text { Mineral name: } & \text { Ettringite } \\ \text { PDF index name: } & \text { Aluminum Calcium Sulfate Hydroxide Hydrate }\end{array}$

Empirical formula: $\quad \quad \mathrm{Al}_{2} \mathrm{Ca}_{6} \mathrm{H}_{64} \mathrm{O}_{50} \mathrm{~S}_{3}$

Chemical formula: $\quad \mathrm{Ca}_{6} \mathrm{Al}_{2}\left(\mathrm{SO}_{4}\right)_{3}(\mathrm{OH})_{12}{ }_{26} \mathrm{H}_{2} \mathrm{O}$

\section{Crystallographic parameters}

Crystal system: Unknown

RIR:

\section{Status, subfiles and quality}

Status:

Subfiles:

Marked as deleted by ICDD

Inorganic

Mineral

Quality:

Doubttul (O)

\section{Comments}

Deleted by:

Color:

Structure:

\section{$\underline{\text { References }}$}

Primary reference:

Optical data:
Deleted: NBS card Set 9. Deleted by 00-031-0251 and 00-041-1451.

White.

Reference reports hexagonal.

LY/mperal Chemical/holutries

Elements at optical hineralogl.

\section{Peak list}

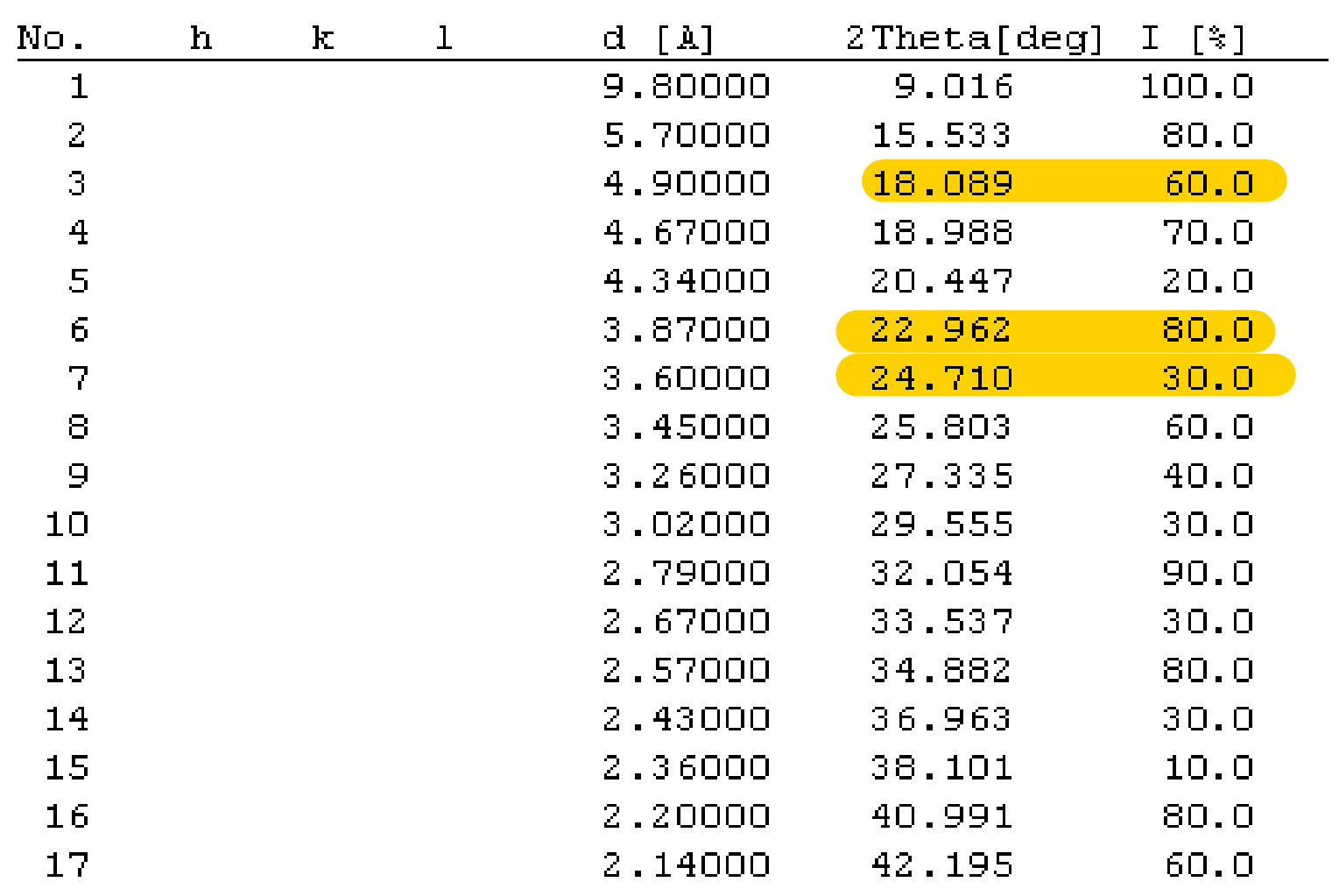




\begin{tabular}{llll}
\hline 18 & 2.06000 & 43.917 & 30.0 \\
19 & 1.94000 & 46.789 & 30.0 \\
20 & 1.89000 & 48.104 & 20.0 \\
21 & 1.84000 & 49.498 & 40.0 \\
22 & 1.80000 & 50.674 & 10.0 \\
23 & 1.75000 & 52.230 & 40.0 \\
24 & 1.70000 & 53.888 & 40.0 \\
25 & 1.66000 & 55.296 & 60.0 \\
26 & 1.62000 & 56.783 & 20.0 \\
27 & 1.57000 & 58.765 & 40.0 \\
28 & 1.54000 & 60.026 & 20.0 \\
29 & 1.50000 & 61.799 & 40.0 \\
30 & 1.45000 & 64.179 & 30.0 \\
31 & 1.34000 & 70.178 & 30.0 \\
32 & 1.30000 & 72.675 & 30.0
\end{tabular}

\section{Stick Pattern}

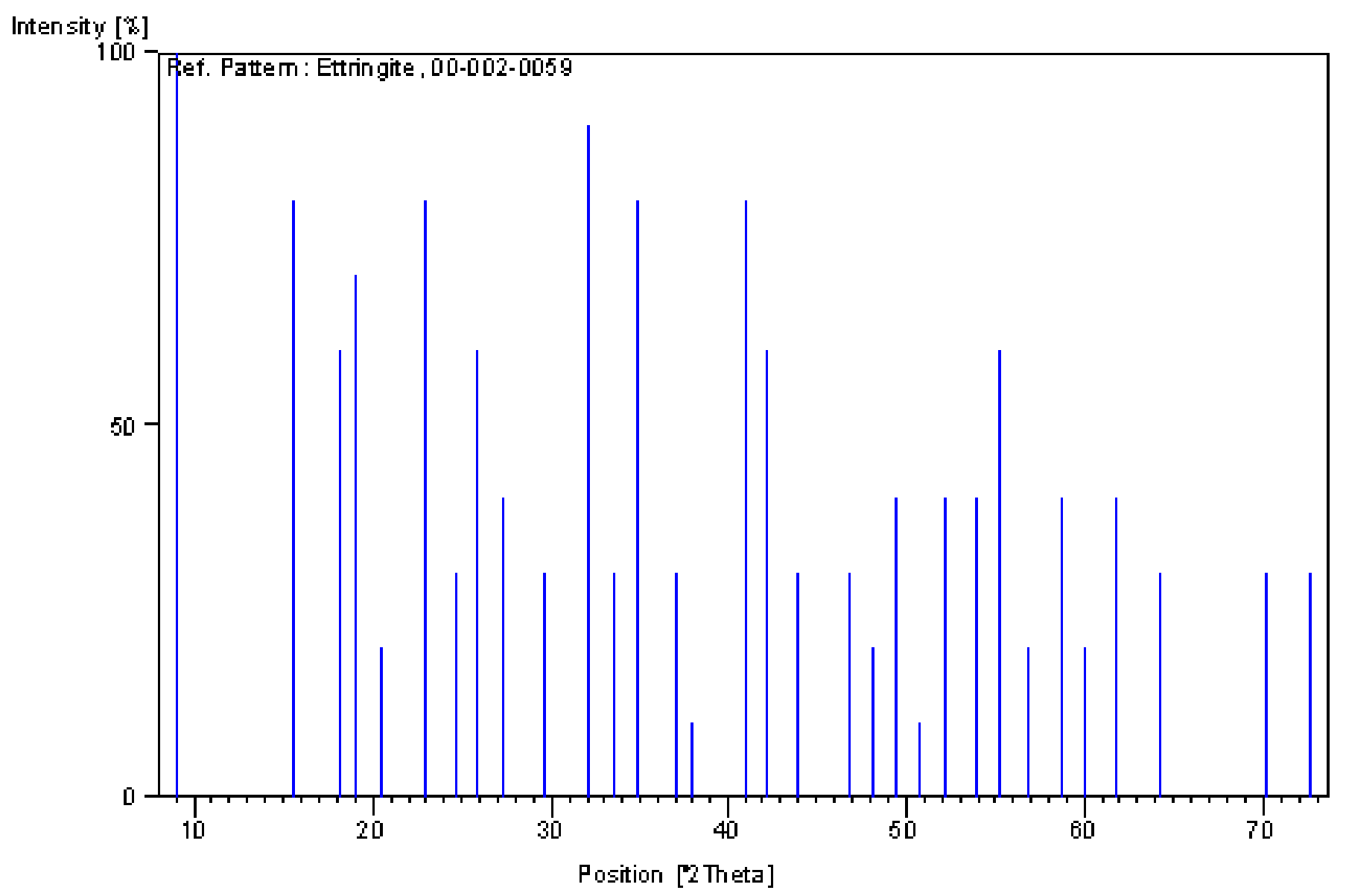




\section{Name and formula}

Reference code: 01-075-3909

PDF index name: Silicon Oxide

Empirical formula: $\quad \mathrm{O}_{2} \mathrm{Si}$

Chemical formula: $\quad \mathrm{SiO}_{2}$

\section{Crystallographic parameters}

Crystal system:

Space group:

Space group number:

$a(A)$ :

$b(A)$ :

$c(\hat{A})$ :

Alpha ():

Beta (\%):

Gamma ():

Volume of cell $\left(10^{\wedge} 6 \mathrm{pm}^{\wedge} 3\right)$ :

Z:

RIR:

\section{Subfiles and Quality}

Subfiles:

Quality:

\section{Comments}

ANX:

Wyckoff Sequence:

Analysis:

Unit cell data source:

ICSD collection code:
Orthorhombic

Pmmm

47

$$
\begin{array}{r}
20.5700 \\
9.7390 \\
20.4600 \\
90.0000 \\
90.0000 \\
90.0000
\end{array}
$$

4098.78

64.00

5.17

Inorganic

Alloy, metal or intermetalic

ICSD Pattern

Hypothetical $(\mathrm{H})$

$\mathrm{A} \times 2$.

A16 z $\times 10 w 2 v \operatorname{trlk}($ PMMM).

$\mathrm{O} 2 \mathrm{Si1}$. Formula from original source: $\mathrm{Si} \mathrm{O}$.

Single Crystal.

171742. Hypothetical Structure: Structure calculated theoretically. Minor Warning: No e.s.d reported/abstracted on the cell dimension.

\section{References}

Primary reference:

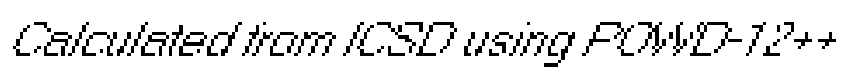

Structure:

Wojdel, J.C. Zwijnenburg, M.A. Bromley, S.T., Chem, Mater, 18, 1464, (2006)

\section{$\underline{\text { Peak list }}$}

\begin{tabular}{rrrrrcr} 
No. & $\mathrm{h}$ & $\mathrm{k}$ & $\mathrm{l}$ & $\mathrm{d}[\mathrm{A}]$ & 2 Theta[deg] & $\mathrm{I}[\stackrel{s}{*}]$ \\
\hline 1 & 0 & 0 & 1 & 20.46000 & 4.315 & 4.0 \\
2 & 1 & 0 & 1 & 14.50610 & 6.088 & 100.0 \\
3 & 0 & 0 & 2 & 10.23000 & 8.637 & 0.9 \\
4 & 0 & 1 & 0 & 9.73900 & 9.073 & 75.8
\end{tabular}




\begin{tabular}{|c|c|c|c|c|c|c|}
\hline 5 & 1 & 0 & 2 & 9.15980 & 9.648 & 1.3 \\
\hline 6 & 1 & 1 & 1 & 8.08570 & 10.933 & 13.9 \\
\hline 7 & 2 & 0 & 2 & 7.25310 & 12.193 & 10.3 \\
\hline 8 & 0 & 1 & 2 & 7.05370 & 12.539 & 12.5 \\
\hline 9 & 3 & 0 & 0 & 6.85670 & 12.901 & 0.2 \\
\hline 10 & 2 & 1 & 1 & 6.67230 & 13.259 & 0.8 \\
\hline 11 & 3 & 0 & 1 & 6.47350 & 13.668 & 4.5 \\
\hline 12 & 2 & 1 & 2 & 5.81710 & 15.219 & 11.1 \\
\hline 13 & 3 & 0 & 2 & 5.69560 & 15.546 & 0.7 \\
\hline 14 & 3 & 1 & 0 & 5.60650 & 15.794 & 1.4 \\
\hline 15 & 3 & 1 & 1 & 5.39120 & 16.429 & 0.1 \\
\hline 16 & 4 & 0 & 0 & 5.14250 & 17.230 & 8.1 \\
\hline 17 & 0 & 0 & 4 & 5.11500 & 17.323 & 9.0 \\
\hline 18 & 4 & 0 & 1 & 4.98740 & 17.770 & 0.3 \\
\hline 19 & 1 & 0 & 4 & 4.96380 & 17.855 & 0.3 \\
\hline 20 & 2 & 1 & 3 & 4.90900 & 18.056 & 0.2 \\
\hline 21 & 3 & 0 & 3 & 4.83540 & 18.333 & 1.8 \\
\hline 22 & 1 & 2 & 1 & 4.61640 & 19.211 & 8.4 \\
\hline 23 & 4 & 1 & 0 & 4.54750 & 19.505 & 0.8 \\
\hline 24 & 0 & 1 & 4 & 4.52840 & 19.588 & 0.8 \\
\hline 25 & 4 & 1 & 1 & 4.43920 & 19.985 & 0.3 \\
\hline 26 & 1 & 1 & 4 & 4.42250 & 20.062 & 0.4 \\
\hline 27 & 3 & 1 & 3 & 4.33100 & 20.490 & 2.2 \\
\hline 28 & 4 & 1 & 2 & 4.14450 & 21.423 & 4.1 \\
\hline 29 & 5 & 0 & 1 & 4.03330 & 22.021 & 1.1 \\
\hline 30 & 1 & 0 & 5 & 4.01340 & 22.131 & 0.8 \\
\hline 31 & 3 & 2 & 0 & 3.97020 & 22.375 & 0.1 \\
\hline 32 & 1 & 2 & 3 & 3.89140 & 22.834 & 3.0 \\
\hline 33 & 5 & 0 & 2 & 3.81690 & 23.286 & 0.2 \\
\hline 34 & 2 & 0 & 5 & 3.80210 & 23.378 & 0.2 \\
\hline 35 & 4 & 1 & 3 & 3.78970 & 23.455 & 0.2 \\
\hline 36 & 3 & 1 & 4 & 3.77250 & 23.564 & 0.2 \\
\hline 37 & 5 & 1 & 1 & 3.72640 & 23.860 & 1.0 \\
\hline 38 & 1 & 1 & 5 & 3.71060 & 23.963 & 1.2 \\
\hline 39 & 4 & 0 & 4 & 3.62650 & 24.527 & 0.1 \\
\hline 40 & 5 & 1 & 2 & 3.55370 & 25.038 & 0.1 \\
\hline 41 & 2 & 1 & 5 & 3.54180 & 25.123 & 0.1 \\
\hline 42 & 3 & 2 & 3 & 3.42830 & 25.969 & 1.3 \\
\hline 43 & 0 & 0 & 6 & 3.41000 & 26.111 & 1.4 \\
\hline 44 & 4 & 1 & 4 & 3.39860 & 26.200 & 1.3 \\
\hline 45 & 1 & 0 & 6 & 3.36410 & 26.474 & 0.2 \\
\hline 46 & 4 & 2 & 2 & 3.33620 & 26.699 & 0.2 \\
\hline 47 & 3 & 1 & 5 & 3.31270 & 26.892 & 0.4 \\
\hline 48 & 6 & 0 & 2 & 3.25060 & 27.416 & 1.7 \\
\hline 49 & 2 & 0 & 6 & 3.23670 & 27.536 & 2.0 \\
\hline 50 & 6 & 1 & 1 & 3.19420 & 27.910 & 0.1 \\
\hline 51 & 1 & 1 & 6 & 3.17970 & 28.039 & 0.1 \\
\hline 52 & 2 & 3 & 0 & 3.09430 & 28.830 & 3.8 \\
\hline 53 & 6 & 1 & 2 & 3.08340 & 28.934 & 4.0 \\
\hline 54 & 2 & 1 & 6 & 3.07150 & 29.048 & 3.5 \\
\hline 5.5 & 5 & 2 & 2 & 3.00400 & 29.716 & 0.1 \\
\hline 56 & 2 & 2 & 5 & 2.99680 & 29.789 & 0.1 \\
\hline 57 & 3 & 3 & 0 & 2.93120 & 30.472 & 0.7 \\
\hline 58 & 0 & 0 & 7 & 2.92200 & 30.570 & 0.7 \\
\hline 59 & 1 & 3 & 3 & 2.90440 & 30.760 & 2.1 \\
\hline 60 & 3 & 2 & 5 & 2.84940 & 31.369 & 0.2 \\
\hline 61 & 7 & 1 & 0 & 2.81330 & 31.782 & 0.2 \\
\hline 62 & 6 & 2 & 0 & 2.79950 & 31.943 & 0.3 \\
\hline 63 & 0 & 2 & 6 & 2.79320 & 32.017 & 0.3 \\
\hline 64 & 5 & 1 & 5 & 2.78050 & 32.167 & 0.7 \\
\hline
\end{tabular}




\begin{tabular}{|c|c|c|c|c|c|c|}
\hline 6.5 & 1 & 1 & 7 & 2.77390 & 32.245 & 0.5 \\
\hline 66 & 6 & 1 & 4 & 2.73340 & 32.737 & 0.6 \\
\hline 67 & 4 & 1 & 6 & 2.72820 & 32.801 & 0.7 \\
\hline 68 & 4 & 3 & 1 & 2.71690 & 32.941 & 0.5 \\
\hline 69 & 7 & 0 & 3 & 2.69520 & 33.214 & 1.0 \\
\hline 70 & 3 & 0 & 7 & 2.68880 & 33.295 & 0.9 \\
\hline 71 & 4 & 3 & 2 & 2.64850 & 33.817 & 2.8 \\
\hline 72 & 8 & 0 & 0 & 2.57120 & 34.866 & 1.0 \\
\hline 73 & 0 & 0 & 8 & 2.55750 & 35.058 & 0.9 \\
\hline 74 & 7 & 0 & 4 & 2.54800 & 35.193 & 0.6 \\
\hline 75 & 5 & 3 & 1 & 2.52890 & 35.468 & 0.8 \\
\hline 76 & 1 & 3 & 5 & 2.52400 & 35.539 & 0.8 \\
\hline 77 & 0 & 2 & 7 & 2.50610 & 35.802 & 0.1 \\
\hline 78 & 2 & 0 & 8 & 2.48610 & 36.100 & 0.5 \\
\hline 79 & 0 & 1 & 8 & 2.47360 & 36.288 & 0.4 \\
\hline 80 & 8 & 1 & 1 & 2.46790 & 36.375 & 0.4 \\
\hline 81 & 6 & 2 & 4 & 2.45590 & 36.559 & 0.2 \\
\hline 82 & 7 & 2 & 2 & 2.44320 & 36.756 & 0.1 \\
\hline 83 & 2 & 2 & 7 & 2.43480 & 36.887 & 0.1 \\
\hline 84 & 4 & 3 & 4 & 2.41880 & 37.140 & 0.7 \\
\hline 85 & 8 & 0 & 3 & 2.40590 & 37.347 & 0.2 \\
\hline 86 & 1 & 4 & 1 & 2.40120 & 37.422 & 0.2 \\
\hline 87 & 3 & 0 & 8 & 2.39620 & 37.503 & 0.2 \\
\hline 88 & 7 & 0 & 5 & 2.38690 & 37.655 & 0.1 \\
\hline 89 & 5 & 0 & 7 & 2.38270 & 37.724 & 0.1 \\
\hline 90 & 0 & 4 & 2 & 2.36860 & 37.957 & 0.6 \\
\hline 91 & 7 & 2 & 3 & 2.36040 & 38.094 & 0.4 \\
\hline 92 & 3 & 2 & 7 & 2.35380 & 38.205 & 0.3 \\
\hline 93 & 6 & 1 & 6 & 2.34650 & 38.328 & 0.5 \\
\hline 94 & 6 & 3 & 1 & 2.34170 & 38.410 & 0.3 \\
\hline 95 & 7 & 1 & 5 & 2.31830 & 38.813 & 0.1 \\
\hline 96 & 5 & 2 & 6 & 2.30820 & 38.990 & 0.1 \\
\hline 97 & 3 & 4 & 0 & 2.29730 & 39.182 & 0.4 \\
\hline 98 & 2 & 3 & 6 & 2.28990 & 39.314 & 0.5 \\
\hline 99 & 3 & 4 & 1 & 2.28010 & 39.490 & 0.6 \\
\hline 100 & 0 & 0 & 9 & 2.27330 & 39.613 & 0.4 \\
\hline 101 & 8 & 2 & 1 & 2.25980 & 39.860 & 0.1 \\
\hline 102 & 4 & 2 & 7 & 2.25060 & 40.030 & 0.1 \\
\hline 103 & 6 & 3 & 3 & 2.22790 & 40.455 & 0.4 \\
\hline 104 & 2 & 0 & 9 & 2.21980 & 40.609 & 0.3 \\
\hline 105 & 9 & 1 & 1 & 2.21210 & 40.757 & 0.1 \\
\hline 106 & 1 & 1 & 9 & 2.20110 & 40.970 & 0.1 \\
\hline 107 & 4 & 4 & 1 & 2.18800 & 41.226 & 0.1 \\
\hline 108 & 3 & 4 & 3 & 2.17460 & 41.492 & 0.3 \\
\hline 109 & 7 & 1 & 6 & 2.16840 & 41.616 & 0.4 \\
\hline 110 & 2 & 1 & 9 & 2.16320 & 41.721 & 0.6 \\
\hline 111 & 3 & 0 & 9 & 2.15780 & 41.830 & 0.4 \\
\hline 112 & 3 & 2 & 8 & 2.14980 & 41.993 & 1.1 \\
\hline 113 & 7 & 2 & 5 & 2.14320 & 42.129 & 0.7 \\
\hline 114 & 6 & 3 & 4 & 2.14080 & 42.178 & 0.6 \\
\hline 115 & 8 & 1 & 5 & 2.12470 & 42.513 & 0.3 \\
\hline 116 & 5 & 1 & 8 & 2.11990 & 42.614 & 0.2 \\
\hline 117 & 3 & 4 & 4 & 2.09240 & 43.202 & 0.1 \\
\hline 118 & 9 & 0 & 4 & 2.08670 & 43.326 & 0.3 \\
\hline 119 & 4 & 0 & 9 & 2.07920 & 43.490 & 0.3 \\
\hline 120 & 7 & 0 & 7 & 2.07230 & 43.643 & 0.4 \\
\hline 121 & 9 & 2 & 1 & 2.05700 & 43.984 & 0.7 \\
\hline 122 & 2 & 4 & 5 & 2.05040 & 44.133 & 0.5 \\
\hline 123 & 10 & 0 & 1 & 2.04600 & 44.233 & 1.0 \\
\hline 124 & 5 & 3 & 6 & 2.04040 & 44.361 & 0.6 \\
\hline
\end{tabular}




$\begin{array}{lllllll}125 & 1 & 0 & 10 & 2.03600 & 44.462 & 0.3\end{array}$

\section{Stick Pattern}

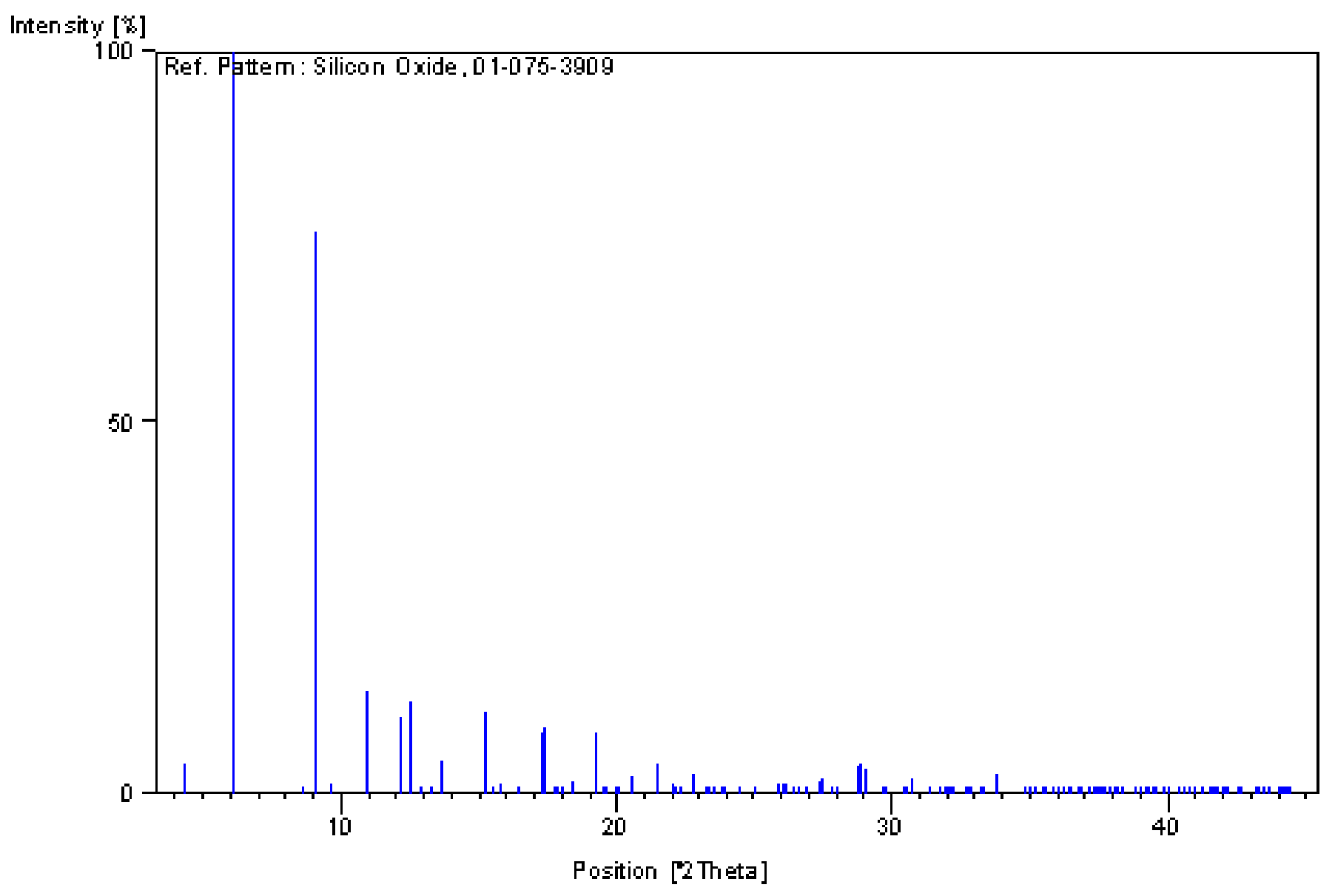




\section{Name and formula}

$\begin{array}{ll}\text { Reference code: } & 00-004-0733 \\ \text { Mineral name: } & \text { Portlandite, syn } \\ \text { PDF index name: } & \text { Calcium Hydroxide } \\ \text { Empirical formula: } & \mathrm{CaH}_{2} \mathrm{O}_{2} \\ \text { Chemical formula: } & \mathrm{Ca}(\mathrm{OH})_{2}\end{array}$

\section{Crystallographic parameters}

Crystal system:

Space group:

Space group number:

a $(\mathrm{A})$ :

$b(A)$ :

$c(A)$ :

Alpha ("):

Beta ("):

Gamma ():

Calculated density $\left(\mathrm{g} / \mathrm{cm}^{\wedge} 3\right)$ :

Volume of cell $\left(10^{\wedge} 6 \mathrm{pm}^{\wedge} 3\right)$ :

Z:

RIR:

\section{Subfiles and Quality}

Subfiles:

Quality:

\section{Comments}

General comments:

Analysis:

CAS Number:

Unit cell data source:

Temperature:

\section{$\underline{\text { References }}$}

Primary reference:
Hexagonal

P-3m1

164

$$
\begin{array}{r}
3.5930 \\
3.5930 \\
4.9090 \\
90.0000 \\
90.0000 \\
120.0000
\end{array}
$$

$$
\begin{array}{r}
2.24 \\
54.88 \\
1.00
\end{array}
$$

1.40

Inorganic

Mineral

Cement and Hydration Product

Common Phase

Educational pattern

Forensic

NBS pattern

Pharmaceutical

Excipient

Indexed (l)
Levi, Giom, Chim. Ind. Applicata, $6333-7$ (1924). Astringent.

NBS analysis shows about $0.21 \% \mathrm{MgO}, 0.1 \% \mathrm{Ba}$ and no other impurities over $0.04 \%$. 1305-62-0.

Powder Diffraction.

Pattern taken at $300 \mathrm{~K}$.

\section{Peak list}

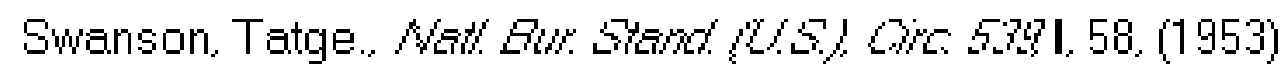




\begin{tabular}{|c|c|c|c|c|c|c|}
\hline No. & $\mathrm{h}$ & $k$ & 1 & $\mathrm{~d} \quad \mathrm{~A}]$ & 2 Theta [ deg] & I $\left[\frac{\hat{s}}{s}\right]$ \\
\hline 1 & 0 & 0 & 1 & 4.90000 & 18.089 & 74.0 \\
\hline 2 & 1 & 0 & 0 & 3.11200 & 28.662 & 23.0 \\
\hline 3 & 1 & 0 & 1 & 2.62800 & 34.089 & 100.0 \\
\hline 4 & 0 & 0 & 2 & 2.44700 & 36.697 & 3.0 \\
\hline 5 & 1 & 0 & 2 & 1.92700 & 47.124 & 42.0 \\
\hline 6 & 1 & 1 & 0 & 1.79600 & 50.795 & 36.0 \\
\hline 7 & 1 & 1 & 1 & 1.68700 & 54.337 & 21.0 \\
\hline 8 & 0 & 0 & 3 & 1.63400 & 56.253 & 1.0 \\
\hline 9 & 2 & 0 & 0 & 1.55700 & 59.304 & 3.0 \\
\hline 10 & 2 & 0 & 1 & 1.48400 & 62.540 & 13.0 \\
\hline 11 & 1 & 1 & 2 & 1.44900 & 64.228 & 13.0 \\
\hline 12 & 2 & 0 & 2 & 1.31400 & 71.779 & 8.0 \\
\hline 13 & 0 & 0 & 4 & 1.22800 & 77.699 & 1.0 \\
\hline 14 & 1 & 1 & 3 & 1.21100 & 79.001 & 1.0 \\
\hline 15 & 2 & 1 & 0 & 1.17620 & 81.825 & 3.0 \\
\hline 16 & 2 & 1 & 1 & 1.14320 & 84.724 & 11.0 \\
\hline 17 & 2 & 0 & 3 & 1.12750 & 86.187 & 2.0 \\
\hline 18 & 2 & 1 & 2 & 1.05990 & 93.232 & 12.0 \\
\hline 19 & 3 & 0 & 0 & 1.03660 & 95.993 & 5.0 \\
\hline 20 & 3 & 0 & 1 & 1.01430 & 98.830 & 7.0 \\
\hline 21 & 2 & 1 & 3 & 0.95510 & 107.513 & 4.0 \\
\hline 22 & 1 & 0 & 5 & 0.93690 & 110.607 & 1.0 \\
\hline 23 & 2 & 2 & 0 & 0.89790 & 118.161 & 1.0 \\
\hline 24 & 2 & 2 & 1 & 0.88380 & 121.285 & 2.0 \\
\hline 25 & 3 & 0 & 3 & 0.87600 & 123.125 & 1.0 \\
\hline 26 & 3 & 1 & 0 & 0.86230 & 126.584 & 2.0 \\
\hline 27 & 2 & 1 & 4 & 0.84950 & 130.125 & 6.0 \\
\hline 28 & 3 & 1 & 2 & 0.81400 & 142.281 & 5.0 \\
\hline
\end{tabular}

\section{Stick Pattern}

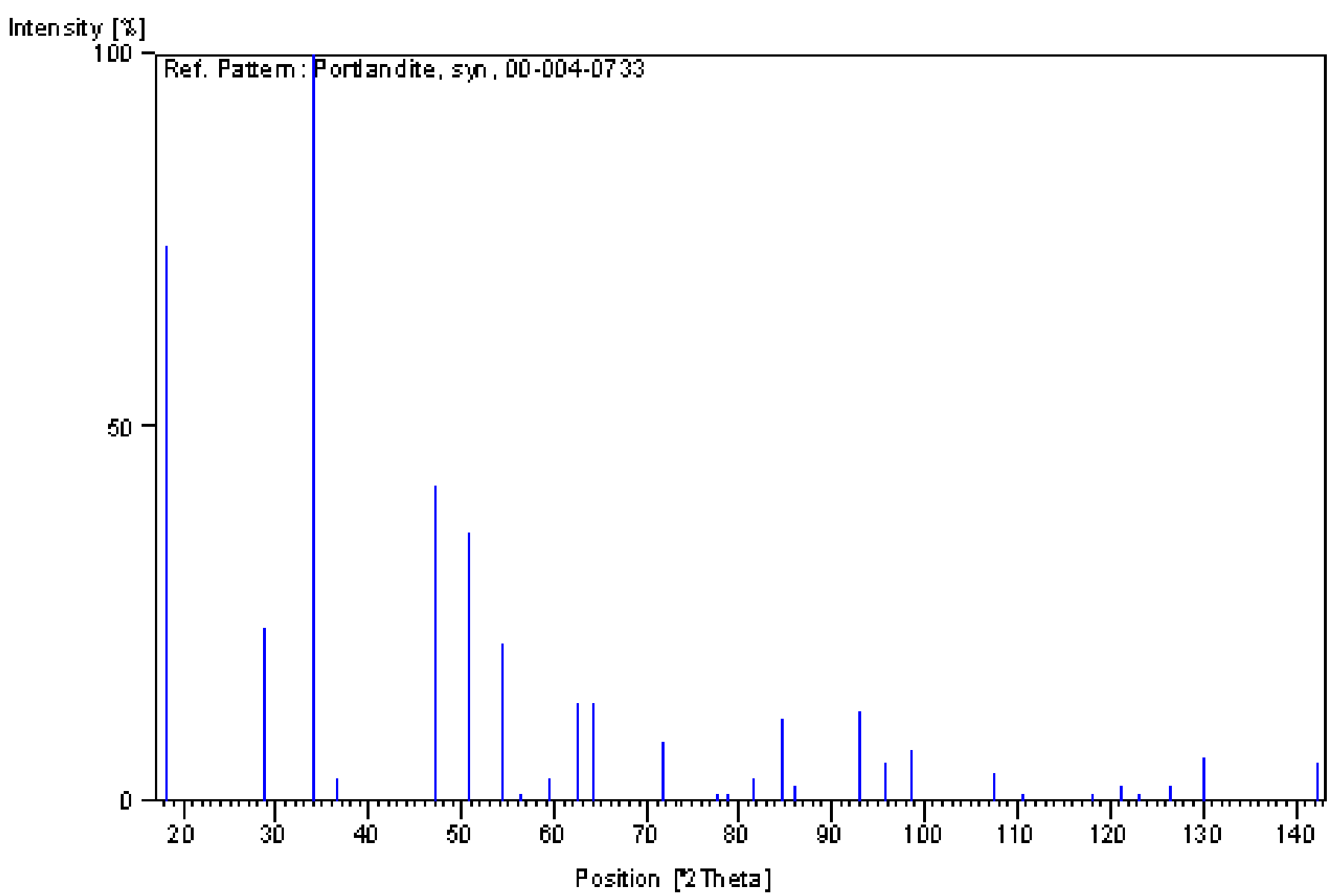




\section{Name and formula}

Reference code: $\quad$ 00-001-0338

Mineral name:

Hydrophilite, syn

PDF index name:

Calcium Chloride

Empirical formula:

$\mathrm{CaCl}_{2}$

Chemical formula:

$\mathrm{CaCl}_{2}$

\section{Crystallographic parameters}

Crystal system:

Space group:

Space group number:

a (A):

b (A):

$c(A)$ :

Alpha ():

Beta ():

Gamma ():

Volume of cell $\left(10^{\wedge} 6 \mathrm{pm}^{\wedge} 3\right)$ :

Z:

RIR:
Orthorhombic

Pnnm

58

169.45

2.00

Status. subfiles and quality

Status:

Subfiles:

Quality:

\section{Comments}

Deleted by:

CAS Number:

Unit cell data source:
Marked as deleted by ICDD

Inorganic

Mineral

Pharmaceutical

Blank (B)

\section{References}

Primary reference:

Hanawalt et al., $A / n \sigma / C / \% m, 10,475,(1938)$

\section{$\underline{\text { Peak list }}$}

\begin{tabular}{ccccccc} 
No. & $\mathrm{h}$ & $\mathrm{k}$ & $\mathrm{l}$ & $\mathrm{d}[\mathrm{A}]$ & 2 Theta[deg] & $\mathrm{I}[\stackrel{\circ}{8}]$ \\
\hline 1 & 1 & 1 & 0 & 4.49000 & 19.757 & 100.0 \\
2 & 1 & 0 & 1 & 3.46000 & 25.727 & 16.0 \\
3 & 1 & 1 & 1 & 3.05000 & 29.258 & 80.0 \\
4 & 1 & 2 & 0 & 2.85000 & 31.362 & 32.0 \\
5 & 2 & 1 & 1 & 2.33000 & 38.610 & 60.0 \\
6 & 2 & 2 & 0 & 2.24000 & 40.227 & 16.0
\end{tabular}




\begin{tabular}{rrrrrrr}
\hline 7 & 0 & 0 & 2 & 2.09000 & 43.254 & 16.0 \\
8 & 1 & 1 & 2 & 1.90000 & 47.835 & 36.0 \\
9 & 3 & 1 & 1 & 1.79000 & 50.978 & 8.0 \\
10 & 2 & 1 & 2 & 1.68000 & 54.582 & 12.0 \\
11 & 1 & 4 & 0 & 1.56000 & 59.179 & 4.0 \\
12 & 4 & 1 & 0 & 1.51000 & 61.345 & 8.0 \\
13 & 3 & 3 & 0 & 1.49000 & 62.260 & 4.0 \\
14 & 4 & 2 & 1 & 1.33000 & 70.785 & 12.0 \\
15 & 0 & 5 & 1 & 1.24000 & 76.809 & 12.0 \\
16 & 4 & 3 & 1 & 1.21000 & 79.079 & 12.0 \\
17 & 4 & 2 & 2 & 1.17000 & 82.352 & 4.0
\end{tabular}

\section{Stick Pattern}

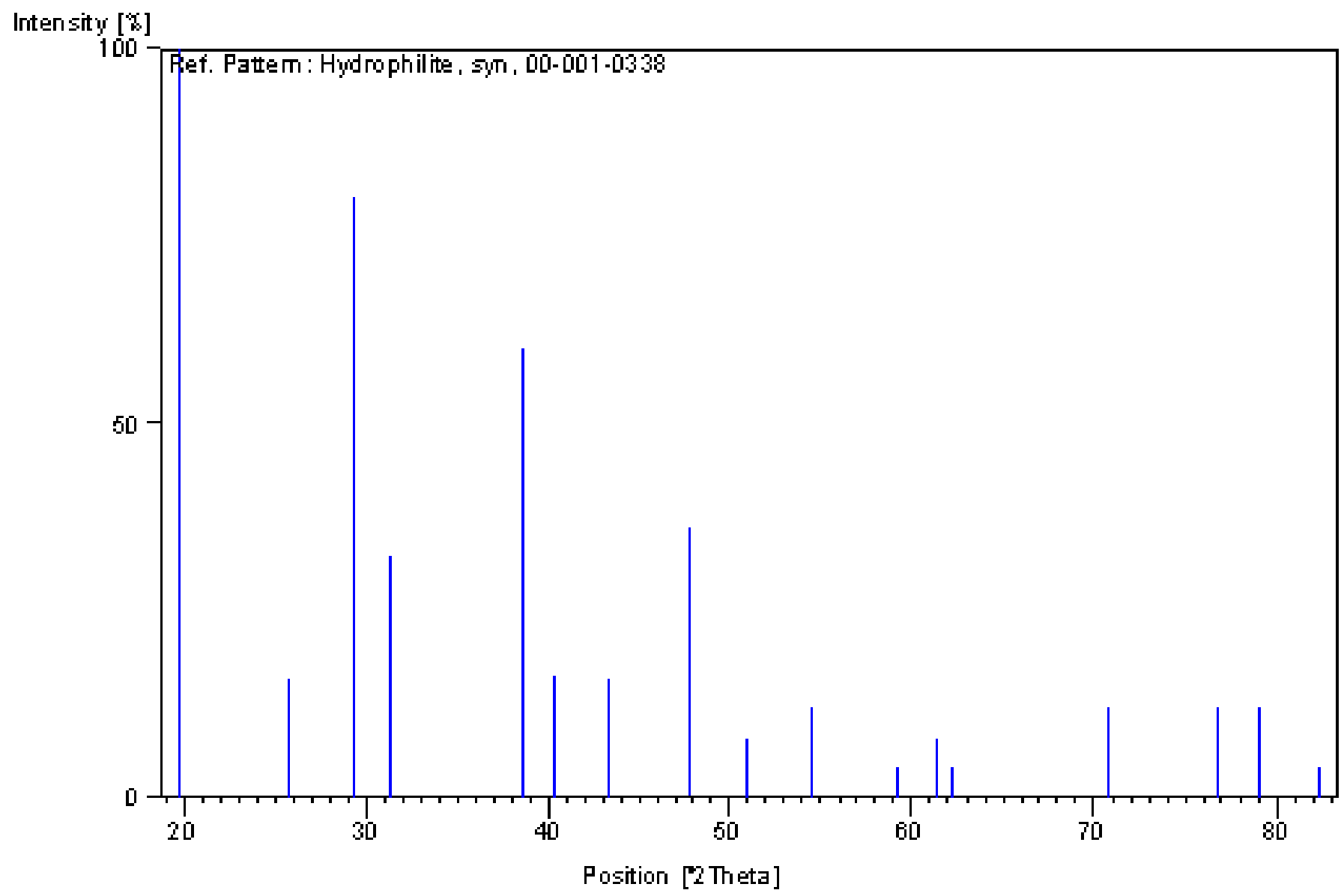




\section{Name and formula}

$\begin{array}{ll}\text { Reference code: } & 00-002-0061 \\ \text { Mineral name: } & \text { Thaumasite } \\ \text { PDF index name: } & \text { Calcium Carbonate Silicate Sulfate Hydrate } \\ \text { Empirical formula: } & \mathrm{CCa}_{3} \mathrm{H}_{30} \mathrm{O}_{25} \mathrm{SSi} \\ \text { Chemical formula: } & \mathrm{CaCO}_{3} \cdot \mathrm{CaSiO} \cdot \mathrm{CaSO}_{4} \cdot{ }_{15} \mathrm{H}_{2} \mathrm{O}\end{array}$

\section{Crystallographic parameters}

Crystal system:

a $(\hat{A}):$
b $(\hat{A}):$
c $(A):$

Alpha ():

Beta (\%):

Gamma (\%):

Measured density $\left(\mathrm{g} / \mathrm{cm}^{\wedge} 3\right)$ :

Volume of cell $\left(10^{\wedge} 6 \mathrm{pm}^{\wedge} 3\right)$ :

Z:

RIR:
Hexagonal

$$
\begin{array}{r}
10.9000 \\
10.9000 \\
10.2900 \\
90.0000 \\
90.0000 \\
120.0000 \\
1.87 \\
1058.76 \\
2.00
\end{array}
$$

\section{Status. subfiles and quality}

Status:

Subfiles:

Quality:

\section{Comments}

Deleted by:

Color:

General comments:

\section{$\underline{\text { References }}$}

Primary reference:

Optical data:

Unit cell:

\section{$\underline{\text { Peak list }}$}

\begin{tabular}{ccccccc} 
No. & $\mathrm{h}$ & $\mathrm{k}$ & $\mathrm{l}$ & $\mathrm{d}[\mathrm{A}]$ & 2 Theta[deg] & $\mathrm{I}[\hat{s}]$ \\
\hline 1 & 1 & 0 & 0 & 9.67000 & 9.138 & 100.0 \\
2 & 1 & 0 & 1 & 7.06000 & 12.528 & 70.0 \\
3 & & & & 6.11000 & 14.485 & 50.0 \\
4 & 1 & 1 & 0 & 5.50000 & 16.102 & 80.0 \\
5 & 0 & 0 & 2 & 5.20000 & 17.038 & 20.0 \\
6 & 1 & 1 & 1 & 4.83000 & 18.354 & 50.0
\end{tabular}

/W/mperia/Lhemical/holutries Elements at optical hineralogl."

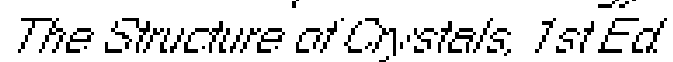




$\begin{array}{rllllll}7 & 1 & 0 & 2 & 4.54000 & 19.537 & 70.0 \\ 8 & 1 & 1 & 2 & 3.76000 & 23.643 & 80.0 \\ 9 & 2 & 0 & 2 & 3.49000 & 25.502 & 50.0 \\ 10 & 2 & 1 & 1 & 3.39000 & 26.268 & 70.0 \\ 11 & 3 & 0 & 0 & 3.17000 & 28.127 & 50.0 \\ 12 & 2 & 1 & 2 & 2.92000 & 30.591 & 40.0 \\ 13 & 3 & 0 & 2 & 2.69000 & 33.280 & 80.0 \\ 14 & 0 & 0 & 4 & 2.57000 & 34.882 & 60.0 \\ 15 & 1 & 0 & 4 & 2.48000 & 36.191 & 80.0 \\ 16 & 3 & 1 & 2 & 2.34000 & 38.439 & 40.0 \\ 17 & 2 & 0 & 4 & 2.27000 & 39.673 & 40.0 \\ 18 & 4 & 0 & 2 & 2.14000 & 42.195 & 80.0 \\ 19 & 2 & 1 & 4 & 2.09000 & 43.254 & 60.0 \\ 20 & 1 & 0 & 5 & 2.01000 & 45.068 & 50.0 \\ 21 & 1 & 1 & 5 & 1.93000 & 47.046 & 50.0 \\ 22 & 5 & 0 & 0 & 1.90000 & 47.835 & 50.0 \\ 23 & 3 & 1 & 4 & 1.84000 & 49.498 & 30.0 \\ 24 & 3 & 3 & 1 & 1.80000 & 50.674 & 60.0 \\ 25 & 5 & 0 & 2 & 1.77000 & 51.596 & 10.0 \\ 26 & 3 & 0 & 5 & 1.73000 & 52.880 & 50.0 \\ 27 & 1 & 0 & 6 & 1.69000 & 54.233 & 30.0 \\ 28 & 3 & 1 & 5 & 1.62000 & 56.783 & 60.0 \\ 29 & 4 & 2 & 3 & 1.59000 & 57.955 & 40.0 \\ 30 & 4 & 3 & 1 & 1.53000 & 60.459 & 50.0 \\ 31 & 5 & 2 & 1 & 1.50000 & 61.799 & 10.0 \\ 32 & 4 & 1 & 5 & 1.46000 & 63.687 & 40.0\end{array}$

\section{Stick Pattern}

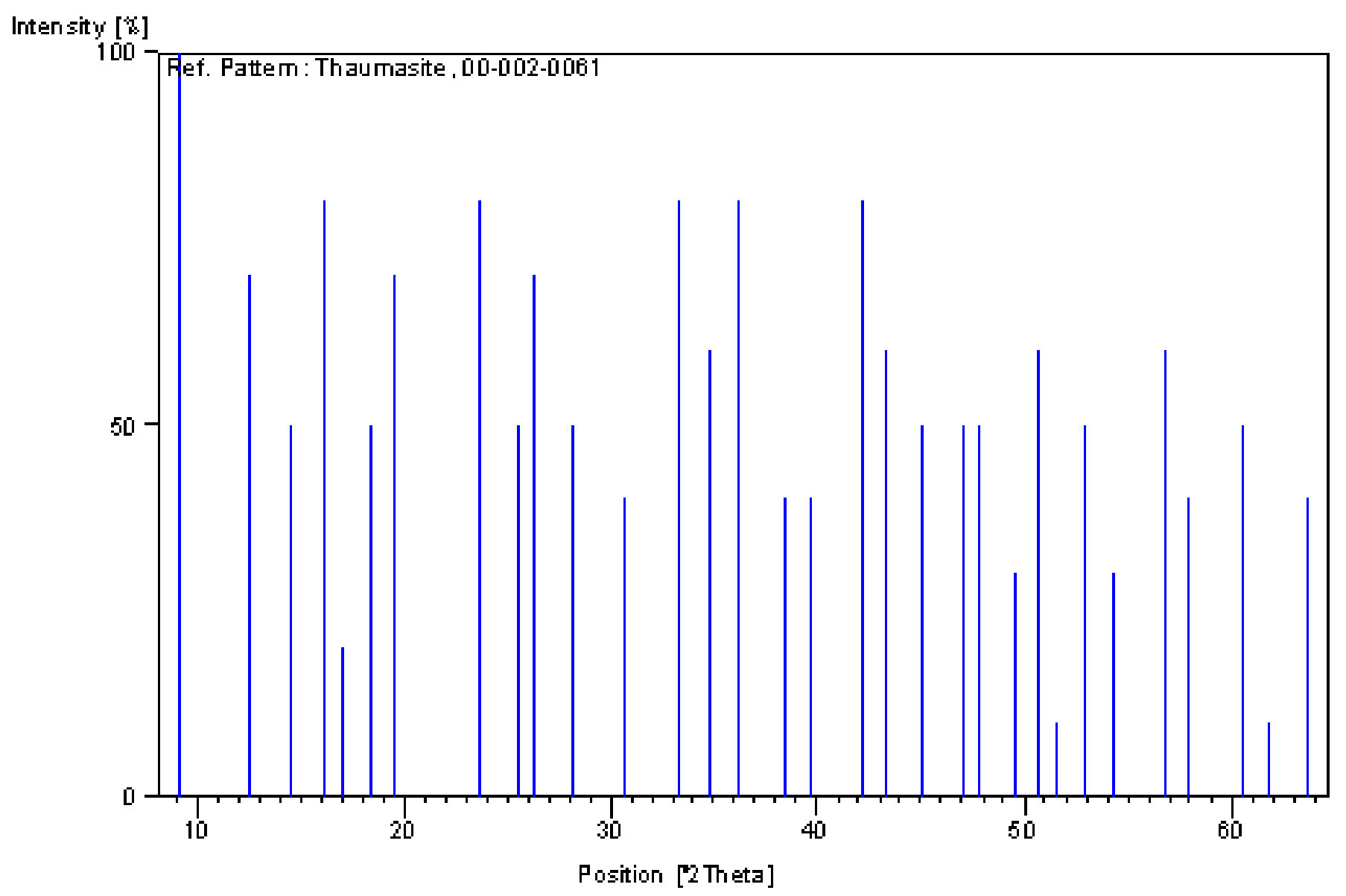




\section{Name and formula}

Reference code:

Mineral name:

PDF index name:

Empirical formula:

Chemical formula:

\section{1-085-0849}

Calcite, syn

Calcium Carbonate

$\mathrm{CCaO}_{3}$

$\mathrm{CaCO}_{3}$

\section{Crystallographic parameters}

Crystal system:

Space group:

Space group number:

a $(\hat{A}):$
b $(A):$
c $(A):$

Alpha (\%):

Beta ():

Gamma ():

Volume of cell $\left(10^{\wedge} 6 \mathrm{pm}^{\wedge} 3\right)$ :

Z:

RIR:
Rhombohedral

R-3c

167

$$
\begin{array}{r}
4.9803 \\
4.9803 \\
17.0187 \\
90.0000 \\
90.0000 \\
120.0000
\end{array}
$$

365.57

6.00

3.12

\section{Status. subfiles and quality}

Status:

Subfiles:

Quality:

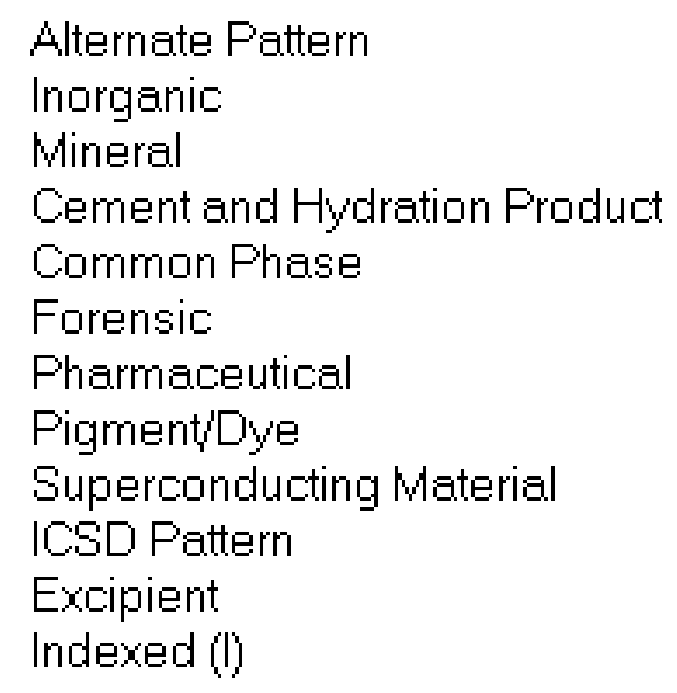

\section{Comments}

\section{ANX:}

Wyckoff Sequence:

Analysis:

CAS Number:

Unit cell data source:

ICSD collection code:
ABX3.

e b a( $(\mathrm{R} 3-\mathrm{CR})$.

$\mathrm{C} 1 \mathrm{Ca} 1 \mathrm{O}$. Formula from original source: $\mathrm{Ca}(\mathrm{C} \mathrm{O})$. 13397-26-7.

Single Crystal. 28827.

\section{$\underline{\text { References }}$}

Primary reference: 


\section{$\underline{\text { Peak list }}$}

\begin{tabular}{|c|c|c|c|c|c|c|}
\hline No. & $\mathrm{h}$ & $\mathrm{k}$ & 1 & $d \quad[A]$ & 2 Theta [deg] & $I \quad[\$]$ \\
\hline 1 & 0 & 1 & 2 & 3.84710 & 23.101 & 12.0 \\
\hline 2 & 1 & 0 & 4 & 3.02890 & 29.466 & 100.0 \\
\hline 3 & 0 & 0 & 6 & 2.83640 & 31.516 & 2.2 \\
\hline 4 & 1 & 1 & 0 & 2.49020 & 36.038 & 13.3 \\
\hline 5 & 1 & 1 & 3 & 2.28020 & 39.488 & 20.5 \\
\hline 6 & 2 & 0 & 2 & 2.09040 & 43.246 & 14.1 \\
\hline 7 & 0 & 2 & 4 & 1.92360 & 47.212 & 6.3 \\
\hline 8 & 0 & 1 & 8 & 1.90790 & 47.625 & 17.9 \\
\hline 9 & 1 & 1 & 6 & 1.87130 & 48.616 & 20.5 \\
\hline 10 & 2 & 1 & 1 & 1.62280 & 56.676 & 3.0 \\
\hline 11 & 1 & 2 & 2 & 1.60110 & 57.515 & 8.6 \\
\hline 12 & 1 & 0 & 10 & 1.58310 & 58.232 & 1.0 \\
\hline 13 & 2 & 1 & 4 & 1.52230 & 60.797 & 5.2 \\
\hline 14 & 2 & 0 & 8 & 1.51450 & 61.143 & 2.5 \\
\hline 15 & 1 & 1 & 9 & 1.50600 & 61.526 & 3.0 \\
\hline 16 & 1 & 2 & 5 & 1.47030 & 63.189 & 1.8 \\
\hline 17 & 3 & 0 & 0 & 1.43770 & 64.795 & 6.5 \\
\hline 18 & 0 & 0 & 12 & 1.41820 & 65.797 & 3.3 \\
\hline 19 & 2 & 1 & 7 & 1.35400 & 69.348 & 1.1 \\
\hline 20 & 0 & 2 & 10 & 1.33600 & 70.420 & 2.0 \\
\hline 21 & 1 & 2 & 8 & 1.29400 & 73.066 & 2.5 \\
\hline 22 & 3 & 0 & 6 & 1.28240 & 73.836 & 0.4 \\
\hline 23 & 2 & 2 & 0 & 1.24510 & 76.437 & 0.9 \\
\hline 24 & 1 & 1 & 12 & 1.23240 & 77.370 & 1.6 \\
\hline 25 & 2 & 2 & 3 & 1.21610 & 78.606 & 0.1 \\
\hline 26 & 1 & 3 & 1 & 1.19330 & 80.409 & 0.1 \\
\hline 27 & 3 & 1 & 2 & 1.18460 & 81.123 & 0.4 \\
\hline 28 & 2 & 1 & 10 & 1.17720 & 81.741 & 2.0 \\
\hline 29 & 0 & 1 & 14 & 1.17000 & 82.352 & 0.3 \\
\hline 30 & 1 & 3 & 4 & 1.15160 & 83.964 & 3.8 \\
\hline 31 & 2 & 2 & 6 & 1.14010 & 85.008 & 2.0 \\
\hline 32 & 3 & 1 & 5 & 1.12860 & 86.083 & 0.1 \\
\hline 33 & 1 & 2 & 11 & 1.12220 & 86.695 & 0.4 \\
\hline 34 & 1 & 3 & 7 & 1.07330 & 91.729 & 0.1 \\
\hline 35 & 0 & 4 & 2 & 1.06970 & 92.127 & 0.1 \\
\hline 36 & 2 & 0 & 14 & 1.05900 & 93.335 & 0.7 \\
\hline 37 & 4 & 0 & 4 & 1.04520 & 94.951 & 2.3 \\
\hline 38 & 3 & 1 & 8 & 1.04270 & 95.251 & 3.6 \\
\hline 39 & 2 & 2 & 9 & 1.03990 & 95.590 & 1.3 \\
\hline 40 & 1 & 0 & 16 & 1.03270 & 96.474 & 1.4 \\
\hline 41 & 2 & 1 & 13 & 1.02070 & 97.995 & 0.3 \\
\hline 42 & 0 & 3 & 12 & 1.00960 & 99.454 & 2.5 \\
\hline 43 & 3 & 2 & 1 & 0.98780 & 102.487 & 0.3 \\
\hline 44 & 2 & 3 & 2 & 0.98290 & 103.201 & 1.1 \\
\hline 4.5 & 1 & 3 & 10 & 0.97870 & 103.824 & 0.3 \\
\hline 46 & 1 & 2 & 14 & 0.97450 & 104.456 & 0.9 \\
\hline 47 & 3 & 2 & 4 & 0.96380 & 106.114 & 0.7 \\
\hline 48 & 0 & 4 & 8 & 0.96180 & 106.431 & 1.8 \\
\hline 49 & 0 & 2 & 16 & 0.95390 & 107.710 & 0.4 \\
\hline 50 & 2 & 3 & 5 & 0.95020 & 108.323 & 0.3 \\
\hline 51 & 0 & 0 & 18 & 0.94550 & 109.116 & 0.1 \\
\hline 52 & 4 & 1 & 0 & 0.94120 & 109.855 & 1.4 \\
\hline 53 & 2 & 2 & 12 & 0.93570 & 110.820 & 0.7 \\
\hline 54 & 1 & 4 & 3 & 0.92850 & 112.119 & 0.1 \\
\hline
\end{tabular}




\begin{tabular}{lllrlll}
\hline 55 & 3 & 2 & 7 & 0.91650 & 114.382 & 0.2 \\
56 & 4 & 0 & 10 & 0.91080 & 115.503 & 0.1 \\
57 & 2 & 3 & 8 & 0.89720 & 118.311 & 0.6 \\
58 & 1 & 4 & 6 & 0.89330 & 119.154 & 0.7 \\
59 & 2 & 1 & 16 & 0.89080 & 119.703 & 0.9 \\
60 & 1 & 1 & 18 & 0.88390 & 121.262 & 0.9 \\
61 & 5 & 0 & 2 & 0.85820 & 127.683 & 0.2 \\
62 & 3 & 2 & 10 & 0.85540 & 128.452 & 0.8 \\
63 & 1 & 2 & 17 & 0.85260 & 129.236 & 0.5 \\
64 & 0 & 5 & 4 & 0.84540 & 131.334 & 0.5 \\
65 & 2 & 2 & 15 & 0.83860 & 133.431 & 0.1 \\
66 & 0 & 1 & 20 & 0.83480 & 134.659 & 0.6 \\
67 & 2 & 3 & 11 & 0.83360 & 135.055 & 0.2 \\
68 & 3 & 3 & 0 & 0.83000 & 136.273 & 0.4 \\
69 & 3 & 3 & 3 & 0.82130 & 139.405 & 0.1 \\
70 & 2 & 4 & 1 & 0.81420 & 142.199 & 0.1 \\
71 & 4 & 2 & 2 & 0.81140 & 143.371 & 0.7 \\
72 & 0 & 4 & 14 & 0.80670 & 145.445 & 0.1 \\
73 & 2 & 4 & 4 & 0.80050 & 148.423 & 0.6 \\
74 & 5 & 0 & 8 & 0.79940 & 148.986 & 0.5
\end{tabular}

\section{Stick Pattern}

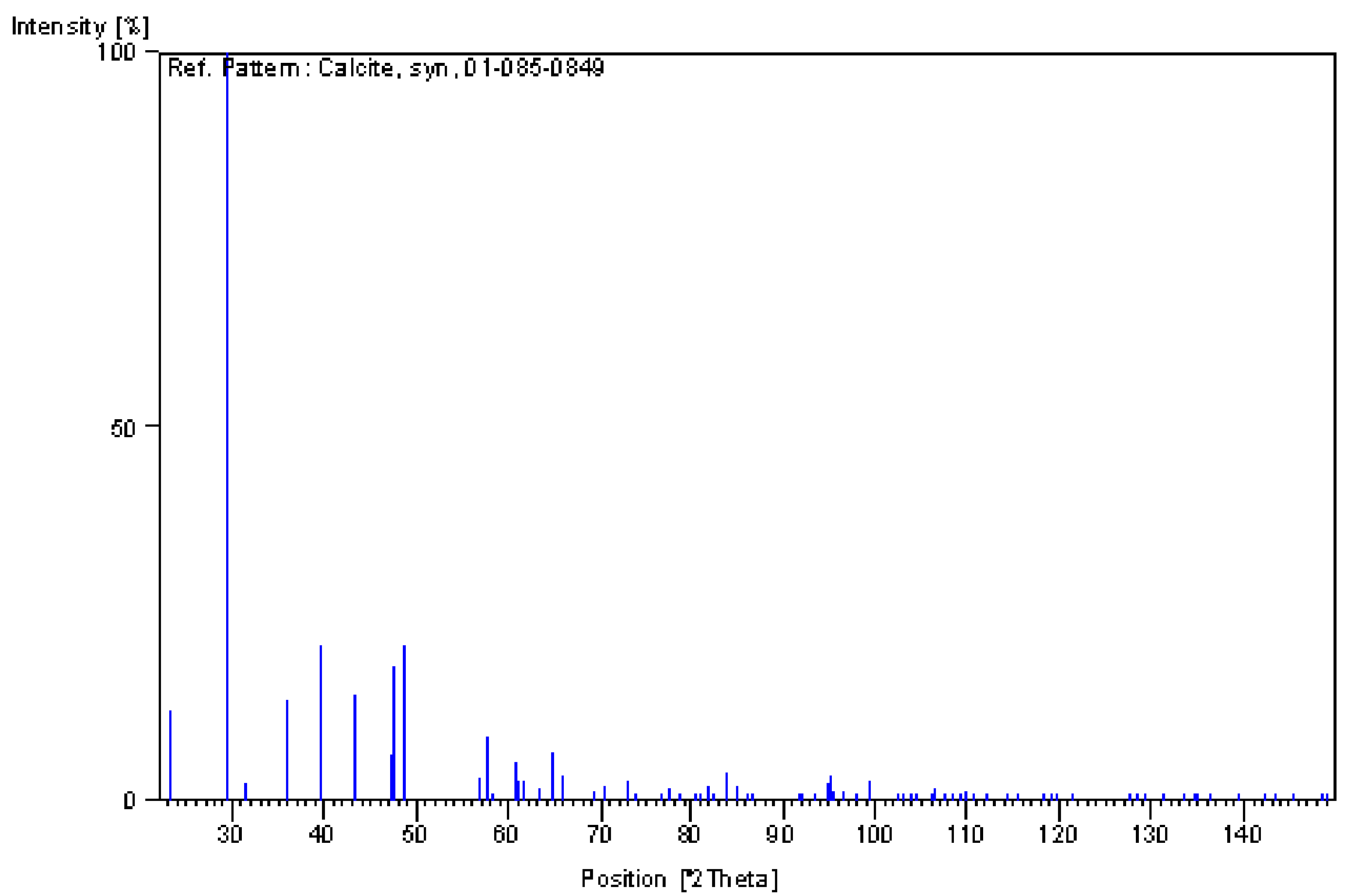




\section{Name and formula}

$\begin{array}{ll}\text { Reference code: } & 00-001-0613 \\ \text { Mineral name: } & \text { Mullite } \\ \text { PDF index name: } & \text { Aluminum Silicate } \\ \text { Empirical formula: } & \mathrm{Al}_{6} \mathrm{O}_{13} \mathrm{Si}_{2} \\ \text { Chemical formula: } & \mathrm{Al}_{6} \mathrm{Si}_{2} \mathrm{O}_{13}\end{array}$

\section{Crystallographic parameters}

Crystal system: Unknown

Measured density $\left(\mathrm{g} / \mathrm{cm}^{\wedge} 3\right): \quad 3.16$

RIR:

\section{Status, subfiles and quality}

Status:

Subfiles:

Quality:

\section{Comments}

Deleted by:

Color:

Structure:

Additional pattern:

Melting point:

\section{$\underline{\text { References }}$}

Primary reference:
Marked as deleted by ICDD

Inorganic

Mineral

Doubttul (O)

\section{Peak list}

Deleted: see Brindley's comments February 1955.

Colorless.

Reference reports orthorhombic.

See PDF 00-006-0259, 00-010-0394.

$2103 \mathrm{Ki}$.

\begin{tabular}{|c|c|c|c|c|c|c|}
\hline No. & $\mathrm{h}$ & $\mathrm{k}$ & 1 & $\mathrm{~d} \quad \mathrm{~A}]$ & 2 Theta [deg] & I $\left[\frac{s}{8}\right]$ \\
\hline 1 & & & & 5.41000 & 16.372 & 50.0 \\
\hline 2 & & & & 3.42000 & 26.033 & 100.0 \\
\hline 3 & & & & 3.39000 & 26.268 & 100.0 \\
\hline 4 & & & & 2.89000 & 30.917 & 42.0 \\
\hline 5 & & & & 2.69000 & 33.280 & 75.0 \\
\hline 6 & & & & 2.55000 & 35.165 & 83.0 \\
\hline 7 & & & & 2.30000 & 39.135 & 33.0 \\
\hline 8 & & & & 2.21000 & 40.798 & 100.0 \\
\hline 9 & & & & 2.12000 & 42.612 & 50.0 \\
\hline 10 & & & & 1.88000 & 48.376 & 25.0 \\
\hline 11 & & & & 1.84000 & 49.498 & 33.0 \\
\hline 12 & & & & 1.69000 & 54.233 & 50.0 \\
\hline 13 & & & & 1.60000 & 57.559 & 50.0 \\
\hline 14 & & & & 1.58000 & 58.357 & 17.0 \\
\hline 15 & & & & 1.52000 & 60.899 & 83.0 \\
\hline
\end{tabular}




$\begin{array}{rrrr}16 & 1.46000 & 63.687 & 17.0 \\ 17 & 1.44000 & 64.678 & 42.0 \\ 18 & 1.40000 & 66.763 & 8.0 \\ 19 & 1.34000 & 70.178 & 25.0 \\ 20 & 1.28000 & 73.997 & 33.0 \\ 21 & 1.26000 & 75.374 & 33.0\end{array}$

\section{Stick Pattern}

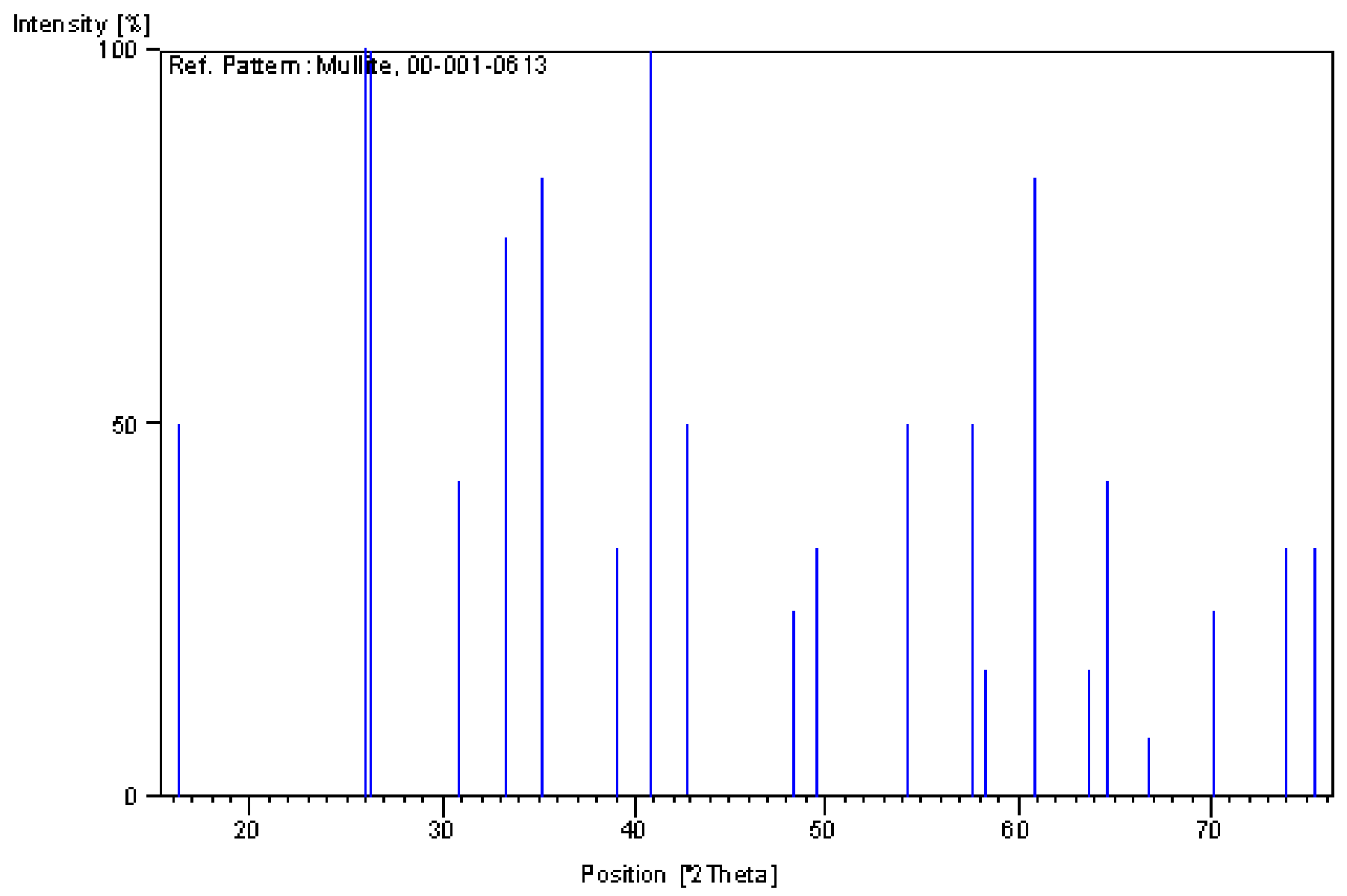




\section{Name and formula}

Reference code: $\quad$ 00-002-0050
Mineral name:
Illite
PDF index name:
Potassium Magnesium Aluminum Silicate Hydrate
Empirical formula:
$\mathrm{Al}_{2} \mathrm{H}_{24} \mathrm{~K}_{4} \mathrm{Mg}_{3} \mathrm{O}_{68} \mathrm{Si}_{24}$
Chemical formula:
$2 \mathrm{~K}_{2} \mathrm{O} \cdot 3 \mathrm{MgO} \cdot \mathrm{Al}_{2} \mathrm{O}_{3} \cdot{ }_{24} \mathrm{SiO}_{2} \cdot{ }_{12} \mathrm{H}_{2} \mathrm{O}$

\section{Crystallographic parameters}

Crystal system: Unknown

RIR:

\section{Status, subfiles and quality}

Status:

Subfiles:

Marked as deleted by ICDD

Quality: Inorganic

Mineral

Ourity.

Doubtful (O)

\section{Comments}

Deleted by:

Berry parcel of September 3, 1957.

\section{References}

Primary reference: Grim, Bray, Badley. Am Minera/ 22, 821, (1937)

\section{$\underline{\text { Peak list }}$}

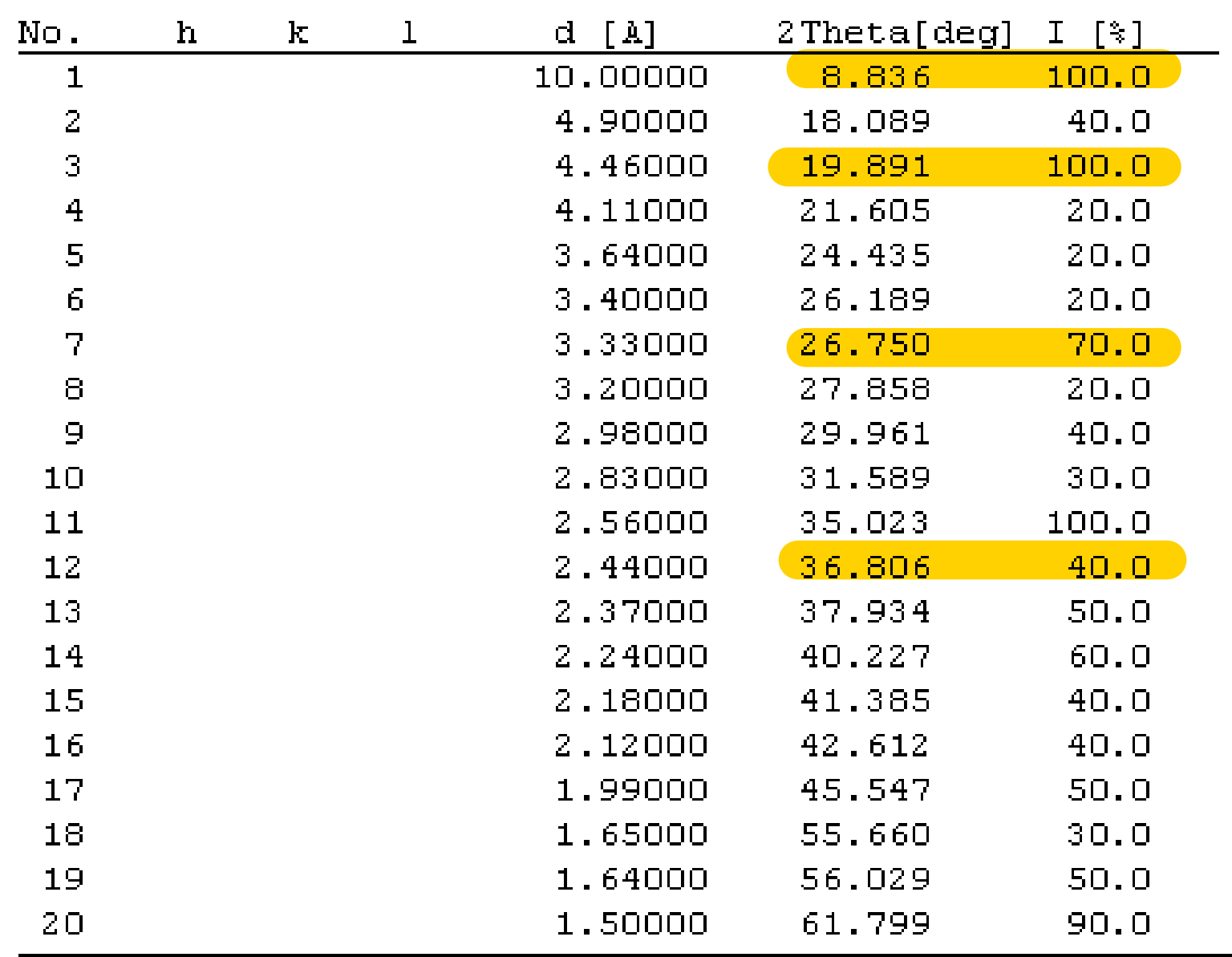




$\begin{array}{llll}21 & 1.38000 & 67.861 & 40.0 \\ 22 & 1.35000 & 69.583 & 20.0 \\ 23 & 1.30000 & 72.675 & 50.0 \\ 24 & 1.25000 & 76.084 & 40.0\end{array}$

\section{Stick Pattern}

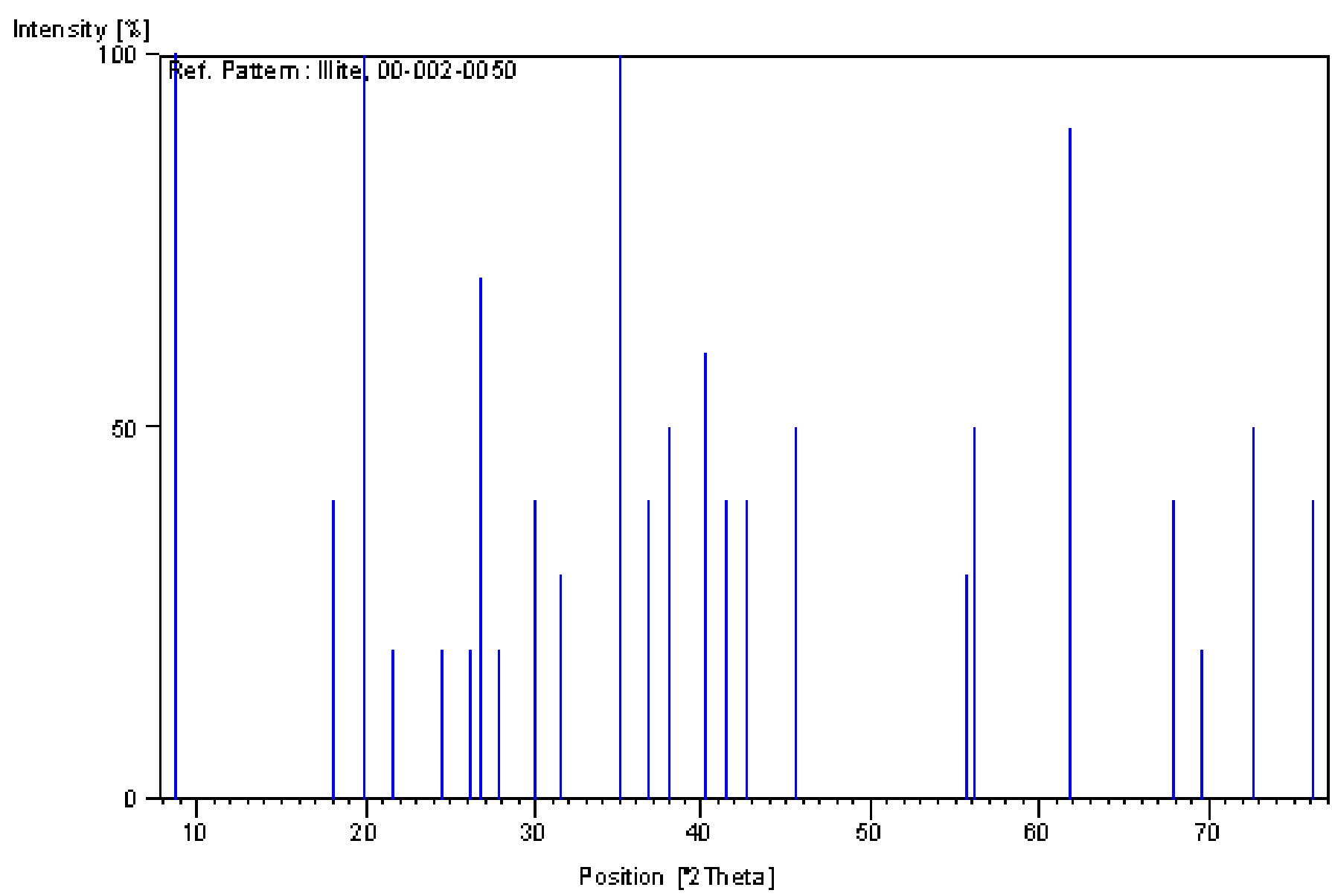




\section{Name and formula}

\section{Reference code:}

Mineral name:

PDF index name:

Empirical formula:

Chemical formula:

\section{1-075-8321}

\section{Quartz}

Silicon Oxide

$\mathrm{O}_{2} \mathrm{Si}$

$\mathrm{SiO}_{2}$

\section{Crystallographic parameters}

Crystal system:

Space group:

Space group number:

a $(\hat{A})$
b $(\hat{A})$
c $(A)$

Alpha (\%):

Beta (\%):

Gamma (0):

Volume of cell $\left(10^{\wedge} 6 \mathrm{pm}^{\wedge} 3\right)$ :

Z:

RIR:
Hexagonal

P3221

154

\author{
4.9180 \\ 4.9180 \\ 5.4070 \\ 90.0000 \\ 90.0000 \\ 120.0000
}

113.26

3.00

3.03

\section{Status. subfiles and quality}

Status:

Subfiles:

Quality:

\section{Comments}

Sample source:

ANX

Wyckoff Sequence:

Analysis:

Unit cell data source:

ICSD collection code:

\author{
Alternate Pattern \\ Inorganic \\ Mineral \\ Cement and Hydration Product \\ Common Phase \\ Forensic \\ Pharmaceutical \\ ICSD Pattern \\ Excipient \\ Indexed (1)
}

\section{References}

Primary reference:

Oomine granite, Tenkawa-mura, Nara, Southwest Japan. Test from external database: The coordinates given in the paper contain an error. The values in the database have been corrected. Minor Warning: Minor test comments from ICSD exist.

$\mathrm{A} \times 2$.

$\mathrm{ca}(\mathrm{P} 3221)$.

$\mathrm{O} 2 \mathrm{Si1}$. Formula from original source: $\mathrm{Si} \mathrm{O} 2$.

Single Crystal.

156197. 
Structure:

Ikuta, D., Kawame, N., Banno, S., Hirajima, T., Ito, K., Rakovan, J.F., Downs, R.T.,

Tamada, 0., Am. Whera/, 92, 57,(2007)

\section{Peak list}

\begin{tabular}{|c|c|c|c|c|c|c|}
\hline No. & $\mathrm{h}$ & $\mathrm{k}$ & 1 & $\mathrm{~d} \quad \mathrm{~A}]$ & 2 Theta [deg] & I $[\stackrel{p}{*}]$ \\
\hline 1 & 1 & 0 & 0 & 4.25910 & 20.840 & 21.0 \\
\hline 2 & 0 & 1 & 1 & 3.34580 & 26.621 & 100.0 \\
\hline 3 & 1 & 1 & 0 & 2.45900 & 36.511 & 6.8 \\
\hline 4 & 1 & 0 & 2 & 2.28250 & 39.447 & 6.7 \\
\hline 5 & 1 & 1 & 1 & 2.23840 & 40.257 & 3.1 \\
\hline 6 & 2 & 0 & 0 & 2.12960 & 42.411 & 4.9 \\
\hline 7 & 2 & 0 & 1 & 1.98140 & 45.755 & 2.6 \\
\hline 8 & 1 & 1 & 2 & 1.81910 & 50.105 & 11.0 \\
\hline 9 & 0 & 0 & 3 & 1.80230 & 50.605 & 0.4 \\
\hline 10 & 0 & 2 & 2 & 1.67290 & 54.833 & 3.3 \\
\hline 11 & 0 & 1 & 3 & 1.65980 & 55.303 & 1.5 \\
\hline 12 & 2 & 1 & 0 & 1.60980 & 57.176 & 0.2 \\
\hline 13 & 1 & 2 & 1 & 1.54290 & 59.901 & 7.7 \\
\hline 14 & 1 & 1 & 3 & 1.45370 & 63.996 & 1.4 \\
\hline 1.5 & 3 & 0 & 0 & 1.41970 & 65.719 & 0.3 \\
\hline 16 & 1 & 2 & 2 & 1.38320 & 67.683 & 4.6 \\
\hline 17 & 2 & 0 & 3 & 1.37580 & 68.097 & 5.9 \\
\hline 18 & 0 & 3 & 1 & 1.37320 & 68.243 & 5.3 \\
\hline 19 & 1 & 0 & 4 & 1.28840 & 73.435 & 1.8 \\
\hline 20 & 3 & 0 & 2 & 1.25690 & 75.593 & 2.3 \\
\hline 21 & 2 & 2 & 0 & 1.22950 & 77.587 & 1.1 \\
\hline 22 & 2 & 1 & 3 & 1.20060 & 79.822 & 2.3 \\
\hline 23 & 2 & 2 & 1 & 1.19890 & 79.958 & 1.0 \\
\hline 24 & 1 & 1 & 4 & 1.18460 & 81.123 & 2.0 \\
\hline 25 & 3 & 1 & 0 & 1.18130 & 81.397 & 2.9 \\
\hline 26 & 1 & 3 & 1 & 1.15400 & 83.749 & 1.3 \\
\hline 27 & 2 & 0 & 4 & 1.14120 & 84.907 & 0.2 \\
\hline 28 & 2 & 2 & 2 & 1.11920 & 86.985 & 0.1 \\
\hline 29 & 3 & 0 & 3 & 1.11530 & 87.366 & 0.2 \\
\hline 30 & 1 & 3 & 2 & 1.08240 & 90.740 & 2.0 \\
\hline 31 & 4 & 0 & 0 & 1.06480 & 92.676 & 0.3 \\
\hline 32 & 0 & 1 & 5 & 1.04810 & 94.606 & 1.1 \\
\hline 33 & 4 & 0 & 1 & 1.04470 & 95.011 & 0.8 \\
\hline 34 & 2 & 1 & 4 & 1.03520 & 96.165 & 1.1 \\
\hline 35 & 2 & 2 & 3 & 1.01570 & 98.646 & 0.9 \\
\hline 36 & 0 & 4 & 2 & 0.98990 & 102.185 & 0.7 \\
\hline 37 & 1 & 3 & 3 & 0.98800 & 102.458 & 0.6 \\
\hline 38 & 0 & 3 & 4 & 0.97900 & 103.779 & 0.2 \\
\hline 39 & 3 & 2 & 0 & 0.97710 & 104.064 & 0.5 \\
\hline 40 & 0 & 2 & 5 & 0.96420 & 106.050 & 0.1 \\
\hline 41 & 2 & 3 & 1 & 0.96150 & 106.479 & 1.0 \\
\hline 42 & 4 & 1 & 0 & 0.92940 & 111.954 & 0.1 \\
\hline 43 & 3 & 2 & 2 & 0.91890 & 113.919 & 0.4 \\
\hline 44 & 4 & 0 & 3 & 0.91670 & 114.343 & 1.1 \\
\hline 45 & 4 & 1 & 1 & 0.91600 & 114.479 & 1.0 \\
\hline 46 & 2 & 2 & 4 & 0.90950 & 115.763 & 0.3 \\
\hline 47 & 0 & 0 & 6 & 0.90120 & 117.464 & 0.1 \\
\hline 48 & 1 & 2 & 5 & 0.89770 & 118.204 & 0.7 \\
\hline 49 & 3 & 1 & 4 & 0.88950 & 119.992 & 0.6 \\
\hline 50 & 1 & 0 & 6 & 0.88160 & 121.795 & 0.2 \\
\hline 51 & 1 & 4 & 2 & 0.87890 & 122.431 & 0.5 \\
\hline 52 & 3 & 0 & 5 & 0.86030 & 127.116 & 0.1 \\
\hline 53 & 2 & 3 & 3 & 0.85900 & 127.466 & 0.1 \\
\hline
\end{tabular}




$\begin{array}{lllllll}54 & 1 & 1 & 6 & 0.84610 & 131.125 & 0.2 \\ 55 & 0 & 5 & 1 & 0.84140 & 132.553 & 0.1 \\ 56 & 0 & 4 & 4 & 0.83640 & 134.137 & 0.1 \\ 57 & 0 & 2 & 6 & 0.82990 & 136.307 & 0.9 \\ 58 & 1 & 4 & 3 & 0.82610 & 137.641 & 1.0 \\ 59 & 3 & 3 & 0 & 0.81970 & 140.014 & 0.3 \\ 60 & 5 & 0 & 2 & 0.81240 & 142.948 & 0.9 \\ 61 & 3 & 3 & 1 & 0.81040 & 143.801 & 0.8 \\ 62 & 4 & 2 & 0 & 0.80490 & 146.279 & 0.7 \\ 63 & 1 & 3 & 5 & 0.79760 & 149.932 & 0.5\end{array}$

\section{Stick Pattern}

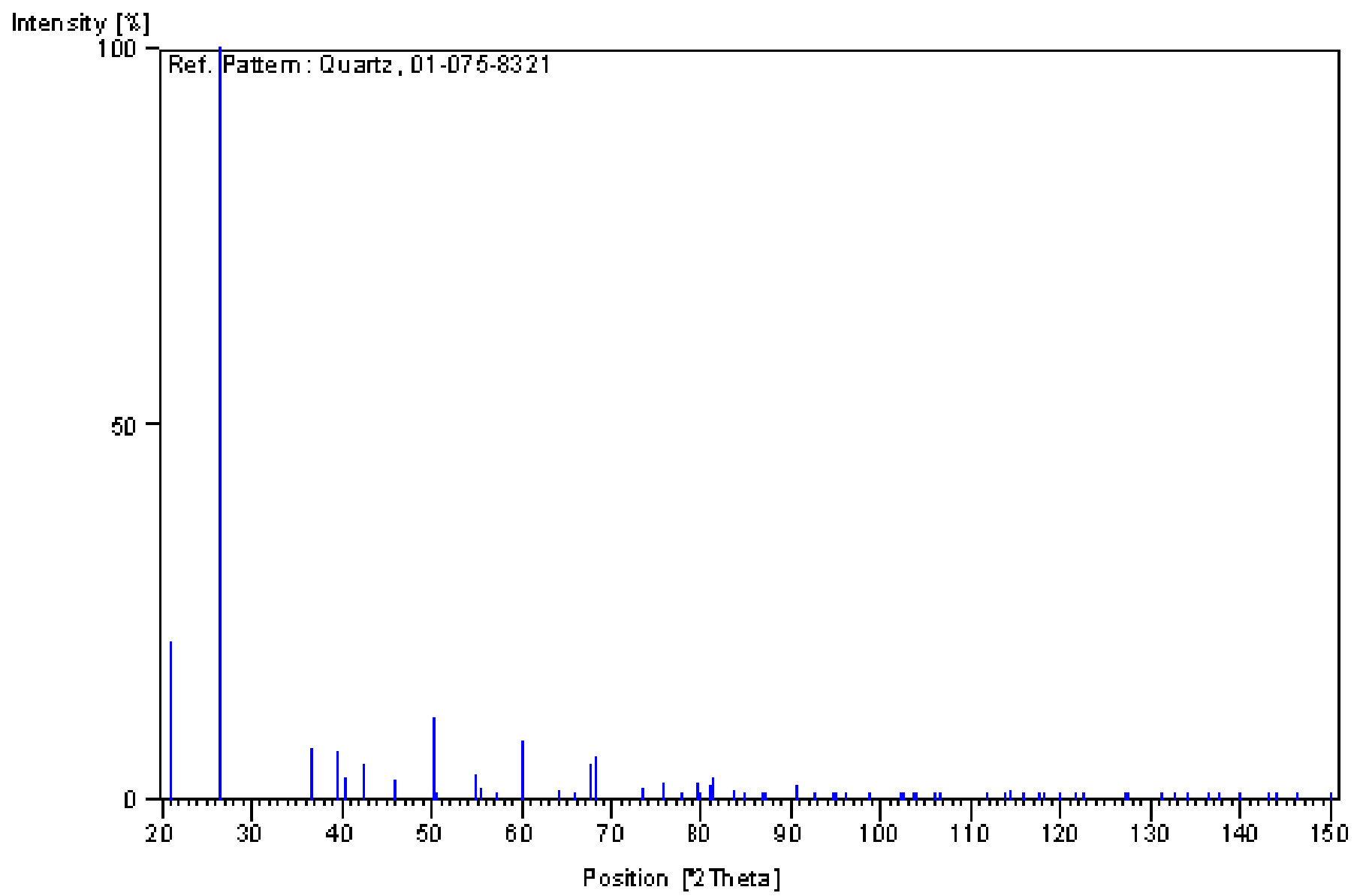




\section{References}

[1] S. Smith, "Quebec pledges \$17M more for pyrrhotite-damaged homes," CBC News, 6 January 2017. [Online]. Available: http://www.cbc.ca/news/canada/montreal/quebecpledges-17m-more-for-pyrrhotite-damaged-homes-1.3924637.

[2] A. Rodrigues, J. Duchesne, B. Fournier, B. Durand, P. Rivard and M. Shehata, "Mineralogical and chemical assessment of concrete damaged by the oxidation of sulfidebearing aggregates: Importance of thaumasite formation on reaction mechanisms," Cement and Concrete Research, vol. 42, no. 10, p. 1336-1347, 2012.

[3] A. Rodrigues, J. Duchesne and B. Fournier, "A new accelerated mortar bar test to assess the potential deleterious effect of sulfide-bearing aggregate in concrete," Cement and Concrete Research, vol. 73, pp. 96-110, 2015.

[4] T. Schmidt, A. Leemann, E. Gallucci and K. Scrivener, "Physical and microstructural aspects of iron sulfide degradation in concrete," Cement and Construction Research, vol. 41, no. 3, pp. 263-269, 2011.

[5] J. Berard, R. Roux and M. Durand, "Performance of concrete containing a variety of black shale," Canadian Journal of Civil Engineering, no. 2, pp. 58-65, 1974. 
[6] R. E. Oberholster and J. E. Kruger, "Investigation of alkali-reactive, sulphide-bearing and by-product aggregates," Bulletin of Engineering Geology and the Environment, vol. 30, pp. 273-277, 1984.

[7] A. Lugg and D. Probert, "Mundic-type problems: a building material catastrophe," Construction and Building Materials, vol. 10, no. 6, pp. 467-474, 1996.

[8] A. Shayan, "Deterioration of a concrete surface due to the oxidation of pyrite contained in pyritic aggregates," Cement and Concrete Research, vol. 18, pp. 723-730, 1988.

[9] H. W. Taylor, Cement Chemistry, 2nd Edition, London: Thomas Telford Publishing, 1997.

[10] A. Aguado, A. Rodrigues-Ferran, I. Casanova and L. Agullo, "Modelling time evolution of expansive phenomena in concrete dams as a decision-making tool," in Commision Internationale des Grandes Barrages, Montreal, 2003.

[11] D. J. Vaughan, U. Becker and K. Wright, "Sulphide mineral surfaces: theory and experiment," International Journal of Mineral Processing, vol. 51, pp. 1-14, 1997.

[12] J. Duchesne and B. Fournier, "Petrography of concrete deteriorated by weathering of sulphide minerals," in 33rd International Conference on Cement Microscopy, San Francisco, California, U.S.A., 2011. 
[13] H. F. Steger, "Oxidation of sulphide minerals VII. Effect, of temperature and relative humidity on the oxidation of pyrrhotite," Chemical Geology, vol. 35, pp. 281-295, 1982.

[14] N. Belzile, Y. W. Chen, M. F. Cai and Y. Li, "A review on pyrrhotite oxidation," Journal of Geochemical Exploration, vol. 84, pp. 65-76, 2004.

[15] S. Shnorhokian, "Development of a Quantative Accelerated Sulphate Attack Test for Mine Backfill," McGill University, 2009.

[16] S. Chinchon-Paya, A. Aguado and S. Chinchon, "A comparative investigation of the degradation of pyrite and pyrrhotite under simulated laboratory conditions," Engineering Geology, vol. 127, pp. 75-80, 2012.

[17] P. Chirita, M. Descostes and M. L. Schlegel, "Oxidation of FeS by oxygen-bearing acidic solutions," Journal of Colloid and Interface Science, vol. 321, no. 1, pp. 84-95, 2008.

[18] C. Ayora, S. Chinchon and A. Aguada, "Weathering of iron sulfides and concrete alteration: thermodynamic model and observation in dams from central Pyrenees, Spain," Cement and Concrete Research, vol. 28, no. 9, p. 1223-1235, 1998. 
[19] D. Borah, M. Barua and M. Baruah, "Dependence of pyrite concentration on kinetics and thermodynamics of coal pyrolysis in non-isothermal systems," Fuel Processing Technology, vol. 86, no. 9, pp. 977-993, 2005.

[20] A. M. Marion, J. Daube and R. Smitz, "The stability of pyrite in calcareous aggregate: investigations in old concrete structures," in 23rd Annual International Conference On Cement Microscopy, Albuquerque, New Mexico, 2001.

[21] C. F. Jones, "Compositional and structural alteration of pyrrhotite surfaces in solution: XPS and XRD studies," Applied Surface Science, vol. 55, no. 1, pp. 65-85, 1992.

[22] A. Tagnit-Hamou, M. Saric-Coric and P. Rivard, "Internal deterioration of concrete by the oxidation of pyrrhotitic aggregates," Cement and Concrete Research , vol. 35, no. 1, pp. 99$107,2005$.

[23] J. S. Chinchon, A. Lopez-Soler, X. Querol and R. Vaquer, "Determination of pyrrhotite (Fe1-xS) occurring in aggregates by $\mathrm{X}$ ray fluorescence," Cement and Concrete Research, vol. 20 , no. 3, p. 394-397, 1990.

[24] M. P. Janzen, R. V. Nicholson and J. M. Scharer, "Pyrrhotite reaction kinetics: Reaction rates for oxidation by oxygen, ferric iron, and for nonoxidative dissolution," Geochemica et Cosmochimica Acta, vol. 64, no. 9, pp. 1511-1522, 2000. 
[25] T. A. Orlova, V. M. Stupnikov and A. L. Krestan, "Mechanism of oxidative dissolution of sulphides," Zhurnal Prikladnoi Khimii, vol. 61, p. 2172-2177, 1989.

[26] J. R. Craig, "The metamorphism of pyrite and pyritic ores: an overview," Mineralogical Magazine, vol. 57, pp. 3-18, 1993.

[27] R. G. Arnold, "Mixtures of hexagonal and monoclinic pyrrhotite and the measurement of the metal content of pyrrhotite by x-ray diffraction," The American Mineralogist, vol. 51, pp. 1221-1227, 1966.

[28] A. R. Graham, "Quantitative determination of hexagonal and monoclinic pyrrhotites by Xray diffraction," The Canadian Mineralogist, vol. 10, pp. 4-24, 1969.

[29] M. Collepardi, "A State-of-the-Art Review on Delayed Ettringite Attack on Concrete," Cement and Concrete Composites, vol. 25, no. 4-5, pp. 401-407, 2003.

[30] A. M. Neville, Properties of Concrete, 5th Edition, Edinburgh Gate, England: Pearson, 2011.

[31] F. Bellmann and J. Stark, "The role of calcium hydroxide in the formation of thaumasite," Cement and Concrete Research, vol. 38, no. 10, p. 1154-1161, 2008. 
[32] P. Hagelia and R. G. Sibbick, "Thaumasite sulfate attack, popcorn calcite deposition and acid attack in concrete stored at the blindtarmen test site Oslo, from 1952 to 1982," Materials Characterization, vol. 60, no. 7, p. 686-699, 2009.

[33] M. Romer, L. Holzer and M. Pfiffner, "Swiss tunnel structures: concrete damage by formation of thaumasite," Cement and Concrete Composites, vol. 25, no. 8, p. 1111-1117, 2003.

[34] F. Mittermayr, D. Klammer, D. Hollen, S. Kohler, M. E. Bottcher, A. Leis and M. Dietzel, "Deterioration of Concrete: Application of Stable Isotopes," in Proceedings of the 10th International Congress for Applied Mineralogy (ICAM), Trondheim, Norway, Springer Berlin Heidelberg, 2012, pp. 435-443.

[35] J. Tritthart, D. Klammer, F. Mittermayr and A. Brunnsteiner, "A Case Study of Thaumasite Formation in an Austrian Tunnel," in 13th International Congress on the Chemistry of Cement, Madrid, Spain, 2011, pp. 431-437.

[36] P. K. Mehta, "Mechanism of Sulfate Attack on Portland Cement Concrete—Another Look," Cement and Concrete Research, vol. 13, no. 3, pp. 401-406, 1983.

[37] A. Neville, "The confused world of sulfate attack on concrete," Cement and Concrete Research, vol. 34, no. 8, pp. 1275-1296, 2004. 
[38] Steven H. Kosmatka, B. Kerkhoff, W. C. Panarese, N. F. Macleod and R. J. McGrath, Design and Control of Cncrete Mixtures, Ottawa: Cement Association of Canada, 2002.

[39] A. Rodrigues, J. Duchesne and B. Fournier, "Petrographic characterization of the deterioration products of a concrete containing sulfide bearing aggregates; a particular case of internal sulphate attack," in 35th International Conference on Cement Microscopy, Chicago, USA, 2013.

[40] J. Herrero, O. Artieda and W. H. Hudnall, "Gypsum, a Tricky Material," Soil Science Society of America, vol. 73, no. 6, pp. 1757-1763, 2009.

[41] J. Nielson, "Investigation of resistance of cement paste to sulfate attack," Highway Research Record, vol. 113, p. 114-117, 1966.

[42] P. K. Mehta, D. Pirtz and M. Polivka, "Properties of alite cements," Cement and Concrete Research, vol. 9, pp. 439-450, 1979.

[43] P. K. Mehta, "Sulfate attack on concrete-A critical review," in Materials Science of Concrete, vol. III, Westerville, OH, USA, American Ceramic Society, 1992.

[44] D. Bonen and M. D. Cohen, "Magnesium sulfate attack on Portland cement paste-I. Microstructural analysis," Cement and Concrete Research, vol. 22, p. 169-180, 1992. 
[45] D. Bonen and S. L. Sarkar, "Replacement of Portlandite by gypsum in the interfacial zone and cracking related to crystallization pressure," in Ceramic Transaction, Proceedings of 95th Annual Meeting, Cement-Based Materials: Present, Future, and Environmental Aspects, Westerville, OH, USA, 1993.

[46] B. Tian and M. D. Cohen, "Does gypsum formation during sulfate attack on concrete lead to expansion?," Cement and Concrete Research, vol. 30, p. 117-123, 2000.

[47] W. C. Hansen, "Crystal growth as a source of expansion in Portland cement concrete," Proceedings of American Society for Testing and Materials, vol. 63, p. 932-945, 1963.

[48] W. C. Hansen, "Attack on Portland cement concrete by alkali soil and water-A critical review," Highway Research Record, vol. 113, p. 1-32, 1966.

[49] F. M. Lea, The Chemistry of Cement and Concrete, London, UK: Edward Arnold Publishers Ltd, 1970.

[50] B. Mather, "Discussion of "the process of sulfate attack on cement mortars,"," Advanced Cement Based Materials, vol. 5 , p. 109-110, 1996. 
[51] N. J. Crammond, "Examination of mortar bars containing varying percentages of coarsely crystalline gypsum as aggregate," Cement and Concrete Research, vol. 14, no. 2, pp. 225$230,1984$.

[52] R. Brueckner, "Accelerating the thaumasite form of sulfate attack and an investigation of its effects on skin friction," University of Birmingham, Birmingham, 2007.

[53] Portland Cement Association , "Fly Ash, Slag, Silica Fume, and Natural Pozzolans," in PCA Manual, 7th Canadian Edition, p. Chapter 3.

[54] K. Wille and R. Zhong, "Investigating the deterioration of basement walls made of concrete in ct," 2016.

[55] Thaumasite Expert Group (TEG), "Department of the Environment, Transport and the Regions. The thaumasite form of sulfate attack: risks, diagnosis, remedial work sand guidance on new construction," London, 1999.

[56] J. Bensted, "Thaumasite - direct, woodfordite and other possible formation routes," Cement \& Concrete Composites, vol. 25, no. 8, pp. 873-877, 2003.

[57] R. G. Sibbick, N. J. Crammond and D. Metcalf, "Cement and Concrete Composites," The microscopical characterisation of thaumasite, vol. 25, no. 8, pp. 831-837, 2003. 
[58] N. J. Crammond, "The thaumasite form of sulfate attack in the UK," Cement and Concrete Composites, vol. 25, no. 8, pp. 809-818, 2003.

[59] B. Erlin and D. C. Stark, "Identification and occurrence of thaumasite in concrete," Highway Res Record, vol. 113, p. 108-113, 1965.

[60] D. Macphee and S. Diamond, "Thaumasite in cementitious materials," Cement and Concrete Composites, vol. 25, pp. 805-807, 2003.

[61] J. A. Bickley, R. T. Hemmings, R. D. Hooton and J. Balinsky, "Thaumasite related deterioration of concrete structures. Proceedings of Concrete," in Concrete Technology: Past, Present and Future, Farmington Hills, American Concrete Institute, ACI SP-144, 1994, pp. 155-179.

[62] M. E. Gaze and N. J. Crammond , "The formation of thaumasite in a cement: lime: sand mortar exposed to cold magnesium and potassium sulfate solutions," Cement \& Concrete Composites, vol. 22, pp. 209-222, 2000.

[63] S. Sahu, S. Badger and N. Thaulow, "Mechanism of thaumasite formation in concrete slabs on grade in Southern California," Cement and Concrete Composites, vol. 25, no. 8, pp. 889897, 2003. 
[64] S. Kohler, D. Heinz and L. Urbonas, "Effect of ettringite on thaumasite formation," Cement and Concrete Research, vol. 36, pp. 697-706, 2006.

[65] G. Collett, N. J. Crammond, R. N. Swamy and J. H. Sharp, "The role of carbondioxide in the formation of thaumasite," Cement \& Concrete Research, vol. 34, pp. 1599-1612, 2004.

[66] J. Bensted, "Thaumasite — background and nature in deterioration of cements, mortars, and concretes.," Cement \& Concrete Composites, vol. 21, no. 2, p. 117-121, 1999.

[67] M. Collepardi, "Thaumasite formation and deterioration in historic buildings," Cement \& Concrete Composites, vol. 21, p. 147-154, 1999.

[68] E. E. Lachowski, S. J. Barnett and D. E. Macphee, "Transmission electron optical study of ettringite and thaumasite," Cement and Concrete Composites, vol. 25, pp. 819-822, 2003.

[69] M. A. Eden, "The laboratory investigation of concrete affected by TSA in the UK," Cement and Concrete Composites, vol. 25, no. 8, pp. 847-850, 2003.

[70] S. J. Barnett, D. E. Macphee and N. J. Crammond, "Extent of immiscibility in the ettringitethaumasite system," Cement and Concrete Composites, vol. 25, no. 8, pp. 851-855, 2003. 
[71] I. Pajares, S. Martinez-Ramirez and M. Blanco-Varela, "Evolution of ettringite in presence of carbonate, and silicate ions," Cement and Concrete Composites, vol. 25, no. 8, pp. 861$865,2003$.

[72] K. Hong, "Cyclic Wetting and Drying and its Effects on Chloride Ingress in Concrete," University of Toronto, Toronto, ON, 1998.

[73] M. A. Thomas, R. D. Hooton, A. Scott and H. Zibara, "The effect of supplementary cementitious materials on chloride binding in hardened cement paste," Cement and Concrete Research, vol. 42, no. 1, pp. 1-7, 2012.

[74] G.-H. Yee-Ching, "The Effect of Low Temperature on the Binding of External Chlorides," Department of Civil Engineering, University of Toronto, Toronto, 2012.

[75] H. Zibara, "Binding of External Chlorides by Cement Pastes," Department of Civil Engineering, University of Toronto, Toronto, 2001.

[76] P. Brown and J. Bothe, "The system $\mathrm{CaO}-\mathrm{Al} 2 \mathrm{O} 3-\mathrm{CaCl} 2-\mathrm{H} 2 \mathrm{O}$ at $23 \pm 2{ }^{\circ} \mathrm{C}$ and the mechanisms of chloride binding in concrete," Cement and Concrete Research, vol. 34, no. 9, p. 1549-1553, 2004. 
[77] P. Suraneni, V. J. Azad, O. B. Isgor and W. J. Weiss, "Deicing Salts and Durability of Concrete Pavements and Joints: Mitigating calcium oxychloride formation," Concrete International, vol. 38, no. 4, pp. 48-54, 2016.

[78] P. W. Brown and A. Doerr, "Chemical changes in concrete due to the ingress of aggressive species," Cement and Concrete Research, vol. 30, no. 3, pp. 411-418, 2000.

[79] Z. Wu, C. Shi, P. Gao, D. Wang and Z. Cao, "Effects of Deicing Salts on the Scaling Resistance of Concrete," Journal of Materials in Civil Engineering, vol. 27, no. 5, 2015.

[80] Q. Yuan, C. Shi, G. De Schutter, K. Audenaert and D. Deng, "Chloride Binding of CementBased Materials Subjected to External Chloride Environment - A Review," Construction and Building Materials, vol. 23, no. 1, pp. 1-13, 2009.

[81] A. K. Suryavanshi, J. D. Scantlebury and S. B. Lyon, "Mechanism of Friedel's salt formation in cements rich in tri-calcium aluminate," Cement and Concrete Research, vol. 26, no. 5, pp. 717-727, 1996.

[82] Y. Farnam, S. Dick, A. Wiese, J. Davis, D. Bentz and J. Weiss, "The influence of calcium chloride deicing salt on phase changes and damage development in cementitious materials," Cement and Concrete Composites, vol. 64, pp. 1-15, 2015. 
[83] A. Shayan, A. Xua, G. Chirgwin and H. Morris, "Effects of seawater on AAR expansion of concrete," Cement and Concrete Research , vol. 40, pp. 563-568, 2010.

[84] A. Shayan, "Effects of $\mathrm{NaOH}$ and $\mathrm{NaCl}$ Solutions and Temperature on the Behavior of Specimens Subjected to Accelerated AAR Tests, Communicated by D.M. Roy," Cement and Concrete Research, vol. 28, no. 1, pp. 25-31, 1998.

[85] S. Zhutovsky and D. Hooton, "Effect of supplementary cementitious materials on the resistance of mortar to physical sulfate salt attack," in 5th International Materials Specialty Conference, Annual Conference of Canadian Society for Civil Engineering, London, Ontario, 2016.

[86] H. Lee and X. Wang, "Heat of hydration models of cementitious materials," Advances in Cement Research, vol. 24, no. 2, pp. 77-90, 2012.

[87] D. M. Roy, P. Arjunan and M. R. Silsbee, "Effect of silica fume, metakaolin, and lowcalcium fly ash on chemical resistance of concrete," Cement and Concrete Research, vol. 31, no. 12, p. $1809-1813,2001$.

[88] Y. Kawabata, K. Yamada and H. Matsushita, "Relation of phase composition of cement hydrates with supplementary cementitious materials to the suppressing effect on asr expansion," Journal of Japan Society of Civil Engineers, vol. 69, no. 4, pp. 402-420, 2013. 
[89] T. Dyer, Concrete Durability, CRC Press, ISBN 9780415564755, 2014.

[90] S. Mindess, F. J. Young and D. Darwin, Concrete, 2nd Edition, Pearson, 2003.

[91] W. Kunther, B. Lothenbach and J. Skibsted, "Influence of the $\mathrm{Ca} / \mathrm{Si}$ ratio of the C-S-H phase on the interaction with sulfate ions and its impact on the ettringite crystallization pressure," Cement And Concrete Research, vol. 69, pp. 37-49, 2015.

[92] Canadian Standards Association (CSA), CSA A3001 Cementitious Materials Used in Concrete, CSA, 2014.

[93] M. Shehata, CV 8106: Advances in concrete materials Course, W2013, Toronto, ON, 2013.

[94] F. Irassar and O. Batic, "Effects of low calcium fly ash on sulfate Esistance of OPC cement," Cement and Concrete Research, vol. 19, no. 2, pp. 194-202, 1989.

[95] T. Bekir and B. Turhan, "Effects of slag fineness on durability of mortars," Journal of Zhejiang University SCIENCE A, vol. 8, no. 11, pp. 1725-1730, 2007.

[96] S. H. Kosmatka, B. Kerkhoff, W. C. Panarese, N. F. Macleod and R. McGrath, Design and Control of Concrete Mixtures, Seventh Canadian Edition, Portland Cement Association, 2002. 
[97] N. Al-Akhras, "Durability of metakaolin concrete to sulfate attack," Cement and Concrete Research, vol. 36, no. 9, pp. 1727-1734, 2006.

[98] H. Moon, S. T. Lee and S. Kim, "Sulphate resistance of silica fume blended mortars exposed to various sulphate solutions," Canadian Journal of Civil Engineering, vol. 30, no. 4, pp. 625-636, 2003.

[99] A. Rodrigues, J. Duchesne and B. Fournier, "Microscopic Analysis of the Iron Sulfide Oxidation Products Used in Concrete Aggregates," in 34th International Conference on Cement Microscopy, Halle-Saale, Germany, 2012.

[100] A. Rodrigues, J. Duchesne, B. Fournier, B. Durand, M. Shehata and P. Rivard, "Evaluation Protocol for Concrete Aggregates Containing Iron Sulfide Minerals," ACI Materials Journal, vol. 113, no. 3, pp. 349-359, 2016.

[101] ASTM C586-11, Standard Test Method for Potential Alkali Reactivity of Carbonate Rocks as Concrete Aggregates (Rock-Cylinder Method), West Conshohocken, PA: ASTM International, 2011.

[102] ASTM D75 / D75M-14, Standard Practice for Sampling Aggregates, West Conshohocken, PA: ASTM International, 2014. 
[103] ASTM C702-98, Standard Practice for Reducing Samples of Aggregate to Testing Size, Conshohocken, PA: ASTM International, 1998.

[104] V. Ramos, A. Rodrigues, B. Fournier and J. Duchesne, "Development of a quick screening staining test for detecting the oxidation potential of iron sulfide-bearing aggregates for use in concrete," Cement and Concrete Research, vol. 81, p. 49-58, 2016.

[105] S. Frais, Y.-L. Ng and K. Gulabivala, "Some factors affecting the concentration of available chlorine in commercial sources of sodium hypochlorite," International Endodontic Journal, vol. 34, pp. 206-215, 2001.

[106] Canadian Standards Association (CSA), A23.1-14/A23.2-14 - Concrete materials and methods of concrete construction / Test methods and standard practices for concrete, CSA, 2014.

[107] Oxygen (Dissolved Oxygen, DO). In Water Chemistry. Retrieved from http://academic.keystone.edu/jskinner/Limnology/Water_Chemistry_LectureNotes.htm

[108] Canadian Standards Association (CSA), A23.2-25A - A test method for detection of alkalisilica reactive aggregate by accelerated expansion of mortar bars, CSA, 2014, pp. A23.2$25 \mathrm{~A}$. 
[109] Erco Worldwide, Sodium hypochlorite solution whmis controlled product: material safety data sheet, Revision 3, Toronto, ON: ERCO Worldwide, A division of Superior Plus LP, 2012.

[110] Y. Farnam, T. Washington and J. Weiss, "The Influence of Calcium Chloride Salt Solution on the Transport Properties of Cementitious Materials," Advances in Civil Engineering, vol. ID 929864, p. 13 pages, 2015.

[111] M. H. Shehata, Effect of fly ash and silica fume on the alkali-silica reaction in concrete, University of Toronto: Ph.D. Thesis, 2001.

[112] S. Diamond and F. Lopez-Flores, "On the Distinction in Physical and Chemical Characteristics Between Lignite and Bituminous Fly Ash: In Effects of Fly Ash Incorporation in Cement and Conc," Proceedings of the MRS Symposium, Materials Research Society, pp. 34-44, 1981.

[113] C. Hea, B. Osbzckb and E. Makovicky, "Pozzolanic reaction of six principal clay minerals: activation, reactivity assessments and technological effects," Cement and Concrete Research, vol. 25, no. 8, pp. 1691-1702, 1995.

[114] F. Glasser, "CAERseminiar2009.pdf," University of Aberdeen, Scotland UK, [Online]. Available: http://www.caer.uky.edu/podcast/Glasser. 
[115] S. Diamond, "Thaumasite in cementitious materials," Cement \& Concrete Composites, vol. 25, pp. 805-807, 2003.

[116] A. Mesbah, M. Francois, C. Cau-dit-Coumes, F. Frizon, Y. Filinchuk, F. Leroux, J. Ravaux and G. Renaudin, "Crystal structure of Kuzel's salt 3CaO $\cdot \mathrm{Al} 2 \mathrm{O} 3 \cdot 1 / 2 \mathrm{CaSO} 4 \cdot 1 / 2 \mathrm{CaCl} 2$. $11 \mathrm{H} 2 \mathrm{O}$ determined by synchrotron powder diffraction," Cement and Concrete Research, vol. 41, pp. 504-509, 2011.

[117] A. Allahverdi and F. Skvara, "Acidic Corrosion of Hydrated Cement Based Materials, Part 1: Mechanism of the Phenomenon," Ceramics-Silikaty, vol. 44, no. 3, pp. 114-120, 2000.

[118] Lenntech BV, "Disinfectants Sodium hypochlorite," Lenntech BV, [Online]. Available: http://www.lenntech.com/processes/disinfection/chemical/disinfectants-sodiumhypochlorite.htm. [Accessed 2016].

[119] J. I. Bhatty, "A Review of the Application of Thermal Analysis to Cement Admixture Systems," Thermochimica Acta, vol. 189, pp. 313-350, 1991.

[120] W. Sha, E. A. O'Neill and Z. Guo, "Differential scanning calorimetry study of ordinary Portland cement," Cement and Concrete Research, vol. 29, no. 9, pp. 1487-1489, 1999. 
[121] N. Saikia, S. Kato and T. Kojima, "Thermogravimetric investigation on the chloride binding behaviour of MK-lime paste," Thermochimica Acta, vol. 444, no. 1, pp. 16-25, 2006.

[122] N. J. Coleman and C. L. Page, " Aspects of the pore solution chemistry of hydrated cement pastes containing metakaolin," Cement and Concrete Research, vol. 27, no. 1, pp. 147-154, 1997.

[123] B. Lothenbach, G. L. Saout, E. Gallucci and K. Scrivener, "Influence of limestone on the hydration of Portland cements," Cement and Concrete Research., vol. 38, p. 848-860, 2008.

[124] K. Weslaw, Cement and Concrete Chemistry, ISBN: 978-94-007-7945-7.

[125] M. A. Florea and H. H. Brouwers, "Chloride binding related to hydration products, Part I: Ordinary Portland Cement," Cement and Concrete Research, vol. 42, pp. 282-290, 2012.

[126] S. O. Ekolu, M. A. Thomas and R. D. Hooton, "Pessimum effect of externally applied chlorides on expansion due to delayed ettringite formation: Proposed mechanism," Cement and Concrete Research, vol. 36, no. 4, pp. 688-696, 2006.

[127] ASTM C192 / C192M - 16a, Standard Practice for Making and Curing Concrete Test Specimens in the Laboratory, West Conshohocken, PA: ASTM International, 2016. 
[128] M. Mbonimpa, M. Aubertin, M. Aachib and B. Bussière, "Diffusion and consumption of oxygen in unsaturated cover materials," Canadian Geotechnical Journal, vol. 40, p. 916932, 2003. 